
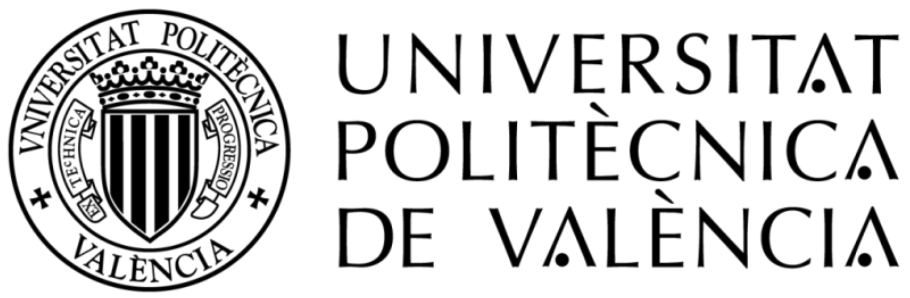

DEPARTAMENTO DE ORGANIZACIÓN DE EMPRESAS

\title{
ANÁLISIS DE LOS OBSTÁCULOS FINANCIEROS DE LAS PYMES PARA LA OBTENCIÓN DE CRÉDITO Y LAS VARIABLES QUE LO FACILITAN
}

TESIS DOCTORAL

Doctorando:

Juan Vaca Estrada

Dirigida por:

Dr. Fernando José Garrigós Simón Dr. Ignacio Gil Pechuán

Valencia, Diciembre 2012 


\section{DEDICATORIA}

A mi Esposa Honey

A mi Hija Natalie

A mis Padres 


\section{AGRADECIMIENTOS}

Hoy es justo decir gracias.

El dar gracias es una de las enseñanzas que más debo recordar cuando he recibido algo. Y hoy es uno de esos momentos en los que me siento muy agradecido. Indudablemente la ocasión amerita el decir gracias a tanta gente, que me preocuparía el no mencionar a alguien, por lo cual quiero disculparme por anticipado si llego a cometer este error, pero mi corazón dice gracias a todos los que me ayudaron para lograrlo, aunque haya sido una palabra de aliento.

La familia es una de mis prioridades en esta vida, y afortunadamente he recibido su apoyo. Mi esposa tuvo que prescindir de mi tiempo, a veces de mi presencia, mi hija, tal vez sin dimensionarlo, sabía que debía destinar tiempo para hacer la tarea. Han sido muchos años desde que emprendí esta aventura, este sueño que cada vez está más cerca de convertirse en una realidad. Natalie, recuerda que para hacer los sueños realidad, primero hay que soñarlos, luego creértelos, y sobre todo, dar tu máximo esfuerzo, para disfrutarlos cuando los alcanzas. Toma como ejemplo lo bueno, si hay algo que podamos dejarte en vida como padres, que sean cosas positivas.

Agradecer a Dios, por que sé que hay un poder divino, que cuida de mi familia y de mi.

A mis padres, por que gran parte de lo que soy se lo debo a ellos, y pequeños instantes y detalles como este son la manera de decirles gracias y de hacerles saber de que este triunfo es también de ellos. 
A mis hermanos, por tantos años compartidos, tantas experiencias y buenos momentos.

A mi asesor, Dr. Fernando, pues en este camino aprendí mucho; no fue fácil, pero hay momentos claros en que tu paciencia, apoyo, ayuda y enseñanzas me ayudaron a lograr este objetivo, camino a la excelencia. Gracias por todo.

Al Dr. Ignacio, por que iniciamos con esta travesía, me dio ánimos, gracias por la hospitalidad. Es un orgullo ser parte de este grupo de élite, como alguna vez platicamos sobre el tener este grado.

A la gente que tanto el plano profesional como el personal me han hecho crecer, ser mejor y recordar que puedo hacer cosas de trascendencia. El saber que puedo contar con el apoyo de alguien, el encontrar soporte en momento difíciles, y que palabras de aliento no llegan a faltar cuando pareciera que todo se vuelve complicado.

A todas y cada una de las personas que confiaron en mí, al responder el cuestionario que formó parte de mi estudio; a las personas que me dieron parte de su tiempo para apoyarme en esta odisea, gracias. A las personas que me ayudaron en la parte de cuestionarios, su ayuda fue invaluable. Mis alumnos del segundo semestre del 2011, fue un relación muy especial.

A aquellas personas, que sin conocernos, han sido motivo de admiración para mi, de saber que puede haber cosas extraordinarias en este mundo, y saber que las personas también podemos ser extraordinarias. Que hay muchos anhelos en esta vida, y que el ser diferente puede ser una cualidad. 
Que la enseñanza puede venir de donde y de quien menos te lo imaginas, y que el agradecer es una forma de regalar lo mejor de ti sin tener que dar un presente. Que puedes cambiar la vida de lo que tienes a tu alrededor de manera positiva, sin tener que intentar cambiar al mundo entero. Y que vivas, no solo respires y sientas que tu cuerpo te responde, sino que disfrutes cada momento como si quisieras que fuera la mejor experiencia que hayas tenido. 


\section{RESUM}

L'objectiu del present treball és analitzar la font d'on obtenen recursos les PIME per a la funcionar. S'hi analitzen les teories de la literatura que parlen de la forma en què les PIME demanen crèdit i dels diversos obstacles que troben per a obtenir-ne. La revisió de la literatura acadèmica mostra que en ocasions les empreses prefereixen mantenir-se operant amb recursos propis, o bé cerquen una font externa a través de l'endeutament i consideren com el darrer recurs l'ingrés de nou capital, ja que aquest pot contribuir a la pèrdua de control de l'empresa.

A més, la literatura ens fa conèixer diversos obstacles que l'empresa troba quan vol demanar un crèdit, com ara els següents: les dimensions: les empreses petites tenen menys possibilitats; l'edat: les menys antigues no tenen l'historial requerit per la majoria d'institucions financeres; l'opacitat: les PIME en general no porten un control adequat de la seua informació i no generen els informes mínims que se'ls requereixen en el tràmit del crèdit; garantia: en moltes ocasions la dilució del risc en l'operació de crèdit es fa mitjançant el dipòsit d'una caució, però aquesta no sempre es té o està disponible per a aquest fi; i taxa d'interès: el cost major en una operació de crèdit és el pagament d'interessos, cost que pot resultar bastant alt per a una PIME.

A partir d'aquestes teories s'estableix un model en el qual s'emmarquen les variables que poden facilitar o limitar l'obtenció de crèdit per les empreses; això a fi d'establir quines són les variables principals i com influeixen en l'obtenció d'un crèdit, i particularment d'esbrinar si algunes d'aquestes variables poden facilitar l'obtenció del crèdit: per exemple, la 
relació de préstec, considerada com el coneixement que el banc té de l'empresa a través del contacte i la relació amb aquesta.

Els resultats s'analitzen a partir de 208 enquestes realitzades a nivell nacional; l'estudi empíric analitzat a través de la tècnica d'equacions estructurals ens ajuda a contrastar les hipòtesis establides i poder validar el model proposat en aquest estudi.

Els resultats empírics confirmen la relació causal de la informació, la garantia, la relació de préstec i l'edat de l'empresa amb l'obtenció de crèdit, i també que aquestes variables tenen influència en el resultat d'aquest. A més, trobem que el cost dels interessos es veu influenciat per la informació, les dimensions de l'empresa i la garantia. Quant a la taxa d'interès, no es veu una influència significativa d'aquesta respecte a l'obtenció del crèdit, amb la qual cosa es rebutja la hipòtesi que defensava el contrari.

Aquest estudi contribueix a un millor coneixement dels obstacles de les PIME per a obtenir crèdit i de la relació entre aquestes per a facilitar-se aconseguir-ne. A més, mostra d'una manera més detallada el paper que en el cost dels interessos tenen les diferents variables que es desprenen dels models establits prèviament. 


\section{RESUMEN}

El objetivo del presente trabajo es analizar la fuente de donde obtienen recursos las pymes para su operación, se analizan las teorías de la literatura que hablan sobre la forma en que las pymes solicitan crédito y los distintos obstáculos que se encuentran para obtenerlo. La revisión de la literatura académica muestra que en ocasiones las empresas prefieren mantenerse operando con recursos propios, o buscan una fuente externa vía endeudamiento, dejando al final el ingreso de nuevo capital, pues este puede contribuir a la pérdida de control de la empresa.

Además, la literatura nos da a conocer varios obstáculos que la empresa tiene cuando desea solicitar un crédito, tales como: el tamaño, las pequeñas tienen menos posibilidades; la edad, las menos antiguas no cuentan con el historial requerido por la mayoría de instituciones financieras; la opacidad, las pymes por lo general no llevan un control adecuado de su información y no generan los reportes mínimos solicitados en el trámite del crédito; garantía, en muchas ocasiones el diluir el riesgo en la operación de crédito se hace mediante el depósito de un colateral, bien que no siempre se tiene o se está disponible para tal fin y, tasa de interés, el costo mayor en una operación de crédito es el pago de intereses, costo que puede resultar bastante alto para una pyme.

A partir de estas teorías se establece un modelo en el cual se enmarcan las variables que pueden ayudar o limitar la obtención de crédito de las empresas. Esto con la finalidad de establecer cuales son las principales y como influyen en la obtención de un crédito. Además, si algunas de estas variables pueden ayudar o facilitar la obtención del mismo, 
por ejemplo, la relación de préstamo, establecida como el conocimiento que el banco tiene de la empresa a través del contacto y relación con la empresa.

Los resultados se analizarán a partir de 208 encuestas realizadas a nivel nacional; el estudio empírico analizado a través de la técnica de ecuaciones estructurales nos ayudará a contrastar las hipótesis establecidas y poder validar el modelo propuesto en este estudio.

Los resultados empíricos muestran que la relación causal entre la información, la garantía, la relación de préstamo y la edad de la empresa con la obtención de crédito está confirmada, y que tienen influencia en el resultado del mismo. Además, encontramos una relación entre el costo del crédito que se ve influenciado por la información, el tamaño de la empresa y la garantía. En cuanto a la tasa de interés, la dependencia que tiene respecto a la obtención del crédito no se ve una influencia significativa, con lo cual se desecha la hipótesis establecida en este precepto.

Este estudio contribuye a un mejor conocimiento entre los obstáculos de las pymes para obtener crédito y la relación entre las mismas para facilitar el conseguirlo. Además, muestra de una manera más detallada el papel del costo del crédito entre las distintas variables que se desprenden de los modelos establecidos previamente. 


\begin{abstract}
The aim of this study is to analyze the source from which SMEs obtain resources for their operation, we analyze the literary theories that talk about how SMEs apply for a credit and the various obstacles they face during the process. The reviewed academic literature shows that firms sometimes prefer to keep operating on their own resources or seek an external source via debt, thus, new capita input becomes last, as this can contribute to company control loss.
\end{abstract}

In addition, the literature reveals a number of obstacles that the company has when it wants to apply for a credit, such as: size, the small ones have less possibilities; the age, the younger companies do not have a credit history which is required by most financial institutions; the opacity, SMEs do not usually have adequate control of their information and do not generate the minimum information required in the processing of crédito approval; guarantee, on many occasions in order to dilute the risk in the credit transaction a collateral is deposited, though SMEs not always have or are available for that purpose and last, interest rate, the highest cost of credit is the interest payment, cost can be quite high for a SME.

A model is provided from these theories which frames variables that can help or limit credit approval from companies. This is done to establish which variables are the main ones and how they influence crédito approval. Also, if some of these variables can help or facilitate the provision thereof, for example, the lending relationship, defined as the information the bank has of the company through the contact and business relation with the company. 
The results were analyzed out of 208 national surveys, the empirical study analyzed through the structural equation technique which it will help us compare the assumptions made and to validate the model proposed in this study.

The empirical results show that the causal relation among information, guarantee, lending relationship and age of the company, with obtaining a credit is confirmed, and does influence the outcome. We also found a relation between the cost of interest which is influenced by information, the size of the company and the guarantee. Regarding the interest rate, the dependence respect to obtaining a credit is not a significant influence, thus, this hypothesis is discarded.

This study contributes to a better understanding among the obstacles of SMEs to obtain a credit and the relation between them to ease the strain. It also shows a more detailed role of the cost of interest among the different variables that arise from the previously established models. 


\section{ÍNDICE DE CONTENIDO}

\section{INTRODUCCIÓN}

1.1. Estado de la cuestión......................................... 29

1.2. Justificación de la tesis..................................... 34

1.2.1. Importancia del tema y área de investigación............................... 34

1.2.2. Carencias de la literatura..................... 38

1.2.3. Problemática del País......................... 41

1.3. Objetivos.............................................. 43

1.4. Posicionamiento Teórico................................... 44

1.5. Estructura de la investigación..........................

\section{MARCO TEÓRICO}

2.1. Introducción.............................................. 53

2.2. Teoría de la estructura de capital........................ 55

2.3. Teoría de la selección jerárquica.......................... 68

2.4. Teoría de equilibrio estático.............................

2.5. Teoría de la información asimétrica...................... 87

2.6. Teoría de la agencia...................................... 94

2.7. Teoría del flujo de efectivo libre......................... 106

2.8. Teoría de sincronización del mercado................... 109

2.9. Otras aportaciones.................................... 113

2.9.1. Obstáculos para acceder al crédito............ 113

2.10. Modelo teórico......................................... 124

\section{HIPÓTESIS}

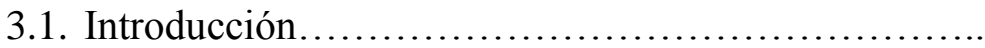


3.2. Información financiera........................... 137

3.3. Garantía...................................... 143

3.4. Relación de préstamo.......................... $\quad 150$

3.5. Edad de la empresa............................. 157

3.6. Relación de préstamo y la falta de información........ 164

3.7. Información financiera y el costo del crédito........... 171

3.8. Tamaño de la empresa............................ 178

3.9. Garantía y el costo del crédito..................... 185

3.10. Costo del crédito................................ 191

3.11. Facilidad en la obtención del crédito............... 197

\section{METODOLOGÍA}

4.1. Introducción....................................... 209

4.2. Análisis documental............................... $\quad 210$

4.3. Variables utilizadas................................. $\quad 210$

4.4. Características del cuestionario...................... 211

4.4.1 Tamaño de la empresa.................... 213

4.4.2 Edad de la empresa...................... 215

4.4.3 Información............................. 217

4.4.4. Tasa de interés......................... 221

4.4.5. Relación de préstamo.................... 226

4.4.6. Garantía................................. 237

4.5. Base de datos.................................. 244

4.6. Fuentes de información........................... $\quad 245$

4.6.1. Población objeto de estudio................ 245

4.6.2. Determinación de la muestra............... 246

4.7. Información de indicadores del cuestionario........... 251

4.7.1. Fuente de financiamiento................. 251 
4.7.2. Plazo del crédito........................... 254

4.7.3. Destino del crédito..................... 255

4.7.4. Rechazo de solicitud de crédito............ 260

4.7.5. Tasa de interés............................ 261

4.7.6. Relación de préstamo..................... 263

4.7.7. Garantía................................ 268

4.8. Técnicas de Análisis............................... 271

4.8.1. Metodología de ecuaciones estructurales... 272

4.8.2. Modelo de ecuaciones estructurales........ 273

\section{ANÁLISIS DE RESULTADOS}

5.1. Introducción..................................... 283

5.2. Validación de escalas y pruebas invariancia............. 283

5.3. Análisis de resultados............................. 287

5.3.1. Análisis de los modelos estructurales sobre la obtención del crédito.................................. 296

5.3.1.1. Influencia directa de la información en la obtención del crédito (Hipótesis

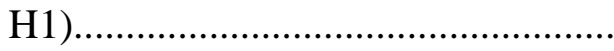

5.3.1.2. Influencia directa de la garantía en la obtención del crédito (Hipótesis $\mathrm{H} 2)$.

5.3.1.3. Influencia directa de la relación de préstamo en la obtención del crédito (Hipótesis H3). 
5.3.1.4. Influencia directa de la antigüedad de la empresa en la obtención del crédito (Hipótesis H4)

5.3.1.5. Influencia directa de la relación de préstamo sobre la información de la empresa (Hipótesis H5)

5.3.2. Análisis de los modelos estructurales que indican la influencia de variables sobre el costo del crédito

5.3.3. Análisis de los modelos estructurales que indican la influencia de variables sobre la tasa de interés

\section{CONCLUSIONES}

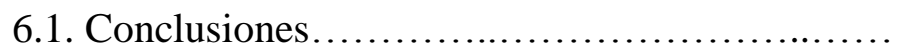

6.2. Limitaciones y futuras líneas de investigación...

\section{ANEXO}

8.1. Cuestionario................................ 


\section{ÍNDICE DE TABLAS Y FIGURAS}

\section{LISTA DE TABLAS}

2.1. Constructos e indicadores del modelo sobre los efectos de coerción.

2.2. Factores de obstáculos entre bancos y pymes

2.3. Obstáculos de financiamiento......

2.4. Fuentes de financiamiento por tamaño de empresa.

2.5. Técnicas de préstamo.

3.1. Uso de fuentes específicas de administración de la información

3.2. Auto evaluación de las restricciones financieras y la edad de la empresa.

3.3. Obstáculos por antigüedad.

4.1. Clasificación de tamaño de empresa........................ 214

4.2. Evidencia empírica sobre relación de préstamo............... 236

4.3. Factores que bloquean el acceso al crédito................. 244

4.4. Ficha técnica del cuestionario.............................. 249

4.5. Características de la muestra (entrevistados)................ 249

4.6. Características de la muestra (empresas)................... 250

4.7. Plazo del crédito obtenido.................................. 254

4.8. Destino u ocupación del crédito............................. 256

4.9. Causa de rechazo de créditos............................ 260

5.1. Medidas de bondad del ajuste del modelo de medida........ 285

5.2. Análisis de la dimensión, confianza y validez de la escala de valor percibido. 
5.3. Medidas de bondad de ajuste de valor percibido............

5.4. Validez discriminante de las escalas relacionadas con el valor percibido......................................

5.5. Análisis de la dimensión, confianza y validez de la medida de escalas.

5.6. Índices del ajuste del modelo factorial de segundo orden de la percepción de valor

5.7. Ecuaciones estructurales. 295

5.8. Fiabilidad de los segundos modelos de la hipótesis H1..... 300

5.9. Fiabilidad de los segundos modelos de la hipótesis $\mathrm{H} 2$....... 306

5.10. Fiabilidad de los segundos modelos de la hipótesis H3.......

5.11. Fiabilidad de los segundos modelos de la hipótesis H4.......

5.12. Fiabilidad de los segundos modelos de la hipótesis H5.......

5.13. Parámetros estimados de las variables en el modelo estimado de las hipótesis H6, H7 y H8

5.14. Fiabilidad de los modelos de medida de las hipótesis H6, H7 y H8.

5.15. Parámetros estimados en el modelo estructural de las hipótesis H6, $\mathrm{H} 7$ y $\mathrm{H} 8$.

5.16. Porcentaje de pymes en Centroamérica

5.17. Parámetros estimados de las variables en el modelo estimado de las hipótesis H9 y H10....

5.18. Fiabilidad de los modelos de medida de las hipótesis H9 y H10.

5.19. Parámetros estimados en el modelo estructural de las hipótesis $\mathrm{H} 9$ y $\mathrm{H} 10$.

5.20. Causas de rechazo en solicitudes de crédito 


\section{LISTA DE FIGURAS}

2.1. Valor de la empresa para diferentes niveles de financiamiento vía deuda

2.2. Continuidad de la empresa y fuentes de financiamiento.

2.3. Modelo hipotético de las finanzas de un modelo familiar

2.4. Valor de empresa y deuda como una función de la promesa de pago a acreedores

2.5. Valor de empresa

2.6. Decisión de inversión.

2.7. Teoría de la jerarquía financiera

2.8. Efectos de la coerción sobre el comportamiento de búsqueda financiera.

2.9. Modelo final sobre los efectos de la coerción sobre el comportamiento de búsqueda financiera

2.10. Valor de la empresa bajo el financiamiento óptimo.

2.11. Mezcla

de

deuda

$\mathrm{y}$

capital

2.12. Mezcla de deuda y capital Coeficiente 0.54 .

2.13. Tasa retorno del banco en relación a tasa de interés cobrada

2.14. Modelo cognoscitivo del contrato.

2.15. Componentes clásicos de la teoría de agencia...............

2.16. Obstáculos en la relación de bancos con pymes

2.17. El ciclo de aprendizaje. 
2.18. Modelo teórico

3.1. Impacto de obstáculos financieros específicos sobre el crecimiento de la empresa..............................

3.2. Efectos de garantía sobre la utilidad del banco....

3.3. Probabilidad estimada de ser desanimado: deudores de bajo riesgo.

3.4. Probabilidad estimada de ser desanimado: deudores de alto riesgo.

3.5. Relación de préstamo marginal

3.6. Préstamos sobre estados financieros de pymes

3.7. Función error de detección.

3.8. Función de los costos de solicitud.

3.9. Marco de desafíos financieros de las pymes.............................................

3.10. Beneficio sobre la tasa de interés al pertenecer a una IGR..

3.11. Tasa de interés en función del volumen del crédito y tamaño de la empresa.

3.12. Hipótesis en modelo teórico.

4.1. Participación de pymes en el sector industrial manufacturero

4.2. Perfil de edad de los costos de endeudamiento.............. 216

4.3. Nivel de tasas de interés bancarias y riesgo tomado.........

4.4. Probabilidad estimada de ser desanimado: deudores de riesgo promedio

4.5. Fuentes de financiamiento

4.6. Fuentes de financiamiento de acuerdo al tamaño de empresa. 
4.7. Tiempo de tramitación del crédito

4.8. Préstamos para inversiones vs. Préstamos para reestructurar.

4.9. Emisión total de líneas de crédito renovables frente a préstamos a largo plazo.

4.10. Cambio de planes de empresas limitadas y no limitadas de financiamiento.

4.11. Niveles de tasa fija.

4.12. Niveles de tasa variable.

4.13. Años de relación con el banco principal.

4.14. Número de bancos con los que trabaja la empresa...

4.15. Número de reuniones al año con su ejecutivo del banco.

4.16. Porcentaje de operaciones que realiza con su banco principal

4.17. Cantidad de servicios utilizados por la empresa de su banco principal.

4.18. Proporción entre el valor de la garantía y el monto del crédito

4.19. Demanda de préstamos por pymes en Italia

5.1. Resultados obtenidos sobre el modelo teórico.

5.2. Diagrama de pasos de los modelos estructurales de la hipótesis $\mathrm{H} 1$ 
5.4. Diagrama de pasos de los modelos estructurales de la hipótesis $\mathrm{H} 2$.

5.5. Ecuaciones estructurales propuestas en la hipótesis $\mathrm{H} 2 \ldots \ldots$

5.6. Diagrama de pasos de los modelos estructurales de la hipótesis $\mathrm{H} 3$

5.7. Ecuaciones estructurales propuestas en la hipótesis $\mathrm{H} 3 . . . .$.

5.8. Diagrama de pasos de los modelos estructurales de la hipótesis $\mathrm{H} 4$.

5.9. Diagrama de pasos de los modelos estructurales de la hipótesis H5.

5.10. Diagrama de pasos de los modelos estructurales de las hipótesis H6, $\mathrm{H} 7$ y H8.

5.11. Ecuaciones estructurales propuestas en las hipótesis H6, $\mathrm{H} 7$ y $\mathrm{H} 8$

5.12. Diagrama de pasos de los modelos estructurales de las hipótesis $\mathrm{H} 9$ y $\mathrm{H} 10$.

5.13. Ecuaciones estructurales propuestas en las hipótesis H9 y H10 


\section{Introducción}




\section{"Si piensas que puedes o piensas que no puedes, tienes razón" Henry Ford}




\subsection{Estado de la Cuestión}

El financiamiento para empresas es de los temas más comentados en el mundo empresarial; el crecimiento y, en ocasiones subsistencia, da una alta relevancia al manejo de recursos externos; para la mayoría de las empresas tiene una gran importancia en su quehacer diario. Sin importar el tipo de economía de que se trate, el crédito forma parte esencial para crear una empresa, potenciar su desarrollo, llevar a cabo un proyecto o mantener un capital de trabajo constante. Ello es así porque solo una minoría puede soportar su viabilidad con recursos propios, y además desde el punto de vista empresarial ello no es lo más eficiente.

Siempre ha sido complicado obtener créditos, por muchas y variadas razones. En especial en los últimos años este problema se ha agudizado. La incógnita global sobre la situación de los principales bancos, algunos de ellos orillados a la quiebra, ha provocado que las medidas sean más estrictas y a un costo más caro. De ahí la importancia que tiene el hecho de que las empresas puedan prevenir, conocer o empiecen a formarse un historial crediticio. Ello es necesario para poder contar con dicha herramienta en caso de necesitarlo en un futuro. El financiamiento, es considerado una de las principales herramientas de crecimiento y desarrollo de las empresas, en consecuencia, también una parte fundamental para la supervivencia del negocio.

El tema de financiamiento es abordado desde diversos ámbitos y que hay varios factores que influyen las características del mismo. Es por ello que para entender el financiamiento disponible para las pymes, se debe entender la situación del financiamiento en general, y las diferentes teorías 
que se desprenden sobre este tema. De acuerdo a Gitman (1997), el financiamiento se define como la adquisición de fondos a nivel de individuos, de empresas y de Gobierno para hacer frente a sus necesidades y lograr su buen funcionamiento. Para Perdomo Moreno (2001:207), el concepto de financiamiento es "la obtención de recursos que requiere una empresa para el desarrollo normal de operaciones", o bien: "la obtención de recursos de fuentes internas o externas, a corto, mediano o largo plazo, que requiere para su operación normal y eficiente una empresa pública, privada, social o mixta".

"El crédito comercial puede ser particularmente importante en economías con sistemas financieros débiles, donde las industrias con alta dependencia del crédito comercial exhiben altas tasas de crecimiento" (Fisman y Love, 2003:1). Un aspecto interesante es que tanto en los países desarrollados como en los países en vías de desarrollo las pymes han tenido menor acceso al financiamiento externo, además de estar más limitadas en su operación y crecimiento. (Berger y Udell, 1998). Además, en países en desarrollo, recursos provenientes de amigos y familiares juegan un rol más importante que en países desarrollados (Beck y Dermiguc-Kunt, 2006).

Como lo menciona Zambaldi et al. (2011), bajo el argumento de que el acceso a crédito de las pequeñas empresas es crucial por su potencial para el desarrollo de mercado e innovación empresarial, varios investigadores dedican esfuerzos para entender los efectos del crédito en la prosperidad de las pequeñas empresas. Esta limitante en cuanto al acceso a financiarse mediante deuda para las pymes, se ha agrupado bajo varios conceptos que muestran los principales obstáculos financieros, tales como: edad, tamaño y estructura de la empresa son algunas categorías que describen los 
obstáculos; además, más antiguas, más grandes y empresas de inversión extranjera reportan menores obstáculos financieros. (Beck et al., 2006)

De acuerdo a cifras de la Secretaría de Economía, alrededor del 95\% de las empresas en el país son pymes, pero la mortandad de las mismas también es muy alta; hay varios motivos sobre esta situación, algunos señalan que es la falta de financiamiento, en este estudio se trata de encontrar las dificultades que encuentran las pymes sobre este aspecto. Jóvenes y menos educados dueños de pymes usan más activamente el financiamiento externo - aunque mayor educación reduce el miedo a denegar un préstamo- mientras que más maduros y más educados dueños se encuentran con menor deseo de conseguir financiamiento externo (Vos et al., 2007).

De acuerdo a Beck et al. (2006), es en los países que tienen sistemas financieros más avanzados en los cuales las pymes tienen más acceso al capital, sugiriendo la posible existencia de una relación causal entre el desarrollo financiero y la viabilidad de las pymes. No obstante, las pymes tienen un papel importante en cualquier nación, Cull et al. (2006:3018) mencionan que "las pymes juegan un rol más significativo que la proporción del total de empleos que pudieran sugerir". También se ha mencionado por parte de De la Torre et al. (2010) que la idea general es de que los bancos grandes y extranjeros no están normalmente interesadas en las pymes.

Una de las teorías principales a la cual nos podemos referir y de la cual derivan algunas otras importantes, es la de Modigliani y Miller (1958). Su teoría de la estructura de capital sugiere que en un capital perfecto y mercados de crédito, la forma de invertir de las empresas es irrelevante en la 
toma de sus decisiones de financiamiento. Pero, sabiendo que la actualidad no nos encontramos en estas condiciones, es interesante encontrar entonces como toman las empresas estas decisiones. La región puede tener algún efecto en la estructura de capital de las pymes (Psillaki y Daskalakis, 2009). El endeudamiento mostrado en la estructura de las empresas permanece con el tiempo, según Lemmon et al. (2008), pero es algo que sentimos no es una regla, y este se pueda dar más por las necesidades y condiciones de la empresa.

Muchas de las pymes son de patrimonio familiar, es en ocasiones una actividad que pasa generacionalmente, en esta se mezclan los recursos para sostener la operación del negocio familiar y la manutención de la familia; considerando las opciones de financiamiento más para mantener la actividad o por una situación extraordinaria que pudiera poner en riesgo la continuidad de la misma, que de una forma de crecimiento.

Cuando hablamos precisamente de la capacidad de deuda, se pueda derivar otra teoría, la teoría de la selección jerárquica; para Lemmon y Zender (2010) esta teoría parece ser una buena descripción de las políticas financieras de una muestra de empresa. Esta teoría nos indica que la empresa prefiere utilizar fondos internos, deuda o capital, en ese orden, para financiar sus inversiones. Myers y Majluf (1984) ven el problema de esta última opción cuando el inversionista no cuenta con la misma información que la empresa, se generan asimetrías en la información.

Se puede ver que se desprenden varios obstáculos cuando se quiere acceder al crédito, y las pymes son las que encuentran mayores restricciones; no obstante el número de las mismas sobrepasa en mucho al 
de las empresas grandes, no solo en México sino a nivel internacional. Una vez comentada la situación en general del crédito para pymes, mediante la revisión a la literatura más importante sobre el tema, trataremos de identificar los aspectos más relevantes que sirvan de base para la elaboración de nuestro modelo teórico. 


\subsection{Justificación de la tesis}

\subsubsection{Importancia del tema y área de investigación}

En mi desarrollo profesional, las cuestiones relativas a la financiación ha sido trabajado, nos solo desde un punto de vista académico. Mi bagaje en este ámbito se ha desarrollado también en negociaciones y solicitudes con instituciones financieras. A su vez, además del medio empresarial he podido escuchar a gente cuando opina sobre el tema. El interesarme por el área financiera ha coadyuvado a definirme por realizar este estudio sobre el financiamiento a empresas, tener un conocimiento mayor sobre el tema y ayudar en la literatura del mismo.

De acuerdo a la literatura a analizar del tema, y trabajos similares anteriores, se puede enriquecer lo que ya existe, tal vez no solo de forma global sino también local. Un nuevo punto de vista, el poder palpar el pulso de diferentes empresas, de cierto sector y se puedan establecer unas hipótesis que fortalezcan el conocimiento sobre financiamiento.

Como se comentó en la introducción, la "Teoría de la estructura de Capital" de Modigliani y Miller (1958) es la referencia más importante sobre la que se desprenden otras teorías en las cuales el endeudamiento o financiamiento de las empresas se toca. Teorías como la "teoría basada en impuestos", "teoría de costos de agencia" y "teoría de información asimétrica" se desprenden del modelo de Modigliani y Miller (Michaelas et al., 1999). Myers (2001) comentaba que bajo esta teoría se explican las fuentes de financiamiento de las empresas; las diferentes fuentes de 
financiamiento podrían afectar tanto positivamente como negativamente, comentan Romano et al. (2001).

Las estructuras de capital son óptimas en diferentes puntos del ciclo de crecimiento financiero de la empresa (Berger y Udell, 1998). En las decisiones de la estructura de capital intervienen varios factores como la industria, utilidades, tamaño de la empresa (Frank y Goyal, 2009). A final de cuentas, las empresas tendrán un objetivo sobre el nivel de deuda o apalancamiento que deseen tener, refieren Kayhan y Titman (2007), lo cual generaría, en consecuencia, su estructura de capital. Más del $80 \%$ establecería dicho objetivo, según Graham y Harvey (2001).

En la actualidad, el sector pyme en particular pareciera no realizar actividades de planeación, del cual pueda desprender el nivel de estructura de capital que desee mantener; además, la percepción del empresario respecto a la oferta de crédito de las instituciones financieras es de un nivel restringido; y si se ha comentado que los créditos son parte importante en el desarrollo de las empresas, es relevante el que realmente conozcan la situación verídica sobre el financiamiento.

Un aspecto que siempre limita el crédito es la información asimétrica. Para López-Gracia y Sogorb (2008) la "teoría de la selección jerárquica" nace como consecuencia de dicha información. Hasta 3 diferentes formas de información asimétrica pudiera existir (Myers y Majluf, 1984), ello complica un poco más el tema. La empresa perseguirá el menor costo al buscar recursos, y el jerarquizar las opciones se hará de forma que se minimicen los costos (Leary y Roberts, 2010). Para Fosberg (2008), las empresas que aplican esta teoría no cuentan con una adecuada 
estructura de capital. Será importante conocer mediante el estudio empírico que tanta asimetría existe en la información de las empresas cual es su prioridad para buscar crédito.

Otra forma de explicar la forma de endeudarse es determinar si existe un beneficio fiscal bajo la "teoría de equilibrio estático" (Myers, 2003), también Fama y French (2002) hacen referencia a que las empresas busquen esta ventaja. Bajo esta teoría, la perspectiva es de que se concilien beneficios y costos cuando hay deuda (Sogorb-Mira y López-Gracia, 2003). Haciendo un resumen de los factores envueltos en esta teoría, Hackbarth et al. (2007) hacen referencia, entre otros, al poder de negociación, situación que nos puede llevar a cuando se tiene una relación con el banco, lo cual es conocido en la literatura académica como "relación de préstamo".

La relación de préstamo refiere al lazo entre prestamistas y prestatarios que puede beneficiar económicamente a ambos (Elsas, 2005); esta relación es de gran relevancia en un préstamo, señalan Behr et al. (2011). La duración de la misma debiera ser un factor relevante para el crédito, menciona Cole (1998). Si hubiera más tiempo invertido en dicha relación, debiera haber más disponibilidad de crédito, comentan Petersen y Rajan (1994). Esto nos indica que una relación con bancos puede ayudar a las empresas para conseguir préstamos, que pasa si la empresa no ha cultivado relación alguna. Aquí podríamos enfrentarnos a un obstáculo, la literatura señala varios obstáculos que encuentran las empresas cuando requieren financiamiento.

Una parte primordial de la tesis sobre la cual se hará énfasis son los obstáculos que encuentran las empresas cuando quieren acceder a un 
crédito. La informalidad, falta de información y falta de garantías, son conceptos que mencionan los bancos para limitar el crédito, mencionan De la Torre et al. (2009). Beck et al. (2005), por ejemplo, analizan si los obstáculos varían en relación con el tamaño de la empresa. Hyytinen y Pajarinen, (2008) mencionan que mientras la operación de las empresas grandes está bien documentada, la ausencia de ello en las pymes resulta en que no puedan ser evaluadas, esto hace referencia a que son opacas. Para Berger y Udell (1998:3), “quizás la característica más importante que defina el financiamiento de las pymes es la opacidad en la información”.

Por mencionar algunos de los obstáculos en este epígrafe, podemos ver que la tramitación de un crédito puede volverse tan complicada que la empresa no lo haga, y volvemos al problema de que las pymes consideran que no hay condiciones establecidas para facilitarles la obtención de este recurso.

Es por ello que mediante este estudio se pretende ayudar a las pymes en esta búsqueda del conocimiento sobre el financiamiento, conozcan las diferentes alternativas para conseguirlo, y de cuales son los obstáculos que generalmente se tienen con las instituciones financieras para determinar si pueden superarse y conseguir su objetivo de adquirir deuda vía financiamiento para cubrir sus necesidades. 


\subsubsection{Carencias de la literatura}

Una de las premisas que se desprenden del modelo de Modigliani y Miller es la consideración de que la empresa cuenta con cierto nivel de flujo de efectivo. Esto lo mencionan Frank y Goyal (2007); aunque partimos de la idea de que la empresa no cuenta con suficientes recursos con lo cual debe buscar de manera externas los fondos suficientes para llevar a cabo sus planes. Aunque se ha comentado la dificultad que tienen las pymes para obtener crédito. Más aún, como señalan Michaelas et al. (1999), las pymes cuentan con menores niveles de deuda en comparación con las empresas grandes debido a que les genera costos mayores. Para Baas y Schrooten (2006) además de los costos que le implica a la empresa, para los bancos les resulta costoso el obtener información de las mismas.

La literatura se ha centrado principalmente en señalar el costo del crédito y las tasas de interés como un obstáculo para que las pymes accedan al crédito; pero no se ha especificado si el costo principal del crédito tiene alguna influencia sobre el nivel de la tasa de interés, situación que se intenta revisar con el modelo planteado.

Siguiendo con otra de las teorías principales relacionadas con el tema, la "teoría de la selección jerárquica", como hace mención Lemmon y Zender (2010), la empresa preferirá fondos internos antes que deuda, y deuda antes que nuevos socios. La literatura no ha mostrado si la empresa cuenta con las mismas posibilidades para seguir este orden jerárquico. Es decir, si la pyme tuviera las mismas oportunidades de elegir cual sería su decisión. Las pymes tienen más altos costos por su información asimétrica, señalan Frank y Goyal (2003), de ahí se ve influenciado el comportamiento 
de financiamiento. En cambio Myers (2001) refiere a que si la empresa en las mismas circunstancias se decidiera por deuda o capital, quienes financian con deuda no tiene un interés mayor por la firma.

Ahora bien, si uno de los mayores costos se genera por la asimetría en la información, y esta se deriva en mucho por la opacidad de las empresas. Para Berger y Udell (1998:3), “quizás la característica más importante que defina el financiamiento de las pymes es la opacidad en la información”. Gertler (1988), por ejemplo, menciona que el problema de la información asimétrica se da mayormente en empresas nuevas y de pocos años de operación; así que la antigüedad de la empresa conlleva este problema. Formas de mitigar este problema se dan, por ejemplo, con el ofrecimiento de una garantía, así lo señalan Berger et al. (2010); dicho requerimiento de garantía afecta más a las pymes que a las empresa grandes (Beck et al., 2005); lo cual supondría un doble problema para la pequeña empresa. Si nos referimos al costo, como lo menciona Jiménez y Saurina (2004), puede ser que los bancos den a elegir entre una tasa alta de interés y no garantía o lo contrario.

Entendemos, de acuerdo a la literatura, que la opacidad genera un problema u obstáculo para obtener un crédito, aunque no se hace referencia si la pyme, desde antes de encontrarse en la situación de requerimiento de recursos se ha preocupado por contar con la información para la mínima administración de su negocio, si cuenta con los servicios de un profesional del tema, o le revisa un experto en el área; más aún, si las pymes tienen dificultades para poder generar la información correcta o cuentan con un sistema de registro adecuado a su tamaño. En nuestro modelo trataremos de contar con estos elementos. 
Una de las herramientas más importantes para subsanar algunas de las carencias de la empresa, como la opacidad, es la relación de préstamo, esta tiene un efecto positivo en cuanto a créditos se refiere (Petersen y Rajan, 1994). Además, entre más relaciones y más duraderas las posibilidades aumentan, consideran Cardone et al. (2005); o pudiera haber un efecto positivo en las tasas del crédito (Degryse y Ongena, 2005). Además este beneficia también a los bancos (Vickery, 2008), al volverse más eficientes en la revisión de la información; no solo eso, pues la gama de servicios a ofrecer por el banco se vuelve más variada (Bharath et al., 2007).

Por supuesto, si el interés inicial es de la empresa, para el obtener fondos; la teoría parte de que es ella quién debiera hacer labor para cultivar la relación de préstamo, mantenerla y hacerla crecer; y aún cuando se ha reflejado como algunos autores muestran las ventajas que conlleva para las mismas instituciones financieras, no se comprueba claramente el papel $\mathrm{u}$ obligación que tienen las instituciones financieras para facilitarle a la empresa la oferta de crédito, más allá de saber que la rentabilidad o beneficio del negocio sea lo atractivo para el acreedor. Así que evaluaremos en nuestro estudio empírico la participación del banco en este tipo de relaciones. 


\subsubsection{Problemática del país}

La oferta de financiamiento en México pudiera considerarse basta para algunos sectores del ambiente económico. No obstante, el sector empresarial, en especial el de pymes, suele quejarse de las oportunidades que existen en el país para obtener crédito. Razones como el costo del mismo, lo complicado de tramitarlo, el riesgo propio de la empresa que no da confianza al acreedor, entre otros factores, resume la falta de recursos con que cuenta este vasto sector para poder crecer y operar.

México cuenta con muchos bancos en su sistema financiero, la mayoría de ellos de capital extranjero o subsidiarias de un banco extranjero, principalmente de España y Estados Unidos. En particular para las pymes resulta complicado el financiarse mediante estas instituciones, por lo cual las Cajas Populares han crecido mucho y su cuota de mercado en pequeños empresarios se ha vuelto más fuerte. Por supuesto, familiares, amigos, casas de empeño, son otras de las opciones que las personas con negocios pequeños utilizan también. Además, mucha gente no desea trabajar con bancos, hay una cultura arraigada en varios sectores de la población que el riesgo de perder bienes o propiedades al trabajar con ellos es muy alto y que los requerimientos son muchos. Esto sin importar que tal vez otras opciones lleguen a ser más caras.

Además, el costo de intermediación financiera en nuestro país, es considerado uno de los más caros en América Latina. El sistema financiero se ha visto engrosado en los últimos años por el ingresos al mercado de nuevas instituciones financieras. Ya no solo la oferta como tal de bancos cuya actividad principal es la intermediación financiera, si no empresas de 
otros giros como aquellas de venta de bienes de consumo han ingresado al sistema financiero creando sus propios bancos; más por la alternativa de ampliar su oferta de bienes y servicios con el consiguiente beneficio económico, que por dar solución a los problemas de las actividades primarias de la banca.

El gobierno en los últimos años ha tratado de implementar varios esquemas para apoyar el desarrollo de las empresas. Desde la Secretaría de Economía hasta una institución descentralizada como es Nacional Financiera, tratan de hacer llegar recursos a las empresas de diferentes maneras, desde factoraje hasta créditos; no obstante, aun la mayoría de empresas en el país no llegan a conocer y aprovechar estas opciones.

En ocasiones esta falta de crédito a pymes pudiera darse por desconocimiento o por que la empresa no realiza lo necesario para poder ser sujeto de crédito. Por ello, este estudio pudiera servir para que la empresa conozca aquellas deficiencias propias que le repercuten la negación del crédito y las ventajas que pudiera tener respecto a lo que ya tiene o realiza, o puede implementar, y que son parte importante en la obtención de crédito. 


\subsection{Objetivos}

Objetivo General: De acuerdo a las opciones de financiamiento existentes, proponer un modelo alternativo que pueda resultar más eficiente en el apoyo a las pymes para recibir financiamiento y poder acceder a mejores condiciones de crédito ya sea de las instituciones de banca gubernamental y/o de la banca privada, o de algunas otras fuentes de financiamiento.

Objetivos específicos: Identificar el papel de la información en la tramitación de un crédito; determinar si la garantía es obligatoria cuando se solicita un crédito; mostrar la importancia que tiene la relación de préstamo cuando se intenta obtener financiamiento; analizar el impacto que tiene la antigüiedad de la empresa al requerir un préstamo; revisar la influencia que tiene la relación de préstamo cuando la empresa no genera la información financiera mínima requerida; mostrar el efecto de la información de la empresa sobre el costo del crédito; determinar como influye el tamaño de la empresa en los intereses pagados del crédito; revisar como afecta el otorgamiento de garantía en el costo del préstamo; identificar como se relaciona el costo del crédito con la tasa de interés y revisar si existe una relación entre la obtención del crédito y la tasa de interés. 


\subsection{Posicionamiento teórico}

Nuestra tesis se basa principalmente en algunas corrientes teóricas en las cuales el tema de capital y deuda es preponderante. Modigliani Miller (1958:261) en su estudio "el costo de capital, finanzas corporativas y la teoría de inversión" dan origen a la "Teorías de la estructura de capital", en la cual comienzan a plantear temas como las "técnicas de financiamiento de las empresas, los presupuestos de capital y los comportamientos de inversión". Además, dentro de su teoría involucran el tema del costo del capital, indicando que de acuerdo a la estructura que se defina dentro de la organización, dependerá el costo que tenga la empresa.

De esta teoría emanaron varias en las cuales podemos encontrar una relación con el endeudamiento de las empresas. Así, por ejemplo, tenemos la teoría cuya principal característica es la asimetría en la información (Myers, 1984). Y la relación que muestra esta teoría nos dirige a analizar la relación de agencia que puede existir en cualquier interacción, en la cual la toma de decisiones es relevante como mencionan Jensen y Meckling (1976). Estas teorías nos ayudarán a comprender la relación que se da entre las partes, y, enfocándonos en la información, las diferencias que surgen en el conocimiento entre las partes de dicha información.

Una situación de decisión nace al definir de donde se obtendrán los recursos para la inversión; reconocida como una extensión de la teoría de Donaldson (1961), para Myers y Majluf (1984), las empresas suelen seguir un orden para uso de recursos, considerando inicialmente los fondos internos, luego la deuda con acreedores y por último capital de nuevos inversionistas, esto es la tema principal de la "teoría de la selección 
jerárquica”. Derivada de esta Jensen (1986) nos hace mención a la liquidez que pueda tener la compañía para decidirse por una u otra fuente de recursos al hacer su selección.

Un equilibrio entre el nivel de endeudamiento y el beneficio en impuestos por el pago de intereses es revisado por Kraus y Litzenberger (1973), esto lo podemos encontrar en la teoría del equilibro (the trade off theory). Situación también señalada por Miller (1977). Posteriormente Bradley et al. (1984) le agregan una presentación estándar para señalar la teoría del equilibrio estático. Pero además podemos hablar sobre la valuación en el mercado de la empresa para determinar las decisiones financieras de la compañía (Baker y Wurgler, 2002).

Así como estas teorías han desarrollado un pensamiento específico sobre las cuestiones de la empresa en el tema de la deuda y capital, otros autores han establecido las restricciones principales que encuentran las empresas en su camino hacia el crédito. Beck et al. (2005) han analizado ciertas variables que dificultan mayormente a las empresas el préstamo; conceptos como la garantía, la tasa de interés, la información financieras, son señalado como obstáculos para que las empresas consigan crédito. Estos y otros obstáculos han sido estudiados en la literatura del tema de financiamiento vía deuda (De la Torre et al., 2009; Baas y Schrooten, 2006; Berger y Udell, 2005)

Nos enfocaremos en estas corrientes teóricas considerando que son la fuente principal para realizar nuestro estudio $\mathrm{y}$, poder desarrollar un modelo teórico que muestre tanto las variables a favor como en contra para las pymes en su búsqueda de crédito. Dichas teorías serán desarrolladas a 
detalle en el marco teórico de nuestra tesis, con lo cual podamos proceder a formular nuestras hipótesis después de haber establecido nuestro propio modelo teórico. 


\subsection{Estructura de la investigación}

Una vez realizada una introducción sobre el trabajo que se pretende realizar con la elaboración de la tesis; además de haber señalado la justificación por la cual hemos decidido enfocarnos en temas de financiamiento a pymes; el haber establecidos los objetivos general y específicos que se persiguen con este trabajo y, señalar la corriente de pensamiento sobre la cual se encuadra esta tesis, pasaremos al desarrollo de la misma.

La tesis será realizada conforme a la siguiente estructura: en el siguiente capítulo se establecerá el marco teórico, se revisarán las principales teorías sobre las cuales gira el tema de estudio, para poder llegar a establecer el modelo teórico propio. Posteriormente, en el tercer capítulo se establecerán las hipótesis surgidas del modelo establecido; la metodología a través de la cual se analizarán los resultados empíricos se desarrollará en el cuarto capítulo; en el quinto capítulo será utilizado para mostrar el análisis de la información empírica y los resultados obtenidos; y, por último, se describirán las conclusiones de nuestro trabajo, así como las limitantes encontradas en el desarrollo del mismo y las futuras líneas de investigación, todo esto en el sexto capítulo. Adicionalmente se reflejará la bibliografía considerada en el estudio y como anexo el cuestionario aplicado para el análisis empírico. 


\section{Marco Teórico}


"El éxito requiere de un criterio de calidad, algunas personas no están acostumbradas a un entorno en el que se espera la excelencia" Steve Jobs 


\subsection{Introducción}

Financiamiento es un tema muy en boga en la actualidad. La crisis financiera acontecida hace poco tiempo pareció haber endurecido las políticas de crédito. Si la historia indica que no ha sido sencillo el acceder al crédito, pareciera que en la actualidad esto resultara más difícil. Los préstamos a grandes empresas descendieron hasta $47 \%$ en el punto más alto del último trimestre de 2008 respecto al tercer trimestre; y en cuanto a inversión (capital de trabajo y gastos de capital) la baja fue de hasta un 14\%, refieren Ivashina y Scharfstein (2010). Campello et al. (2010) preguntando a directores financieros sobre el tema de la restricción de crédito, mencionaron que tendrían que hacer cortes en varias partidas presupuestales.

El panorama entonces no es sencillo, si ya las empresas contaban con algunos obstáculos por superar, pareciera que esto se agudiza. La realidad es de que el crédito siempre ha sido complicado de obtener, para algunas empresas menos que otras. Las pymes en particular adolecen de este tema. Uno de estos problemas es la asimetría en la información, Berger y Udell (1998) la señalan como uno de las principales limitantes en el tema de financiamiento. El ser opaco acarrea muchas dificultades a las pymes que desean crédito (De la Torre et al., 2010).

Así como la opacidad es un tema que debe superarse en tema de crédito, hay algunos otros que son solicitados por el banco o representan una limitación con la cual las empresas deben lidiar, tales como: el tamaño de la empresa (Pissarides, 1999; Schiffer y Weder, 2001; Vickery, 2008) , la antigüedad de la misma (Gregory et al., 2005; Robb, 2002; Beck, 2007), el 
costo del crédito (Booth y Booth, 2006; Jiménez y Saurina, 2004; Ayyagary et al., 2008) y la garantía (Berger y Udell, 2004; Steijvers et al., 2010).

Para entender el origen, se requiere identificar las teorías que hablan sobre algún aspecto inherente a la intención de la empresa de obtener recursos para sus inversiones y su operación. Conocer los obstáculos que enfrentan las pymes, analizar de que forma han superado estas restricciones a fin de proponer un modelo que pueda complementar la literatura existente que de una alternativa para el acceso al crédito.

En los siguiente epígrafes se detallarán dichas teorías que tienen alguna conexión con el tema de crédito, de las características de las empresas, de los obstáculos que enfrentan y de las condiciones o formas que han encontrado para sobrellevarlo. 


\subsection{Teoría de la Estructura de Capital}

Muchos autores comentan que la teoría base sobre las cuales se desprenden varias teorías que tocan el tema de la deuda de empresa es la “Teoría de la estructura de Capital” de Modigliani y Miller (1958), dentro de su teoría hacen referencia en que en algunos casos podría resultar más redituable el buscar deuda en lugar de utilizar el capital para financiar un proyecto. Modigliani y Miller consideraban que en esa época había dos objetivos principales: "maximización de utilidades y maximización del valor de mercado". Esto podría ser una forma de explicar lo que representaba el costo de capital de acuerdo al origen del mismo, ya fuera deuda o capital propio.

Myers (1984) dentro de su análisis de la teoría de estructura de capital contrasta dos formas de pensar sobre esta teoría, una respecto al marco de la teoría de la compensación (static tradeoff), en la cual la empresa establece un objetivo para la razón financiera deuda-valor, y la otra sobre la teoría de la jerarquía financiera (pecking order) en la cual la empresa prefiere financiamiento interno a externo, y deuda a capital. Lemmon y Zender (2010) también menciona que la discusión para describir las oportunidades de financiamiento por parte de las empresas se basa en estas dos teorías (tradeoff $\mathrm{y}$ pecking order). Para ellos la teoría de la compensación parte de la idea de que las empresas elegirán la mezcla de deuda y capital de acuerdo a los costos y beneficios de la deuda. En tanto que en la teoría de la jerarquía financiera no se tiene un objetivo de una estructura de capital óptima, sino la elección de las formas de financiamiento, empezando por los fondos internos generados, después deuda y dejando al final la opción de nuevo capital. 
De acuerdo a un análisis realizado por Céspedes et al. (2010), las empresas en Latinoamérica aplican la teoría de la jerarquía financiera cuando requieren recursos. González y González (2008) analizan si la validez de las teorías de la compensación y jerarquía financiera para explicar la estructura de capital de una empresa varía con el tamaño de la misma. De acuerdo a esto, la relación positiva del financiamiento de la empresa con oportunidades de inversión y activos intangibles y la relación negativa con la utilidad de la empresa son más fuertes en las pequeñas empresas que en las grandes y medianas. Esta reflexión es un indicativo de la influencia que puede tener el tamaño de la empresa, variable que se tomará en consideración como parte de nuestro modelo teórico.

Derivado de los estudios realizados por Modigliani y Miller (1958), demostraron que al decidirse por hacerse llegar de recursos vía deuda o capital no tenía incidencia en el valor de la empresa o en el costo de capital; aunque la utilización de una u otra herramienta de financiamiento podría incidir en la rentabilidad obtenida para los accionistas, considerando a la deuda una opción de mejor tasa de retorno a la de uso del capital. Myers (2001) está de acuerdo en que Modigliani y Miller probaron esta teoría. Además, señala que generalmente la razón financiera de endeudamiento es baja o negativa cuando las utilidades o riesgo de las empresas es alto.

Ju et al. (2005) examinan la relación entre valor de la empresa y la estructura de capital. De acuerdo a sus estimaciones el impacto en el valor de la empresa es mínimo cuando se dan cambios moderados en la estructura óptima de capital. Comentan que la administración de las compañías podría considerar una capitalización de la misma cuando la estructura de capital tenga una desviación de hasta 10 puntos porcentuales. En la figura 2.1. 
muestran este concepto de valor de empresa, usando valores estimados en un modelo dinámico la empresa refinancia deuda antigua y eso cuenta en el impacto de la cobertura de interés, los costos de quiebra sobre el valor total de la empresa endeudada.

Figura 2.1.

Valor de la empresa para diferentes niveles de financiamiento vía deuda.

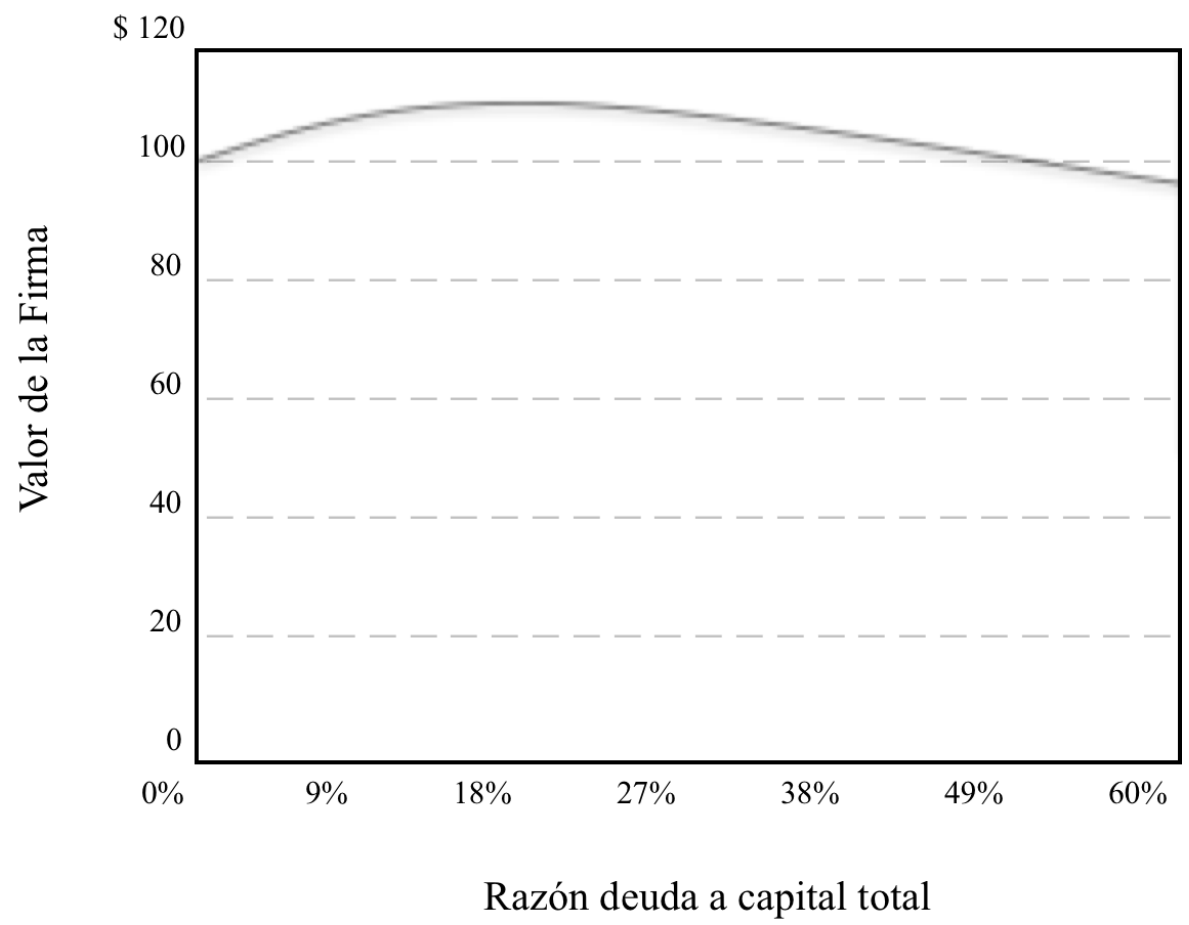

Fuente: Ju et al., (2005)

Para Frank y Goyal (2007), Modigliani y Miller partían de la consideración de que la compañía tenía cierto nivel de flujo de efectivo, para lo cual una vez que se ha definido la proporción de deuda y capital solo tiene que dividir sus flujos entre los inversionistas. Se estima que tanto la compañía como los inversionistas pueden acceder a las mismas fuentes de financiamiento. De acuerdo a Myers (2001), el estudio de la estructura de 
capital trata de explicar las fuentes de seguridad y financiamiento que tienen las empresas para realizar inversiones. Además, consideraba que la investigación realizada hasta ese momento sobre la estructura de capital se basaba en la proporción de la deuda contra el capital mostrada en el balance general. Berger y Udell (1998) esquematizan su explicación sobre las fuentes de financiamiento y la continuidad de la empresa, como se muestra en la figura 2.2.

Figura 2.2.

Continuidad de la empresa y fuentes de financiamiento

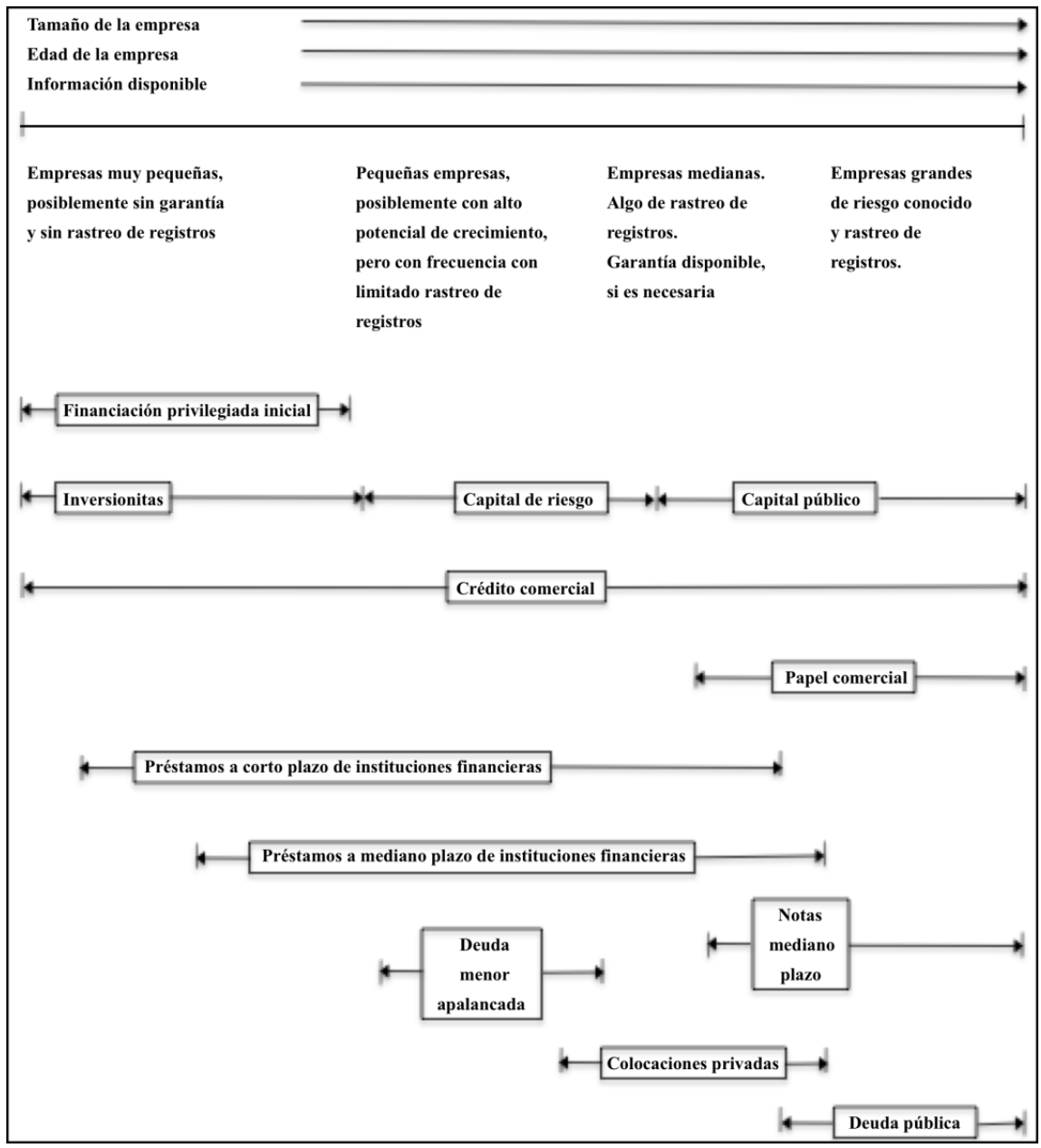

Fuente: Berger y Udell (1998) 
En esta figura, Berger y Udell (1998) muestran como las empresas de acuerdo al tamaño, edad e información de la misma, se van desarrollando, y durante su crecimiento y desarrollo las fuentes de financiamiento van cambiando. Así se ve que las más pequeñas, jóvenes y opacas no cuentan con muchas fuentes, de hecho el financiamiento vía instituciones financieras es casi nulo, ni hablar del que es a largo plazo. De este modelo nosotros vamos a tomar para el nuestro lo referente al tamaño de la empresa, la edad de la empresa y la información de la misma. Consideramos muy relevantes estas variables, como ellos lo muestras, para el modelo que deseamos desarrollar.

En un balance general, la proporción de deuda y capital se nota en su parte derecha, ello indica la forma en que los activos con que la compañía realiza su operación se encuentran financiados, en qué proporción es a través de deuda y en cual a través del capital propio. Cuando los niveles de concentración de la propiedad en las empresas son altos, la relación entre apalancamiento y propiedad es positiva, partiendo de la idea que este tipo de empresas con alta concentración no desean perder el control de las mismas (Céspedes et al., 2010). A partir de ello se entiende que la decisión se basa con qué proporción de deuda - capital se encuentra cómoda la compañía; los gerentes pueden llegar a considerar las calificaciones crediticias cuando llegan a tomar una decisión sobre la estructura de capital (Kisgen, 2006). Las calificaciones crediticias son un parámetro para conocer la fiabilidad de las empresas cuando se va a otorgar un financiamiento.

Para Michaelas et al., (1999), la teoría de la estructura de capital se puede dividir en tres categorías: "teorías basadas en impuestos", "teorías de costos de agencia" y "teorías de información asimétrica y señalización". 
Además, señala que estas teorías no hacen referencia alguna a si se trata de pequeñas o grandes empresas. En cambio, Myers (2001) menciona que aun cuando no hay una teoría universal específica sobre la opción de deuda y capital, algunas teorías pueden ayudar a llevar a cabo este análisis como la teoría de la compensación (tradeoff theory) en la cual se hace mayor referencia a impuestos, la teoría de la selección jerárquica (pecking order theory) que menciona mayormente las diferencias en la fuente de recursos y la teoría del flujo libre de efectivo (free cash flow theory) en la que se remarca lo referente a costos de agencia.

De la aplicación de la teoría de estructura de capital a las pymes, Michaelas et al., (1999:117) opinan que en conclusión las pymes cuentan con menores niveles de deuda en comparación a las grandes corporaciones debido principalmente a: "menores tasas marginas de impuestos corporativos, mayores costos de bancarrota, mayores costos de agencia y mayores costos para resolver la mayor asimetría en la información”. Baas y Schrooten (2006) manifiestan que obtener información sobre las pymes es complicado y costoso para los intermediarios financieros, ello provoca tasas de interés altas aun en una relación de largo plazo entre el prestatario y el banco. Esta aseveración del costo que representa el crédito traducido en altas tasas de interés será una de las premisas que se mostrarán en nuestro modelo.

La teoría identifica a la garantía como una herramienta para reducir los problemas de asimetría en la información entre el prestamista y el prestatario, de acuerdo a Berger et al. (2010). En resultados obtenidos sugieren que cualquier avance en el mercado como nuevas tecnologías o herramientas financieras de contratación o, innovaciones en procedimientos 
como mejorar las normas de información, las cuales reduzcan de manera importante la opacidad en la información pueden ayudar a reducir el uso de garantías costosas. Nos llama la atención esta forma de reducir la asimetría, por ello puede ser una variable a incluir en el modelo.

Siguiendo con el tema de los costos, en cuanto a los generados por el otorgamiento de crédito, los costos de operación significan el costo inherente en mantener un portafolio de crédito, de acuerdo al estudio de Rauch y Hendrickson (2004), quienes relatan las características del crédito como tamaño del crédito, garantía y tasa de interés e información asimétrica para el costo de monitorear los contratos de crédito.

De acuerdo a la opinión de Berger y Udell (1998), las empresas son vistas bajo un paradigma de un ciclo de crecimiento financiero en el cual las diferentes estructuras de capital son óptimas en diferentes puntos de dicho ciclo. Estos muestran el financiamiento de pymes y como la estructura de capital varía de acuerdo al tamaño y edad de la empresa. Además, consideran que los intermediarios financieros también evalúan las finanzas personales de los propietarios, así que los activos personales son tomados en cuenta al analizar la estructura de capital de la empresa.

Esta situación origina que las instituciones que evalúan a la empresa, en muchas ocasiones revisan los bienes no solo de la empresa, sino que involucran la situación patrimonial del dueño. En general, las pymes son empresas familiares, o así fueron en un principio, por lo cual la figura del fundador toma relevancia en temas de financiamiento. Romano et al., (2001) elaboraron un modelo en el cual consideran como las diferentes fuentes de financiamientos que tendrían este tipo de negocios pudieran afectar positiva 
o negativamente, además considerando si el objetivo es incrementar el valor del negocio o hacerlo crecer. En la figura 2.3., Romano et al., (2001) muestran como de acuerdo a las diferentes características analizadas están se relacionan de manera favorable o no, dependiendo de la fuente de los recursos.

Para Romano et al. (2001), varios factores, adicionales al tamaño de las empresas, han sido mostrados que tienen influencia en las decisiones de financiamiento, tales como: cultura, metas organizacionales, razón financiera deuda - capital, actitud hacia la deuda, así como actitud hacia el riesgo personal. Frank y Goyal (2009) al analizar los factores que consideran más importantes en las decisiones de estructura de capital, establecen un grupo de factores llamado "factores centrales" y al modelo que los incluye como "modelo central de financiamiento". Entre estos factores se refieren los siguientes: Media del financiamiento en la industria, utilidades, tamaño de empresa, inflación estimada. Las existentes teorías sobre estructuras de capital no incluyen factores tales como: los objetivos de los dueños y las decisiones sobre planes de negocio, conceptos esenciales para tomar decisiones de financiamiento (Romano et al., 2001). 
Figura 2.3.

Modelo hipotético de las finanzas de un modelo familiar

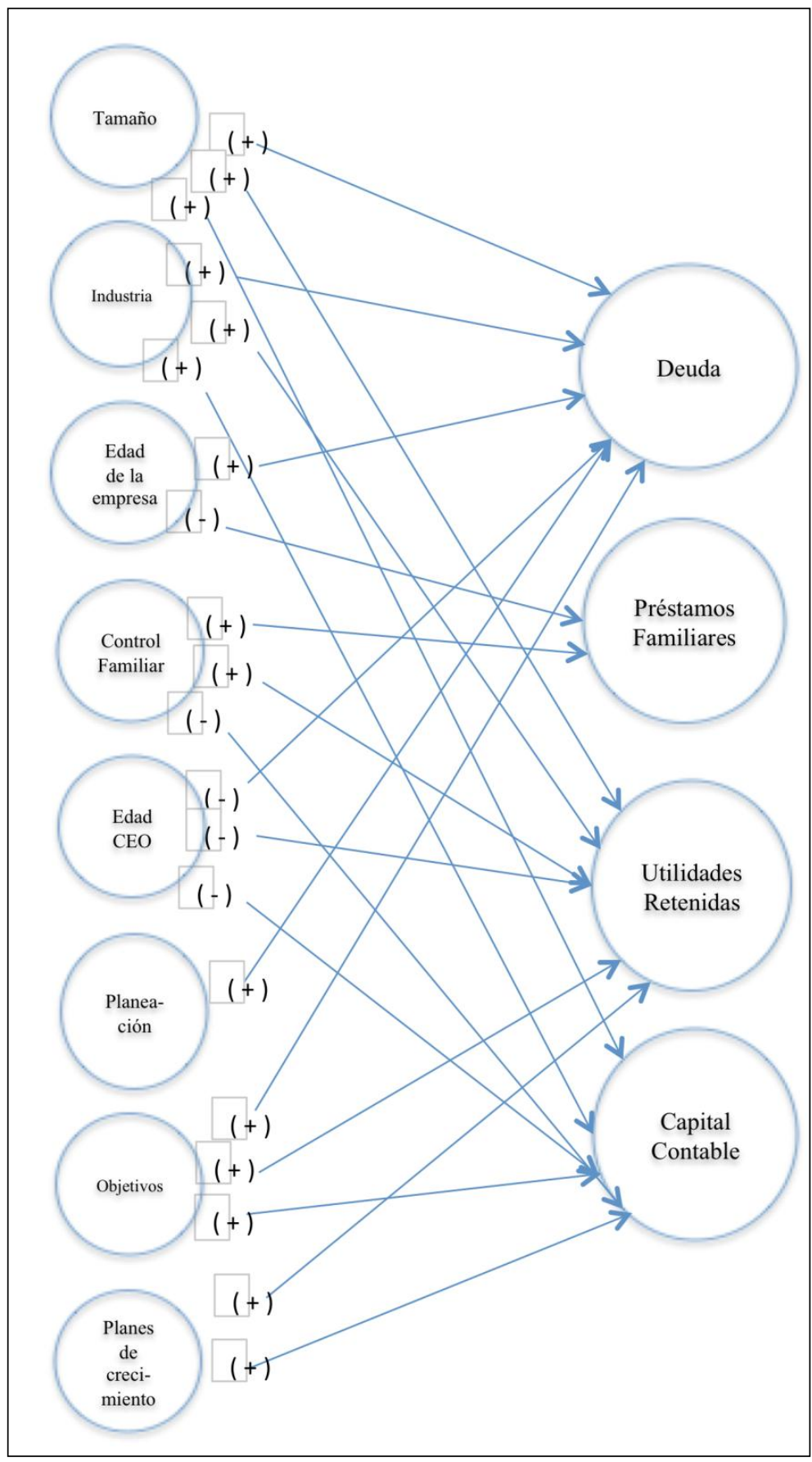

Fuente: Romano et al., 2001. 
Kayhan y Titman (2007) señalan que la teoría de la estructura de capital sugiere que las empresas cuentan con un objetivo de razón financiera de deuda o apalancamiento, determinada por las ventajas y desventajas entre los costos y beneficios de la deuda contra capital. De hecho, Graham y Harvey (2001) muestran que más del $80 \%$ de las empresas consideran un objetivo en la razón de deuda cuando realizan sus decisiones de financiamiento de deuda. Para Psillaki y Daskalakis (2009) el marco teórico de la determinación del apalancamiento en las pymes no difiere mucho de la teoría de estructura de capital de empresas grandes. No obstante, deben considerarse algunos aspectos como: costos de agencia, información asimétrica e impuestos. De acuerdo a Lemmon et al. (2008), las estructuras de capital de las corporaciones son estables por períodos de tiempo largos; para ellos las empresas que cuentan con financiamiento, ya sea alto o bajo, tienden a mantener esa tendencia por períodos promedio de 20 años.

Margaritis y Psillaki (2007) dentro de su análisis encuentran que el efecto de eficiencia sobre financiamiento es positivo en empresas cuya razón de endeudamiento tienen niveles bajos a medios, y es negativo en altos niveles de financiamiento. Si el banco conoce la calidad del prestatario que solicita el préstamo, Boot et al. (1991) muestran que el contrato establecerá que solicitantes de alto riesgo otorgarán garantía y los de bajo riesgo no. Como saber entonces si la empresa es eficiente o tiene buen desempeño; habrá que analizar las formas que requieren las instituciones financieras para conocer la situación de la empresa.

Zhao et al. (2009), por ejemplo, comentan que señalizar es un concepto muy importante en la relación entre el prestatario y el deudor, el cual influye en el costo y disposición de capital. Haciendo referencia en 
específico a granjeros, comentan que la señalización está basada en la premisa de que los prestatarios prefieren a los deudores de alta calidad con el menor riesgo de crédito. Para reconocer un prestamista de estas características mencionan que estos envían señales creíbles, de importancia y que no dejen dudas. Así entonces, las instituciones financieras confiarán en la promesa de pago de aquellos deudores que puedan asegurar la devolución del crédito, de acuerdo también a sus capacidades de financiamiento. Myers (1977) explica este concepto en la figura 2.4. En ella se muestra el valor de la empresa (V) y el valor de la deuda (D), así como la promesa de pago (P). VD nos indica el nivel máximo que pudiera endeudarse la empresa, si lo quisiera, este valor será menos que V y que todo el financiamiento del capital. Si sobrepasara este punto correría el riesgo de no realizar su pago comprometido.

Figura 2.4.

Valor de empresa y deuda como una función de la promesa de pago a acreedores

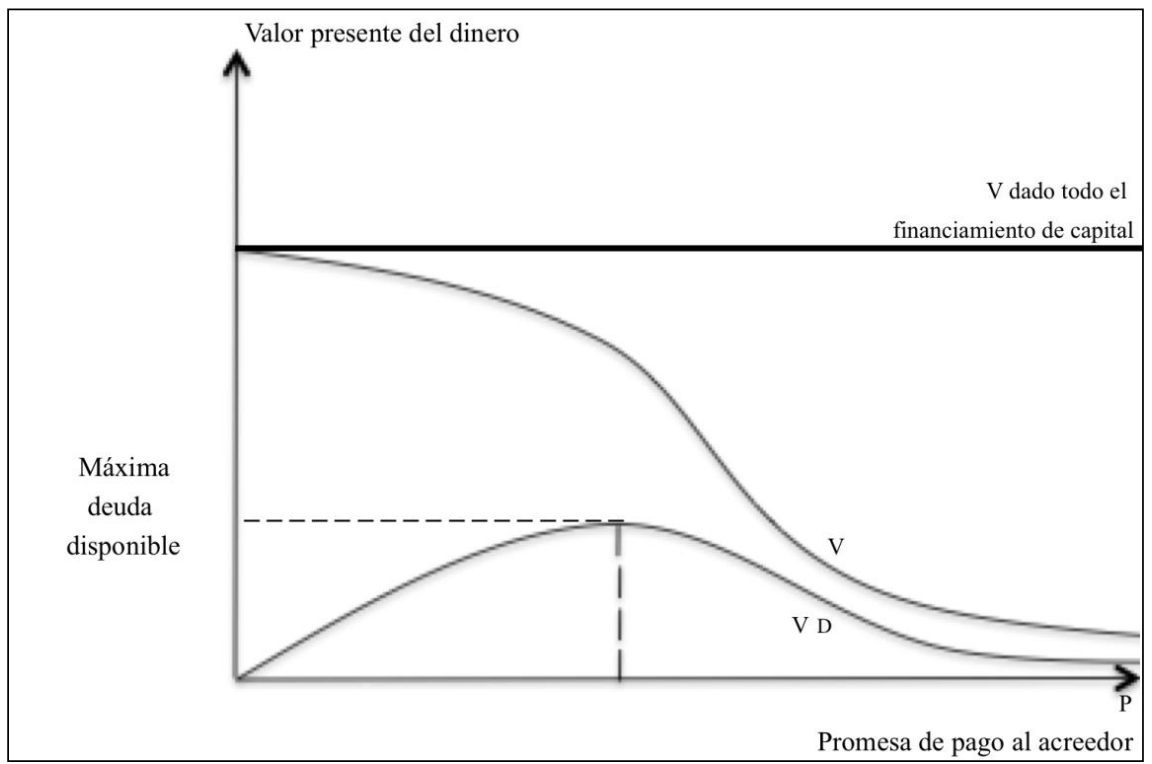

Fuente: Myers (1977) 
Mismo Myers (2003) nos muestra el valor de la empresa que se origina de acuerdo al teorema de Modigliani y Miller. El valor de mercado de la deuda de la empresa y capital, D y E, suman un valor total de la empresa V. El teorema de Modigliani y Miller dice que V es una constante, independientemente de las proporciones de D y E, siempre que los activos y oportunidades de crecimiento a la izquierda del balance permanezcan constantes. Así se muestra en la Figura 2.5.

Figura 2.5.

Valor de la Empresa

\begin{tabular}{|c|lc|}
\hline $\begin{array}{c}\text { Activos en la } \\
\text { empresa y } \\
\text { Oportunidades } \\
\text { de crecimiento }\end{array}$ & Deuda & ( D ) \\
& Capital & (E) \\
\cline { 2 - 2 } & Valor Empresa ( V ) \\
\hline
\end{tabular}

Fuente: Myers (2003)

Derivado de un análisis realizado por La Rocca et al. (2011) las estrategias de diversificación de productos desarrolladas por las empresas afectan de hecho las decisiones sobre la estructura de capital, junto con características específicas de las empresas, así como factores industriales e institucionales. Encuentran que las empresas propensas a desarrollar varias líneas de productos cuentan con razones financieras de endeudamiento más altas que aquellas que no están diversificadas.

El análisis de la literatura que habla sobre la estructura de capital de Modigliani y Miller nos indica que puede haber varias ramificaciones sobre el tema de la deuda que pueden ser de utilidad en nuestro modelo, además, 
nos da idea de otras teorías que emanan de esta, como también de las restricciones que suelen encontrar las empresas, en algunos casos ejemplificando a las pymes, para poder ser sujetos de crédito. Ahora evaluaremos algunas otras teorías que ayuden a definir el modelo teórico. 


\subsection{Teoría de la selección jerárquica (Pecking Order Theory)}

De acuerdo a López-Gracia y Sogorb (2008) la teoría de la selección jerárquica nace como consecuencia de la información asimétrica en los mercados financieros. Como resultado de esto, la teoría lleva a jerarquizar las fuentes de financiamiento que las compañías establecen como política. La información asimétrica entre la gente de la compañía y los inversionistas externos juega un papel muy importante en las teorías referentes a la estructura de capital (Bessler et al., 2011). Para ellos, la estricta interpretación de la teoría de la jerarquía financiera predice que no hay un óptimo nivel de deuda debido a que el capital está tanto en lo más alto (liquidez) como en lo más bajo (capital externo) de la jerarquía.

Como se ha comentado cuando existe información asimétrica una de las partes suele contar con mayor información, así que se estima que los gerentes de las empresas contarían con mayor información a la que tienen los inversionistas. Este hecho sería del conocimiento de ambas partes.

Myers y Majluf (1984) consideran 3 casos de información asimétrica: a) cuando los administradores cuidan los intereses de todos los accionistas sin importar su antigüedad, b) cuando solo cuidan los intereses de los accionistas más antiguos y, c) cuidan los intereses de los accionistas antiguos, pero consideran que estos tratarán de equilibrar su inversión conforme van aprendiendo las acciones de la compañía. La figura 2.6. ilustra este concepto. Myers y Majluf consideran que la decisión de inversión parte de dos premisas, a) cuando los gerentes saben más que los inversionistas sobre el valor de los activos de la empresa y, b) el valor presente neto de su oportunidad de inversión. La empresa emite acciones 
sólo si $(\mathrm{a}, \mathrm{b})$ se encuentre en la región $\mathrm{M}^{\prime}$. E es el monto de nuevo capital requerido para financiar la inversión, P' el valor de equilibrio condicional de la empresa y $\mathrm{S}$ es el monto de holgura financiera.

Figura 2.6.

Decisión de inversión

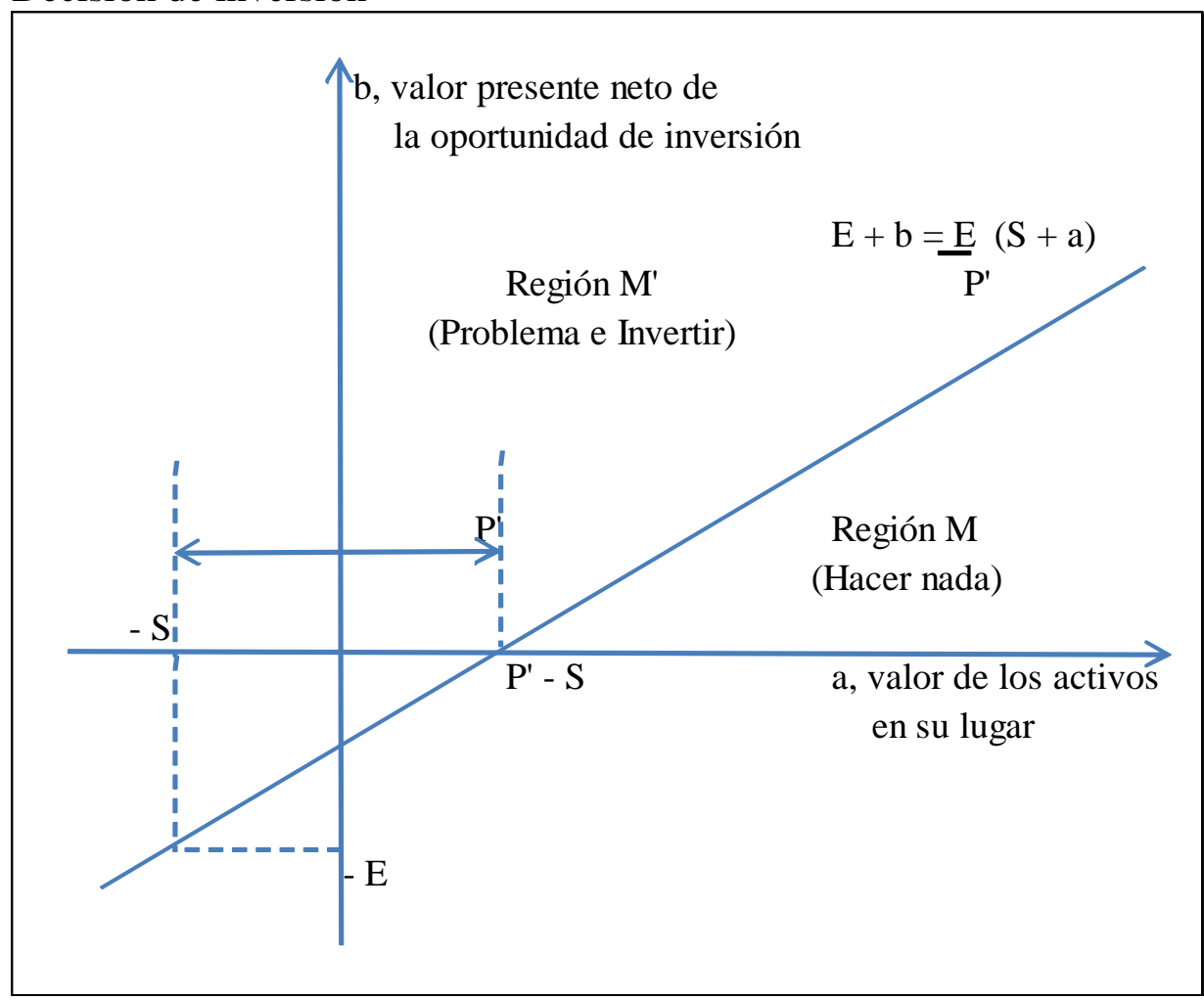

Fuente: Myers y Majluf (1984)

La selección jerárquica en las fuentes de financiamiento, de acuerdo a esta teoría, inicia con fondos internos, seguidos por deuda, y después por nuevo capital; las empresas jerarquizan su forma de financiamiento de forma que puedan minimizar los costos de selección (Leary y Roberts, 2010). Como se muestra en la figura 2.7., queda plasmada la relación entre la elección de la fuente de financiamiento y el nivel de inversión, ello bajo la hipótesis de que orden jerárquico se les da a las diferentes fuentes. En ella 
"C" representa el monto disponible de fondos internos para invertir. En tanto que " $\mathrm{D}-\mathrm{C}$ " representa el nivel de deuda que una firma podría adquirir sin provocar un endeudamiento excesivo.

Figura 2.7.

Teoría de la Jerarquía Financiera

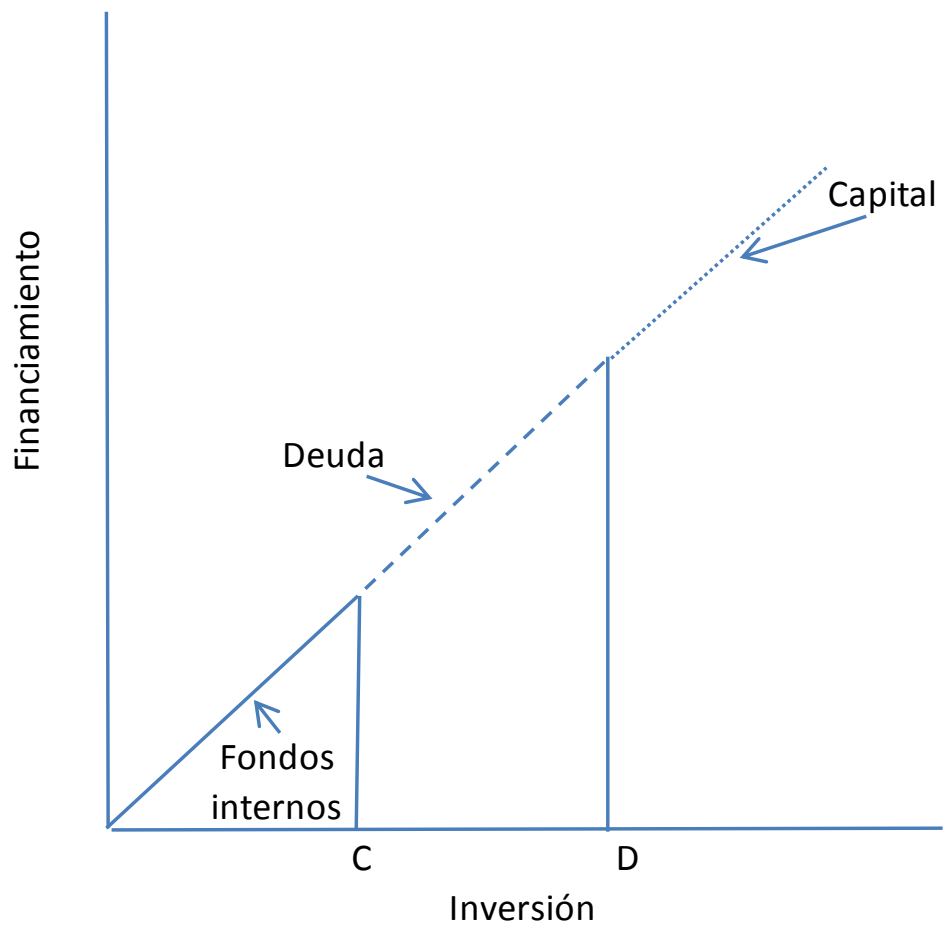

Fuente: Leary y Roberts (2010)

Esta teoría nos ayudará a encontrar en nuestro modelo mediante un indicador, cuales son las fuentes que utilicen las empresas materia de estudio. O si la deuda, considerada una forma común de financiamiento sea el medio para obtener los recursos. Fosberg (2008) considera que las empresas que aplican la teoría de la jerarquía financiera no cuentan con una óptima estructura de capital, así que la estructura con la que cuentan es solo 
un medio que refleja sus oportunidades de inversión en el pasado y la disponibilidad de fondos generados internamente.

Para Frank y Goyal (2003) la teoría de la jerarquía financiera es una de las teorías más influyentes en cuanto a endeudamiento corporativo se refiere. De acuerdo a esta teoría, el comportamiento de financiamiento se verá regido por los costos adversos de selección. De ahí que las pymes tengan mayores costos por su información asimétrica. Los mismos Frank y Goyal (2007) se refieren a que la selección adversa se basa en que el dueño o administrador de la empresa conoce el valor real de los activos y oportunidades de crecimiento, lo cual aventaja al posible inversionista. Por otro lado, la idea de que los gerentes tengan que detallar la situación de la compañía a externos hace que puedan verse sujetos a una supervisión o monitoreo.

Para Kisgen (2006), en la teoría de la jerarquía financiera las empresas tratarán de financiar sus inversiones con recursos propios, y solo cuando estos se hayan agotado y se ha cubierto la capacidad de deuda, entonces las empresas buscarán capital nuevo. Un punto interesante en el cual pudiera verse modificada esta secuencia de financiamiento es cuando las empresas buscan mejorar su calificación crediticia, para ello, según Kisgen, las empresas preferirían capital en lugar de deuda. Myers (2001) supone el caso de que la compañía pudiera en las mismas circunstancias obtener financiamiento vía deuda o capital. Como en deuda se tiene cierta preferencia en la liquidación con activos y utilidades se deja el capital como última instancia, por lo cual quienes financian vía deuda no se preocupan por el valor de la firma. Berggren et al. (2000) presentan su modelo teórico 
sobre la aversión al control que puede perder la empresa, se muestra en la figura 2.8 .

Figura 2.8.

Efectos de la coerción sobre el comportamiento de búsqueda financiera

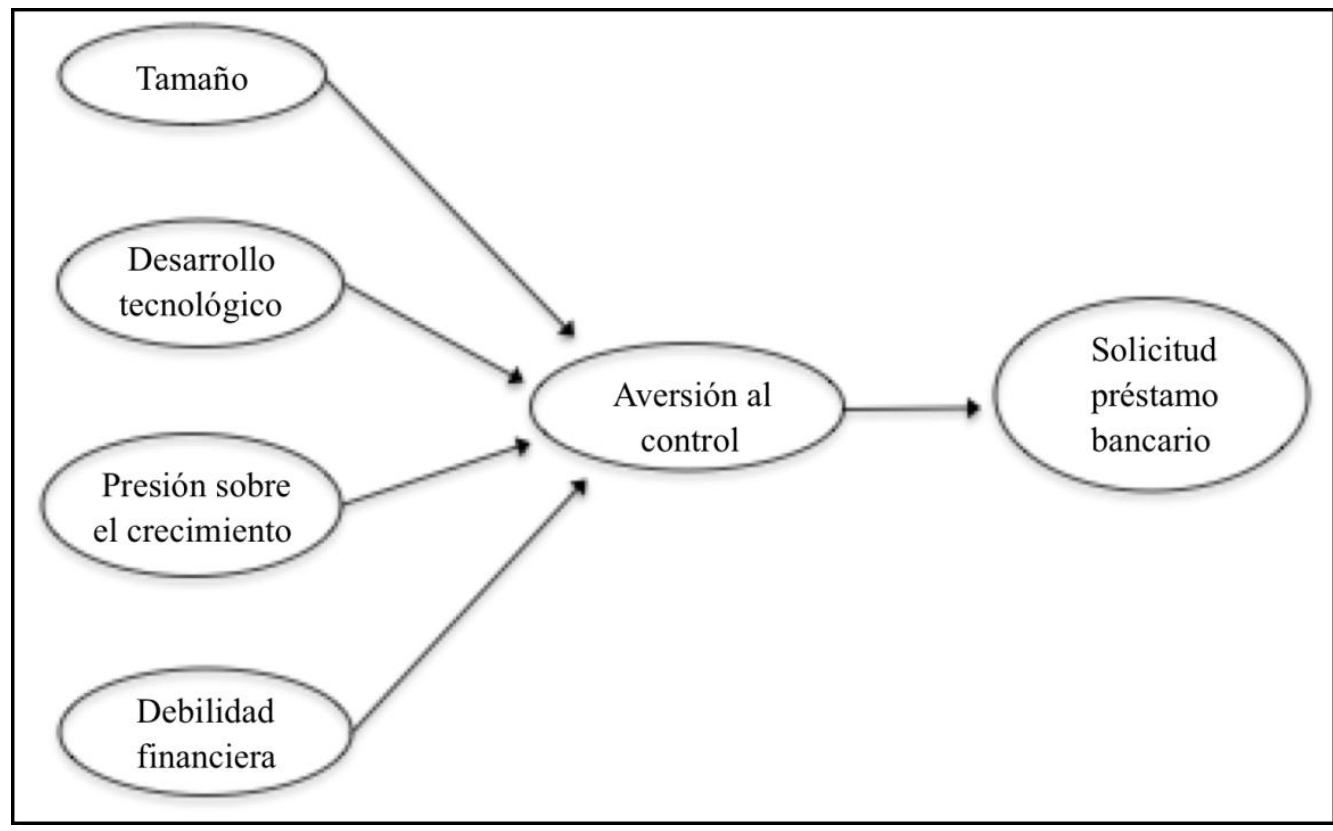

Fuente: Berggren et al., (2000)

En este modelo, Bergreen et al., (2000) consideran que el tamaño, el desarrollo tecnológico, la presión sobre el crecimiento y la debilidad financiera, están directamente correlacionadas a un cambio en la aversión al control, y por lo tanto, a un cambio real en el tipo de financiamiento solicitado. Mencionan que una vez probado el modelo, encuentran una correlación entre el tamaño y la solicitud de crédito al banco; mencionan que las empresas más grandes no tienen tanta aversión al control como las pequeñas, que confían más en los recursos internos, cuando las grandes realizan un uso bastante extenso de alternativas de financiamiento, no solo 
bancario. También encuentran una correlación entre la debilidad financiera y la solicitud de préstamo, sugiriendo que las empresas con un menor capital a la razón de deuda tienden a evitar el financiamiento bancario. De ahí se desprende su nuevo modelo conforme a la figura 2.9 .

Figura 2.9.

Modelo final sobre los efectos de la coerción sobre el comportamiento de búsqueda financiera

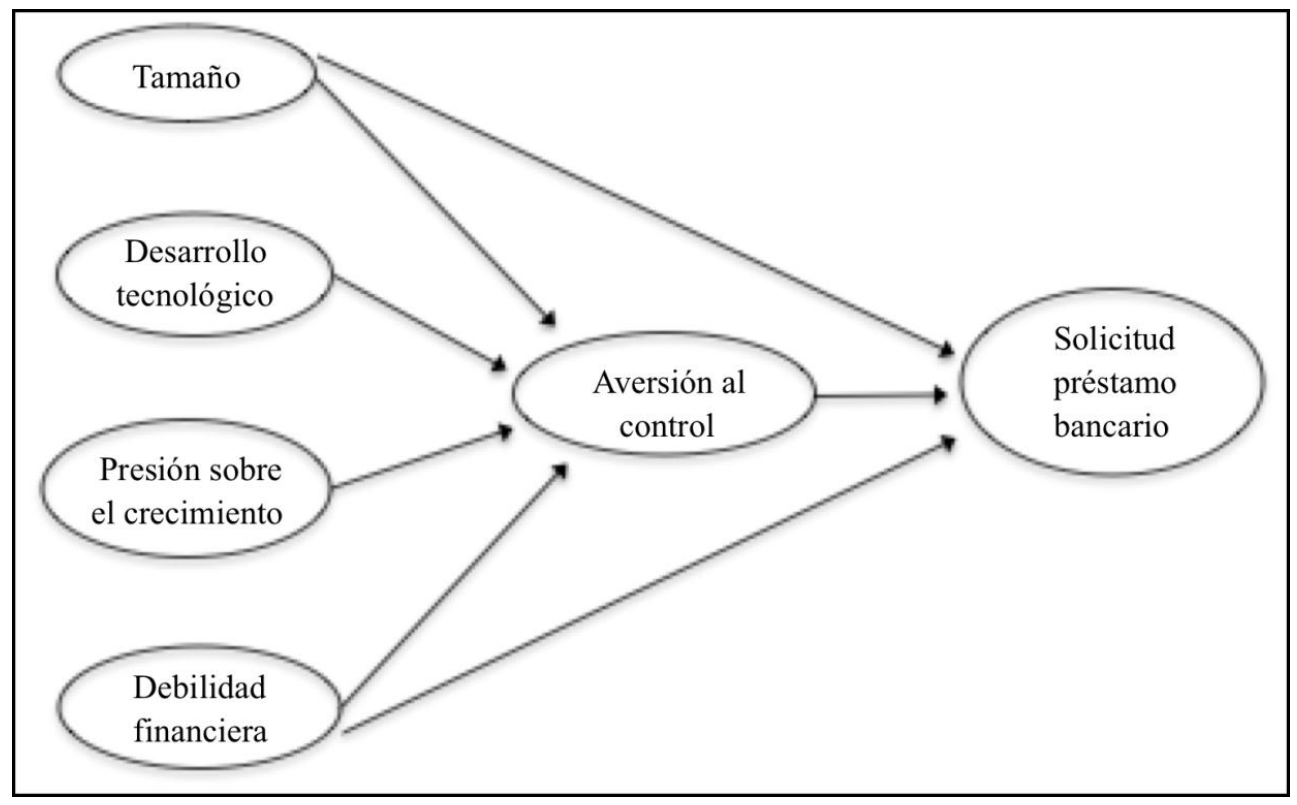

Fuente: Berggren et al., (2000)

Para explicar más a detalle el modelo final que Berggren et al., (2000) nos señalan, se incluye la tabla de los constructos que utilizaron y la descripción de dichos constructos en los cuales hacen constar el concepto que manejan para los mismo. Esto se explica en la tabla 2.1.: 
Tabla 2.1.

Constructos e indicadores del modelo sobre los efectos de coerción

\begin{tabular}{|l|l|}
\hline Constructo & Indicadores \\
\hline Desarrollo tecnológico & $\begin{array}{l}\text { Necesidad percibida para invertir en } \\
\text { maquinaria y otro equipo }\end{array}$ \\
\hline $\begin{array}{l}\text { Presión sobre } \\
\text { crecimiento }\end{array}$ & $\begin{array}{l}\text { Importancia percibida del crecimiento para } \\
\text { sobrevivir (en términos de número de } \\
\text { empleados) }\end{array}$ \\
\hline Tamaño & $\begin{array}{l}\text { Tamaño de la empresa medido en número de } \\
\text { empleados }\end{array}$ \\
\hline Debilidad financiera & Capital a razón de deuda \\
\hline Aversión al control & $\begin{array}{l}\text { Primera razón percibida para introducir nuevos } \\
\text { dueños es capitalización }\end{array}$ \\
\hline Solicitud préstamo & Uso real del préstamo \\
bancario & \\
\hline
\end{tabular}

Fuente: Berggren et al., (2000)

Estamos viendo como influyen los constructos de la tabla 2.1. en la solicitud de crédito, situación similar que pensamos plantear en nuestro modelo, pero más allá del trámite, establecer la obtención misma del crédito hecha la solicitud, y como se relaciona esta con los demás constructos que tomaremos en cuenta. Además, como se ha comentado, consideraremos el tamaño de empresa, y también importante tomar en cuenta el uso que le está dando la empresa a los recursos obtenidos.

El financiamiento es clave para el crecimiento de las empresas, así lo demuestran Vanacker y Manigart (2010). De acuerdo a un análisis realizado por ellos, la mayoría de empresas rentables prefieren utilizar fondos 
internos; ya se ha comentado que las utilidades retenidas son parte primordial para que las empresas puedan autofinanciar sus inversiones. Esta aseveración también es mencionada por Vasiliou et al. (2009), aseguran que aquellas empresas con utilidades altas y un volumen de ingresos grande se espera que utilicen menor capital externo que aquellas con niveles de utilidad bajos o nulos.

Asimismo, estas compañías que utilizan los fondos internos, reservan su capacidad de deuda y no atraen dicho financiamiento. Cuando las empresas tienen un elevado apalancamiento menores razones de liquidez es cuando deciden financiarse vía capital; esto también como consecuencia que con dichos índices no es atractiva la empresa para las instituciones financieras que financian la deuda.

Los países emergentes serían una excelente herramienta para el estudio de la teoría de la jerarquía financiera, de acuerdo a Seifert y Gonenc (2010). Esto derivado de la fuerte información asimétrica existente y costos de agencia. Como lo menciona Hallberg (2001), las "Pymes son el sector privado emergente en los países pobres, y con ello, la base del sector privado dirigiendo el crecimiento". De acuerdo a lo que piensan Seifert y Gonenc (2008), podría ser atrayente el considerar que la estructura de capital sería diferente de un país a otro dependiendo de las leyes, políticas tributarias, prácticas corporativas, así como el papel de los bancos y los mercados, entre otras cosas. Así, en países como Estados Unidos o Inglaterra se tiende a confiar más en capital que en los sistemas de relaciones como en Alemania y Japón. 
La realidad es que la mayoría de autores concuerda en que la generalidad de las empresas se siente más cómoda utilizando recursos propios para sus nuevas inversiones antes de voltear a ver otras fuentes de financiamiento, tales como: deuda y capital externo. El riesgo, costo y pérdida de control que pueden generar estas últimas dos fuente de recursos son los principales temores de la administración hacia voltear a otros horizontes para sustentar el crecimiento de las empresas. Esto se puede aprovechar para conocer en el estudio empírico si las empresas siguen esta tendencia o prefieren mayormente el solicitar un crédito. 


\subsection{Teoría de Equilibrio Estático (The Static Trade Off Theory)}

Como se ha comentado, existen varias teorías que tratan de explicar las formas en que las compañías realizan decisiones de financiamiento. Una de ellas es la "teoría del equilibrio estático". Frank y Goyal (2007) mencionan que el nombre de esta teoría es usado por varios autores para describir un grupo de teorías relacionadas. En estas teorías quien toma las decisiones evalúa ventajas y desventajas de los diferentes planes de endeudamiento, asumiendo que al final la decisión será la que se obtenga de equilibrar los costos y beneficios. A su vez Lemmon y Zender (2010) sugieren que la teoría predice que las empresas elegirán una mezcla de financiamiento de deuda y capital para equilibrar los beneficios y costos. Esta situación también es señalada por Sogorb-Mira y López-Gracia (2003), además de comentar que en el punto óptimo de la estructura de capital de la compañía, tanto los beneficios como los costos de deuda están equilibrados.

Esto nos hace pensar que cuando se va a contraer deuda, bajo esta teoría, la decisión deberá estar fundamentada en cuanto a los costos que representa y los beneficios que se obtendrán al realizarla, tratando de mediar ambas posiciones, para ello habría que ver más a detalle tanto los beneficios y costos que se exponen en esta teoría.

Muchos investigadores han intentado determinar si la teoría del equilibro estático o la teoría de la jerarquía financiera es más adecuada para interpretar el comportamiento de las empresas en materia de financiamiento (La Rocca et al., 2011). Hablando sobre la teoría del equilibrio estático, esta trata de explicar cómo las compañías fijan sus objetivos del ratio de deuda, intercambiando los beneficios fiscales de deuda contra los costos de una 
posible quiebra o dificultades financieras (Myers, 2003). Esta situación también es manejada por Fama y French (2002), en la cual exponen que las empresas identifican su óptimo financiamiento mediante la evaluación de los costos y beneficios de un importe adicional de deuda, manifestando como algunos beneficios la deducibilidad en impuestos de los intereses y reducción de problemas de liquidez; asimismo, identificando algunas desventajas como costos de quiebra y conflictos de agencia entre accionistas y tenedores.

Esta teoría puede ser aplicada tanto en pymes como en empresas grandes que cotizan en bolsa (Mac an Bhaird, 2010). Haciendo mención también a dos factores principales a considerar bajo el enfoque de esta teoría, rentabilidad y dificultad financiera. En cuanto a las dificultades financieras estas orillan a la quiebra en un caso extremo, considerando a las empresas pequeñas con una tasa mayor a las grandes respecto a este tema. La quiebra "se produce cuando las obligaciones con los acreedores no pueden ser satisfechas”. En este caso, habría una transferencia de propiedad, además de una reorganización de la estructura de capital. (Haugen y Senbet, 1978:384)

Como lo menciona Franks y Sussman (2005:10), “una compañía se define estar en dificultades cuando la sucursal del banco local y el oficial de crédito regional decide transferir la cuenta a la Unidad del banco de apoyo empresarial (BSU)". Esto podría suceder ya sea por no realizar un pago de interés establecido, o exceder su límite de crédito, o que el oficial de crédito considere un futuro incierto por factores como alto nivel de endeudamiento o bajos niveles de rentabilidad. Esto en particular en empresas del Reino Unido. Para Purnanandam (2008:707) la definición de dificultades 
financieras es "un estado de bajo flujo de efectivo de la empresa en la cual incurre en pérdidas sin ser insolvente". Estas pérdidas pueden traducir en perder clientes, proveedores valiosos y empleados clave. En ocasiones, las empresas quieren subsanar estas dificultades con crédito.

Las dificultades financieras obligan a la empresa a realizar varias acciones. Para Asquith et al., (1994) las empresas deben realizar una reestructuración en sus activos y pasivos para evitar la bancarrota. Acciones como venta de activos, fusiones, reducciones de gastos de capital, reestructuración de deuda, son importantes para evitar la quiebra. La venta de activos cuando se hace de manera voluntaria, antes de entrar en una quiebra, se posiciona como una decisión de enriquecimiento del accionista (Lasfer et al., 1996). Almeida y Philippon (2007) consideran que las dificultades financieras tienen tanto costos indirectos como directos. Indirectos como la pérdida de mercado o directos como gastos legales.

El tocar el tema de dificultades financieras resulta de identificar si por esta razón la empresa hace uso del crédito. Es decir, cual es el fin último de los recursos obtenidos. Situación que pudiera extraerse del estudio empírico, y ver si el cubrir esta necesidad forma parte de las opciones para pedir prestado.

Dentro de los diferentes modelos existentes relativos a la teoría del equilibrio estático, Hackbarth et al. (2007) realizan un resumen de los mismos, en el cual muestran cuales son los conceptos analizados por los distintos autores que hacen referencia a esta teoría. Ello nos ayuda a determinar algunos de los principales factores analizados, entre los cuales se encuentran: la deuda negociable y no negociable, el poder de negociación, 
recapitulación después de quiebra, prioridad óptima. Con su análisis demuestran que con la teoría del equilibrio se explican varios factores relativos a la estructura de deuda de las empresas. Es interesante identificar el tema de la negociación, parte importante en la tramitación del crédito, que pueda darnos una idea sobre la capacidad de la empresa en el manejo de la solicitud de préstamo.

Shyam-Sunder y Myers (1994) consideran que las compañías al maximizar su valor como empresa equilibrarán las ventajas en impuestos por la deuda contraída y las dificultades que la empresa tiene cuando se da cuenta que se ha endeudado demasiado. Se ilustra este concepto en la figura 2.10., algunas empresas con ratios de deuda altos pueden mostrarse con la curva de arriba, impuestos altos por pagar y activos cuyos valores podrían escapar de ciertas dificultades financieras. El beneficio fiscal de la deuda es el ahorro que resulta de deducir los intereses de los ingresos gravables (Graham, 2000). Para él, la teoría del equilibrio muestra que la empresa utiliza una menor deuda cuando las dificultades financieras son altas. 
Figura 2.10.

Valor de la empresa bajo el financiamiento óptimo

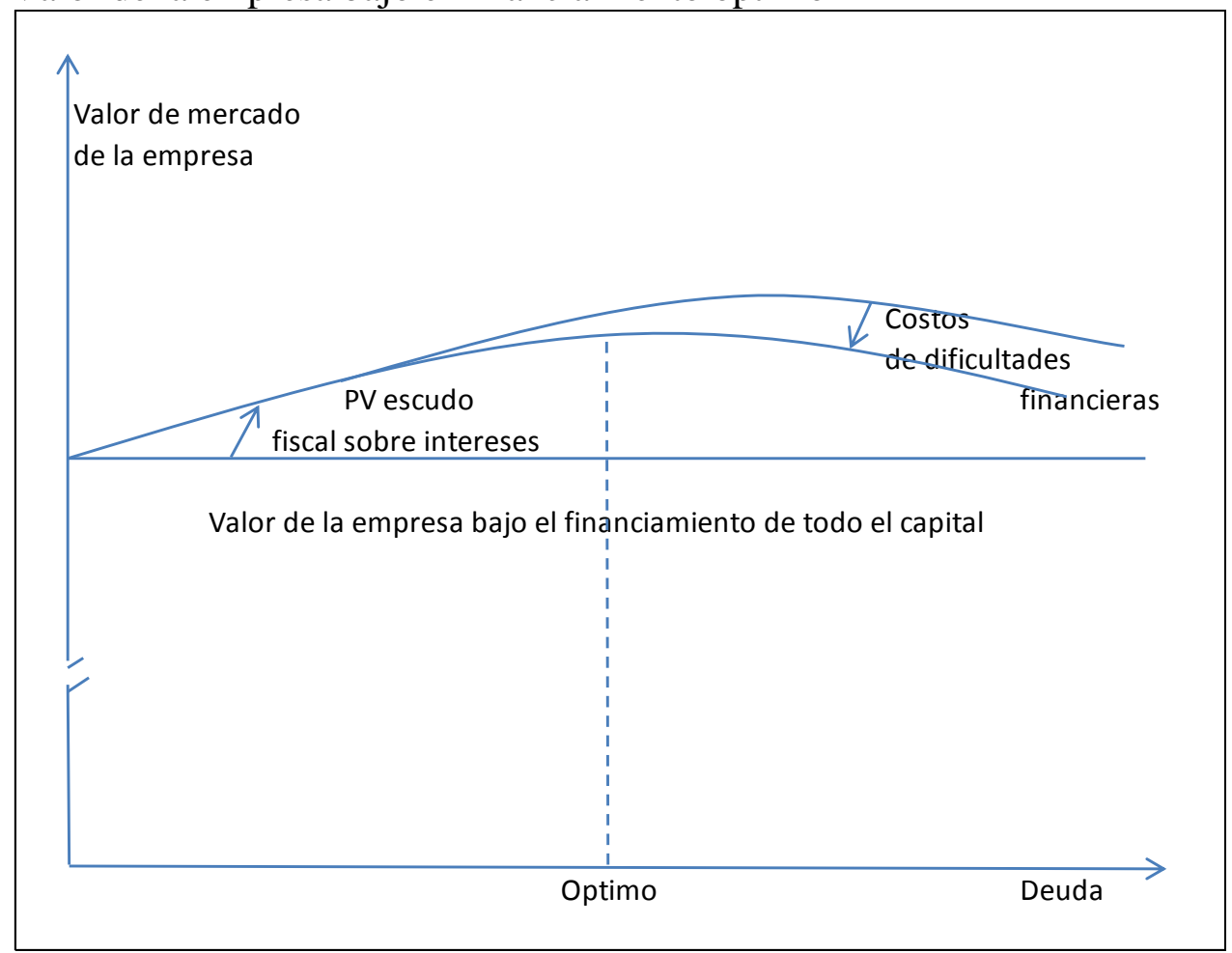

Fuente: Shyam-Sunder y Myers (1994)

La idea de encontrar un óptimo también es comentada por Lemmon y Zender (2010). Ellos manifiestan que una predicción empírica de esta teoría es que los ratios de deuda tienden a reversar hacia la media conforme las empresas utilicen los mercados de capitales externos estratégicamente, precisamente para estar cerca o mantenerse en sus óptimos. Los mismos Hackbarth et al. (2007) comentan que la estructura de deuda óptima para empresas débiles es financiarse solo con bancos, en tanto que para empresas fuertes lo óptimo es usar una mezcla de deuda entre el banco y el mercado.

También podríamos definir las ventajas y desventajas al aplicar esta teoría, bajo diferentes enfoques, como lo mencionan Frank y Goyal (2009), 
la perspectiva de la "compensación impuesto-quiebra" es que la empresa equilibra los beneficios en impuestos de la deuda contra los costos originados por la quiebra. Otra perspectiva es sobre la "agencia", en la que la misma deuda disciplina a los administradores para mantener el pago de interés y principal de la deuda, y disminuye problemas de agencia con los accionistas, derivado que con ello se reduce el flujo de efectivo disponible para gastar a discreción de los administradores (Jensen, 1986).

El tema de impuestos no nos interesaría en nuestro modelo, pero si el costo que implica la deuda, puesto que el tema del gasto que implica para la empresa el endeudarse pudiera ser de mucho impacto en la misma, que quizás le limite la posibilidad de contar con dicho costo o soportarlo.

Si bien es cierto que algunos costos de ajuste pudieran existir y fueran un impedimento para lograr una óptima estructura de capital, la existencia de un ajuste parcial para un endeudamiento óptimo es sugerido dentro de la teoría del equilibrio (González y González, 2008). Una estructura de capital óptima sería definida como "el valor de la deuda que maximiza el valor total apalancado de la empresa y calcula la estructuras de capital óptima para varias características de la empresa" (Ju et al., 2005:269). Además para ellos, las principales variables que afectan las decisiones de financiamiento son los impuestos corporativos y los costos de bancarrota. López-Gracia y Sogorb-Mira (2008) señalan que si la estructura óptima de capital se logra, los beneficios e insuficiencias se compensan, con lo cual se logra el equilibrio buscado.

Con un análisis un poco más estricto, López-Gracias y Sogorb-Mira (2008) señalan dos limitaciones en este enfoque de llegar al óptimo: a) es 
que la deuda observada no debe considerarse como la óptima, pues se caería en el error de omitir el conocer los problemas que conlleva a las empresas el ajustar su estructura de capital, y b) un análisis empírico estático no es capaz explicar la naturaleza dinámica de la estructura de capital, esto es, que esto no examina realmente si la deuda de la empresa regresa a un nivel óptimo o que rapidez regresa a dicho nivel. Haciendo una comparación entre la teoría del orden jerárquico y la teoría del equilibrio, Chirinko y Singha (2000), presentan la figura 2.11.:

Figura 2.11.

Mezcla de deuda y capital

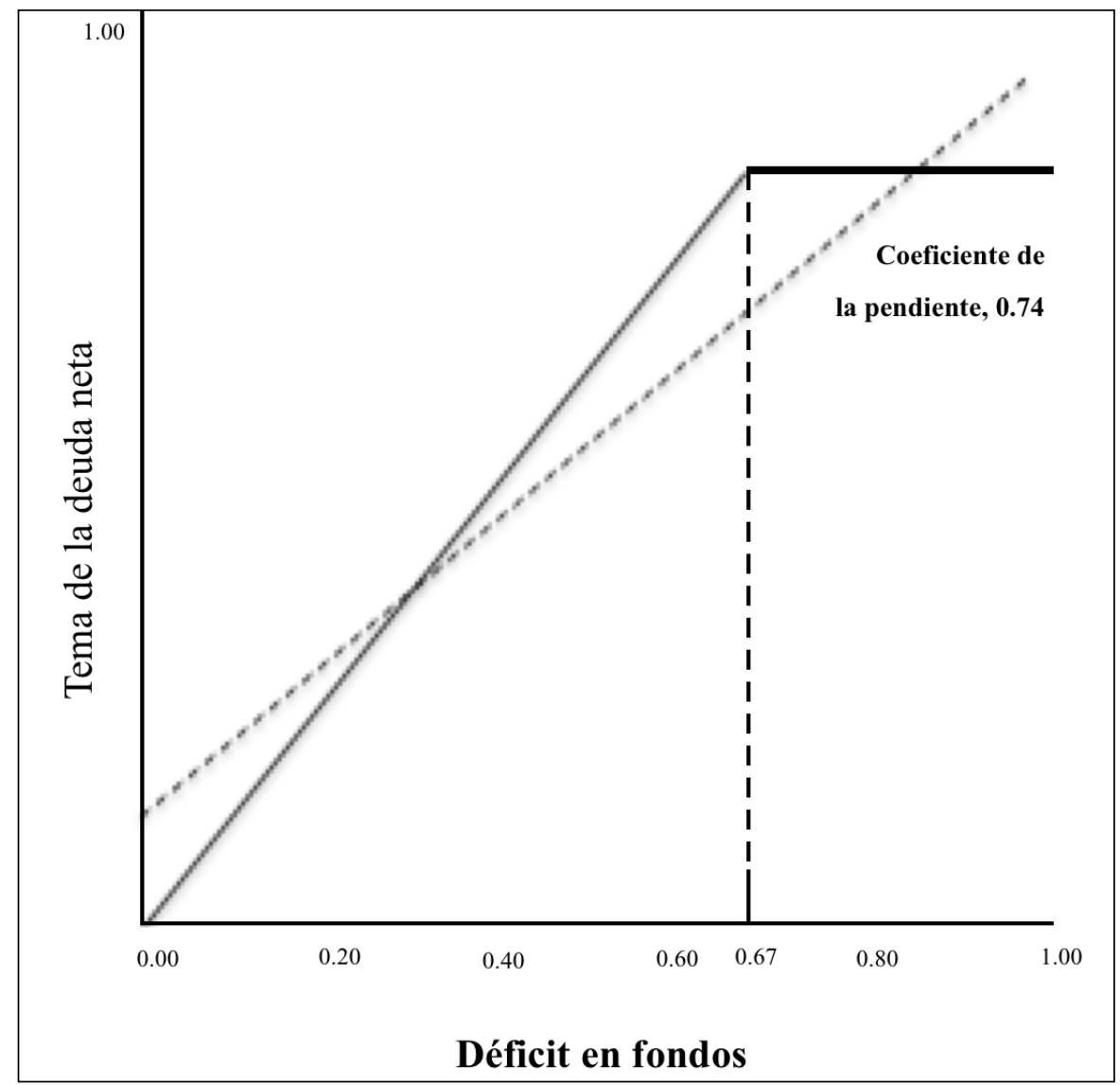

Fuente: Chirinko y Singha (2000) 
Chirinko y Singha (2000:420) hacen referencia a que "las historias de financiamiento de deuda son simuladas usando un modelo específico de la estructura de capital y datos de entrada de empresas reales, y entonces un modelo alternativo es evaluado econométricamente usando estas series estimuladas". Demuestran que la teoría del equilibrio estático tiene un bajo poder sobre la teoría de la jerarquía financiera cuando los datos son generados por el modelo del orden jerárquico. El modelo del equilibrio estático esta representada por una regresión de deuda sobre investigación y desarrollo, planta, utilidades y pérdidas fiscales de ejercicios anteriores.

En la figura 2.12., la línea sólida representa el modelo real, en el cual el $89 \%$ de déficit en fondos se satisface solo por temas de la deuda neta con el remanente cubierto por el capital neto. Esta mezcla de deuda y capital refleja que, del $67 \%$ de las observaciones, el déficit en fondos se satisface solo con la emisión de deuda. 
Figura 2.12.

Mezcla de deuda y capital Coeficiente 0.54

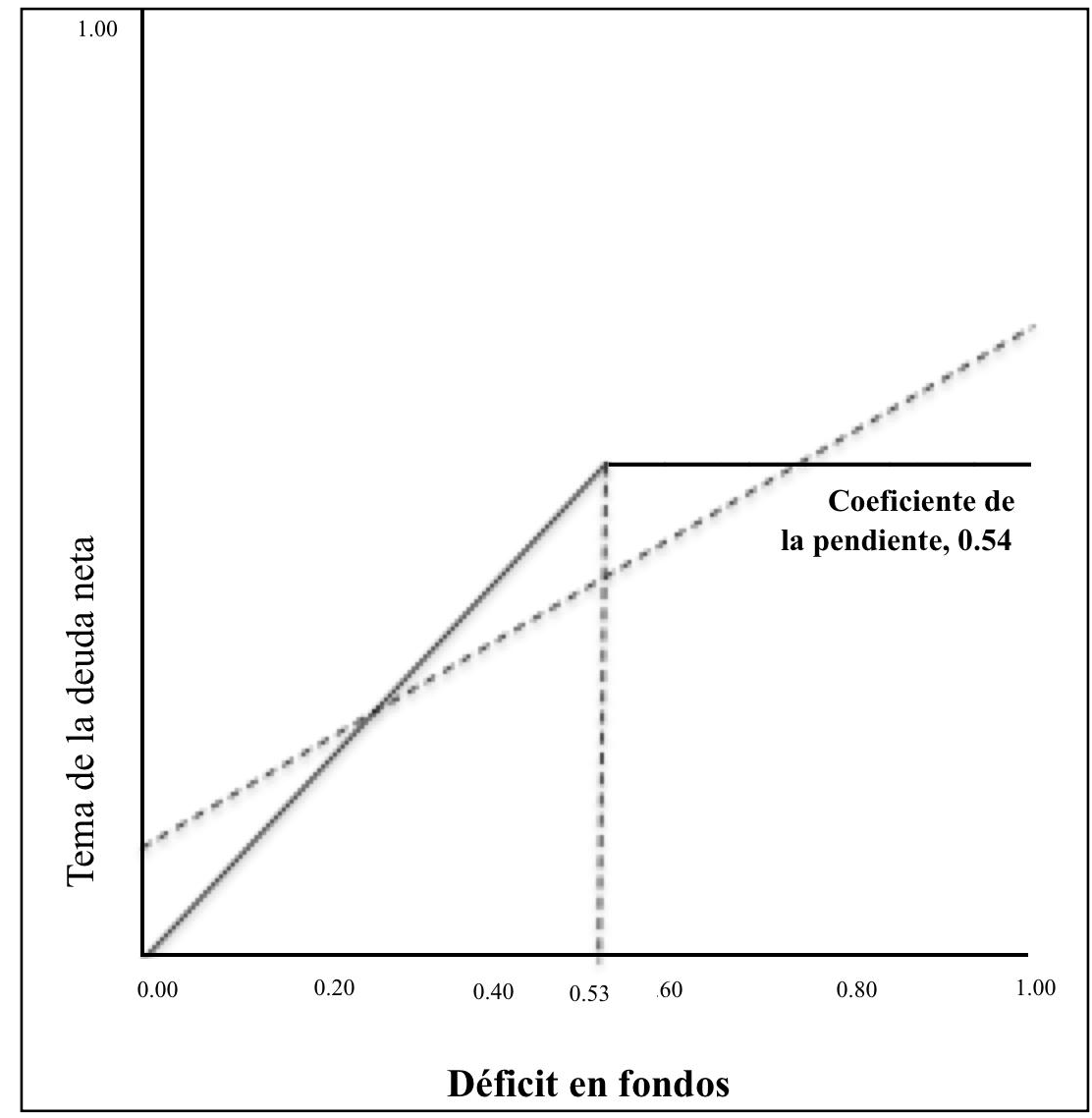

Fuente: Chirinko y Singha (2000)

En la figura 2.12, a diferencia de la anterior, la línea sólida representa el modelo real, en el cual el $78 \%$ del déficit en fondos se satisface solo con temas de la deuda neta con el déficit remanente cubierto por el capital neto. La mezcla de deuda y capital señala, que para el $53 \%$ de las observaciones, el déficit en fondos se satisface solo con la emisión de deuda. Para los períodos remanentes, el déficit es cubierto por una mezcla de deuda (la distancia del eje horizontal y la línea sólida horizontal) y capital (la 
distancia de la línea sólida horizontal a $45^{\circ}$ de la línea que emana del origen).

Como se puede apreciar, la empresa determinará su estructura de capital entre una mezcla de deuda y de capital, siendo que hasta cierto nivel podrá endeudarse, mucho depende también como señala la selección jerárquica de la decisión de la empresa; o como señala el equilibrio estático, del beneficio fiscal por pago de intereses.

Como podemos ver, esta teoría entre sus señalamientos, menciona el beneficio fiscal y determinar el nivel de endeudamiento posible. Aunque hay países en los cuales los beneficios por deducción de intereses se ven cortados, como el caso del más reciente impuesto en México que no permite la deducibilidad de los intereses de deudas otorgadas por instituciones financieras; el tema del costo de la deuda formaría parte de nuestro modelo, pues resulta interesante conocer el impacto del crédito en los resultados y operación de la pyme. 


\subsection{Teoría de la Información Asimétrica (Asymmetric Information)}

En las finanzas de una corporación, la información asimétrica es conceptualizada en el sentido de que la gente interna, principalmente administradores, tienen mayor y mejor información que la gente externa, referido principalmente al valor de los activos y oportunidades de inversión en la compañía (Klein et al., 2002). Un concepto similar es mencionado por Narayanan (1988), indica que dentro de la compañía, el conocimiento de la misma empresa como tal es mayor al que tiene la gente externa a ella. Señala que las empresas más rentables utilizan la deuda como una medida para alejar a las pequeñas compañías de sus mercados. De hecho, cuando la estructura de capital es definida por una empresa, esta puede verse afectada por el tema de la información asimétrica (Riley, 2001). Es necesario precisar que la estructura de capital se puede ver afectada por diversos factores, no solo información asimétrica, tales como: impuestos, dificultades financieras, costos de quiebra, entre otros.

Varios mercados o áreas tienen diferencias de información entre vendedores y adquirentes. En un análisis realizado por Varian (1980), muestran como el establecer precios en forma aleatoria ha sido utilizado por las tiendas con el fin de distinguir entre los consumidores informados y los no informados, considerando a un consumidor informado el que conoce la totalidad de oferta de precios; con ello este tipo de consumidores sabrán en que momento y lugar podrán contar con el mejor precio, acudiendo a tal tienda para efectuarlo, situación contraria con los consumidores no informados, lo cual es de beneficio para la empresa oferente. Riordan (1985) al hablar sobre los precios establecidos en el mercado sugiere el suponer que los productos fueran diferenciados y las compañías establecieran el precio. 
Si una compañía incrementara su precio, la competencia tendría una mayor demanda, lo que originaría tal vez un aumento de precio en el corto plazo.

Los mercados financieros no son la excepción, además de que son altamente identificables (Leland y Pyle, 1977). Quienes prestan dinero no conocen tan bien lo que es la garantía del deudor, así como su posición moral y su desempeño en la industria. Además, cuando van a requerir recursos para una inversión, los empresarios saben más que nadie de qué forma tienen conceptualizado su proyecto y muchas veces el acreedor no entiende este concepto. Ellos indican que cuando se trata de un buen proyecto, para que se dé el financiamiento forzosamente deberá darse a conocer la información que no es del conocimiento del acreedor, además, indican que una forma de indicar su compromiso con el proyecto es que la empresa como tal invierta de sus recursos internos un porcentaje de la inversión total, lo cual daría confianza a la institución que se está solicitando el financiamiento.

Una forma de mitigar la información asimétrica sería el ofrecer una garantía por parte del deudor, tal como lo comentan Berger et al. (2010), además de reducir el problema de la asimetría, se podría reducir el racionamiento del crédito. Además comentan que entre menor sea el grado de asimetría en la información entre el deudor y el prestamista, esto debe influir en que también se reduzca el nivel de la garantía dada. Cuando las instituciones financieras otorgan algún crédito, se crea una incertidumbre en el sentido de que no se pueden evaluar ciertas características y acciones de los deudores (Dell'Ariccia, 2001), lo cual llevaría a racionamiento del crédito. Tratando de explicar lo que significa el racionamiento de crédito, Stiglitz y Weiss (1981) nos hablan de lo que en economía es definido como 
equilibrio de mercado, en el cual la oferta iguala a la demanda; si la demanda empieza a superar la oferta los precios subirán, y ya sea que la demanda empiece a disminuir o que la oferta se incremente, se llegue a un nuevo equilibrio en el cual se ajuste el precio en el mercado.

Con este ejemplo de oferta y demanda, asimilando al financiamiento, vemos que puede haber limitante de crédito cuando la demanda de los mismos empieza a superar dicha oferta, además de que lo encarece. Cuando las instituciones realizan préstamos, mencionan, les preocupa mucho la tasa de interés y el riesgo del contratante. Stiglitz y Weiss (1981) nos ilustran este concepto en la figura 2.13. La tasa de retorno estará basada principalmente en estas dos variables, sin menospreciar otras variables como la garantía o el monto mismo del préstamo. De hecho, para ellos la tasa de retorno del banco crecerá más despacio que la tasa de interés, llegará a un punto máximo de rentabilidad a cierta tasa de interés y a partir de ahí decrecerá, tal como se muestra en la siguiente figura, siendo " $\mathrm{r}$ " la tasa óptima para el banco en la cual maximiza su rentabilidad.

Figura 2.13.

Tasa retorno del banco en relación a tasa de interés cobrada

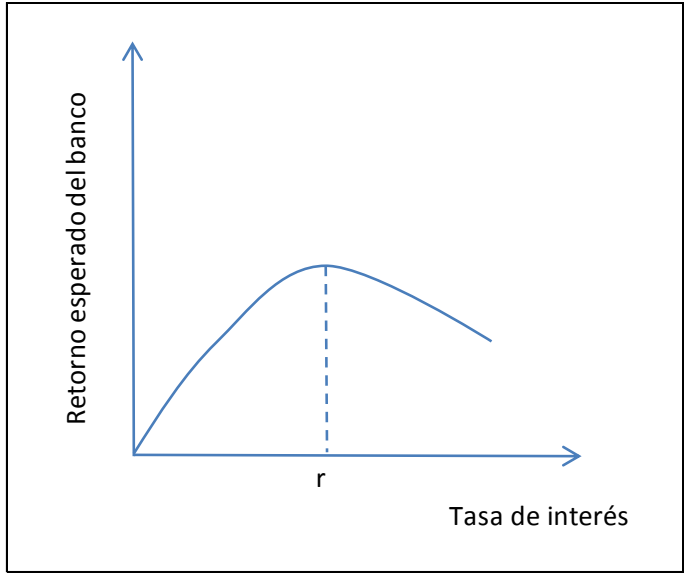

Fuente: Stiglitz y Weiss (1981) 
Esto nos indicaría que el banco fija su tasa de interés en base al rendimiento que espera obtener, bajo el esquema de Stiglitz y Weiss, no forzosamente a mayor tasa el banco tendrá mayor ganancia; aunque como forma de mitigar el riesgo o cubrir costos de asimetría, el banco usa estas bases para asignar un nivel de tasa.

De acuerdo a Dierkens (1991) los administradores podrían realizan algunas proyecciones en el futuro de la empresa, lo cual representa una ventaja que deriva en información asimétrica respecto a los inversionistas existentes en el mercado. Normalmente entendemos que el banco solicita información histórica, se puede pensar en que la empresa pueda presentar esta información proyectada, aunque en principio parezca ilógico si en inicio no cuenta con información. Se puede decir que la información asimétrica es mucha cuando la información que tienen los administradores supera en mucho a la información que conocen los inversionistas externos y, viceversa.

A veces las empresas que tienen proyectos a largo plazo se financian con deuda a corto plazo, esta pregunta se la realizan Berger et al., (2005), de acuerdo a ellos una respuesta generalizada es que el vencimiento de la deuda hace énfasis en el riesgo cuando existe información asimétrica. Además, mencionan otro punto de la literatura de este tema, en el cual se establecen bajo contrato mayor control a los prestamista, como una garantía o cláusulas de restricción, por supuesto, con aquellos deudores de mayor riesgo, con lo cual se pueda disminuir el mismo. Para Goswami et al., (1995) la utilización de deuda a largo plazo se ha incrementado mucho en los últimos años. En estudios realizados por ellos, indican que cuando la información asimétrica está relacionada con proyectos a largo plazo, se prefiere contratar deuda a 
largo plazo con la consecuente restricción de pago de dividendo, en cambio, cuando hay prevalencia de asimetría en la información en el corto plazo la empresa considerará el contratar deuda también a corto plazo, o en su caso, deuda a largo plazo pero bajo la cual no se tenga que restringir el pago de dividendos.

Otra situación referente a la información asimétrica es referente a los pasivos financieros que se tienen en la compañía. Flannery (1986) argumenta que si tanto los administradores como los inversionistas contaran con la misma información sobre los proyectos, entonces sus obligaciones no se verían afectadas por la magnitud de sus pasivos financieros. Pero, si aparece la asimetría, entonces los administradores mostrarán la mejor cara financiera de la compañía a los inversionistas; acreedores en nuestro estudio. En un análisis realizado por Bharath et al., (2009) intentan encontrar si la información asimétrica es determinante cuando se establece la estructura de capital en las empresas. Autore y Kovacs (2010) suponen que a las empresas con un alto nivel de información asimétrica les conviene más emitir nuevas acciones que aquellas con niveles bajos de información asimétrica. Encontraron que financiarse con capital es mejor si la información asimétrica en el pasado reciente es baja.

Ross (1977) asume que los administradores de las empresas poseen información relevante de las mismas, pero no cuentan con información sobre otras empresas. Cuando se realiza un refinanciamiento, la empresa contraparte tiene a su vez a sus propios administradores, pero no hay intercambio de información. Blazenko (1987) comenta que si la reputación de los administradores se ve afectada por el desempeño de la empresa, entonces querrán realizar las decisiones sobre la cuestión financiera. Así, 
una inversión en activos tratarán de realizarla con el capital propio; esto es que ante la situación de información asimétrica preferirían tomar del capital. Si tuvieran mayor información a los inversionistas, como suele ocurrir, y no quieren tomar riesgos entonces se van a financiar con deuda. También considera que la estructura de capital ayuda a disminuir las situaciones adversas de la información asimétrica una vez que se ha determinado.

Michaelas et al., (1999) realizan un estudio de cómo afecta la asimetría de la información en las pymes. Comentan que los costos de la información asimétrica tienen doble efecto, tanto en el corto como en el largo plazo en las pymes. Estos altos costos puede traducirse en que las pymes con razones financieras muy bajas, además de no contar con muchos activos para garantizar el crédito, son de riesgo para las instituciones financieras que las califican, quienes las consideran muy sensibles a los cambios económicos, así que no pueden depender mucho del financiamiento externo, pues les resultará complicado y costoso obtenerlo.

El firmar contratos por cada cierto período es costoso para empresas y bancos, aunque estos últimos no tienen ganancia alguna por el período de relación con sus clientes, no están acostumbrados a realizar un mejor servicio vía tasas de interés, de hecho la competencia hace que los bancos traten de ganarse al cliente cotizando las menores tasas precisamente al principio, cuando no se le conoce de manera profunda (Sharpe, 1990). Una vez que se han contratado con un banco, las empresas se mantienen con este por que ha conseguido de alguna manera conocerlo y a su información, no tanto por el trato. Von Thadden (2004) está en desacuerdo con los resultados obtenidos por Sharpe. Considera que la oferta más alta, en este caso la tasa de interés más baja, en caso de quedarse con el contrato es porque los demás 
consideraron que fue muy bajo, entonces no solo es considerar la información sino que la oferta sobrepasa a la de otros.

En resumen, podemos distinguir que la información asimétrica juega un papel muy importante en el financiamiento de las empresas, ya sea vía deuda o capital, puesto que no solo dependerá de la aceptación de este hecho como tal de las empresas o inversionistas que fondearían los recursos, sino también de la actitud de los administradores hacia las decisiones que tomen en este tema dentro de la empresa. Adicionalmente nos señalan los costos que se originan con esta situación, que puede traducirse en otro obstáculo para la empresa. 


\subsection{Teoría de la Agencia (Agency Theory)}

La relación de agencia es una de las formas más antiguas y comunes de la interacción social (Ross, 1973). Eisenhardt (1989) menciona que la teoría de la agencia ha sido utilizada en diversas disciplinas como: contabilidad, economía, finanzas, mercadotecnia, entre otras. De los diversos conceptos que se abordan en la literatura de la teoría de la agencia hay uno llamado el problema de la agencia que ocurre cuando una de las partes tiene diferentes objetivos. Para ello hay una relación de agencia en la cual una de las partes (el principal) delega un trabajo a otra (el agente) quien es el que efectúa el trabajo. En tanto que para Jensen y Meckling (1976) la relación de agencia se da cuando una o más personas (principal (s)) contratan otra persona (el agente) para realizar un servicio en su nombre lo cual involucra el delegar autoridad para la toma de decisiones por parte del agente.

Esta introducción nos resume que la teoría de la agencia trata de resolver dos situaciones, la primera es el problema de agencia que surge cuando las partes tienen diferentes objetivos y además resulta difícil o costoso para el principal identificar lo que realiza el agente. La segunda situación surge cuando las partes tienen diferentes puntos de vista respecto al riesgo. Para esto se puede realizar un contrato, a través del cual, por un cierto pago (que puedo ser fijo o variable), una persona acuerda acatar las reglas impuestas por el empresario bajo ciertos límites (Coase, 1937). Coase comenta que la esencia del contrato debería solamente fijar los límites que impone el empresario. Él parte de la idea, en cierto caso, de que una de las partes prefiera trabajar bajo la directriz de otra; por supuesto, tal vez la mayoría querrán tener el control, pero para ello habrá que erogar o realizar 
un pago para obtener los servicios de la otra persona y tener la autoridad de dirigirla. Señala también, en cuanto a los costos, que elaborando uno largo en lugar de varios cortos, se puede eliminar los gastos inherentes a la realización de los mismos.

La mayoría de relaciones de agencia llevan implícitos ciertos costos, además de que ocurrirán diferencias de opinión entre el principal y el agente. Jensen y Meckling (1976) definen los costos de agencia como la suma de: los gastos de supervisión realizados por el principal, los gastos efectuados por el agente y la pérdida residual, la cual es definida por ellos mismos como el importe en que se vería afectado el bienestar del principal por las diferencias en las decisiones entre este y el agente. Las pymes generan mayores costos de agencia por sus propias características que provocan mayor asimetría en la información (Mac an Bhaird, 2010), además considera que la teoría de agencia cuando se aplica a pymes se enfoca más en la relación del dueño con los inversionistas de capital.

El hablar de la teoría de agencia nos puede dar un conocimiento más profundo de lo que sucede en la "relación de préstamo", variable que puede resultar muy importante al elaborar nuestro modelo teórico. El objetivo de la pyme lo podemos traducir en la obtención de crédito para su operación, la institución financiera es obtener un beneficio económico al otorgar crédito pero con el mínimo riesgo de que tenga una pérdida. La pyme debe demostrar que no hay riesgo, el banco deberá supervisar que no aparezca durante el contrato.

Williamson (1985) señala que la "transacción" es la unidad básica de análisis en las organizaciones. Los costos de las transacciones son un tema 
relevante en las operaciones realizadas en un marco económico. Estos costos traducidos a la organización se ven reflejados en los costos generados al contratar. Se generan costos al inicio, durante la negociación y en la salvaguarda del acuerdo. La salvaguarda más segura se dará a través de la propiedad en común, cuando las partes sean dueños de una parte del negocio. Por supuesto, en la operación de crédito, habrá varios costos, que tanto afectará a la empresa estos, es una de las situaciones que se analizarán con el modelo. Los costos de la relación de agencia incluyen supervisión y los derivados de la relación con el agente con los cuales no se obtenga una maximización del valor de la empresa (Mann y Sicherman, 1991), y esto aun cuando haya inversiones en proyectos rentables.

Señala además Williamson (1985) como parte importante para explicación de los costos del contrato lo que refleja en su mapa como se muestra en la figura 2.6. Menciona que el enfoque del monopolio se sale de la norma clásica y lo compara con la eficiencia, la cual tiene propósitos principalmente económicos. Los enfoques sobre la línea del monopolio se agrupan en dos conceptos. El primero analiza costumbres del cliente así como sus limitantes territoriales, mientras la segunda trata de identificar el impacto de las prácticas rivales. La línea de eficiencia resalta tanto los incentivos como los costos que origina la contratación entre ambas partes. 
Figura 2.14.

Modelo Cognoscitivo del Contrato

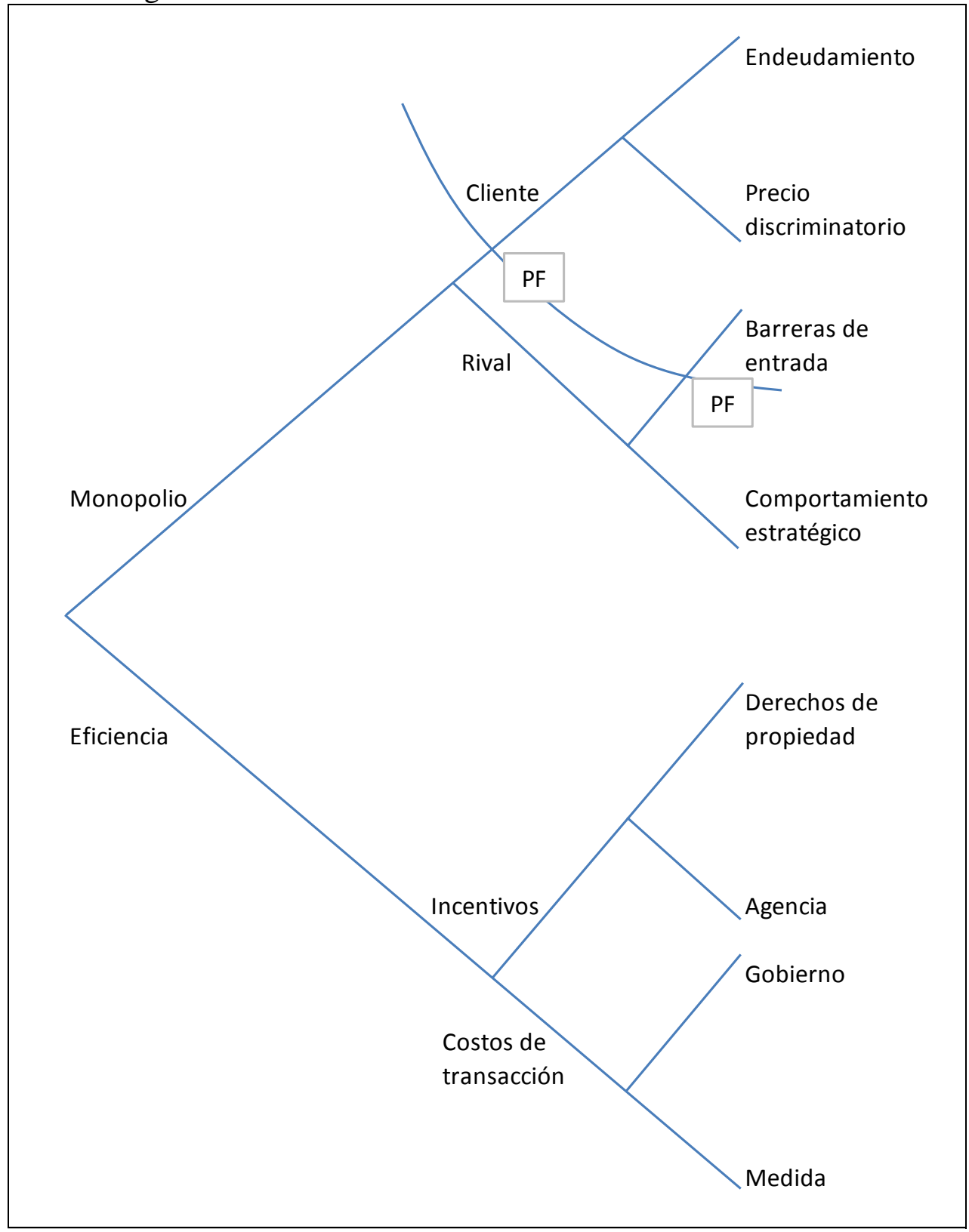

Fuente: Williamson (1985) 
La literatura de agencia, toma bastante en cuenta los riesgos que pueden resultar con motivo de la realización de un contrato, comenta Williamson. Pues la separación entre la propiedad y el control de la empresa afecta tanto los incentivos como las utilidades. Esta figura del contrato, nos muestra unos costos de transacción, en el crédito entendemos que existirá un cobro de la institución por ese servicio, además refleja el endeudamiento, parte principal de lo que analizamos en nuestra tesis. De aquí podemos extraer que la relación que tenga la empresa, puede ser múltiple, para evitar el monopolio como lo marca Williamson en la figura 2.14.

Para Williamson (1975) resulta muy compleja la elaboración de contratos cuando existen diversos factores tales como la relación entre principal y agente así como las características propias de las personas en su desempeño, por lo cual ante condiciones de contingencia la empresa evitaría el mercado como tal, y entonces, recurrir a la jerarquización de los mercados pero de manera organizacional. Jensen y Smith (1985) concuerdan en que la teoría de la agencia ha resultado en dos enfoques, la teoría positiva de la agencia y otra literatura enfocada al estudio de la relación principal - agente. Para ellos la literatura sobre principal - agente se ha enfocado más sobre los aspectos de preferencia e información asimétrica que en la tecnología del control y contratante. Además, mencionan que la clave para entender el problema de agencia es reconocer que las partes en el contrato deben soportar los costos de la relación de agencia. Esperamos que con nuestro análisis empírico podamos ver quien cubre el mayor costo en la relación que se da con el crédito.

Tirole (1990) considera dentro de la relación principal agente en la cual se tiene al accionista y al administrador, que el objetivo del accionista 
es la utilidad del negocio menos su pago correspondiente, mientras que el administrador tiene como objetivo cual será su utilidad obtenida. Si se revisa esta relación bajo la figura de la información asimétrica en la que los accionistas solo conocen la utilidad del negocio, ellos tendrían menor control en la empresa, sujeta a esperar la utilidad proyectada. En el caso de la deuda, el administrador decidirá la forma y el acreedor.

Un modelo sobre principal - agente es desarrollado por Bitler et al. (2005), aplicado sobre empresas privadas, en el cual se sugiere que los costos de agencia pueden ayudar a explicar el por qué los empresarios concentran parte importante de su riqueza en el capital de una empresa. Explican que aunque existen varios mecanismos para alinear los incentivos de los administradores con los de los accionistas como: reputación del capital, mercados laborales competitivos y la amenaza de adquisición o quiebra; no obstante, el contrato ha prevalecido como el mecanismo más eficiente. La separación entre el control y propiedad de las empresas es una forma eficiente de organización económica (Fama, 1980). La empresa es disciplinada por la competencia con otras empresas, ello obliga a evolucionar en la forma de supervisar el desempeño del equipo y sus miembros.

La especialización y la división de trabajo ha elevado la importancia de organizaciones que otorguen servicios altamente profesionales, tal como lo comenta Sharma (1997) aunque la relación entre el principal y el profesional tiene bastantes características de lo que es una relación de agencia, hay algunas diferencias, como por ejemplo, al ser los profesionales los agentes también se está realizando una división del conocimiento en el cual es el especialista. Sharma puntualiza que derivado de los problemas 
contractuales que pudieran surgir entre el principal y el agente, este último actuará en su propio beneficio más que en la persona que le ha realizado el encargo, apoyado además por la información que cuenta y desconoce el principal, ello lo lleva a concluir que la teoría de agencia se basa en el oportunismo del agente, la información y el riesgo. Situación esta última que más le preocupa al banco y que forma una barrera para otorgar el crédito.

Cuando se habla de riesgo, se determina que la predisposición sobre este tema es diferente entre el principal y el agente. Los agentes son adversos al riesgo en las decisiones de la empresa con el fin de reducir el riesgo a la riqueza personal (Wright et al., 2001). Para ellos la extensión de la teoría de agencia puede permitir una valoración más equilibrada de relaciones de agencia, no solo entre dos personas sino también en el contexto de un grupo y una organización. Además, mencionan 4 aspectos básicos que componen la teoría de la agencia, tal como se muestra en la figura 2.15 .

Figura 2.15.

Componentes clásicos de la teoría de agencia.

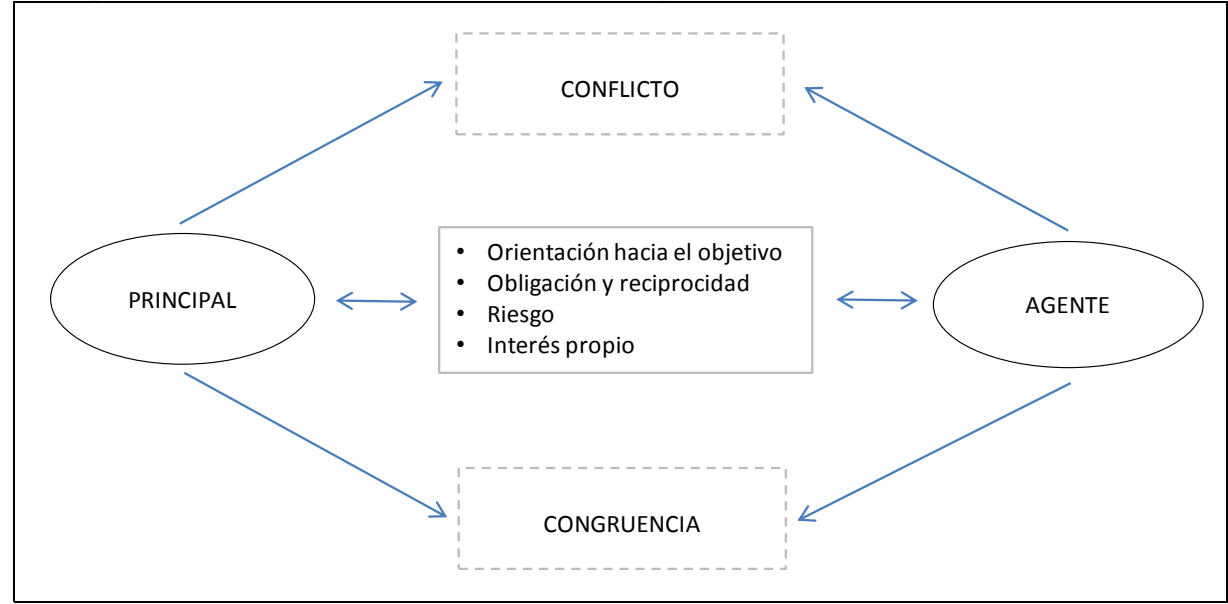

Fuente: Wright et al., (2001) 
Para Wright et al., (2001) la teoría de la agencia está basada sobre supuestos explícitos y críticos acerca del comportamiento de los agentes. Considerando además que los estudios hacen referencia a la eficacia de contratos, incentivos y sistemas de supervisión a los agentes. Con ello se busca alinear las acciones y metas de los agentes con el principal. Al hablar de los objetivos, la teoría señala que el principal derivará ciertos beneficios y costos de la relación con el agente, y este a su vez tendrá también algunos beneficios, que en dado momento podrían ser tanto económicos como de otro tipo.

Nyberg et al., (2010) mencionan que el escepticismo con que la teoría de la agencia considera la alineación entre el principal y el agente ha sido acompañada por el desarrollo de teorías referentes al pago que recibiera el presidente del consejo de administración de la empresa. Además, aunque se lograra esta alineación financiera, los costos de agencia no desaparecerían ni tampoco garantiza que los administradores tomaran las mejores decisiones. Starks (1987) encuentra que el incentivo económico óptimo para el administrador elimina uno de los posibles problemas de agencia. Cuando tiene que definir el nivel de riesgo, es posible que pueda tomar una decisión acertada, pero si también debe definir el monto a gastar, esto no eliminaría por completo el problema. Esto significa que a final de cuentas el incentivo no cubriría al cien por ciento el objetivo del inversionista al otorgarlo.

Otra derivación de la teoría de la agencia es analizada por Crutchley y Hansen (1989) en la cual los conflictos de intereses se dan entre los administradores, accionistas externos y tenedores de bonos. Mac an Bhaird (2010) menciona que los conflictos entre accionistas y tenedores de deuda se derivan de la desigualdad de ganancias manifestadas en los contratos. Los 
administradores eligen su posición accionaria en la empresa, y la mezcla de financiamiento entre deuda y capital, así como los dividendos para reducir los costos de estos problemas de agencia (Crutchley y Hansen, 1989). Sabiendo que los accionistas por la naturaleza de sus actividades delegarán a los administradores las decisiones financieras además de otras, con ello se crea una relación de agencia. Y sabiendo, que en una relación de agencia la potencial aparición de conflictos aparece en un alto porcentaje, describen unas formas de disminuir los costos de agencia provocados en esta relación.

Denis et al., (1999) recomiendan mitigar los conflictos de interés entre administradores y accionistas inicialmente de dos maneras, una es incentivar a los administradores de manera que realicen acciones de acuerdo a los intereses de los accionistas y, como segunda opción, que los administradores sean supervisados por la junta directiva o por los mismos accionistas. La pregunta sería en una relación de préstamo quien debe o quien está interesado en mitigar estos conflictos. Williamson (1975) comenta que una forma de incentivar y armonizar los intereses entre las partes es la integración vertical. Se involucran variables como el control, la cooperación de los niveles menores, los costos burocráticos, entre otros, dentro de la organización, para lo cual se establecen los incentivos con el fin de obtener la cooperación requerida. Para Díez (2007), la mayoría de trabajos en referencia a la integración vertical han asociado esta con mercados imperfectos, aunque señala que además hay otros conceptos que afectan la integración vertical, como los recursos de la empresa.

La teoría del gobierno corporativo menciona que el endeudamiento afecta los costos de agencia y en consecuencia el desempeño de la empresa (Berger y Bonaccorsi, 2006). Para ellos, los costos de agencia representan 
un tema importante en las corporaciones sean estas del ramo financiero $\mathrm{u}$ otro diferente. La teoría sugiere que la elección de la estructura de capital podría llegar a ayudar en la reducción de costos de agencia. Situación que se expuso en la teoría de Modigliani y Miller. Fama y Jensen (1983) intentan explicar la sobrevivencia de las organizaciones cuando se da esta separación entre la propiedad y el control. Consideran que la separación de las decisiones y funciones de riesgo sobrevive en parte por los beneficios que produce la especialización en la administración en cuanto a gente profesional más preparada en este tema y el manejo del riesgo, pero también por el enfoque de controlar los problemas de agencia causados por dicha separación de funciones.

Como mencionan Harris y Raviv (1991), gran parte de la investigación realizada sobre la estructura de capital es basada en la repercusión de los costos de agencia, como los resultantes cuando se presentan conflictos de intereses. $\mathrm{Y}$ pueden existir conflictos con características específicas dependiendo del principal y el agente, por ejemplo, cuando surgen las necesidades de endeudamiento, esto orillaría a que parte de la decisión no dependa exclusivamente de los accionistas quienes buscarían los recursos para fondearlos. Aunque el aumento de endeudamiento pudiera reducir los costos de agencia entre inversionistas y administradores, podría haber un efecto contrario con los costos de agencia que aparecerían entre los acreedores y los accionistas. Estos costos resultan en altos pagos de intereses para compensar a los acreedores por las pérdidas esperadas. La Rocca et al., (2011) señala que los accionistas se saben con la capacidad de influir en las decisiones de los administradores, ello con la finalidad de evitar la diversificación, con ello, promueven el uso de la deuda para controlar las acciones de los administradores. 
Para Frankforter et al., (2000) la literatura de la teoría de agencia ha descrito tres tipos de control del comportamiento de los administradores de la empresa. Incentivos a los agentes para que sus objetivos estén alineados a los de los accionistas, una junta directiva que pueda estar supervisando las acciones de los administradores y tener que cambiar al administrador cuando no actúa alineado por un grupo o personas que puedan ejercer el control debidamente. Dickinson y Villeval (2008) determinan que la teoría de agencia asume que una supervisión férrea por parte del principal tendrá como consecuencia que el agente se esfuerce más, aunque algunos consideran que pasaría lo contrario. El agente podría considerar una situación de desconfianza el verse cotidianamente cuestionado sobre su desempeño, podría verse afectado su esfuerzo y tomar decisiones erróneas por ese sentimiento de desconfianza o incomodidad. Si los administradores no reciben las ganancias que generan, esta podría ser una razón de que sus intereses no se alineen con los de los inversionistas (Tirole, 2006).

Los mecanismos de gobiernos corporativos son considerados instrumentos esenciales para alinear objetivos de administradores con los de accionistas (Elsayed, 2007). El crecimiento de las empresas en grandes corporativos forzó la separación de la propiedad de la empresa y la administración de la misma. El problema de contratación entre un inversionista y un administrador se define de dos maneras por Dybvig et al., (2010), uno de ellos como un problema de riesgo moral puesto que el inversionista no puede presenciar el esfuerzo efectuado por el administrador; además puede haber información oculta o privada que el administrador podría no usar necesariamente en beneficio del principal. Sugieren un modelo de contrato en el cual se busca encontrar el nivel óptimo de riesgo compartido entre el administrador y el inversionista; con lo 
cual la utilidad marginal para el administrador debiera ser proporcional a la que obtenga el accionista.

La teoría de la agencia nos ilustra, en cuanto a la repercusión de la estructura de capital, como la decisión del nivel de endeudamiento y la fuente del mismo puede ser definida por factores adicionales a la empresa como tal, a la persona que administre el negocio, a su posición respecto al capital social de la misma, y a la relación en dado momento que se tenga con accionistas o acreedores, un punto que tal vez en las otras teorías de la estructura de capital no se consideraba de manera profunda como nos muestra el análisis realizado hasta ahora. 


\subsection{Teoría del Flujo de Efectivo Libre (The Free Cash Flow Theory)}

Si la teoría de la jerarquía financiera nos señala un orden para financiar las inversiones, entre fondos internos, deuda y capital. Es lógico pensar que habrá empresas con la liquidez suficiente para olvidarse de las últimas dos opciones. De ahí que se derive la teoría del flujo de efectivo libre.

Uno de los conceptos establecidos en esta teoría es lo que menciona Jensen (1986), el flujo de efectivo libre es el flujo en exceso al requerido para invertir en todos los proyectos con un valor presente neto positivo. En cambio, para Richardson (2006) el flujo de efectivo libre es el efectivo requerido para mantener los activos en su lugar y financiar las nuevas inversiones esperadas. Para McCabe y Yook (1997) con la utilización de los excedentes se podrían realizar inversiones internas o nuevas adquisiciones, aunque esta pudiera no ser positiva, argumentan que a final de cuentas lo que predominaría es el pago de fondos; otras empresas podrían ocupar el efectivo en incrementar activos líquidos o mejorar su capacidad de deuda.

Jensen (1986) considera que los administradores que manejan un flujo de efectivo libre pueden incrementar dividendos o recomprar acciones y poder pagar fondos actuales en lugar de ser invertidos en proyectos muy poco rentables o en dado momento desperdiciar el dinero. Mann y Sicherman (1991) comentan que los administradores representan los intereses de los accionistas, y a menos que otra cosa suceda, se encargarán de maximizar las utilidades del negocio. Un punto interesante, consideran que, aun cuando ya se haya invertido en proyectos rentables los excedentes 
de efectivo, aún pueden resultas costos interesantes resultantes de la relación de agencia. Para ellos, los inversionistas llegan a tener dudas sobre el incremento de efectivo en las compañías si no hay un compromiso sobre el pago futuro con los incrementos de efectivo.

Cuando las empresas tienen excedentes de flujo de efectivo, una razón podría ser porque no tiene algo rentable en que gastarlo (Wells y Cox, 1995). Siendo que uno de los usos del flujo de efectivo excedente podría ser para realizar nuevas inversiones (Richardson, 2006). En cuanto al crecimiento de las empresas, Brush et al., (2000) comentan que académicos en general mencionan que el crecimiento beneficia más a los administradores que a los inversionistas, soportando su punto de vista en que en ocasiones los administradores toman decisiones para su propio beneficio más que para el de los accionistas. Esto nos origina un problema de agencia, además de cierta asimetría en la información en la que el mejor conocimiento de los administradores de la compañía les beneficiaría frente a los dueños. No obstante, el incrementar el endeudamiento es un efectivo método para contrarrestar esta situación (Howton et al., 1998), puesto que esto obliga a la empresa a realizar pagos futuros programados.

Jensen (1988) señala que el exceso de efectivo tendría que ser pagado a los accionistas para que la empresa pueda ser más eficiente y maximizar el valor de los accionistas. Cuando las empresas son de reciente creación, los intereses de los administradores concuerdan con los de los accionistas (Oded, 2009); sin embargo, conforme va pasando el tiempo, ya no están alineados los objetivos de ambas partes. Los accionistas podrían dejar las cosas de esa manera o solicitar a los administradores mantener el pago de dividendos bajo un programa, situación que en cierto momento 
podría afectar a la compañía en cuestiones de liquidez. Así como lo señala Dhumale (1998), la teoría de flujo de efectivo recomendaría un incremento en los dividendos pagados a los accionistas o aumento en la deuda de las empresas con potencial de crecimiento que tengan excedentes de efectivo. Así que otra causa para definir la necesidad de un crédito es la misma descapitalización por los dueños de la empresa.

El conocimiento empresarial nos indica que la mayoría de pymes no cuentan con tales excedentes de efectivo. Pero la parte importante que podemos tomar de esta teoría para nuestro estudio es si las necesidades de crédito parten para un pago de dividendos, un proyecto conjunto con recursos excedentes o tal vez la realidad nos diga que las empresas no necesitan un crédito por la liquidez excedente con que cuentan para su operación e inversiones nuevas. 


\subsection{Teoría de Sincronización del Mercado (The Market Timing Theory)}

Como se mencionó en la teoría de la jerarquía financiera, normalmente las empresas dejan como última instancia el emitir nuevo capital y, por consiguiente, la entrada de nuevos socios, aunque hay momentos en los que las condiciones del mercado de acciones podría dejar resultados favorables para las empresas que deciden incursionar en este ramo, incluso sin llegar a perder el control de sus empresas, pero obteniendo una fuente de financiamiento.

En la búsqueda de estructuras de capital a través de valuaciones históricas de mercado, Baker y Wurgler (2002) encuentran que las empresas no apalancadas son aquellas que han incrementado sus fondos cuando sus valuaciones fueron altas, lo cual se determinó por la razón financiera de valor de mercado a libros. Situación contraria cuando se trataba de empresas con valuaciones bajas. Baker y Wurgler manifiestan que muchas decisiones de financiamiento se basan en las valuaciones de mercado. Su definición práctica de la estructura de capital es "el resultado acumulado de las decisiones de financiamiento pasadas" (Baker y Wurgler, 2002:1). Al hablar de la teoría de sincronización del mercado comentan que los administradores se programan para el momento de tomar las decisiones de acuerdo a los precios vigentes en el mercado.

Para Baker y Wurgler la teoría de sincronización de mercado es más consistente como parte de la teoría de la estructura de capital. Además, esta teoría puede considerarse una variante de la teoría de la jerarquía financiera, los administradores se pueden programar en cuanto al mercado pues están 
más interesados en los accionistas actuales que en nuevos, o ellos mismos son accionistas. Adicionalmente, afirman que tampoco en la teoría de sincronización de mercado se persigue un óptimo de estructura de capital. La importancia de esta teoría para nuestro estudio estriba en la variación de las teorías mencionadas en este párrafo, su enfoque entre deuda vía crédito o capitalización nos indicaría cual es lo que persiguen las pymes.

En las decisiones del financiamiento corporativo, uno de los factores que influyen en el mismo es la sincronización del capital en el mercado de acciones. Cuando el costo del capital aparenta estar bajo es cuando las empresas empiezan a promover esta actividad (Alti, 2006). Cuando se realiza una oferta pública por primera vez, el momento en el mercado deriva dos situaciones: las empresas se decidirán por hacerse públicas cuando los empresarios sienten que el mercado es favorable y, cuando sucede esto las empresas emitirán mayor capital que cuando hubieran sido desfavorables las condiciones del mercado. Esta teoría de la sincronización de mercado ofrece a los administradores el conocer el momento oportuno para emitir nuevo capital resultando menos costoso, esto comparando con algunas otras fuentes de financiamiento en el mismo momento. Ello presupone que los beneficios para los accionistas actuales será de los máximos a costa de los nuevos accionistas (Elliot et al., 2008).

De acuerdo a estudios realizados por Jenter (2005), los administradores tienen la tendencia de contar con puntos de vista diferentes a la valuación de las empresas que dirigen, lo cual es un factor relevante en su toma de decisiones. De ahí parte que la información asimétrica se basa en la idea de que los administradores tratan de activar el mercado con la venta de acciones cuando consideran que están sobrevaluadas o de esperarse en 
caso contrario. Para Elliott et al., (2007) cuando se evalúa la teoría de sincronización del mercado de la estructura de capital, esta se aplica considerando el determinar si las acciones de la empresa ofrecen un precio equivocado a los inversionistas. De hecho, cuando las empresas están sobrevaluadas son más propensas a emitir capital para financiarse, caso contrario cuando están subvaluadas en las cuales preferirían financiarse con deuda. "Una oferta pública inicial (IPO por sus siglas en inglés) se realiza cuando un título es vendido al público en general por vez primera, con la idea que se desarrollará un mercado líquido, pudiendo ser un título de deuda o de capital" (Ritter, 1998:6).

Muchos autores argumentan que ni la teoría de la compensación ni la teoría de la jerarquía financiera son consistentes con el efecto negativo de las razones financieras "valor de mercado a libros" y "endeudamiento" de las empresas. Entonces, dichos autores argumentan que los cambios en la estructura de capital no son atendidos por la empresa pues no les interesa ajustar los resultados de sus razones financieras en un futuro (Hovakimian, 2004). También encontró que un efecto negativo en endeudamiento, cambio en el endeudamiento o deuda contra capital se encuentra usando un promedio en el futuro más que en una razón histórica. Leary y Roberts (2005) comentan que un punto de vista común en finanzas corporativas es que las empresas tratan de mantener una estructura de capital que equilibre los beneficios y costos derivados de un endeudamiento financiero; argumentan que algunos estudios asumen que el balancear esta estructura cuando se ha modificado no tiene costo alguno, y por lo tanto pueden equilibrar hasta llegar a un óptimo, pero si se presenta un costo, la empresa esperará antes de capitalizar o incrementar deuda. 
Mahajan y Tartaroglu (2008) mencionan que la teoría de la sincronización del mercado ha generado cierta controversia por señalar algunas diferencias con las teorías emanadas de la estructura de capital. Haciendo un análisis de esta teoría dentro de los países del llamado G-7 (grupo de los 7 países económicamente más fuertes del mundo) encontraron que la razón financiera histórica de valor de mercado a libros tiene una relación inversa al endeudamiento en estos países, lo cual es consistente con la teoría. Definen el endeudamiento de dos maneras, en base a libros como la deuda dividida entre el total de activos, conocida también como el apalancamiento de las empresas, y otra en base al mercado, en el que el total de activos será tomado por su valor de mercado de dichos activos.

La teoría de la sincronización de mercado nos deja con la idea sobre la empresa entrando en el mercado público para obtener recursos mediante la emisión de títulos accionarios o bien con deuda pero en el mercado público, pero nos señala como la estructura de capital, el nivel de endeudamiento o las cuestiones de asimetría pueden influir en la decisión del administrador o de la empresa, así que este punto nos puede sugerir también como deriva esto al decidirse por tramitar un crédito. En países como en México solo una minoría, un pequeñísimo porcentaje de las empresas del país cotizan en bolsa; pero factores como la valuación de los activos, la información financiera misma, las razones financieras enunciadas son parte relevante para que se de esta situación, de otra manera, como pasaría con la mayoría de las pymes, la primera opción sería la deuda. 


\subsection{Otras Aportaciones}

\subsubsection{Obstáculos para acceder al crédito}

Además de las teorías señaladas, y de las cuales se desprenden varias limitantes para el acceso al crédito, varios autores señalan o han estudiado conceptos particulares que limitan, específicamente a las pymes, el obtener préstamos. Muchas son las variables que se deben tomar en cuenta para la obtención de recursos. Después de la crisis económica y financiera que se agudizó en 2008, en todos los países las condiciones o restricciones para su otorgamiento dificultaron aún más el cubrir los requisitos para aquellas compañías que ya tenían problemas para conseguirlo.

La estructura de capital que fue inicialmente analizada por Modigliani y Miller (1958) ha sido base para diferentes vertientes de muchos autores con los cuales se trata de entender la posición de las empresas en cuanto al nivel de apalancamiento que buscan para obtener el mejor rendimiento. Hablando de las pymes, estas representan el mayor porcentaje a nivel mundial, es claro que un número reducido de empresas puedan tener cubierto una gran parte de mercado en cada uno de los distintos rubros y servicios que son demandados por el consumidor, pero las demás empresas en conjunto representan mayoría, y derivado de ello participan de manera importante en el PIB de los países. Sin embargo, no suelen contar con el apoyo por las autoridades gubernamentales, el suficiente para poder desarrollar una actividad sana en cuanto al aspecto financiero, y muchas de ellas cierran al poco tiempo de haber iniciado.

Los bancos toman en cuenta distintos factores para otorgar financiamiento a las pymes. De acuerdo a un análisis realizado por De la 
Torre et al. (2010), las utilidades no son el único aspecto a tomar en cuenta, el riesgo inherente es también un factor a considerar. Las instituciones financieras que otorgan créditos refieren como algo sobresaliente la informalidad de las pymes. Encuentran que la tecnología de préstamo utilizada y otros aspectos específicos de los bancos no son obstáculos tan relevantes que limiten la relación con las pymes. A continuación en la figura 2.16. se muestran los principales obstáculos señalados por los bancos en 4 diferentes países.

Figura 2.16.

Obstáculos en la relación de bancos con pymes.

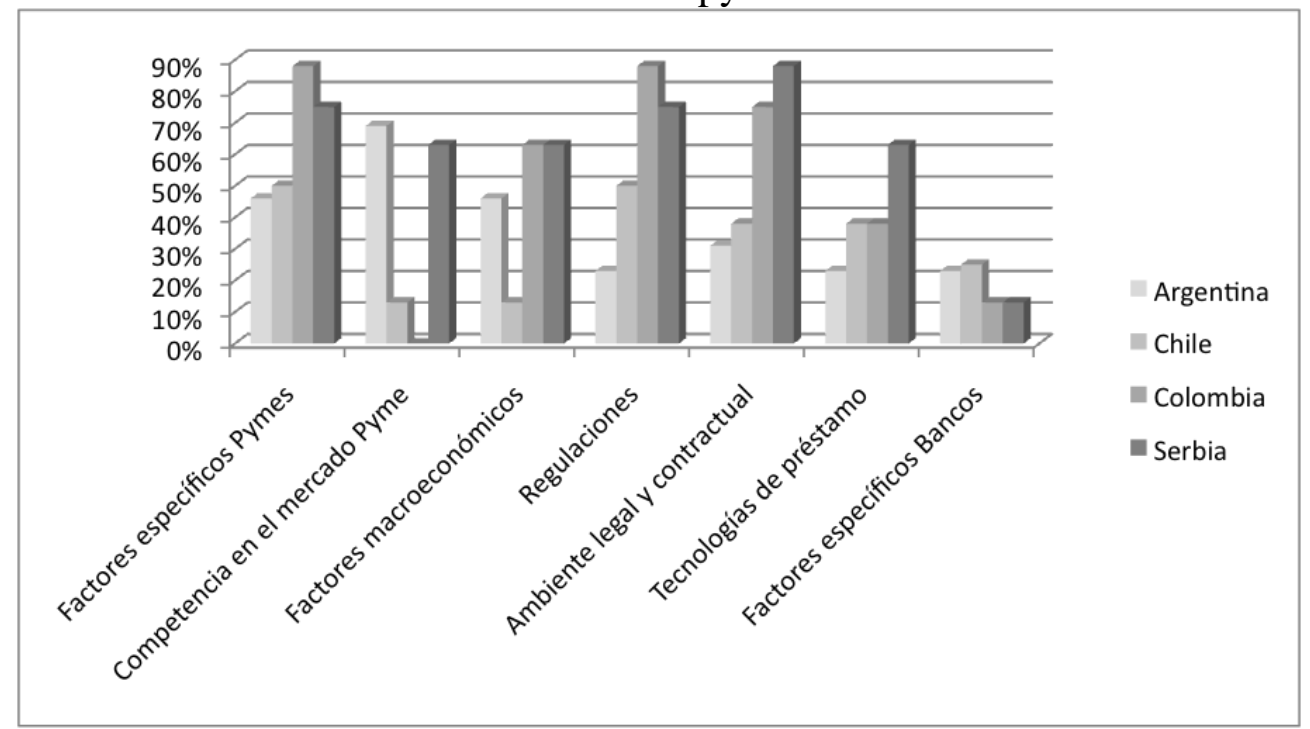

Fuente: De la Torre et al. (2010)

Como se puede apreciar los factores que envuelven las características de las pymes, son aspectos relevantes que los bancos consideran en su relación para otorgamiento de financiamiento, sobresaliendo también situación en cuestión de la regulación existente en el aspecto jurídico, la parte contractual se toma muy en cuenta y las 
tecnologías de préstamo son otra base sólida cuando se determina el estudio para el otorgar créditos.

El resumen mostrado en la figura anterior se desglosa más a detalle en otro estudio realizado por ellos mismos. En este, De la Torre et al. (2009) describen algunos de los conceptos más mencionados por la gente de los bancos, lo cual muestra en la tabla 2.2.:

Tabla 2.2.

Factores de obstáculos entre bancos y pymes

\begin{tabular}{|l|l|}
\hline Factores específicos de las pymes & Informalidad \\
\hline & Falta de información de calidad \\
\hline & $\begin{array}{l}\text { Los costos para mejorar la información son } \\
\text { altos }\end{array}$ \\
\hline Regulaciones & Administración familiar \\
\hline & Falta de garantías adecuadas \\
\hline & Demasiada documentación requerida \\
\hline & Inflexibilidad \\
\hline Tecnología de préstamo & Impuestos a las operaciones financieras \\
\hline & $\begin{array}{l}\text { Reglas a bancos para actuar como } \\
\text { autoridades fiscales }\end{array}$ \\
\hline Factores específicos del banco & Costoso \\
\hline & $\begin{array}{l}\text { Dificultad para estandarizar productos y } \\
\text { procedimientos }\end{array}$ \\
\hline & Altos costos de entrada \\
\hline & Bancos nuevos en el segmento \\
\hline & Ineficiencia \\
\hline & Falta de tecnología y persona calificado \\
\hline Falta de analistas expertos \\
\hline Limitada presencia geográfica \\
\hline
\end{tabular}

Fuente: De la Torre et al. (2009) 
Tal como se refiere en el estudio que realizan De la Torre et al. (2009), uno de los factores específicos de las pymes que obstaculizan la obtención de créditos es la información. Tal como lo mencionan Baas y Schrooten (2006), cuando la técnica de préstamo de la institución financiera se basa en los estados financieros, mucho dependerá de la aceptación el que se presente información de calidad. Esta situación limita el entendimiento de los oferentes de deuda para conocer si podrán liquidar la deuda o si en el último de los casos estarán comprometidos a pagar; por otro lado, la necesidad urgente de la compañía por la obtención de un crédito puede derivar en aceptar condiciones de desventaja de tal manera que pueda obtener los recursos, ya sea mediante una garantía muy gravosa, o una tasa de interés alta en relación a otras oportunidades en el mercado.

Beck et al. (2005), realizan un análisis para determinar si los obstáculos financieros para obtener crédito varían en relación con el tamaño de la empresa. En base a ello, se puede apreciar en la tabla 2.3. como si hay diferente afectación si se trata de una empresa grande o una pequeña. De acuerdo a los diferentes obstáculos, las empresas grandes prácticamente no se ven afectadas con la solicitud de garantía, la burocracia del banco o la necesidad de conexiones especiales, en cambio las pymes, en particular la pequeña empresa, son afectadas por estos mismos conceptos, además de las altas tasas de interés y la falta de dinero para préstamo de los bancos. 
Tabla 2.3.

Obstáculos de financiamiento

\begin{tabular}{|lccccccccc|}
\hline & $\begin{array}{c}\text { Obstáculo } \\
\text { de }\end{array}$ & $\begin{array}{c}\text { Requerimiento } \\
\text { de } \\
\text { Empresa }\end{array}$ & $\begin{array}{c}\text { Financiamiento } \\
\text { Garantía }\end{array}$ & $\begin{array}{c}\text { Documentos } \\
\text { Requeridos/ } \\
\text { Burocracia }\end{array}$ & $\begin{array}{c}\text { Alta } \\
\text { Tasa de } \\
\text { Interés }\end{array}$ & $\begin{array}{c}\text { Necesidad } \\
\text { Conecciones } \\
\text { Especiales } \\
\text { con el Banco }\end{array}$ & $\begin{array}{c}\text { Falta de } \\
\text { Dinero } \\
\text { del banco } \\
\text { para préstamo }\end{array}$ & $\begin{array}{c}\text { Información } \\
\text { financiera } \\
\text { de } \\
\text { Clientes }\end{array}$ & $\begin{array}{c}\text { Acceso a } \\
\text { préstamos } \\
\text { a largo } \\
\text { plazo }\end{array}$ \\
\hline Grande & $(0.023)$ & $(0.019)$ & $(0.012)$ & $(0.024)$ & $(0.007)$ & $(0.020)$ & 0.012 & - \\
Mediana & $(0.031)$ & $(0.025)$ & $(0.027)$ & $(0.031)$ & $(0.021)$ & $(0.029)$ & $(0.001)$ & $(0.012)$ \\
Pequeña & $(0.034)$ & $(0.031)$ & $(0.031)$ & $(0.037)$ & $(0.028)$ & $(0.034)$ & $(0.001)$ & $(0.012)$ \\
\hline
\end{tabular}

Fuente: Beck et al. (2005)

Enfocándonos en los principales obstáculos que deben superar las pymes, podemos apreciar como la garantía, el papeleo, la tasa de interés y el dinero disponible por parte de los bancos son de los principales factores que limitan la obtención de deuda para las pymes. Tomaremos de este modelo para el nuestro el evaluar la afectación por el tamaño de la empresa, la tasa de interés, la información y la garantía. La documentación en exceso que solicita el acreedor para otorgar el crédito, tal como lo mencionan Beck et al. (2005), representa otro problema para la pyme.

Además, muchas de las instituciones financieras en la actualidad realizan análisis más profundos de las empresas cuando se está calificando un crédito; lo mencionan De la Torre et al. (2009) dentro de las características específicas de las pymes, factores como la antigüedad de la empresa es relevante para determinar su posición en el mercado y si su proyección a futuro no pone en riesgo el capital invertido en ella. Otro aspecto que en ocasiones también se califica es no solo el desempeño de la empresa, sino también la situación del dueño, su reputación y los bienes con que cuenta, de tal manera que funja como aval con sus bienes personales, además de calificar que tan bien preparado está como para estar al frente de la operación de la empresa analizada; ello en cierta forma puede darse a 
conocer mediante el trato y el tiempo en el cual ha llevado una relación con el banco, como lo mencionan Baas y Schrooten (2006).

Dentro de las principales fuentes de financiamiento, como se ha comentado, no solo las instituciones financieras son la única opción para que las pymes obtengan recursos, existen diversas fuentes, y, la gente cercana como familiares o amigos representan una parte importante en este sentido. Así, Cull et al. (2006), ofrecen una muestra de empresas en las cuales se analizan diferentes grupos de fuentes de financiamiento que utilizan las empresas, dividiendo estas por el tamaño de las mismas. A continuación se muestra la tabla 2.4. que indica los niveles de financiamiento por concepto:

Tabla 2.4.

Fuentes de financiamiento por tamaño de empresa

\begin{tabular}{|c|c|c|c|c|c|c|}
\hline Empresa & $\mathbf{N}$ & $\begin{array}{c}\text { Familia, amigos, } \\
\text { fuentes } \\
\text { informales son } \\
\text { principales fuentes }\end{array}$ & $\begin{array}{c}\text { Bancos } \\
\text { son la } \\
\text { principal } \\
\text { fuente } \\
\end{array}$ & $\begin{array}{c}\text { Capital, venta } \\
\text { de acciones } \\
\text { es la principal } \\
\text { fuente } \\
\end{array}$ & $\begin{array}{c}\text { Arrendamiento, } \\
\text { tarjeta de crédito, } \\
\text { fondos desarrollados } \\
\text { son fuente principal }\end{array}$ & $\begin{array}{c}\text { \% de empresas } \\
\text { que no tienen } \\
\text { financiamiento } \\
\text { externo } \\
\end{array}$ \\
\hline Micro & 1756 & $14.40 \%$ & $9.50 \%$ & $3.20 \%$ & $8.90 \%$ & $64.00 \%$ \\
\hline Pequeña & 2988 & $9.40 \%$ & $17.60 \%$ & $3.00 \%$ & $15.40 \%$ & $54.60 \%$ \\
\hline Mediana & 1036 & $4.60 \%$ & $25.20 \%$ & $2.80 \%$ & $16.60 \%$ & $50.80 \%$ \\
\hline Grande & 1036 & $3.60 \%$ & $29.50 \%$ & $4.10 \%$ & $17.00 \%$ & $45.90 \%$ \\
\hline Muy Grande & 1317 & $2.70 \%$ & $31.50 \%$ & $2.90 \%$ & $14.70 \%$ & $48.10 \%$ \\
\hline
\end{tabular}

Fuente: Cull et al. (2006)

Existe una tendencia marcada en el grupo que representa la fuente de financiamiento de acuerdo al tamaño de la empresa, vemos, por ejemplo, que familiares y amigos son la principal fuente para las empresas más pequeñas, y esto va disminuyendo conforme la empresa es más grande, 
situación contraria al financiamiento con bancos, el cual es mayor a mayor tamaño de empresa siendo menor conforme va decreciendo el tamaño de la compañía. Nuestra variable endógena que puede ser la obtención del crédito, podemos captar en nuestra estudio empírico cual es la fuente del crédito.

Es claro que las personas que otorgarían un crédito necesitan información sobre los deudores. Aun en el caso de que los bancos pudieran supervisar a las empresas, este monitoreo también acarrea costos (Baas y Schrooten, 2006). Ellos consideran, por ejemplo, que si el banco elige la técnica de relación de préstamo, los costos de monitoreo dependerán de la madurez de la relación entre el banco y el deudor. En el caso de la técnica con estados financieros, esto es constante y no variarán con la duración de la relación comentada en el punto anterior. Así que los costos de monitoreo varían en base a la técnica de préstamo aplicada, en la tabla 2.5. se resumen este tipo de técnicas.

Tabla 2.5.

Técnicas de préstamo

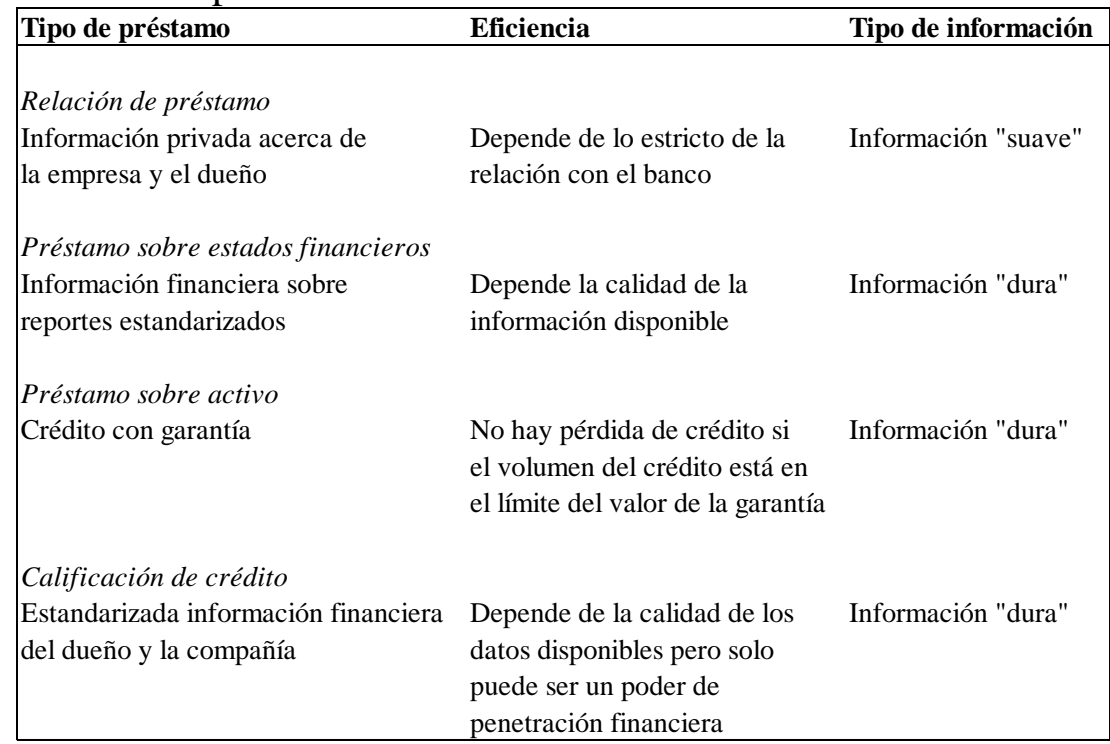

Fuente: Baas y Schrooten (2006). 
El modelo que se propone trata de explicar cuáles son las razones por las que las pymes tienen problemas mayores para la obtención de financiamiento y de qué forma podrían superar los obstáculos que impiden el ser sujetos de financiamiento como las empresas grandes, o como algunas empresas logran disminuir aquellas condiciones que pudieran restringir su acceso al crédito. A su vez, de este modelo tomamos lo referente a relación de préstamo. Binks y Ennew (1997:176), haciendo referencia a la relación de préstamo, en su estudio sugieren que "puede haber beneficios significativos de la mejora en las relaciones entre los bancos y sus pequeños clientes y la provisión y uso de información relevante será central en este proceso". Vuelven a remarcar que la información es clave para una más acertada evaluación del riesgo y una más eficiente asignación de financiamiento a pymes. En la siguiente figura 2.17. se esquematiza este concepto.

Figura 2.17.

El ciclo de aprendizaje

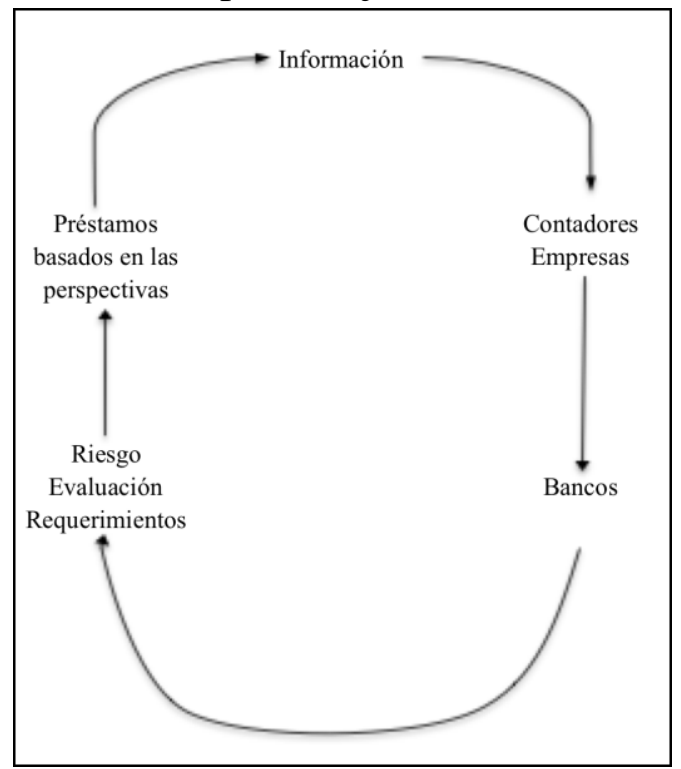

Fuente: Binks y Ennew (1997) 
Lo que nos indica Binks y Ennew (1997) en la figura anterior es que los contadores y las empresas confían uno al otro para proporcionar información a los bancos para que puedan evaluar el riesgo inherente. Mientras mejor sea esta información, los bancos serán capaces y tendrán la confianza para aplicar los préstamos basados en las perspectivas del negocio, más que usar una garantía para asegurar el crédito. Para nuestro modelo, vemos que es muy importante la información, ver si la empresa tiene un contador como indicador, y la relación con el banco. Estas variables serán consideradas en nuestro modelo.

Otra de las variables más relevantes en la negociación del crédito es la tasa de interés, como se puede apreciar en el estudio efectuado por Beck et al. (2005), encuentran que las altas tasas de interés es el obstáculo mayor dentro de este estudio. Dos formas sugeridas para minimizar o eliminar estos obstáculos son el otorgamiento de una garantía o la relación que el cliente va estableciendo con el banco o institución financiera que otorga el financiamiento. Beck et al. (2005) lo mencionan como uno de los obstáculos para obtener el crédito, pues no siempre la empresa cuenta con algún bien para garantizar el crédito. Baas y Schrooten (2006) lo mencionan como una técnica de préstamo que utilizan los bancos para minimizar el riesgo de la operación financiera.

En resumen, una vez analizado el marco teórico sobre el cual se basa nuestro modelo, analizando las teorías que tienen relación con el objeto de estudio, las diferentes aportaciones que se han hecho sobre el mismo, a continuación se resumen algunas de dichas aportaciones sobre las cuales crearíamos el nuestro. 
Se toma inicialmente como eje el modelo del teorema de Modigliani y Miller (1958) la "Teoría de la estructura de Capital", donde hacen referencia en que en algunos casos podría resultar más redituable el buscar deuda en lugar de utilizar el capital para financiar un proyecto. Para nosotros las pymes suelen recurrir al crédito principalmente. Romano et al., (2001) en su modelo sobre empresas familiares hacen referencia al tamaño y edad de la empresa, estas variables también son consideradas.

Myers (2001) supone el caso de que la compañía pudiera en las mismas circunstancias obtener financiamiento vía deuda o capital. No se refleja tal cual en el modelo pero parte del estudio empírico será conocer la fuente del recurso. Hackbarth et al. (2007) comentan que la estructura de deuda óptima para empresas débiles es financiarse solo con bancos, en tanto que para empresas fuertes lo óptimo es usar una mezcla de deuda entre el banco y el mercado. Aunque Frank y Goyal (2003) de acuerdo a la teoría de la jerarquía financiera, mencionan que el comportamiento de financiamiento se verá regido por los costos adversos de selección. De ahí que las pymes tengan mayores costos por su información asimétrica. Se está incluyendo en nuestro modelo tanto el constructo de información como el de los costos, pues representan también uno de los aspectos importantes del tema.

Cuando se habla de relación de préstamo y que tomamos conceptos de la teoría de agencia, Jensen y Meckling (1976) definen los costos de agencia como la suma de: los gastos de supervisión realizados por el principal, los gastos efectuados por el agente y la pérdida residual. Las pymes generan mayores costos de agencia por sus propias características que provocan mayor asimetría en la información (Mac an Bhaird, 2010), ello apoya más la teoría que desarrollamos sobre la importancia de la 
información. Los costos de la relación de agencia incluyen supervisión y los derivados de la relación con el agente con los cuales no se obtenga una maximización del valor de la empresa (Mann y Sicherman, 1991).

Además, hay conceptos conocidos como obstáculos que deben superar las pymes, Beck et al. (2005) mencionan en su modelo los siguientes que incluimos en el nuestro: la garantía, la tasa de interés, la información y tamaño de empresa. Más adelante en nuestras hipótesis comentaremos más a detalle los autores que han analizado las variables que hemos incluido. 


\subsection{Modelo teórico}

En base a las teorías expuestas y habiendo comentado las partes que son útiles para el modelo que se desea crear, es entonces que se presenta el modelo teórico propuesto que se muestra en la figura 2.18.

Figura 2.18.

Modelo Teórico

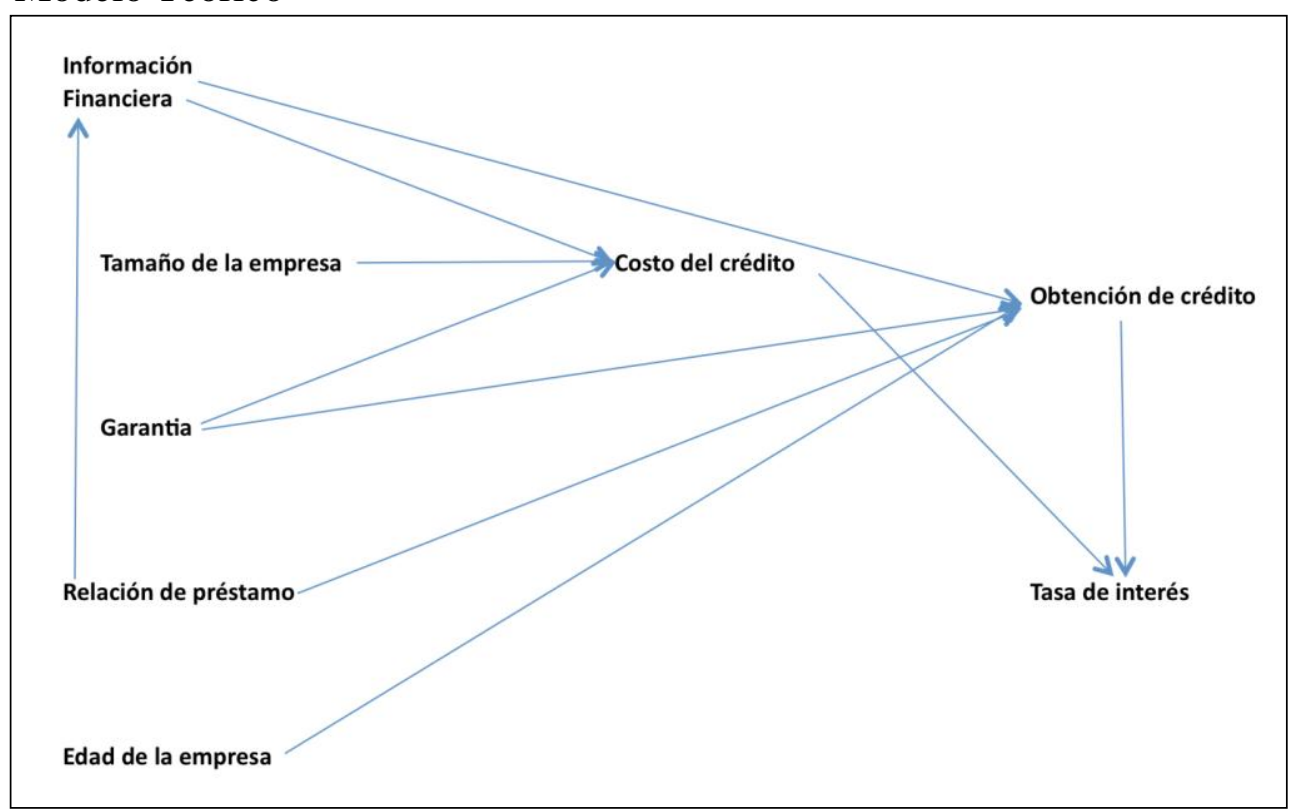

En base al análisis hecho en este capítulo, con el estudio se pretenderá obtener algunas áreas de oportunidad con el cual se pudiera minimizar los obstáculos para acceder al crédito. De que forma o mediante cuales técnicas se puede ser más efectivo a la hora de solicitar deuda. Determinar si la empresa realmente carece de este recurso, o hay algunos otros factores, y como se encuentra la situación del tema en México. Las condiciones en las cuales se encuentre el sistema financiero de cada país puede llegar a impactar la facilidad o dificultad con que las pymes puedan 
obtener el crédito, con lo que aquellos en los cuales haya un sistema más avanzado podría facilitar el camino para el endeudamiento de las compañías, como lo han mencionado Beck et al., (2006).

Este modelo intenta describir a las pymes el conocimiento del tema de crédito, las limitantes mayores que realmente existen, y posibles formas de lograr el objetivo de conseguir los préstamos, tratando de que sea con las mejores condiciones. 


\section{Hipótesis}


"Para ser exitoso no tienes que hacer cosas extraordinarias. Haz cosas ordinarias, extraordinariamente bien" Jim Rohn 


\subsection{Introducción}

Como se ha comentado en la parte teórica, el acceso al crédito no es sencillo, mucho menos para las pymes. Estas encuentran mayores dificultades que las grandes empresas, las cuales en ocasiones hasta sin buscarlo o necesitarlo pueden obtenerlo o tenerlo ofrecido por parte de las instituciones financieras. En cambio, las pymes deben superar muchos obstáculos para poder contratar un crédito, considero que los principales se han establecido en el modelo teórico.

De acuerdo a nuestro modelo propuesto, las relaciones indican diez hipótesis, las cuales desarrollaremos más adelante. Estamos viendo la relación directa que tienen cuatro constructos con la variable endógena “obtención de crédito". Por ejemplo, estaremos analizando la variable exógena de la información, que como comentan Watson y Wilson (2002), otra limitante generalizada es la información asimétrica, cuando la información tiene esta característica se puede dar una contracción importante en el financiamiento. "Asumimos que la empresa tiene información que los inversionistas no, y que tanto los administradores como los inversionistas se dan cuenta de ello", esto es referido como información asimétrica por Myers y Majluf, (1984:189).

La información financiera es básica para los analistas de crédito, pues es la forma inicial de conocer el desempeño y posición de la empresa; sin la información resulta muy complicado para la institución financiera el evaluar las condiciones económicas de las compañías que den certeza en cuanto al cumplimiento de las obligaciones contraídas en la contratación de un préstamo. Por lo que sin información la mayoría de oferentes del crédito 
no otorgarán financiamiento. Está técnica de información "dura” representa una de las principales que utiliza el oferente del crédito, así que ello nos indica el grado de afectación al no poder presentar una información confiable.

Un conocimiento convencional en la actualidad es que las pymes son opacas en cuanto a información. Hyytinen y Pajarinen, (2008) mencionan que mientras la operación de las empresas grandes está bien documentada, la ausencia de ello en las pymes resulta en que no puedan ser evaluadas. Para Berger y Udell (1998:3), “quizás la característica más importante que defina el financiamiento de las pymes es la opacidad en la información". La literatura hace referencia a opacidad como lo difícil de determinar si las empresas tienen capacidad de pago y/o la voluntad de pagar (De la Torre et al., 2010).

El hacer énfasis en el tema de la información se deriva, pues al revisar nuestro modelo podemos apreciar que tiene una relación con varios constructos, la obtención de crédito, la relación de préstamo y el costo del mismo, nos resaltan la importancia de este tema cuando hablamos de créditos.

Gertler (1988), menciona que el problema de la información asimétrica se da mayormente en empresas nuevas y de pocos años de operación, derivado que las instituciones financieras no han tenido suficiente tiempo para evaluarlas y, a su vez, estas empresas no han tenido suficiente tiempo para construir relaciones de confianzas con estas instituciones. De aquí se derivan otras dos variables, la referente a la antigüedad y a la relación de préstamo. Además, Vos et al. (2007) 
mencionan que en cuanto las pymes van creciendo y formando antigüedad, estas son capaces de tener mejor acceso a fondos externos. Este concepto viene del hecho de que empresas más antiguas y grandes tienen mejores activos para garantía y mejores tecnologías para reducir la opacidad de la información.

Por otro lado, cuando el prestatario es opaco, puesto que no se puede evaluar su condición crediticia, puede ser que el costo del financiamiento sea el que defina el otorgamiento del crédito; tal como lo menciona Jiménez y Saurina (2004), puede ser que los bancos den a elegir entre una tasa alta de interés y no garantía o lo contrario. Beck y Dermiguc-Kunt (2006) consideran que mientras los solicitantes de crédito tengan acceso a mayor número de competidores bancarios, la probabilidad de tener que dejar una garantía o garantizar personalmente disminuirá. Ray (1998) define dos tipos de garantía: 1) garantía que es altamente valiosa tanto para el prestamista como para el prestatario y 2) garantía que es altamente valiosa para el prestatario pero no para el prestamista. Nuestro modelo señala la importancia que puede tener la garantía en la obtención del crédito o en el costo del mismo, con lo cual se proponen las hipótesis correspondientes.

Aquellas empresas que exceden en demasía su endeudamiento en relación con su capital pueden llegar a tener problemas para poder liquidar su crédito o hacerlo conforme a lo acordado (Holmstitom y Tirole, 1997). Para ellos otra forma de asegurar el retorno del crédito además de la garantía es la supervisión intensiva. En síntesis, la garantía representa una de las principales formas de asegurar al banco el retorno de su dinero. Desafortunadamente, las pymes no cuentan normalmente con los activos suficientes que puedan responder a los requerimientos del acreedor, y con 
ello no podrá solucionar los obstáculos que se le hayan presentado en su solicitud.

"La idea generalizada en círculos académicos y políticos es que mientras bancos grandes y extranjeros no están interesados generalmente en servir a las pymes, bancos pequeños y de nicho tienen una ventaja porque ellos pueden superar la opacidad de las pymes a través de la relación que se construye con los préstamos" (De la Torre et al., 2010:1). La relación que ha formado la empresa con el banco origina un conocimiento mayor de la compañía que puede subsanar la opacidad por falta de información o facilitar el crédito. Esta relación da a conocer tanto la reputación de la empresa como del dueño, la experiencia en el mercado, la confianza en quien maneja el destino de la empresa.

Ayyagari et al. (2008) examinan cuales son las variables del ambiente de negocios que más afectan a las empresas en su crecimiento. De acuerdo a la información utilizada de una encuesta del banco mundial, analizan si las características señaladas representan un obstáculo que afecte su crecimiento, la importancia económica de los obstáculos que limitan el crecimiento, si hay relación entre los obstáculos o si fortalecen algún otro de manera directa. Ellos encuentran tres tipos principales de obstáculos, los de financiamiento, los de inestabilidad política y la inseguridad. En la figura 3.1. se contempla el resultado de este estudio en cuanto a los obstáculos de financiamiento. 
Figura 3.1.

Impacto de obstáculos financieros específicos sobre el crecimiento de la empresa.

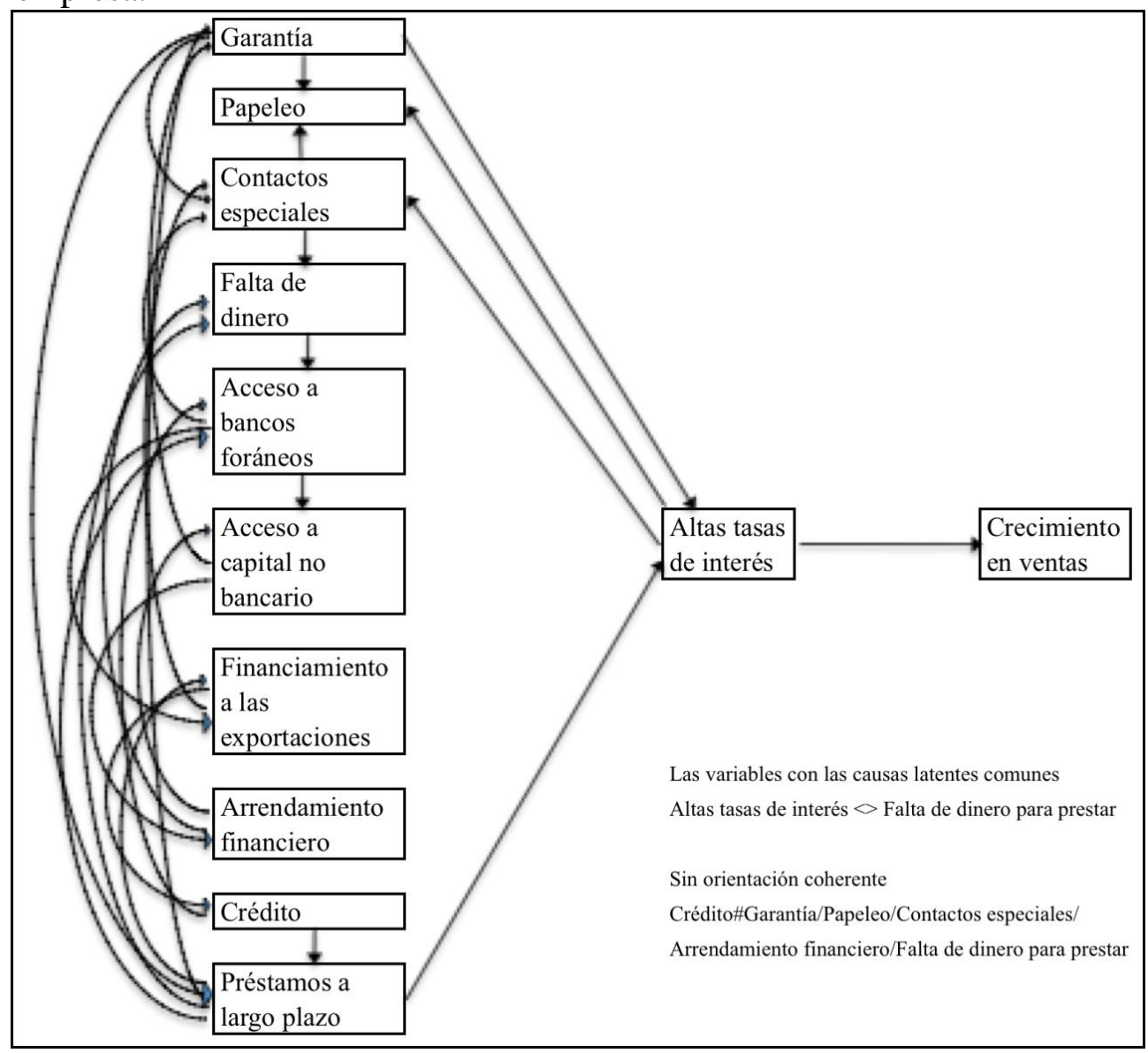

Fuente: Ayyagari et al. (2008)

De acuerdo a la figura anterior, Ayyagari et al. (2008) mencionan que las altas tasas de interés es el único obstáculo financiero directo sobre el crecimiento de las empresas, nosotros lo consideramos en nuestro modelo pero relacionado con la obtención del crédito. Mencionan además que el haber encontrado que la tasa de interés alta limita el crecimiento no es sorpresa, pues que este obstáculo significa el costo de financiamiento y es en sí misma una variable endógena que depende de la habilidad del sistema 
financiero para satisfacer la demanda de capital. En este modelo vemos también algunas variables consideradas en el nuestro como la garantía, además de indicadores que podríamos considerar como el papeleo o contactos especiales.

El identificar los obstáculos para crédito, los constructos que facilitan la obtención del mismo, las relaciones que existen entre estas variables, nos lleva a la determinación de nuestras hipótesis. En los siguientes epígrafes desarrollaremos cada una de las relaciones de nuestro modelo con la finalidad de definir las hipótesis que se intentarán contrastar con el estudio empírico. 


\subsection{Información Financiera}

"La opacidad significa que la información es comúnmente asimétrica entre la pequeña empresa y su prestamista" (Hyytinen y Pajarinen, 2008:2). Antoniou et al. (2006) comentan que en cierta forma se puede decir que las empresas grandes tienen menores problemas de información asimétrica, mayores activos y más fácil acceso a deuda, situación que representa mayores problemas para evaluar a la empresa pequeña en términos de crédito y, también consideran que los problemas de agencia son mayores en las empresas pequeñas.

Uno de los requisitos fundamentales que solicitan las instituciones financieras a las empresas que solicitan crédito es la entrega de información financiera, muchas veces mediante una opinión profesional externa que garantice la razonabilidad de la información, el problema estriba en que las pymes generalmente no cuentan ni con información interna que dé a conocer la situación de la compañía, mucho menos, en consecuencia, una opinión de alguien que haya revisado esa información.

Berger y Udell (2004) hacen mención a la creciente necesidad de financiamiento por parte de las empresas y como algunos elementos del sistema financiero pueden influir en limitar el crédito, Además, hacen referencia al tipo de tecnologías aplicadas para el otorgamiento de un préstamo, el cual se basa en información denonimada "dura"(hard- término utilizado en inglés) y otra "suave" "(soft- término utilizado en inglés). La información dura es relacionada con información cuantitativa, información que puede ser observada y verificada, lo cual se resume principalmente en los estados financieros, información obtenida de burós de crédito o cuentas 
por cobrar en dado caso. La información "suave" puede incluir desde la confianza y carácter que muestre el dueño de la pyme hasta el historial que se tenga en anteriores préstamos u otros servicios proporcionados por el banco, o el conocimiento que se tenga derivado de sus mismos contactos con proveedores, clientes o socios comerciales.

Para Petersen (2004) la naturaleza de la información (dura o suave) puede incrementar la competitividad de los mercados. Pero entre el uso de información dura y suave quién se puede ver afectado es el deudor si no se establecen claramente las políticas del banco respecto al uso de una $\mathrm{u}$ otra, además puede haber deudores excelentes, pero si su situación en papel no es buena, como es presentada, entonces serán incorrectamente juzgados y negado el crédito. En un estudio realizado en Italia, Howorth y Moro (2010) concluyen que la confianza (información suave en general) puede jugar un papel muy importante, más allá de lo que se tiene conocimiento hasta ahora. Pues, como se ha indicado, la reputación del dueño puede ser suficiente para avalar a su empresa.

Cuando se habla de información suave, se ha indicado que esta se origina de la relación que el prestatario pueda desarrollar con el banco, Kano et al. (2006) investigan si los beneficios de esta relación varían de acuerdo a tres factores: verificación de la información, tamaño del banco y complejidad y competencia entre los bancos. Así, comentan que no solo la relación con el banco puede ayudar a la obtención del crédito, sino que también cuando se proporciona información que se pueda verificar, como estados financieros auditados, es de gran ayuda para generar el crédito; aunque es importante comentar que hemos partido de la idea de que la 
generalidad de las pymes en primer lugar no cuentan con información financiera.

Hemos visto que las empresas más pequeñas y jóvenes tienen mayores dificultades para el acceso al crédito. No solo ello, Hyytinen y Pajarinen (2008) comentan que además son más dependientes del financiamiento externo, y que desde el punto de vista de información son más opacas que las empresas grandes y de mayor edad. Ellos examinan un panel de pymes para identificar los determinantes de la opacidad de las pymes. Cuando una pyme es opaca y entonces el banco no puede determinar su calidad aún las empresas investigadoras de crédito estarán en desacuerdo con la solvencia de la pyme. Dentro de sus conclusiones hacen una observación interesante, mencionan que una pregunta relevante que ni este estudio ni otros han contestado es si la opacidad de la pymes, y particularmente el desacuerdo en las calificaciones puede ser ligada al uso de financiamiento externo por parte de las pymes.

Wu et al. (2008) comentan respecto a las tecnologías de préstamo como la información de la cual dependen las instituciones financieras para determinar si se otorga crédito mientras cubren la opacidad de las empresas. Realizando un análisis de una muestra de pymes en 3 ciudades de China encuentran que dentro de las restricciones que encuentran con los bancos para obtención de crédito está la documentación contable, que se traduce en información financiera de la empresa. Así también Shen et al. (2009) en otro estudio realizado en China, comentan que la literatura ha enfatizado el uso de información suave en bancos pequeños, considerando que ocuparán en lo máximo posible dicha información cuando la tienen. En sus conclusiones obtienen que la información suave es un factor importante en la decisión de 
los créditos, además encuentran que es más sencillo aplicando está técnica cuando se trata de bancos pequeños o medianos.

Sarapaivanich y Kotey (2006) realizan un estudio en Tailandia para determinar cómo influye la información financiera para la obtención de crédito por parte de pymes. Tal como sucede en diversos países, en Tailandia es común el acudir a gente externa para la preparación de la información financiera. No obstante, se menciona que las pymes tienen dificultad para cumplir los requerimientos de los bancos en cuanto a información en término de administración profesional y procedimientos contables estándar. Por otro lado, Altman et al. (2007) usan una muestra de casi 6 millones de empresas del Reino Unido además de establecer una premisa de que el ofrecimiento de crédito debiera dividirse en soluciones dirigidas a pymes específicamente y otro para grandes corporaciones, por primera vez adhieren características cualitativas como variables predictivas de las dificultades financieras, encontrando que cuando está información está disponible puede incrementar hasta en un 13\% la efectividad del modelo. Alguna de la información cualitativa señalada es: juicios actuales, cuentas auditadas, flujos de efectivo proyectados (siendo en estricto sentido cuantitativo), subsidiarias, edad de la empresa, sector.

La infraestructura de información tendrá un efecto significativo en la disponibilidad de crédito para las pymes. Un aspecto que afecta esta infraestructura es el ambiente contable, señala Berger y Udell (2004), la existencia de normas de contabilidad y firmas contables independientes de buena reputación. Cuando la base principal para el préstamo son los estados financieros estos deben tener ciertas características que las instituciones evalúan. Por supuesto, la empresa debe contar primeramente con dicha 
información, y segundo debe mostrar una condición que garantice la seguridad a la institución de la recuperación de su dinero.

Haciendo una investigación respecto a la información financiera que presentan las empresas a los bancos al solicitar crédito, de una muestra reducida a 2,288 empresas de una base de 270,000. Collis y Farvis (2002) encuentran que el $58 \%$ de los encuestados utilizan a un contador, mientras que el $34 \%$ cuenta con uno o dos contralores. Encontraron que el $82 \%$ prepara estados financieros. Además, como se muestra en la tabla 3.1., mencionan las principales fuentes de información. Una situación interesante, es que a pesar de que la idea que la literatura nos menciona respecto a las pymes de no contar con información, es que ellos encontraron que la administración financiera encontrada en las pymes estudiadas es de relativa sofisticación, con lo cual su generación de información no presenta problemas al ser solicitada por las instituciones financieras. Un estudio que revela una situación atípica de los anteriores, que puede servir de ejemplo, pero que es menor ante la abrumadora muestra que comenta lo contrario.

Lo que nos muestra la tabla 3.1., nos deja claro que a la administración de las empresas les interesa principalmente conocer si se está ganando o perdiendo en la operación. También llama la atención que el tercer reporte más revisado es el estado de cuenta bancaria, indicador que nos sugiere que las compañías tienen relación con el banco. Después ya se manejan algunos otros reportes, pero es clara la importancia de la información. La encuesta realizada a pymes nos indicaría que el tema de la información está cubierto, pero veremos si en nuestro estudio también existe esta tendencia. 
Tabla 3.1.

Uso de fuentes específicas de administración de la información

\begin{tabular}{|l|c|}
\hline \multicolumn{1}{|c|}{ Gestión de la información } & \% de empresas \\
\hline Estado de pérdidas y ganancias & 86.8 \\
\hline Balance general & 78.2 \\
\hline Estado de cuenta bancario & 73.0 \\
\hline Estado de flujo de efectivo & 58.7 \\
\hline Estado de resultados presupuestado & 57.7 \\
\hline Proyección de flujo de efectivo & 56.1 \\
\hline Análisis de variaciones presupuestales & 51.4 \\
\hline Presupuesto & 42.8 \\
\hline Razones financieras & 26.2 \\
\hline Tendencias de la industria & 22.4 \\
\hline Análisis punto de equilibrio & 21.3 \\
\hline Comparación con empresas del sector & 15.9 \\
\hline
\end{tabular}

Fuente: Collis y Farvis (2002)

Una vez analizado lo referente a la información y lo que representa para las pymes en cuanto al requerimiento de crédito, podemos darnos cuenta de la importancia de la misma para las instituciones financieras, sea de forma cuantitativa o cualitativa, de ahí que se establezca la primera hipótesis:

Hipótesis H1: Las empresas con menor requerimiento de información financiera por parte de los bancos tienen mayor oportunidad de conseguir financiamiento cuando lo solicitan. 


\subsection{Garantía}

Dentro de los constructos establecidos, otra de las variables que pudieras facilitar o complicar la obtención de un crédito con el banco es la garantía. En ocasiones la empresa no tendrá problema para garantizar el importe recibido, pero en ocasiones, sobre todo en las pymes, no se tendrá algún bien que pueda servir como depósito o que sea aceptado por la institución financiera. Por otro lado fungirá como la parte que facilite la obtención del crédito.

Voordeckers y Steijvers (2006) realizan un estudio entre empresas belgas examinando simultáneamente la garantía que ofrece la empresa contra garantía propiedad del dueño o compromiso personal. Esto puede originarse de que las pymes al no contar con activos sea el dueño el que tenga que ofrecer una garantía personal para efectos del crédito empresarial. Corroboraron que la garantía disminuye de acuerdo a la duración de la relación entre el prestatario y el prestamista.. Coco (2000) menciona dos tipos de garantía, algún activo que este siendo usado dentro del proyecto financiado o un activo que este fuera de dicho proyecto.

Chan y Kanatas (1985) detallando un poco más los tipos de bienes que se ofrecen, mencionan que la garantía puede ser un activo ya existente propiedad del prestatario, haciendo mención que este tipo de garantía se da normalmente en contratos comerciales siendo la garantía: equipo, edificios, cuentas por cobrar o inventarios. Por otro lado, en el contrato la garantía es un activo adicional que normalmente no sería parte del negocio, y esto se da en pequeños préstamos siendo la garantía algún bien personal del dueño. 
Avery et al. (1998) señalan que es común el utilizar bienes personales en las pymes para garantizar créditos.

Aunque pudiera visualizarse como una desventaja, la realidad es que un aspecto positivo o de ventaja para las pymes es el que si la empresa no cuenta con un bien que pueda ofrecer al banco, este pueda aceptar alguno que no esté dentro de la operación, claro que ello significa un riesgo para el dueño, pero también es un voto de confianza para el acreedor el aportar este tipo de colateral.

Berger y Udell (2004) consideran que los términos del contrato entre el prestamista y prestatario pueden originar el requerimiento de una garantía del negocio, del dueño o algún aval, el nivel de los mismos o su requerimiento dependerá de que tan sana está su situación financiera. En la práctica, al prestar a pymes se adiciona normalmente una garantía (Kon y Storey, 2003). Para ellos, con esta práctica el banco asegura una parte de la propiedad de la empresa para en caso de que no se pague en determinado momento el crédito, se vende el bien y recupera el dinero.

Preguntándose qué determina el uso de una garantía al contratar un crédito, Jiménez et al. (2009) estiman que el uso de la garantía involucra las características del prestatario, el prestamista, el mercado, la relación entre ellos, el préstamo en sí y las condiciones económicas. Con datos de la encuesta nacional de finanzas de la pequeña empresa de 1998, Steijvers et al. (2010) examinan el impacto de las características de relación, propiedad familiar y efectos del uso de garantía en el préstamo a pymes. Mencionan como ventajas del otorgamiento de garantía el reducir los costos de agencia, limitar posibles demandas y reducir asimetrías en la información. 
El primer impacto positivo que se tendría, entonces, con el otorgamiento de garantía es que hay menor riesgo pues la empresa no piensa perder el bien dado en garantía, además de que le ayuda en eliminar los aspectos negativos que lo afectan en la calificación del crédito; ello dando confianza al banco que proporciona los recursos.

Para Scholtens (1999) cuando se otorga financiamiento y existe asimetría en la información esto lleva consigo tanto una transferencia de fondos como de control. La posibilidad de ofrecer una garantía depende de la industria y los activos de la empresa. Scholtens (1999) menciona que entre más joven y pequeña la empresa, menor capacidad tendrá para ofrecer una garantía. La relación contractual entre prestatario y prestamista se ve obstaculizado por información asimétrica, selección adversa y riesgo moral, lo cual inhibe el crédito (Voordeckers y Steijvers, 2006). Ellos comentan que estos riesgos se pueden disminuir con el uso de la garantía. Colateralización, como le llaman Chakraborty y Hu (2006), es considerada una herramienta muy útil para eliminar los problemas de información asimétrica y riesgo en los préstamos.

En un estudio posterior Steijvers y Voordeckers (2009) comentan que el crédito es racionado cuando prevalecen asimetrías en la información. Berger et al. (2010) en un estudio tratando de determinar por qué los prestatarios deben otorgar una garantía al existir información asimétrica encuentran que los bancos pudieran disminuir los efectos de asimetría utilizando una nueva tecnología surgida de modelos de información privada, con ello se reduciría la necesidad también de una garantía en un número significativo de préstamos. De hecho, consideran que cualquier avance en el mercado, como nuevas tecnologías de préstamos, o herramientas de 
contratación de financiamiento, o también innovación en políticas, que puedan reducir esas diferencias de información entre prestatario y prestamista puede eficientar el mercado de deuda vía la reducción del costo que implica la garantía. No obstante, hay que considerar la fuerza que aún tiene en la actualidad el uso y requerimiento de garantía.

Galindo y Micco (2007) comentan en referencia al tamaño de las empresas que la literatura escrita sobre las dificultades financieras ha resaltado que las pequeñas empresas tienden a tener mayores obstáculos que las grandes. Refieren al concluir de un estudio realizado que las asimetrías en la información tienden a incrementar las restricciones financieras de los deudores pequeños, quienes generalmente cuentan con menores activos que pudieran servir de garantía. Y como la asimetría y opacidad limitan el crédito, la garantía puede convertirse en una variable que influya directamente en términos positivos para facilitar el préstamo.

La garantía puede ser ofrecida por el prestatario cuando el prestamista tiene una valuación menor del proyecto, comentan Chan y Kanatas (1985:85). "El uso de garantía está claramente ligado a la asimetría entre el prestatario y el prestamista". Se ha comentado que cuando el prestamista no tiene la misma información que el prestatario entonces se consideraría una falta de información para evaluar el crédito, dificultando entonces el financiamiento. Hulburt y Scherr (2003) comentan que el nivel de información asimétrica puede jugar un papel en la necesidad de la garantía. Para Coco (2000:194), "la información asimétrica es la principal explicación en la literatura para el uso de garantía". Berger y Udell (1995) comentan sobre las empresas nuevas con relaciones bancarias recientes que 
están dispuestas a incurrir en los costos que impliquen la garantía, una vez que esta atenuará los problemas asociados con la información asimétrica.

Elsas y Krahnen (2002) tratan en su estudio de verificar ciertas cuestiones: si la garantía en el financiamiento sirve para determinar el prestamista con mayor antigüedad, si el banco que tenga una mayor forma de decidir respecto al prestatario tenga el mayor grado de la garantía y, si ambas situaciones influyen en los bancos para determinar si toman el riesgo o no. De acuerdo a los resultados obtenidos sugieren que la garantía es usada para definir antigüedad entre varios bancos que prestan y lo consideran un complemento de información acerca de la calidad del prestatario, más que un sustituto. Rajan y Winton (1995) mencionan que cuando hay varios prestamistas debe establecerse la prioridad en caso de reclamos. Sabiendo que los más antiguos tendrán prioridad sobre flujos y activos, si hay acreedores ya garantizados estos tiene prioridad sobre los vienen que constituyan la garantía. Contrario a lo que se menciona en la teoría respecto al uso de la garantía Ono y Uesugi (2009) encuentran, en un estudio en Japón en una encuesta de alrededor de 15,000 empresas de las cuales la mayoría son pymes. Comentan que aquellas que cuentan con una larga relación con sus bancos son más propensas a constituir una garantía.

Así como se ha comentado que la garantía la usa la empresa para facilitar la obtención del crédito, o como veremos en otra hipótesis para disminuir el costo del crédito; Zambaldi et al. (2011) en su estudio sobre pymes en Brasil, hacen referencia al impacto que tiene la garantía, sea líquida o no, sobre las utilidades del banco, este punto de vista es interesante ya que el banco usa normalmente la garantía como seguro o aminorar el riesgo del deudor. La figura 3.2. muestra dichos efectos. 
Figura 3.2.

Efectos de garantía sobre la utilidad del banco

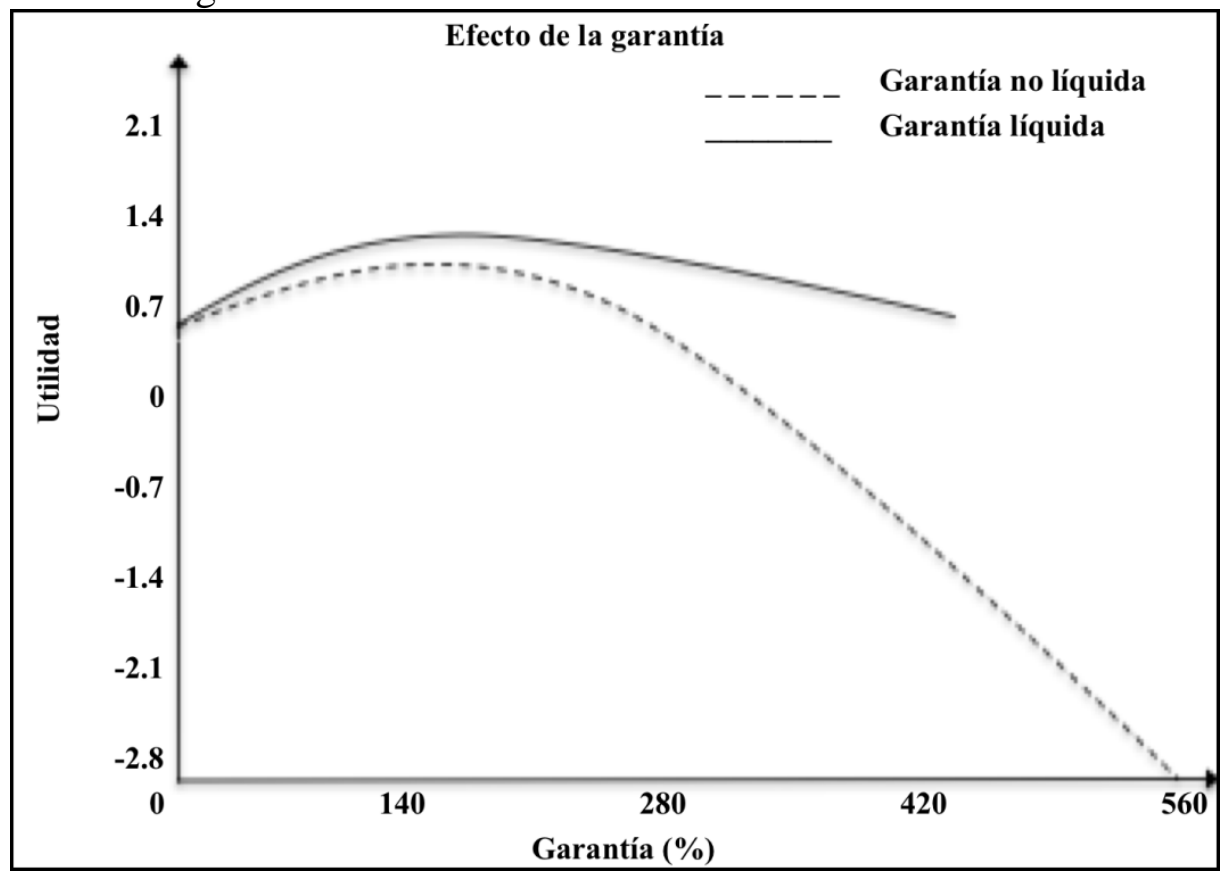

Fuente: Zambaldi et al. (2011)

En la figura 3.2, se nota el efecto sobre la utilidad de una garantía, podemos ver que a mayor porcentaje hay un momento en que ya no le es rentable al banco, este resultado nos indica una ventaja para la pyme, puesto que, a reserva de que le requieran la garantía, esta no debiera ser tan alta respecto al monto de crédito solicitado, pues llega un momento en que el banco ve afectado sus utilidades. Los resultados de Zambaldi et al. (2011) señalan la existencia de un monto óptimo de garantía para los acreedores en un contrato de crédito.

La teoría y resultados de modelos empíricos aplicados a los préstamos y la garantía que es requerida, nos indican que la garantía es una herramienta importante para superar estas carencias. Por supuesto, si es 
menor o nulo el requerimiento de garantía por parte del banco, esto facilita el trámite respectivo, de aquí se deriva la segunda hipótesis:

Hipótesis H2: Las empresas con menor exigencia de garantía tienen mayor oportunidad de conseguir financiamiento cuando lo solicitan. 


\subsection{Relación de préstamo}

El relacionarse es un tema muy comentado en el mundo empresarial y de negocios, puede haber varios objetivos dependiendo del tipo de relación, enfocándonos en el tema de crédito, la relación con el acreedor, prestamista o banco puede llegar a ser de gran ayuda cuando diversos obstáculos se presentan para la obtención de un préstamo. Elsas (2005) hace referencia a la teoría de la relación de préstamo como aquella en la que la relación entre prestamistas y prestatarios está muy unida y puede beneficiar económicamente a ambos. Para Cole (1998) la duración de una relación entre el deudor y el potencial prestamista debiera ser una importante determinación para que ver si se puede extender crédito a la empresa.

Un estudio realizado por Behr et al. (2011:12) muestra la relevancia de la relación de préstamo, como comentan: "encontramos evidencia confiable de que la intensidad de la relación tiene una positiva influencia en el acceso al crédito"; además de que también el tiempo de definición disminuye con este tipo de relaciones. Petersen y Rajan (1994:35) en estudios encuentran que "los resultados empíricos sugieren que la disponibilidad de financiamiento de las instituciones se incrementa cuando la empresa gasta más tiempo en una relación”. El prestar a pymes generalmente está limitado en áreas locales donde el monitoreo puede llevarse a cabo de manera más precisa (Elyasiani y Goldberg, 2004). Además comentan que se puede esperar que entre más larga la relación entre el prestatario y el prestamista mayor será la información generada entre ambas partes y dicha relación es más importante, esto adicionado de que la recolección de la información requiere contacto permanente y eso se facilita por la proximidad geográfica. 
Estudiando el efecto de relaciones bancarias en empresas españolas, Cardone et al. (2005:1) encuentran que: "las pymes que tienen varios bancos y largas relaciones con dichos bancos tiene mayor acceso al crédito". En este estudio se aprecian las ventajas de mantener una relación bancaria a largo plazo para ayudar a la empresa en la contratación de créditos, de ahí la importancia de establecer una relación con dichas instituciones por parte de las empresas. Farinha y Santos (2002) encuentran en un estudio que la relación exclusiva entre un banco y una empresa buena duran más que aquellas con una empresa cuyo desempeño no es bueno. Analizando lo que ha pasado un año después de haber iniciado múltiples relaciones, encuentran que el $75 \%$ de empresas aun piden prestado al banco con el que tenían una relación exclusiva, y esto pasaba con el $54 \%$ de empresas después de dos años de iniciar múltiples relaciones.

Hernández-Cánovas y Koëter-Kant (2010) analizan las relaciones múltiples con bancos usando una encuesta con pymes de 19 países europeos. Encuentra que las pymes localizadas en países con una baja eficiencia legal son más propensos a utilizar múltiples relaciones bancarias; no solo eso sino también en sistemas bancarios frágiles y concentrados, donde el refinanciamiento se dificulta, las empresas prefieren el establecer múltiples relaciones para hacer crecer sus posibilidades de refinanciamiento con algún banco.

El tener relaciones fuertes puede alargar el vencimiento de los préstamos (Hernández-Cánovas y Koëter-Kant, 2008). Para ellos la relación de préstamo aumenta el plazo de los créditos en países con menor competencia bancaria y viceversa. La fortaleza de la relación bancaria puede ser medida de varias maneras, una de ellas, mencionan, es que se enfoca en 
la información privada, aquella que solo es conocida por el banco y su cliente; otra de ellas es el que determina el número de bancos con que se relaciona la empresa, esta situación reduce la privacidad, y en consecuencia, el valor de dicha información. Vickery (2008) menciona que los bancos con la relación a través del tiempo se vuelven más eficientes al supervisar la información privada, con lo cual aquellas empresas con fuertes relaciones con su banco tienen mayor acceso a financiamiento. Hernández-Cánovas y Martínez-Solano (2010) analizan una alternativa que fortalezca la relación entre deudor y acreedor con lo cual tenga mayores beneficios para las pymes, el resultado es el tener el "banco de casa" basado en la confianza entre el banco y la empresa.

Petersen y Rajan (1995) opinan respecto a las relación que no siempre es posible generarlas a través de contratos. Esto haciendo referencia a que la relación pasa a un sentido de mayor control en el cual parte del capital pueda verse comprometido para obtener crédito. Mencionan que la competencia y las relaciones a largo plazo no son necesariamente compatibles, haciendo referencia tanto a las múltiples relaciones como a la duración de las mismas. Binks y Ennew (1997) hacen notar que la mayoría de pymes no requieren una relación cercana con su bancos pues los servicios requeridos son comunes. Pero hacen notar que lo positivo de una relación de este tipo genera una percepción de mayor calidad, menores obstáculos y eliminar la idea de cambiar de banco, lo que a la larga genera una relación de mayor conocimiento entre ambas partes. Esta perspectiva nos muestra que hay un efecto positivo en la relación, y que aun cuando la empresa en el momento pudiera no necesitar recursos, debe empezar por relacionarse para facilitar el crédito cuando llegue a solicitarse. 
Bharath et al. (2007) mencionan que también los bancos se pueden beneficiar de las relaciones de préstamo, podrían generar una utilidad mayor con la venta de otros productos bancarios a sus deudores. Entre sus resultados encuentran que la probabilidad de una préstamo futuro con un deudor con el que se tiene relación es del $42 \%$, mientras que con una empresa con la que no se tiene relación es del 3\%. Cocco et al. (2009), por ejemplo, encuentran en su estudio algunos datos interesantes como que los bancos más pequeños tienden a tener limitado acceso a mercados internacionales y confían más en las relaciones. Por su parte Berger y Black (2011) comentan que los bancos pequeños tienen una ventaja comparativos respecto a los bancos grandes en relaciones de préstamo, pero esta ventaja es más fuerte para las relaciones con las empresas más grandes.

Ivashina y Kovner (2011) haciendo referencia a relaciones entre bancos y empresas apalancadas mencionan que estas empresas requieren mantener la competencia en cuanto al precio de los préstamos mediante la relación con varios bancos. Un incremento en el número de bancos incrementa la posibilidad de oferta de menores tasas de crédito, comentan Degryse y Ongena (2005). Analizando la importancia de las relaciones para la disponibilidad de crédito Cole (1998) encuentra que un potencial prestamista otorgará crédito a une empresa con la cual tiene una relación preexistente como una fuente de servicios financieros, pero que la duración de esta relación no es importante.

Los créditos pueden dividirse "una línea de crédito como una tarjeta de crédito, y un préstamo que no es línea de crédito usado para financieras activos a largo plazo" de acuerdo a Chakraborty y Hu (2006:99,103), comentan que a diferencia de los préstamos como líneas de crédito, los 
segundos se basan en información "dura" y los costos de la misma se pueden reducir mediante la oferta de diversos servicios. Para visualizar el impacto que puedan tener las relaciones de préstamo en estos préstamos, consideran algunos indicadores como: los años de relación, el número de servicios financieros, las fuentes de recursos, la edad de la firma, entre otros. Concluyen que la relación entre el banco y la empresa "puede ser una fuente valiosa de información privada que puede reducir la incertidumbre $\mathrm{y}$, la necesidad de asegurar el préstamo a la pequeña empresa"

"Las características de las relaciones tienen una influencia significativa, pero no siempre en la dirección esperada" comentan Steijvers et al. (2010:243) al estudiar el impacto de las características de las relaciones, entre otros conceptos, en préstamos a pymes. Haciendo una referencia entre la duración de la relación y garantía, menciona que a mayor larga relación hay más probabilidad de no otorgar garantía en la tramitación del crédito. Un tema que puede desalentar el cultivar una relación es cuando no se logra el financiamiento. Han et al. (2009) mencionan que el desaliento disminuye entre buenos deudores cuando la relación se incrementa. Mucho dependerá del riesgo del deudor, que tanta factible es que liquide su deuda o se convierta en incobrable para el banco. Ellos realizan una conjunción entre la calidad del deudor, la duración de la relación y la concentración del mercado.

En la figura 3.3, se muestra las probabilidades estimadas de ser desanimado en la búsqueda de crédito, sobre la duración de la relación. Esta figura nos muestra que la posibilidad de ser desalentado por el banco entre los buenos deudores disminuye con la duración de la relación, en relación con el grado de concentración del mercado bancario local. También 
muestran que los deudores en mercados competitivos hay más probabilidad que se desalienten.

Figura 3.3.

Probabilidad estimada de ser desanimado: deudores de bajo riesgo.

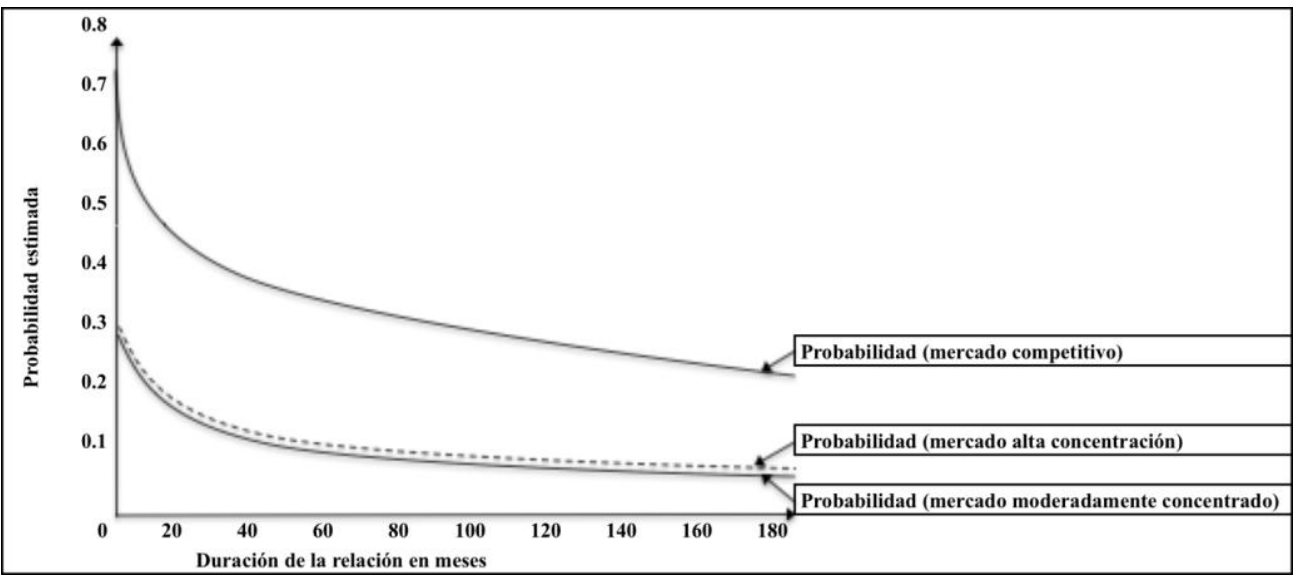

Fuente: Han et al. (2009)

Pero que pasa cuando el deudor es riesgoso, el impacto se muestra en la siguiente figura 3.4.:

Figura 3.4.

Probabilidad estimada de ser desanimado: deudores de alto riesgo.

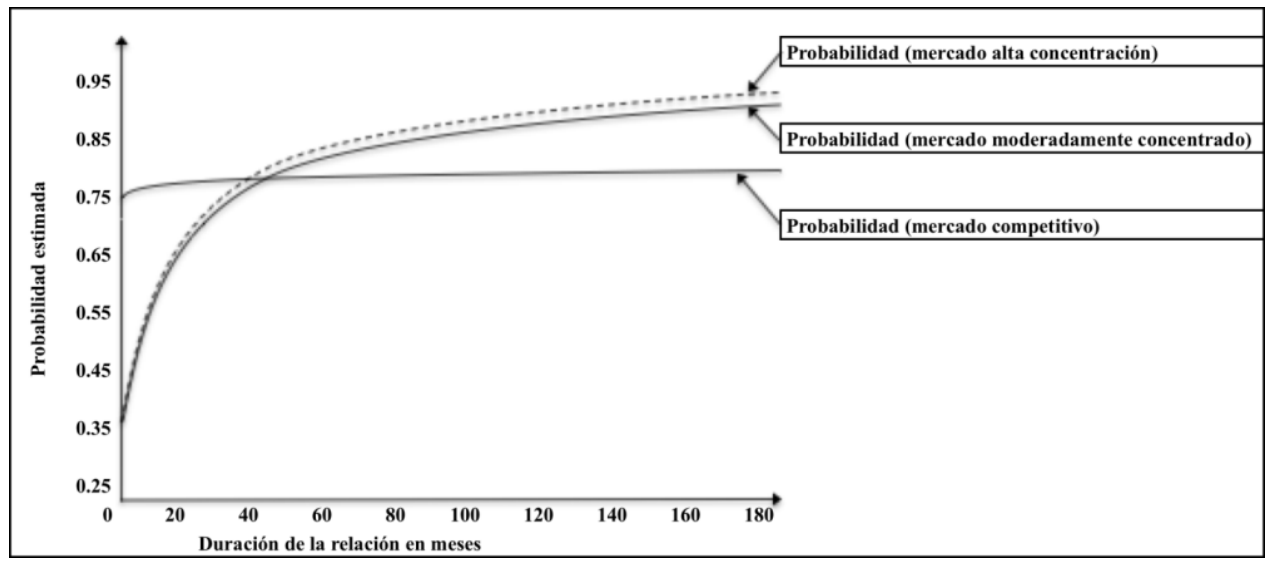

Fuente: Han et al. (2009) 
En esta gráfica 3.4., se aprecia el impacto cuando se trata de malos deudores, riesgos arriba del promedio. En mercados competitivos, la probabilidad no cambia con la duración de la relación. Mientras que en los mercados concentrados si cambia significativamente conforme la relación avanza. Esto sugiere, de acuerdo a Han te al. (2009), que los mercados concentrados son más eficientes que los mercados competitivos en desalentar a los malos deudores del otorgamiento de crédito. Lo que nosotros vemos es de que la relación tiene su impacto en la aceptación del crédito, y como lo hemos señalado en nuestro modelo, puede tener una influencia para la obtención del mismo.

Lo analizado nos muestra la importancia de contar con una relación con alguna o algunas instituciones financieras para cuando se va a requerir un crédito, esto, independiente a las demás características de la compañía, como opacidad o edad de la misma. De aquí se deriva nuestra tercera hipótesis.

Hipótesis H3: Las empresas que mantienen una mayor relación con su banco tienen mayor posibilidad, que aquellas empresas carentes de relación, de conseguir financiamiento cuando lo soliciten. 


\subsection{Edad de la Empresa}

Otro aspecto que también es evaluado por los bancos al momento de otorgar un crédito es la edad de las empresas, lo cual se refiere a los años de operación que tiene la compañía en el mercado, dedicándose a la actividad, giro o servicio que desempeña en la actualidad. Para las instituciones financieras este indicador les muestra la permanencia del negocio, la posición que tienen en el sector, las condiciones actuales que puedan sugerir como se ha desempeñado durante su vida económica, así como su proyección a mediano y largo plazo.

El tiempo va dando un aprendizaje y también una perspectiva para estimar si el negocio subsistirá a los factores que puedan ver imposibilitado su desarrollo cuando son de reciente creación, por lo cual si ya se llevan varios años en el mercado, no da la seguridad, pero si da confianza de que la empresa tiene fortalezas o ventajas o cierto posicionamiento que pueda minimizar el riesgo para los bancos. Las fuentes de financiamiento van a depender tanto de características del negocio como del propietario. Los negocios más nuevos (menores a 3 años) son más propensos a usar "ahorros personales, familiares, amigos y tarjetas de crédito", y tienden a utilizar menos los créditos provenientes de instituciones financieras (Vos et al., 2007).

Como lo comentan Gregory et al. (2005:386), “empresas antiguas, por definición han tenido mayor oportunidad para acumular utilidades que las empresas jóvenes, y así más fondos que están disponibles para financiar las operaciones de crecimiento". En base a esto comentan que las empresas jóvenes tienen que recurrir más a fuentes externas de financiamiento. 
Analizando la situación de empresas jóvenes, Robb (2002) encuentra que este tipo de empresas son más propensas a no solicitar préstamo en algún momento que lo necesitan por el temor a que su solicitud sea negada, no obstante, esto no significa que nunca lo hayan solicitado, pero demuestra la preocupación desde el inicio por el acceso al financiamiento. Egeln et al. (1997), analizan empresas de Alemania, encontrando las limitantes de crédito, en este caso considerando la edad de las empresas como se muestra en la tabla 3.2.:

Tabla 3.2.

Auto evaluación de las restricciones financieras y la edad de la empresa

\begin{tabular}{|l|c|c|c|}
\hline $\begin{array}{l}\text { Edad de la } \\
\text { empresa }\end{array}$ & $\begin{array}{c}\text { (Restricciones } \\
\text { importantes en actividades de innovación) en \% } \\
\text { Capital } \\
\text { externo }\end{array}$ \\
\hline$<5$ años & 42 & 40 & 21 \\
\hline $5-10$ años & 58 & 52 & 45 \\
\hline $10-20$ años & 40 & 37 & 24 \\
\hline$>20$ años & 35 & 34 & 16 \\
\hline
\end{tabular}

Fuente: Egeln et al. (1997)

De acuerdo a los resultados de Egeln et al. (1997), la falta de capital depende más del tamaño que de la edad de la empresa. No obstante, vemos en su estudio que aun cuando para efectos de innovación las empresas menores a 5 años no tienen tanta restricción como las de 5 a 10 años, vemos que esta limitación va disminuyendo a partir de esa antigüedad. En estudio realizado por Van Geenhuizen y Soetanto (2009) se centran en los obstáculos para el crecimiento, tomando en consideración las diferentes 
edades de la empresa. Encuentran evidencia general de que los obstáculos empiezan a disminuir cuando la empresa tiene una antigüedad de 4 años. La tabla 3.3., muestra parte de estos obstáculos.

Tabla 3.3.

Obstáculo por antigüedad

\begin{tabular}{|l|c|c|c|}
\hline \multicolumn{1}{|c|}{ Obstáculos } & $<\mathbf{3}$ años & $\mathbf{3}-\mathbf{5}$ años & $>$ 5 años \\
\hline Relación de mercado & 28 & 14 & 10 \\
\hline Financieros & 21 & 9 & 4 \\
\hline Administración & 18 & 12 & 5 \\
\hline Física (alojamiento) & 10 & 1 & 1 \\
\hline Restante (regulación) & 4 & 2 & 21 \\
\hline Todos los obstáculos & 81 & 38 & \\
\hline
\end{tabular}

Fuente: Van Geenhuizen y Soetanto (2009)

Como se puede ver en la tabla, las empresa más jóvenes tienen los mayores obstáculos, además de que aparecen simultáneamente, tales como: problemas con flujo de efectivo, demanda de mercado, administración. Y esto comienza a disminuir conforme la empresa va ganando experiencia en el mercado. Si nos enfocamos en lo financiero vemos como los 3 primeros años de las empresas de este estudio cuentan con obstáculos mayores, por mucho, respecto a los siguientes años. Situación que agudiza su supervivencia, o que puede sugerir contar desde un principio con un capital suficiente.

Evidencia de estudios sugieren que la mayoría de negocios jóvenes y pequeños tienen complicado crecer vía recursos internos, a menos que puedan obtenerlos de los mismos dueños, familiares o amigos (Binks y 
Ennew, 1997). Berger y Udell (1998) dentro de su modelo del ciclo de crecimiento financiero de las empresas consideran que las necesidades de la empresa van cambiando de acuerdo a su crecimiento, su mayor experiencia y su menor opacidad. Cuando la empresa inicia, comentan, su fuente de financiamiento debe basarse en fondos propios, crédito comercial u otra fuente cercana como familiares o amigos. Con el paso del tiempo puede acceder a intermediarios financieros, a incrementar deuda en el pasivo a largo plazo, y en dado momento llegar a emitir acciones. Hyytinen y Pajarinen (2008) realizan un estudio cuyos resultados muestran un efecto negativo a la edad de la empresa, lo cual sugiere que mientras más joven la empresa más opaca es; ello repercute en mayores dificultades cuando se solicita un crédito.

Beck (2007) analiza encuestas realizadas por el Banco Mundial, en el cual encuentra que las pymes tienen mayor dificultad para recibir financiamiento que las empresas grandes, y menciona que esta situación se incrementa por la debilidad de los sistemas financieros en países en desarrollo. Las empresas más pequeñas, jóvenes y nacionales fueron las que reportan mayores obstáculos, de acuerdo a este estudio, más que otras características. Cuando una empresa es joven o con ciertas dificultadas, sus posibles flujos de liquidez futuros pueden ser altos, mientras que su generación actual es baja, así lo comentan Petersen y Rajan (1995). Usando datos de la encuesta nacional de las finanzas de pequeñas empresas realizan un análisis sobre determinados puntos. Uno de ellos es identificar si la actividad de préstamo varía con la edad de la empresa y la concentración del mercado. Examinando empresas de diferentes edades pueden realizar supuestos de cómo cambian las condiciones de préstamo durante la vida de la compañía. 
Usando la base denominada "AMADEUS", la cual incluye información de 97,000 empresas públicas y privadas (82\% son pymes) en 15 países del este y centro de Europa; Klapper et al. (2002) identifican la afectación en cuanto al financiamiento de acuerdo a la edad de las empresas. Muestran que dentro de los primeros 3 años de operación el 85\% son pymes, porcentaje que se ve reducido en las empresas mayores a 10 años cuyas pymes abarcan el $59 \%$ en este análisis. Encuentran además que aunque en general las razones financieras de endeudamientos son bajas en la región, las empresas más pequeñas y jóvenes se encuentran más endeudadas, lo cual sugiere tendería a disminuir con el crecimiento en tamaño y edad, y, la mayor deuda es de corto plazo, lo que implica el poco acceso al crédito de largo plazo.

El acceso a fondos externos vía préstamo y los términos bajo los cuales son realizados son asuntos muy importantes en los proyectos de negocios de las empresas, especialmente en las empresas pequeñas, así lo señalan Sakai et al., (2010). Aunque esto se les dificulta, mencionando una de las causas la poca historia crediticia con que cuentan y la información asimétrica existente. Para ellos, las empresas con mayor experiencia se benefician de mayor forma del crédito así como en los términos que se contratan respecto a las más nuevas. Love y Mylenko (2003) evalúan si un registro o base datos sobre historial de las empresas en temas crediticios tiene algún efecto en empresas jóvenes y antiguas. Las empresas más jóvenes normalmente no cuentan con historial.

Utilizando la encuesta de ambiente empresarial (WBES por sus siglas en inglés) entre 10,000 empresas en 80 países y respuestas de registro de crédito público y privado en encuestas dirigidas por el banco mundial, 
Love y Mylenko (2003) tratan de investigar los efectos del reporte de crédito sobre las dificultades para el financiamiento. Encontraron que la existencia de un registro de crédito privado se asocia con menor incidencia de dificultades financieras y un mayor promedio de financiamiento bancario. Los resultados obtenidos indican que las empresas con mayor antigüedad no parecen tener beneficios mayores a la de empresas nuevas con motivo del registro de crédito. En cuanto al registro público y la edad de la empresa la relación es positiva y significante, lo cual indica que en los países con este registro hay una mayor tasa de financiamiento bancario a nuevas empresas. Mencionan como una posible explicación el que la mayoría de registros públicos únicamente informan sobre la situación actual del deudor, y no tanto el historial del mismo por un período largo de tiempo.

Gregory et al., (2005) elaboran un estudio que analiza el modelo del ciclo de crecimiento financiero de las pymes, el cual postula que las empresas cuando se hacen más grandes, más antiguas y con mayor información encuentran opciones de financiamiento más atractivas. Al analizar los resultados que se enfocan a la edad de las empresas encontraron resultados contradictorios. Los resultados sugieren que las empresas más jóvenes, a diferencia de las de mayor experiencia, estarán más cómodas usando recursos provenientes de la emisión de acciones al público o financiamiento a largo plazo que usando recursos de capital de riesgo o crédito de mediano plazo, lo cual se contradice al modelo de Berger y Udell (1998). Con lo cual resumen que este modelo no puede ser aplicado de manera universal.

No obstante estos hallazgos, se muestra que la edad de la empresa influye en las decisiones de financiamiento, así como en este estudio se 
encontraron ciertos parámetros o fuentes específicas de recursos, como se ha visto en algunos otros, las fuentes de financiamiento se concentran en recursos propios o de intermediarios financieros.

Como hemos visto, la experiencia de las empresas, traducida en los años de operación o la edad de la compañía, puede afectar en dado momento la situación de solicitud de crédito, de ahí que se planteé la siguiente hipótesis.

Hipótesis H4: Las empresas con mayor edad o antigüedad tienen mayor oportunidad de conseguir financiamiento cuando lo solicitan. 


\subsection{Relación de préstamo y la falta de información}

En hipótesis anteriores hemos marcado la relación existente entre los constructos "relación de préstamo" e "información financiera" con la variable endógena "obtención de crédito". Ahí se han desprendido como influyen estas variables endógenas con la variable principal de nuestro modelo. Ahora analizaremos la relación entre la relación de préstamo y la información para determinar cual es la causalidad entre una y otra.

Una forma de poder superar la falta de información financiera por parte de las empresas es relacionándose con las instituciones financieras. Ortíz-Molina y Penas (2008:362) comentan que "las pymes no cuentan con estados financieros auditados, y no pueden ser monitoreados por agencias de investigación". Por ello, comentan, los intermediarios financieros toman decisiones de crédito de manera que puedan mitigar los problemas asociados al riesgo y asimetrías en la información. Scott (2006:545) señala que "sin la obtención de información privada, el acceso a los mercados de crédito para la pyme estará limitada debido a la opacidad en la información.

Berger y Udell (2002) realizan un modelo en el que identifican tres características en la relación de préstamo: la primera depende de la información suave, hacen mención de que dicha información no es fácilmente observada, verificada o transmitida; en segundo lugar, el oficial del crédito tiene la relación más importante con la empresa y dueño, pero es complicado compartir la información derivada de esta relación y por último, se crea un problema de agencia entre el oficial del crédito y el administrador del banco por la naturaleza de la información suave. 
Aunque, de hecho, hay una posibilidad de que el financiamiento a pymes pueda verse afectado por su opacidad; cuando se trabaja con un solo banco se tiene la ventaja que este cuenta con toda la información del prestatario, o lo conoce de manera más detallada que si existieran varios bancos trabajando con la empresa, ello puede ayudar a dar crédito a menor costo a deudores solventes aunque sean opacos (Berger et al., 2001). Aunque también mencionan que las empresas pueden mejor utilizar el servicio de varios bancos para no verse en desventaja por la relación que se tenga con uno solo por la dependencia con este. Petersen y Rajan (1995) consideran que podría ser más sencillo para las pequeñas empresas en áreas rurales el obtener crédito, debido a que los acreedores tienen mejor información por tratarse de comunidades pequeñas donde las noticias son prácticamente de dominio público y ello les facilita el contar con información sobre el deudor.

La concentración de la relación con bancos varía de acuerdo al país, Suiza en particular, de acuerdo a Neuberger et al. (2008) es de los países con una alta concentración. De acuerdo a sus resultados, las pymes tiene relación bancarias con solo uno o pocos bancos, este número se incrementa con el tamaño de la empresa. Consultando estudios previos, encuentran efectos significativos del tipo de industria, forma legal y tipo de préstamo. Comentan que esto soporta la hipótesis de que el número de relaciones bancarias disminuye con la opacidad de la información y se incrementa con la demanda de servicios financieros. Elsas y Krahnen (1998) hacen mención del banco principal como el banco de casa (housebank en inglés), de acuerdo a los resultados de un estudio que realizan, encuentran que a pesar de la competencia con otros bancos, los bancos de casa son capaces de establecer una política de compromiso a largo plazo con sus clientes. 
Thakor (1996) en su modelo que examina el efecto de contar con múltiples relaciones, considera que esto reduce el valor de la información obtenida por cualquier banco. El preguntarse por qué las empresas, en especial las pequeñas, necesitan más de un banco, es estudiado por Detragiache et al. (2000). Utilizando información resultante de una investigación en Italia, consideran que la mayoría de empresas utiliza más de un banco, entendiendo esto una vez que si se llegara a ver afectada la relación con uno por alguna causa imputable al banco, esto le originaría más problemas que el de acercarse a otro banco con el que no se tiene relación para pedir préstamo.

Indudablemente cuando se tienen varias relaciones, es posible que no se pueda tener la misma profundidad que si existiera una sola, pero por otro lado hay competencia entre acreedores y para el deudor una oferta mayor con la cual definir de acuerdo a las condiciones que se otorguen y la ventaja será tener un mejor financiamiento o al menos contar con el mismo que de otra manera entre menos opciones le pueda resultar más difícil el contratar el crédito. Esto, entonces, refleja una situación positiva para la empresa.

La idea generalizada es de que los bancos grandes no están interesados en atender a las pymes, comentan De la Torre et al. (2010), ello origina que los bancos pequeños puedan superar la opacidad mediante la relación con las empresas. Para ellos, la opacidad de la empresa "significa que es difícil identificar si la empresa tiene capacidad de pagar (que tienen proyectos viables) y/o la voluntad de pagar (debido al riesgo moral)”. No obstante se pueda cubrir la opacidad con la relación, consideran que aun así el banco le prestará menos a la pyme que si tuviera la certeza de su transparencia bajo otra perspectiva a la relación. 
Información confiable en pymes es rara y costosa, comentan Baas y Schrooten (2006), por lo cual consideran a la relación de préstamos como la mejor técnica crediticia que existe. Berger y Udell (2002) también consideran que una de las tecnologías de préstamo más importante usada por los bancos sobre las pymes opacas es la relación de préstamo, la cual está basada en la acumulación de información en el tiempo a través del contacto con la empresa, su dueño y su comunidad; aunque también consideran que la relación crea un problema de agencia a través de la organización, la cual puede ser resuelta por algunos bancos y otros no.

Aquí vemos el mayor impacto positivo que puede generar la relación entre empresa y banco, y principalmente con las pymes, el que pueda cubrirse la falta de información con el conocimiento que vaya generando el banco con el trato a través del tiempo con su cliente, a través de los demás servicios que ofrece, la reputación del mismo, el cumplimiento de obligaciones, entre otras situaciones que se van conociendo con el trato; ello encaminado a que mediante esto se pueda obtener financiamiento.

Para Uchida et al. (2012), varios estudios empíricos sugieren que el director de la institución de préstamos es un factor principal en la relación de créditos al producir la información suave de las pymes. Lo cual hace pensar que en él recae la responsabilidad de entender y captar dicha información para permitir el acceso al crédito de las pymes opacas. Probando esta hipótesis en empresas japonesas, ellos encuentran que realmente el director juega un papel importante en la recolección de la información suave y en la generación de la relación de préstamo. De esta forma, estas relaciones deben servir al empresario para superar la carencia de información y cuenten con una herramienta que facilite el crédito. Bajo la 
hipótesis de relación de una empresa opaca con uno o más bancos, Berger et al. (2001) encuentran que las pymes opacas tienden más a relacionarse con un solo banco por los beneficios de la información que es explotada por el banco en sí.

Nuestro modelo señala la relación que existe entre la relación de préstamo y la información. Puede existir asimetría en la información o la empresa puede ser opaca. Baas y Schrooten (2006) estiman asimetrías en la información causadas por las diferentes antigüedades en las relaciones de préstamo. Sus resultados muestran que solo hay un equilibrio posible, el cual sería la tasa de interés (precio) igual al acreedor con menor costo marginal, como se muestra en la figura 3.5.:

Figura 3.5.

Relación de préstamo marginal

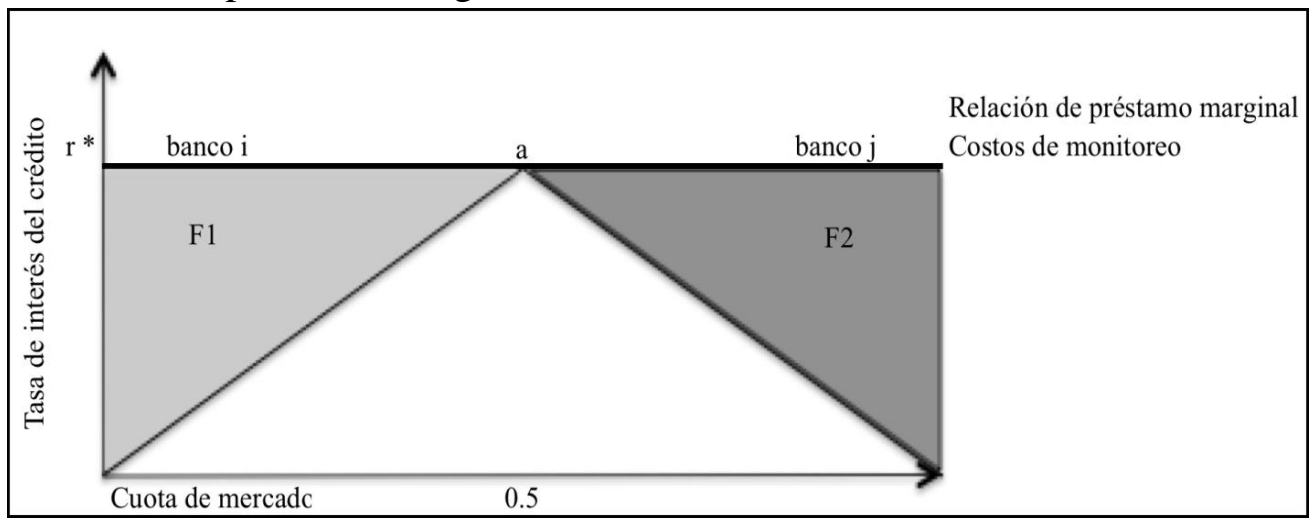

Fuente: Baas y Schrooten (2006)

En la figura se muestra que la cuota del mercado entre los dos bancos relacionados es al 50\%, con un costo de monitoreo similar. Baas y Schrooten (2006) también analizan cuando el préstamo se da en base a la información financiera solicitada. Como se muestra en la figura 3.6., si se 
argumenta que el mercado del crédito de pymes está caracterizado por un bajo nivel de información disponible, esto resultaría en un mercado para las relaciones de préstamo, como se mostró en la figura anterior, o se tendería a un costo relativamente alto de préstamos bajo información financiera como la figura de abajo. Cuando se incrementa la información, como es el caso de empresa grandes, los costos marginales del crédito se reducen. Además, si se presume que se requiere conseguir al menos la mitad del mercado, la relación de préstamo del banco subsidiaría el área F1b con el área F1a. Este podría ser el caso si el banco tuviera que ganar deudores jóvenes; esto causa, asumen, costos altos de supervisión.

Figura 3.6.

Préstamos sobre estados financieros de pymes

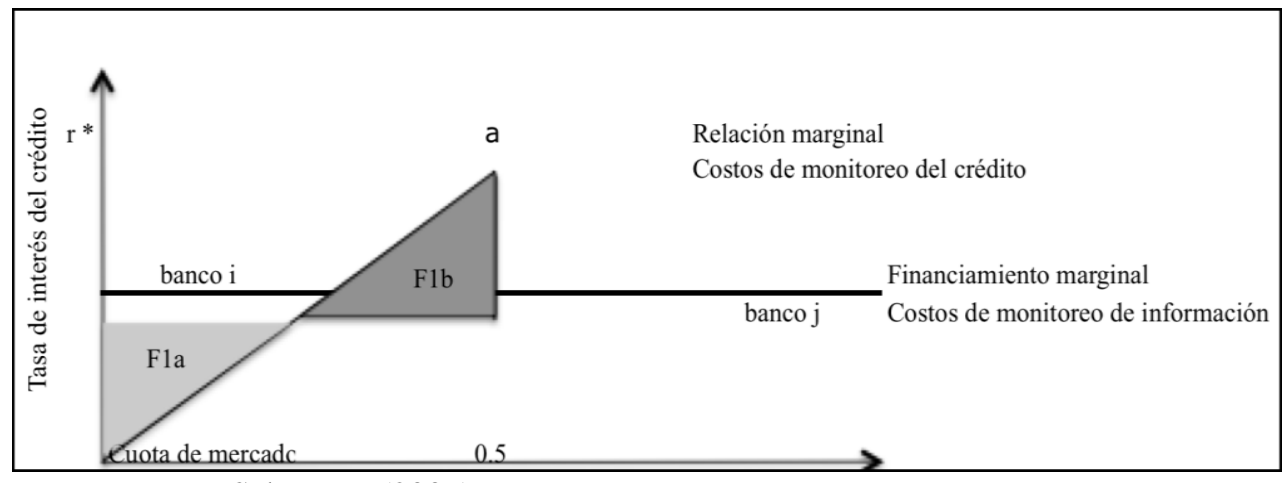

Fuente: Baas y Schrooten (2006)

Indudablemente, sopesando las ventajas y desventajas de contar con una relación a largo plazo con uno o más bancos, se traduce que es de gran utilidad para las empresas, en particular las pymes y su probable opacidad el contar con una relación de este tipo. Puesto que la falta de información representa un obstáculo para las pymes al solicitar recursos, y el buscar una forma de cubrir esta dificultad es una necesidad para la empresa, se ha mostrado que la relación con el banco es una forma efectiva para lograrlo. 
De acuerdo a ello se deriva la quinta hipótesis definida de la siguiente manera:

Hipótesis H5: La relación establecida con el banco cubre la falta de información de la empresa, con ello puede superar su opacidad y conseguir financiamiento cuando lo soliciten. 


\subsection{Información financiera y el costo del crédito}

Los bancos normalmente reflejan en el costo de interés cobrado a las empresas el riesgo que representa el otorgarles un crédito. Esto es, que el no tener la certeza de que recuperaran los recursos autorizados en determinado a una empresa, eleva el costo que esta va a tener con tal de obtener financiamiento. Por ello, cuando la empresa puede justificar que su operación es sana, y que liquida sus deudas, el banco es el más interesado en otorgar financiamiento. Una forma común de reflejar la situación de la empresa es a través de su información financiera, el que la empresa cuente con números sanos puede lograr que el financiamiento sea más barato que el no poder ofrecer información.

Kon y Storey (2003) dentro de su modelo realizan varias suposiciones, una de ellas se refiere a que en el estudio del banco realizan una detección de las características de la pyme, y si no cuentan con información sobre los mismos el análisis se acerca a una selección aleatoria. La ventaja para ellos es que esto no es tan profundo y el costo es bajo. Pero si el banco cuenta con algo de información o esta va creciendo, entonces la actividad de detección por parte de ellos mejora, y las empresas tendrán que proporcionar mejor información lo cual aumentará los costos por motivo de verificación. Sugieren que el monitoreo de los bancos mejora cuando se incrementa la información, pero solo si ha acumulado suficiente información para realizar comparaciones entre los nuevos solicitantes y los actuales.

Realizando un estudio sobre pymes belgas, no solo respecto a la cantidad de información financiera sino también a la calidad de la misma, 
Van Campenhout y Van Caneghem (2009) analizan como es afectada la estructura financiera de las pymes. Encuentran que, en línea con argumentos comunes de información asimétrica, tanto la cantidad como la calidad de información está relacionada positivamente con el endeudamiento de las pymes. Entonces, sus resultados soportan la opinión de que la falta de información y la baja calidad de la misma inhibe a la empresa de la utilización de fondos externos, situación contraria a las pymes que cuentan con mayor información y es más confiable, con lo cual otorgan más peso al uso de deuda externa.

De manera más específica, Van Campenhout y Van Caneghem (2009) encuentran que el endeudamiento es positivo en relación a la estructura de activos, crecimiento y a la media de endeudamiento de la industria, y negativo en relación a la edad y rentabilidad de la empresa. Popov y Udell (2010) hacen referencia a la reciente crisis de 2007-2008, comentan que el problema clásico cuando se identifica un problema de este tipo es que las empresas demandan un cambio durante una crisis de crédito que sigue a un deterioro de los estados de situación financiera.

Won y Heshmati (2008) argumentan que derivado de una falta de información y después de evaluar la solicitud de crédito de prestatarios riesgosos se dificulta la obtención del préstamo o el tenerlo con más altas tasas de interés. Keys et al. (2010:350) hacen referencia cumplir con toda la documentación requerida por el banco, lo definen como si la información "dura" importa, de acuerdo al análisis crediticio de los prestamistas consideran que estos "tienen mayor voluntad de asegurar a un umbral de bajo crédito por préstamos con documentación completa por que hay menor 
incertidumbre sobre estos deudores que sobre aquellos que proveen menos documentación.

Información confiable en pymes es rara y costosa, comentan Baas y Schrooten (2006), en su estudio muestran que la falta de información repercute en altas tasas de interés aún y si existe una relación de largo plazo entre al banco y la empresa; situación relevante que pone una excepción a la idea generalizada en la literatura. Petersen y Rajan (1994:2) comentan que "la alta tasa de interés pagada por las empresas en mercados concentrados puede llegar a reducir su confianza en el uso de recursos externos, afectando su crecimiento”. Degryse y Ongena (2005) consideran que un incremento en el número de bancos incrementa la posibilidad de recibir una menor tasa de interés debido a la competencia.

Liu et al. (2011:2195) analizan información de Nueva Zelanda comparando los costos de las tasas promedio sobre hipotecas respecto a las tasas por préstamos a empresas. Encuentran que "los ajustes en las tasas de préstamo a negocios en respuesta a los cambios en los costos de los fondos es más lento que aquellos de hipotecas flotantes tanto en el corto como en el largo plazo". Los resultados muestran que los costos de crédito no son tan competitivos que los de hipotecas. Las pymes son muy pequeñas en aquel país y la tasa de quiebra alta, con lo cual los bancos ven costoso y mucho tiempo invertido para obtener y procesar la información de las pymes.

Los diferenciales de tasas de préstamos entre empresas grandes y pequeñas son sorprendentes, comenta Dietrich (2010), inicialmente se da como resultado de la poca eficiencia en pequeñas empresas. De acuerdo a su estudio no solo la falta de información es causante de dichos costos de 
interés, sino también por los costos de operación y la falta de poder de negociación en los préstamos. El estudio, realizado en Suiza, muestra que generalmente los bancos no incrementan la tasa de interés después de cierto punto, aun y si existe exceso de demanda de fondos o las empresas ofrecen pagar más, puesto que la ganancia de los bancos empezará a decrecer en dicho límite.

Además, Dietrich (2010) hacen mención sobre como influye el aumentar la información de la empresa sobre los costos del crédito. Inicialmente muestra gráficamente como influye el aumento de información sobre los errores de detección de los bancos. Como se muestra en la figura 3.7., suponiendo que los bancos no tiene información sobre la empresa, la detección la tendrían que hacer aleatoriamente. Pero, mientras los bancos se vuelven mejor informados sobre la empresa, su habilidad de detección mejora. Cuando los bancos no tienen información, el error de detección está a un máximo de bGN. Entonces el error de detección desciende, a una tasa acelerada, hasta cero bajo una información perfecta.

De acuerdo a la figura 3.7., bG se refiere a la probabilidad de que el banco perciba la solicitud de crédito como buena, bGN señala que cuando no hay información el error será mucho. Dependiendo del análisis que deba hacer el banco respecto a la empresa, este será mayor respecto a un estudio más profundo por la falta de información. Además Dietrich (2010) hace referencia a los costos de solicitud de acuerdo a la figura 3.8. 
Figura 3.7.

Función error de detección

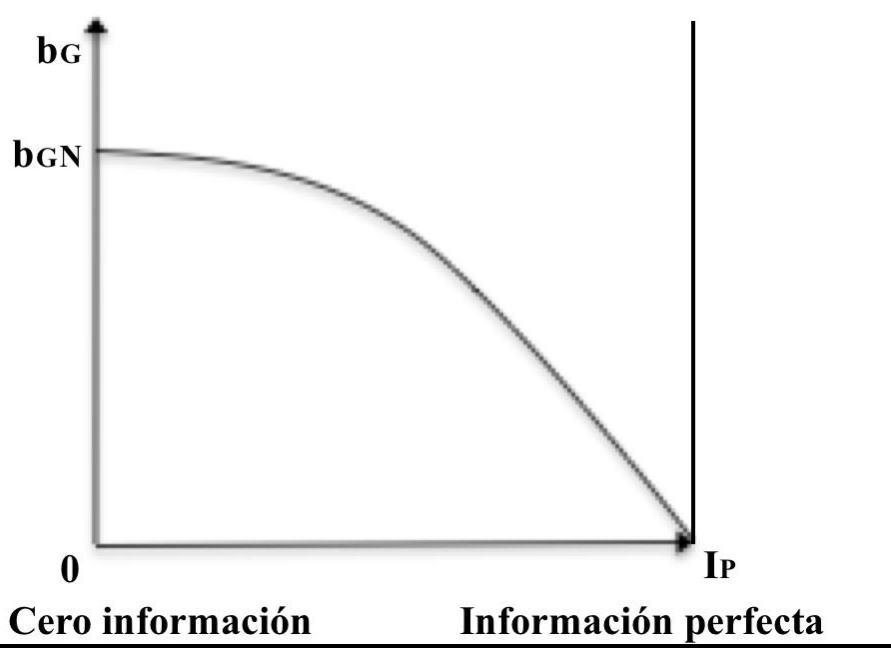

Fuente: Kon y Storey (2003)

Figura 3.8.

Función de los costos de solicitud.

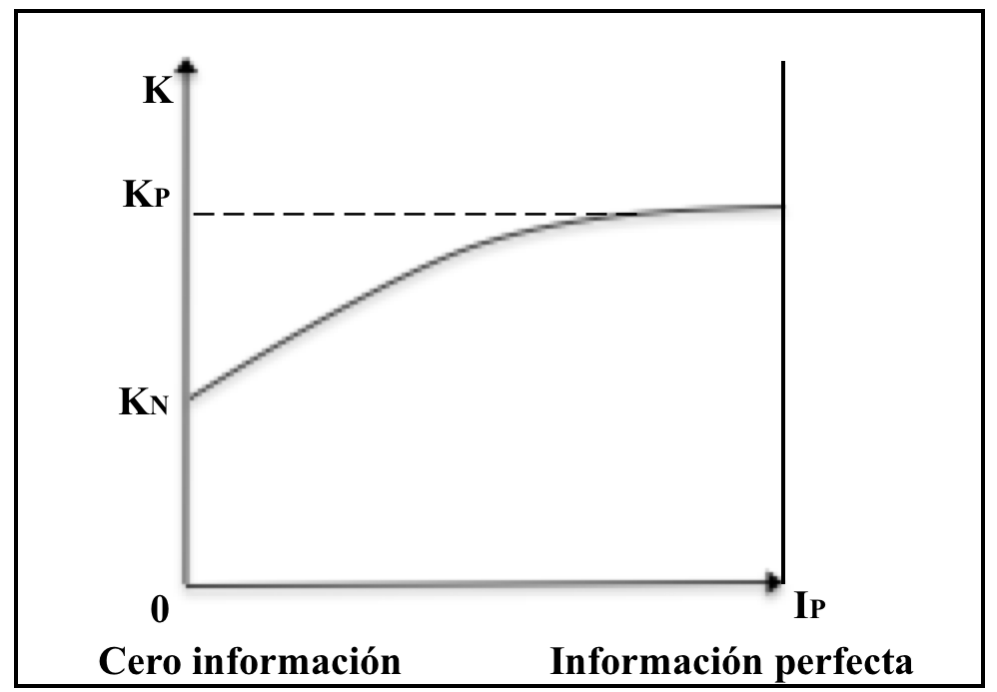

Fuente: Kon y Storey (2003) 
En la figura anterior se muestra como cuando la empresa sabe que el banco tiene ciertas cualidades para evaluar a la empresa, tiene que incurrir en algunos costos para preparar su solicitud de financiamiento. De acuerdo a esta teoría, cuando los bancos no tienen información, los costos de solicitud es de cero; no obstante, una vez que el banco tiene cierta información, la empresa tiene un costo mínimo $\mathrm{KN}$, costos que se incrementarán a una tasa decreciente hasta un costo KP de una información perfecta. Lo que rescatamos de este modelo es como el costo del crédito se ve influenciado por la información proporcionada, desde el mismo inicio del trámite con la solicitud.

Maudos y Solís (2009:1929) analizan los costos de interés en México por el período de 1993 - 2005, “comparado con los estándares internacionales, México tiene altos márgenes bancarios que reflejan altos costos de intermediación, lo cual repercute negativamente en el crecimiento del ahorro, inversión, empleo, y en consecuencia del crecimiento de la economía del país”. Además, señalan que bancos con altos costos de operación los traspasan a sus clientes mediante altas tasas de interés en créditos y bajas tasas en depósitos, con lo cual se convierte en un alto margen de intermediación. En otro estudio en México, Solís y Maudos (2008) hacen referencia al poder de los bancos, los cuales si cuentan con un poder grande ofrecen una calidad baja de servicios.

Entre las limitantes del flujo de capital a nivel internacional se encuentra la asimetría en la información, comenta Ashta (2009), además de los costos de la operación para préstamos pequeños. Señala que mientras los prestamistas usan su propio capital, instituciones microfinancieras se fundan bajo una mezcla de capital, préstamos, garantías y depósitos. Por otra parte, 
haciendo la comparación entre estos dos tipos de instituciones, comenta que la reducción de la asimetría en la información no se realiza de la misma forma.

En resumen, el ofrecimiento de información por parte de las empresas a las instituciones financieras les da un panorama sobre la situación de la misma y puede ayudar a dar certeza con lo cual se puede disminuir el riesgo del crédito, con lo cual, el costo del crédito puede verse disminuido, no así cuando la empresa presenta opacidad, con ello se establece la sexta hipótesis.

Hipótesis H6: El costo del crédito se ve afectado por la información financiera otorgada por la empresa, a menor información financiera otorgada por la empresa el costo del crédito será más alto. 


\subsection{Tamaño de la empresa}

El tamaño de la empresa es uno de los obstáculos que encuentran las pymes al solicitar créditos. Las pymes son parte importante en la economía de países emergentes, como manifiesta Pissarides (1999:519), "las pymes se mueven en áreas de ventaja comparativa y valor agregado, no obstante enfrentan muchos obstáculos económicos, institucionales y legales"; comentando que definitivamente, la falta de financiamiento es el principal obstáculo manifestado en las pymes en encuestas realizadas. Utilizando una encuesta que realiza el banco mundial, Schiffer y Weder (2001) encuentran que en general las pymes encaran mayores obstáculos que las empresas grandes en cuanto a temas de financiamiento, impuestos, inflación, corrupción, entre otros. Además, encuentran que esta situación es más notoria en América Latina y el caribe, así como en economías de transición.

No obstante que las pymes forman parte importante en las economías de los países, estas empresas son las que mayores problemas o dificultades encuentran para obtener financiamiento. Así lo menciona Vickery (2008), remarca que las pymes generalmente encaran mayores obstáculos financieros que las empresas grandes, derivado de las economías de escala en el monitoreo y la información. Para Beck y Demirguc-Kunt (2006:2941) "el acceso al financiamiento es un obstáculo importante en el crecimiento de las pymes”. Rahaman (2011) señala también que el acceso al financiamiento es un factor determinante en el crecimiento de las pymes, aunque este acceso se dificulta respecto a las empresas grandes. Beck (2007) señala que el acceso al financiamiento es citado por alrededor del $30 \%$ de las pymes como la mayor restricción. 
Al día de hoy, esta situación de falta de recursos prevalece tanto en las economías como en el círculo empresarial, la situación de poder obtener recursos es una idea de que es restringida, que no está disponible para todo mundo, esta idea en ocasiones provoca que desde un principio no se realice el intento para solicitar financiamiento en muchas de las pequeñas empresas, que haya desaliento anticipado ante esta situación; o más aún que el costo para poder acceder a él quede fuera de sus posibilidades.

"El principal desafío financiero que encaran las pymes es acceso a crédito a bajo costo por un período razonable de tiempo" (Tagoe et al., 2005:331). Ellos comentan que las necesidades financieras de las pymes reflejan sus requerimientos operacionales, mientras que la acción de los inversionistas depende en la percepción del riesgo y lo atractivo de las alternativas de inversión. El préstamo gubernamental, el clima económico, la disponibilidad de garantía, la calidad de la información de la pyme y las habilidades de relación con inversionistas afectan la forma en que el desafío es manejado. Analizando el impacto de la liberalización del sector financiero en la administración financiera de las pymes en Ghana, utilizando seis casos de estudio previos, agrupan sus resultados dentro de un modelo, el cual se muestra en la figura 3.9. 
Figura 3.9.

Marco de desafíos financieros de las pymes

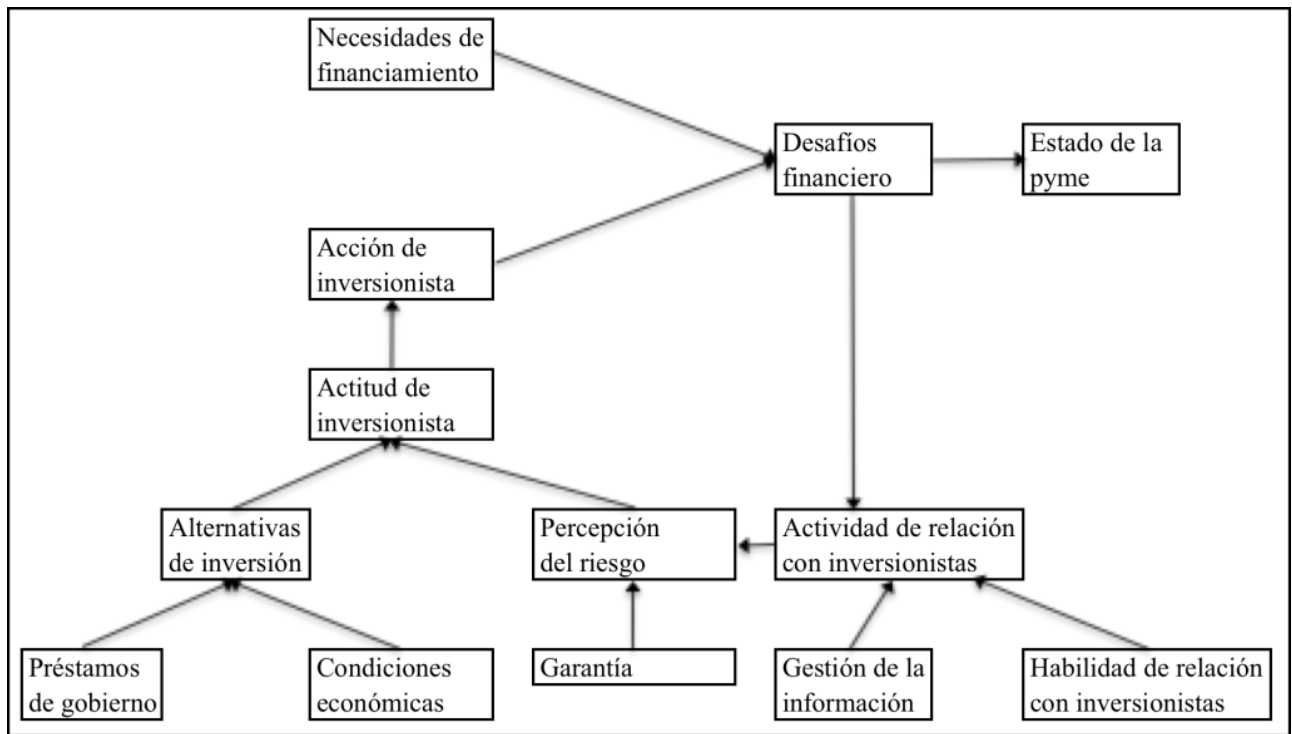

Fuente: Tagoe et al. (2005)

Berger y Udell (2002) señalan que las pymes son vulnerables por su alta dependencia de las instituciones financieras para obtener crédito. Estas empresas no cuentan con acceso al mercado de valores público. Ello conlleva a contar con un menor número de oportunidades de financiamiento frente a las empresas de mayor tamaño. "Las pymes usan menor financiamiento externo, especialmente de bancos", así lo mencionan Beck et al. (2008:485), sugiriendo que para mejorar el acceso al financiamiento de las pymes se deberían realizar reformas institucionales que superen las debilidades de los sistemas legal y financiero. De ahí suponemos, aunque haya particularidades dependiendo del país, la región, y más específicamente, la industria o características de la empresa, que en los últimos años se ha visto una reducción en la oferta del crédito. 
Aunque el acceso al financiamiento muestra un gran interés generalizado para tener un entendimiento al respecto, y en particular de las pymes, los patrones de financiamiento a través de los países no han sido bien entendidos, así lo comentan Klapper et al. (2002). Usando la base denominada “AMADEUS", la cual incluye información de 97,000 empresas públicas y privadas (82\% son pymes) en 15 países del este y centro de Europa; señalan que normalmente los estudios realizados sobre el acceso al financiamiento de pymes muestran las dificultades de las pymes para obtener préstamos externos y sugieren las condiciones económicas del país que pueden influir en ello; sugieren que los bancos podrían otorgar más préstamos en aquellos países que ofrecen bastante seguridad a los acreedores. Aun cuando encontraron en los países analizados un porcentaje predominante de pymes respecto al total de empresas, dichas pymes son muy pequeñas y con un número muy reducido de empleados. Además, refieren que estas pymes están obteniendo créditos solo para el corto plazo, pues pareciera el único tipo de financiamiento al que pueden acceder.

Este análisis en países de transición rompe un poco el esquema visto en otros análisis en la cual las pymes no cuentan con grandes accesos al financiamiento, pero las características propias de estos países en los que predominan las empresas de este tamaño puede ser la situación que origine el abastecimiento de recursos, aunque estos son a corto plazo tal como muestra en dicho estudio.

Hashi y Toci (2010:48) refieren en un estudio que "el coeficiente estimado en pymes es positivo y altamente significativo en todas las especificaciones, indicando que las pymes encaran mayores obstáculos financieros comparados con las empresas grandes”. Psillaki y Daskalakis 
(2009) consideran que el tamaño de la empresa está relacionado positivamente con la deuda, analizando razones de deuda de varias empresas en las cuales las empresas grandes cuentan con razones de este tipo más altas; ello nos indica que sus niveles de deuda o financiamiento, en consecuencia, son mayores. Cull et al. (2006), analizando una encuesta realizada por el banco mundial confirman que son las empresas grandes quienes generalmente tienen más acceso a crédito bancario, tanto local como extranjero, mientras que las pymes confían primordialmente en fondos internos y en utilidades.

En otro análisis, Beck et al. (2006), utilizando otra muestra de 10,000 empresas de 80 países tratan de identificar qué determina los obstáculos financieros de las empresas, encontrando que las empresas más antiguas, más grandes y de capital extranjero reportan menores obstáculos para el financiamiento. Dentro del análisis encontraron que las pequeñas empresas reportaron mayores obstáculos que las empresas medianas, además de que ambas reportaron tener más obstáculos que las grandes. Shen et al. (2009) señalan también que a pesar de la contribución a la economía, la dificultad de las pymes para obtener financiamiento externo es ampliamente conocida. En una encuesta realizada en China por el banco mundial, se muestra que la falta de financiamiento entre las pequeñas empresas empeora mientras la empresa es cada vez más pequeña. Así, los resultados arrojan que empresas con al menos 100 empleados financian $27 \%$ de su capital a través de préstamos bancarios, empresas con número de empleados entre 20 y 100 reflejan un $13 \%$ de créditos bancarios, en tanto que las compañías con menos de 20 empleados en promedio solo tienen el $2.3 \%$ de financiamiento a través de instituciones bancarias. 
Love y Mylenko (2003) combinan datos de la encuesta realizada por el banco mundial, así como de los registros de crédito público y privado con la finalidad de identificar si la utilización de un registro de crédito se asocia con menores dificultades de financiamiento. Encuentran que un registro privado se asocia con menores dificultades financieras mientras que un registro público de crédito parece no tener efecto alguno sobre dichas dificultades. Para ellos, la principal contribución de su estudio está en el uso de datos del nivel de empresa, contestando preguntas no realizadas anteriormente. Primero, se preguntan si la existencia de registros de crédito tienen efecto desproporcional en empresas de diferente tamaño; ello, argumentando que es posible que las pequeñas empresas se beneficien de la presencia de registros al ser más opacas y con asimetrías en la información. Encuentran que en aquellos países donde existen registros privados de crédito, las pymes tienen mayor proporción de financiamiento bancario.

Se ha comentado que las pymes requieren recursos para sobrevivir y crecer su operación, pero también hay autores que mencionan que muchos de los pequeños empresarios prefieren no obtener créditos que puedan poner en riesgo el control de su empresa, tal como lo comentan Berggren et al. (2000). Esta situación puede originar que se detenga el crecimiento a expensas de su generación interna de recursos, hasta el momento en que requiera de mayor apoyo para la administración de su negocio. Hashi y Toci (2010:54) mencionan que "comparadas con las empresas grandes, las pequeñas empresas confían más en recursos internos y menos en préstamos bancarios, son menos propensas a pedir un préstamo, son más propensas a que se les niegue crédito y encaran mayores dificultades en acceder a préstamos de corto y largo plazo". 
En general, podemos decir que el tamaño tiene repercusión en la obtención del crédito y, en consecuencia, en las condiciones del mismo, dado esto en el costo de interés pagado por el mismo; por ello, una vez expuesto lo relativo al tamaño de la empresa, y considerando sus implicaciones se establece la séptima hipótesis que se enuncia de la siguiente manera.

Hipótesis H7: El costo del crédito se ve afectado por el tamaño de la empresa, a menor tamaño de la misma el costo del crédito será más alto. 


\subsection{Garantía y el costo del crédito}

Una de las formas en que el costo de intereses puede ser disminuido es con el otorgamiento de una garantía o colateral, esta situación garantiza al acreedor de cierta forma la devolución del préstamo y da confianza respecto al deudor. Como se ha comentado, el costo de un crédito recae mayormente en los intereses, por lo cual al querer disminuir el costo del préstamo, el esfuerzo se enfoca principalmente en este concepto. Las empresas tiene que lidiar con esta dificultad para que puedan acceder al financiamiento, y además de poderlo hacer vía la relación de préstamo, al igual que con la opacidad, la garantía puede jugar un papel relevante en la búsqueda del crédito.

Para Scholtens (1999) cuando se otorga financiamiento y existe asimetría en la información esto lleva consigo tanto una transferencia de fondos como de control. Además menciona que el colateral o garantía (como podemos nombrar para efectos de este estudio indistintamente) reduce la tasa de interés y mitiga el riesgo, con dicho colateral el empresario provee, en cierta forma, de un pago anticipado al banco. Esta ventaja encontrada por Scholtens (1999) apoya la teoría de que la garantía tendrá un efecto positivo en la tasa de interés cargada por el banco.

Hay una nueva forma que pueda disminuir la tasa de interés de los créditos mediante el ofrecimiento de una garantía parcial sobre el monto del mismo (Honohan, 2010). Para él, algunos gobiernos han mostrado interés sobre este tema para promover el acceso de la pequeña empresa al financiamiento. Aunque la reciente aplicación de estas técnicas innovadoras, el beneficio social es difícil de estimar pues los objetivos han sido vagos. 
Menciona que prácticamente todos los bancos desarrollados tienen algún programa de garantías, así como de préstamos, cuyo objetivo de dichos programas es aumentar el crédito a pymes. Se resalta que dicho programa de garantía ayudará a resolver el problema de la información que tienen las pymes, esto pues la tasa de interés será más baja, en tanto hemos visto que la banca comercial para cubrir dicho riesgo realiza mayores cargos en el crédito y tasa de interés.

Mistrulli y Casolaro (2008) consideran que la distancia geográfica entre el banco y el deudor influyen en el porcentaje de la tasa de interés. Analizando información de más de 370 mil préstamos derivados de 120 instituciones financieras italianas encuentran que hay una correlación negativa entre la tasa de interés y la distancia entre el banco y el prestatario, y que las tasas de interés bajan si el préstamo cuenta con una garantía real. Además, si hay sucursales del banco que realiza el préstamo donde está localizado el prestatario entonces la tasa de interés tiende a bajar, ello presupone el poder tener un conocimiento mayor del cliente que ayude a mitigar el riesgo. Enfocándonos en el uso de la garantía, el comentario relevante dentro de este estudio es que sí notamos un efecto positivo en la tasa de interés.

Berger y Udell (1995) no encontraron una relación estadística entre la tasa de interés y la garantía establecida, sin embargo, tanto la tasa de interés como la garantía podrían disminuir ante una relación positiva de la empresa con el banco. Ellos establecen una premisa diferente a la que se desea establecer, considerando una relación adicional, aunque hemos visto que otros autores si han encontrado resultados que soportan la estimación que realizo en esta hipótesis. Las tasas de interés pueden aumentar o 
disminuir dependiendo de la competitividad de los bancos, o canales específicos a través de los cuales las reformas mejoren la habilidad del deudor para posicionar una garantía, comentan Jappelli et al. (2005).

Wang (2010:220) muestra en sus resultados que los empresarios "tienden a elegir una combinación de mayor garantía y menor tasa de interés". Comenta que bajo las circunstancias de una empresa de bajo riesgo con insuficiente capital, se ven obligados al otorgamiento de la garantía, aunque como se arroja su análisis, esto ayuda a reducir los costos del préstamo. Booth y Booth (2006) examinan la relación entre los costos del crédito y la garantía del mismo. La evidencia es consistente con la elección de las empresas en el otorgamiento de garantía para disminuir los costos derivados del préstamo bancario. Benmelech y Bergman (2009) analizan el efecto de la garantía sobre el costo de la deuda. Comentan que la teoría indica que la garantía incrementa la disponibilidad de crédito y reduce su precio mediante la disminución del riesgo de los deudores. Sus resultados sugieren la ventaja al tener una garantía que ofrecer, entre otras cosas, el disminuir el costo del financiamiento externo, apoyando la teoría a la que hacen referencia.

Estos autores apoyan nuestra idea, como se pretende realizar nuestra hipótesis, que la garantía tiene un efecto inverso en el costo del crédito, es decir, a mayor garantía el costo del interés puede bajar, con lo cual hay un beneficio a la empresa cuando puede otorgarla.

Cuando se tiene implícita la ausencia de una tasa de interés alta es derivado de que el propio banco considera que su exposición al riesgo es limitada derivada de su requerimiento de garantía (Black et al., 1996). 
Jiménez y Saurina (2004) parten del concepto del nivel de riesgo del deudor, así, los prestatarios de alto riesgo escogen altas tasas de interés sin otorgar una garantía, mientras que aquellos de bajo riesgo establecen una garantía y obtienen tasas de interés más bajas. Ello nos indica que la garantía tiene un peso en la tasa, independientemente que hablemos del nivel de riesgo del deudor. Consideran que bajo este concepto, la garantía podría ser referencia de deudores de calidad; aunque los bancos refieren la garantía con aquellos deudores riesgosos.

Brick y Palia (2007) encuentran en un estudio realizado que la garantía tiene un impacto económico estadístico significativo sobre las tasas de interés de los préstamos. Además, encuentran que el impacto económico del requerimiento de una garantía personal es mayor al de la garantía de la empresa, esto es, que tendría un mayor peso un activo del dueño que el del propio negocio. Para Chan y Kanatas (1985) la tasa de interés del préstamo dependerá, en parte, del valor de la garantía que la empresa ofrezca. Barro (1976) analiza el papel de la garantía en la determinación de las tasas de interés de mercado de préstamos. Para él, un análisis equilibrado del mercado de préstamos explicaría la cantidad de garantía que se requeriría conjuntamente con la tasa de interés y el importe de préstamo a obtener.

Hablando sobre el riesgo, Machauer y Weber (1998) analizan evidencia de la relación de los términos del préstamo con el riesgo del deudor. Encontraron que la tasa de interés del préstamo y las líneas de crédito están relacionadas con la calificación del crédito, mientras que la garantía no mostró una relación clara. Al analizar cambios en las tasas de interés, la garantía y la línea de crédito, estos no dieron alguna pista sobre los cambios en los términos del préstamo. Esto nos muestra un punto de 
vista diferente al relacionar la garantía y la tasa de interés, siendo que derivado de dicho estudio no hay una influencia clara entre estos dos conceptos.

Una figura importante que puede ayudar a las pymes en el otorgamiento de garantía cuando estas no la tienen, son las "Instituciones de garantía recíproca" (IGR), una sociedad que dará el aval mediante una fianza a las instituciones de crédito, y cuya relación de garantía será con la pyme, pero el banco teniendo este soporte puede facilitar el crédito. Columba et al (2010) mencionan las ventajas de este tipo de sociedades (IGR), y hacen un estudio para determinar cual es el efecto en la tasa de interés cobrada por los bancos, cuando las pymes se unen a este tipo de sociedades. Parten de la idea de que las IGR's son más capaces de monitorear y revisar las pymes opacas que los bancos. Ver la figura 3.10.

Figura 3.10.

Beneficio sobre la tasa de interés al pertenecer a una IGR

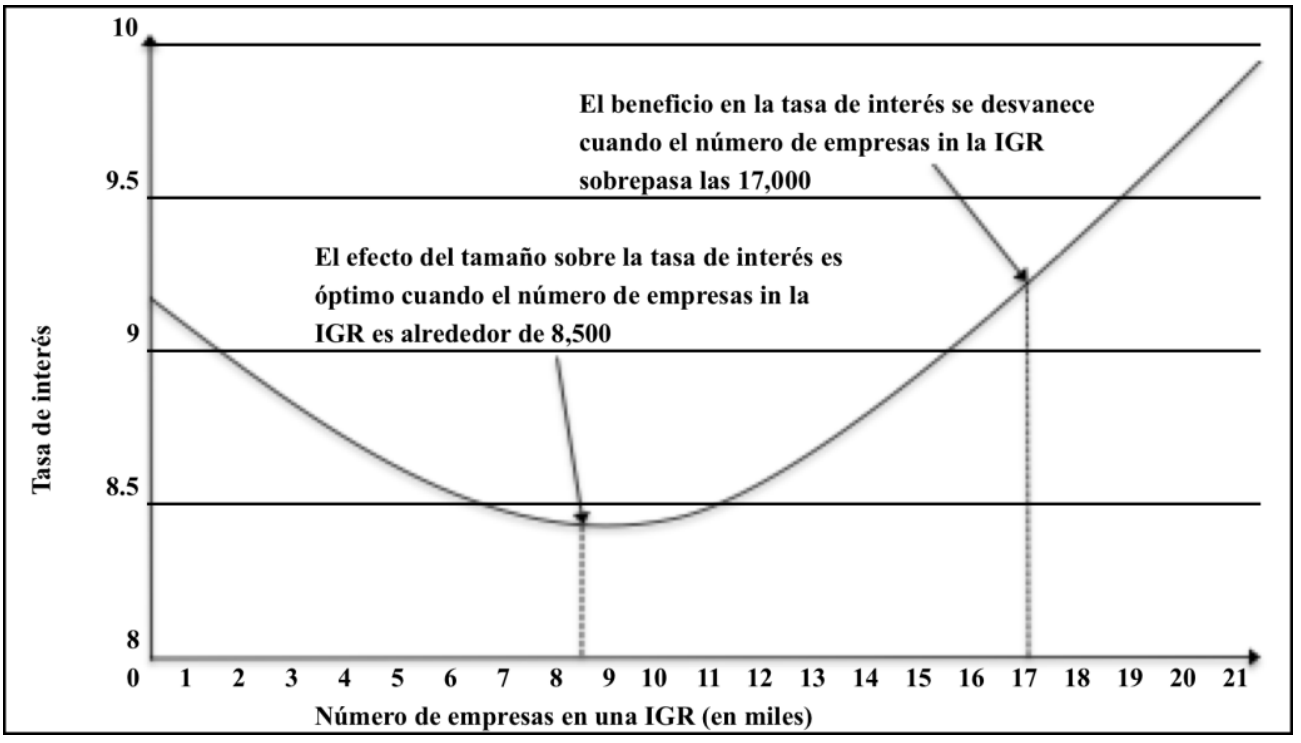

Fuente: Columba et al. (2010) 
Esta forma de garantizar el crédito, como muestra la figura 3.10., es una opción interesante con la finalidad de que al no tener garantía, pero esto sea requerida, se pueda ejercer la opción. Además de tener un beneficio adicional en el costo del crédito. Columba et al. (2010) encuentran que pymes afiliadas a una IGR tienen un interés menor que aquellas pymes similares no afiliadas. Aunque mencionan que cuando el número de empresas en una IGR llega a cierto nivel (como el mostrado en la figura) ya no se obtiene el mismo beneficio. Hay una debilidad en este tipo de instituciones cuando los fondos públicos disponibles para IGR aumentan, consiste que el efecto de riesgo moral compensa parte de los beneficios obtenidos con el monitoreo de pares.

Podemos apreciar que la garantía puede jugar un papel importante en la disminución del costo del crédito, el cual en su parte principal es representado por la tasa de interés, ello invita al análisis de esta idea con la finalidad de encontrar la alternativa que pueda ayudar a la empresa en tener una condición favorable respecto a la tasa que aplicará el banco, de aquí se deriva la octava hipótesis, que se plantea de la siguiente manera:

Hipótesis H8: El costo del crédito varía en función del nivel de la garantía otorgada por la empresa, así, las empresas obtienen un menor costo de crédito cuando otorgan una mayor garantía. 


\subsection{Costo del crédito}

El pago de intereses se vuelve una limitante fuerte para que las pymes obtengan y soporten un crédito. En ocasiones una tasa alta es la forma en que las instituciones financieras intentan mitigar su riesgo, pero si lo vemos de una manera más profunda está situación puede orillar que haga más crítica la devolución por parte del deudor, cuando empieza a tener problemas para enterar las amortizaciones y la tasa moratoria empieza a elevar de manera crítica el monto del préstamo.

En ocasiones, la tasa de interés no se muestra como tal, el deudor sabe cuántos pagos tendrá que realizar de acuerdo al pago contratado, y de preferencia querrá pagar un importe igual de capital más interés a lo largo del crédito, por lo cual el importe de interés estará inmerso en dicho pago, de esta manera no se puede apreciar que porcentaje de tasa se está pagando, siendo la necesidad del recurso una limitante para que el deudor pueda negociar una tasa que no esté en su contra.

Las tasas de interés varían de acuerdo al país, también influirá la moneda que se maneja, la posición cambiaría respecto a las monedas líderes y las políticas que rijan por parte del banco central del país correspondiente. Servirán como referencias estas variables, pero a final de cuentas es de donde la banca de crédito se basa para establecer sus propias tasas, determinando que rangos estará rigiendo de acuerdo al tipo de empresa que está solicitando el financiamiento, si es que califica de acuerdo al estudio que se realice, y entonces proceder a fijar la tasa. Ceccetti (1995) menciona que cuando la política establecida incrementa las tasas de interés puede causar una afectación en la empresa que limite su capacidad de crédito y de 
pago y, en consecuencia, de contratación de crédito. De acuerdo a una muestra de empresas en Francia, Savignac y Sevestre (2008) mencionan que las pequeñas empresas contratan a una mayor tasa de interés, lo que repercute en una menor demanda de créditos de este grupo de empresas.

Binks y Ennew (1997) utilizan una muestra de 6,000 pequeñas empresas de una encuesta privada de 1994 realizada en el Reino Unido. Analizando la información, encuentran que las principales barreras para el acceso del crédito se basan en dos conceptos, los cargos bancarios (costos o comisiones) y las tasas de interés. En 1998, el porcentaje que citaba a los cargos bancarios y la tasa de interés como las principales restricciones del crédito ascendían a $30.70 \%$ y $19.70 \%$, respectivamente, dos años después los porcentajes se invertían quedando en $26.60 \%$ y $37.20 \%$, respectivamente, pero permaneciendo como las principales restricciones citadas. Ello nos indica la posición que tiene la tasa de interés como obstáculo para obtención de financiamiento. "Las empresas podrían tener acceso a financiamiento externo, pero esto no significa que no paguen un riesgo asociado con la asimetría en la información" comentan Hashi y Toci (2010:51); hablando de la tasa de interés como un obstáculo, analizando el grado de cómo las empresas lo consideran como un obstáculo en la operación y crecimiento de sus negocios.

Dietrich (2010) elabora un modelo donde menciona los diferentes factores del costo que influyen sobre la tasa del crédito. Considera que el tamaño del crédito va en función del tamaño de la empresa; menciona que los costos de financiamiento del banco no van en función del tamaño de la empresa; además considera que los costos por rechazo de la solicitud debieran adicionarse; en cuanto a la utilidad del banco señala que esta es 
menor frente a empresas grandes, por que las pequeñas no tienen habilidades de negociación; además los costos del crédito son porcentualmente mayores para créditos pequeños respecto a grandes, por que algunos costos son fijos. En cuanto a los costos de riesgo, mencionan que no son tanto por el tamaño de empresa, pero, normalmente son mayores en las pymes por que los bancos no son capaces de asignar un riesgo correcto en este tipo de empresas, las pymes no cuentan con un historial de información adecuado como las grandes. El modelo se presenta en la figura 3.11 .

Derivado de este modelo Dietrich (2010), establece varias hipótesis, entre las que se encuentran: hay una correlación negativa entre el tamaño del crédito y la tasa de interés; entre más pequeño el crédito mayor los costos del mismo. Aspecto interesante de nuestro estudio, es la relación entre el crédito y la tasa, aunque nosotros nos basaremos entre el costo mismo del crédito y la tasa del crédito.

Figura 3.11.

Tasa de interés en función del volumen del crédito y tamaño de la empresa.

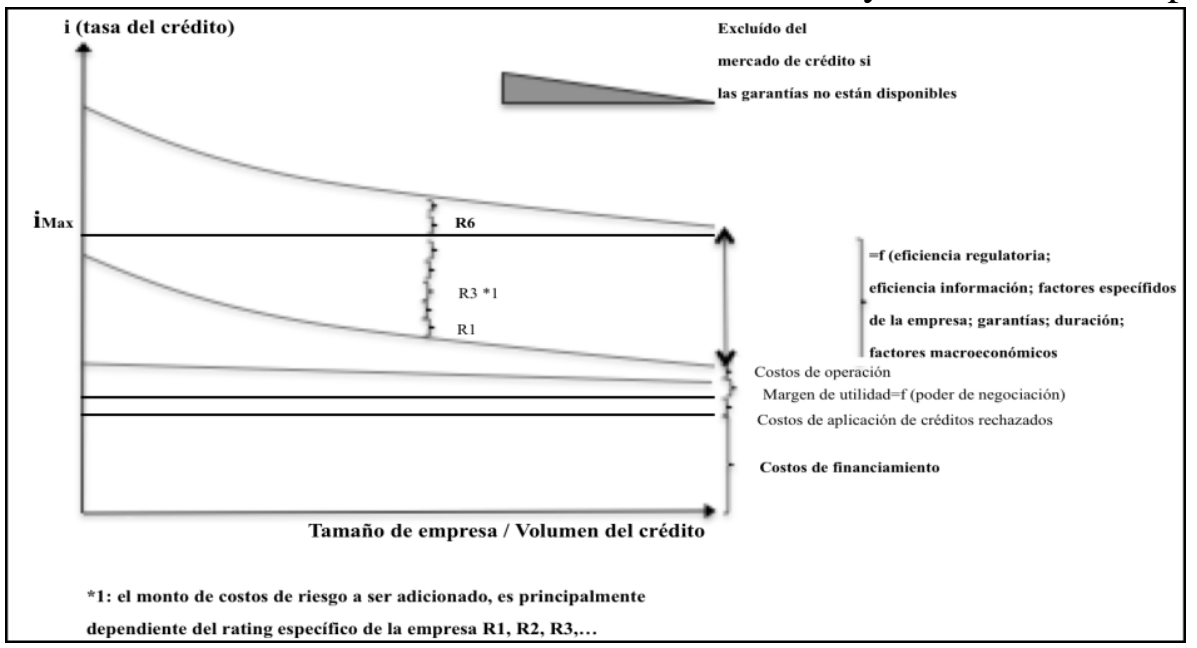

Fuente: Dietrich (2010) 
Para Ayyagari et al. (2008:27) "el encontrar que las altas tasas de interés restringe el crecimiento de la empresa no sorprende desde que el obstáculo del alta tasa de interés captura el costo del financiamiento y es en si misma una variable endógena que depende de la habilidad del sistema financiero para satisfacer la demanda de capital", de hecho consideran que puede esperarse que sea una restricción para todas las empresas en todos los países. Petersen y Rajan (1995) consideran que los acreedores en mercados concentrados tienen una mayor seguridad en cuanto a los flujos futuros de la empresa por el conocimiento de la misma, tomando en cuenta que los bancos consideran recuperar su inversión inicial vía altas tasas de interés, ello orilla a que este tipo de empresas traten de usar menos financiamiento.

Howorth y Moro (2010) analizan una muestra de empresas en Italia, de la cual estudian la relación existente entre la integridad y la tasa de interés. Así, si hay menor confianza en el deudor esto origina una menor demanda de financiamiento de las pymes y un comportamiento que recaiga en menor confianza. El estudio intenta encontrar si la percepción de los banqueros sobre la integridad de los dueños de las pymes se asocia con la tasa de interés cobrada. Utilizan en su modelo como variable dependiente la tasa de interés, reflejada en el interés pagado por la pyme al banco. Como variable independiente maneja la confianza, la integridad del dueño será considerada con su habilidad, benevolencia y honradez. Entre más altos niveles de confianza se espera que los costos de crédito (intereses principalmente) sean menores pues se entenderá un riesgo menor así como costos de monitoreo más bajos. En sus conclusiones mencionan que donde las empresas fueron altamente supervisadas la relación con el banco fue caracterizada por falta de confianza en ambos lados y los dueños se sintieron menos obligados para con los bancos. 
Utilizando una muestra en particular de empresas españolas por el período de 1997-2004 López-Gracia y Mestré-Barberá (2011) tratan de analizar la relación positiva entre la tasa de interés la volatilidad de la misma a corto plazo así como con la estructura de deuda. Consideran que las empresas cuentan con una deuda alta cuando las tasas de interés van hacia arriba. Antoniou et al., (2006) analizan empresas de Francia, Alemania y Reino Unido sobre el vencimiento de su deuda. En referencia a las tasas de interés y su volatilidad, encuentran efectos positivos la estructura temporal de dichas tasas en Alemania y el Reino Unido, en Francia los efectos de la estructura de vencimiento de la deuda es negativo. En el Reino Unido, por ejemplo, consideran que el efecto no es significativo derivado de la baja tasa de interés en los últimos años. El entorno económico tiene influencia en el mercado de crédito, indudablemente, aunque partimos de la idea en que la necesidad del crédito marca la pauta de la búsqueda de recursos, y la tasa de interés será el que determine si es viable o no para la empresa de acuerdo a su proyecto el contratar el recurso.

Mistrulli y Casolaro (2008) analizando información de más de 370 mil préstamos derivados de 120 instituciones financieras italianas encuentran que la tasa de interés disminuye con el tamaño del préstamo. Haciendo referencia a los obstáculos que mencionan las instituciones financieras para realizar préstamos a las pymes, Stephanou y Rodriguez (2008) mencionan sobre la tasa de interés que el "techo" o límite máximo es una fuente de incertidumbre tanto en el aspecto legal como regulatoria. Dicho techo se aplica a todos los préstamos realizados por las instituciones financieras, el estudio se basa en bancos de Colombia. Ello, consideran, pareciera restringir el crédito para las pymes con mayor riesgo, con lo cual 
la tasa de interés se convierte en un obstáculo para acceder al financiamiento.

Analizando el concepto de "prestatario desalentado", Kon y Storey (2003), comentan que dicho término se refiere a una buena empresa que prefiere no solicitar crédito alguno pues considera por anticipado que el banco rechazará su solicitud. En su trabajo muestran que dicho desaliento depende del error de detección de los bancos respecto a las empresas, la escala de costos que se aplican y el grado en el cual la tasa de interés bancaria difiere de aquella establecida por los prestamistas. En ocasiones, el acreedor ofrece también algún programa de cobertura para asegurar al deudor que la tasa de interés no sobrepasará un cierto límite. Cuando el financiamiento externo es más caro que el interno, es que las empresas consideran la cobertura (Froot et al., 1993). Resumen que la óptima cobertura para una empresa dependerá de la naturaleza de su competencia en el mercado que se desenvuelve y en las estrategias de cobertura aplicada por su competencia.

A través de este análisis encontramos que el costo de interés puede representar una carga muy fuerte para la empresa cuando obtiene financiamiento, ello puede dificultar o complicar el trámite del crédito, o las condiciones en que operará la compañía al afectar en demasía sus resultados o rentabilidad, en consecuencia, para las pymes puede representar una tasa muy alta, de aquí se deriva la novena hipótesis.

Hipótesis H9: El costo del crédito pagado por la empresa se traduce en una de tasa de interés alta cuando dicho costo financiero representa un porcentaje importante de sus ingresos y utilidades. 


\subsection{Facilidad en la obtención del crédito}

La obtención de crédito, como se ha comentado, es parte importante en el crecimiento, la tasa de interés es parte importante para saber la disponibilidad o aceptación del mismo, de aquí que se estudie la relación entre ambas variables para conocer su impacto.

Considerando el efecto que tiene la relación con el banco sobre tasas de interés y garantía solicitadas a pymes, Hernández-Cánovas y MartínezSolano (2006) encuentran que las pymes que trabajan con menos bancos obtienen deuda a menor costo. Esto sugeriría, a opinión de ellos, que el concentrar las relaciones bancarias reducen la incertidumbre de prestar a empresas riesgosas, y esto se traduce en menores tasas de interés. ¿Cómo se reduce el riesgo?, bueno, algunas de las cuestiones que argumentan son el resultado de mayor flexibilidad en la negociación, mayor control sobre la inversión, entre otros.

"Múltiples relaciones de préstamos pueden ayudar a resolver el problema de cautividad y disminuir el promedio del costo de la deuda", comentan D'auria et al. (1999:1073), estas son unas de las varias razones por las que las empresas y los bancos encuentras conveniente prolongar un sistema de múltiples relaciones de préstamo, aseveran. $\mathrm{Su}$ análisis de regresión muestra que si el banco cuenta con una proporción de deuda mayor respecto al total de la empresa hay una asociación con menores tasas de interés. Para Foglia et al. (1998:1444) “un monopolio en la relación de préstamo expone a la empresa al riesgo de que el banco pueda explotar su posición para incrementar las tasas de interés”. Las relaciones nacen entre el banco y la empresa por que en el proceso de préstamo el banco aprende 
sobre sus clientes, comenta Sharpe (1990:1069), "la información asimétrica permite a los bancos capturar algo de las rentas generadas por sus clientes antiguos; la competencia guía a los bancos a prestar a las nuevas empresas a tasas de interés que inicialmente generan pérdidas esperadas”. Esto conlleva a que el capital sea dirigido a empresas mas inexpertas.

Angelini et al. (1998:949) analizan una muestra de empresas italianas para verificar el costo y disposición del crédito. Como comentan "una primera serie de resultados muestran el impacto de la duración de la relación con el banco sobre el costo del crédito". Su muestra indica que las relaciones de préstamo de largo plazo se asocian con tasas de interés por arriba del promedio en cuestión de créditos con bancos que no son cooperativas a sus clientes o bancos cooperativas a clientes que no son miembros. Berger y Udell (1995) encuentran que los deudores con relación de préstamo más largas pagan menores tasas de interés, afirmando que esta situación es consistente con los argumentos teóricos de que la relación de préstamos genera información valiosa sobre la calidad del prestatario.

Blackwell y Winters (1997:288) soportan en su estudio que las relaciones de préstamo son valiosas. "Mostramos que las empresas con mayor concentración de préstamo en un banco determinado pagan menores tasas de interés, además mostramos que las empresas con relaciones mas largas son monitoreadas con menor frecuencia por los bancos y que esas empresas monitoreadas menos frecuentemente pagan menores tasas de interés en promedio". Berlin y Mester (1998) hablan de que las relaciones continuas se asocian con menores tasas de préstamo, consideran que los bancos aplican menores tasas de interés en préstamos con clientes de alto riesgo como parte de contratos implícitos de largo plazo. 
Comentando como podría influir la relación de préstamo en una menor tasa de interés para la empresa, Behr et al. (2011) hacen referencia a la intensidad de esas relaciones. Para ellos la intensidad de la relación no tiene efecto sobre la tasa de interés, de acuerdo a sus resultados. Elsas y Krahnen (1998:1287) hablan de que "la relación de préstamo es un tipo de información intensiva de financiamiento la cual puede afectar los costos de crédito en una forma predecible".

Petersen y Rajan (1994:14) en su estudio de "los beneficios de las relaciones de préstamo" estiman que las relaciones de préstamos disminuyen el costo de los créditos de las pymes. "Estimamos el efecto de la relación en la tasa de interés cargada". Comentando a su vez que las empresas que han hecho negocios por un corto período de tiempo con el banco debieran pagar una tasa de interés mayor, lo cual afecta a las empresa más jóvenes. Sus resultados, en particular, indican que el efecto es mínimo de las relaciones sobre la base de interés cargada. Sin importar la duración de la misma o la intensidad de servicios financieros proporcionados la diferencia en la tasa de interés no es significativamente menor.

Berlin y Mester (1998) analizan los costos de la relación de préstamo. Consideran que suavizar la tasa de préstamo en respuesta a una sacudida de la tasa de interés es parte de una óptima relación de largo plazo entre el banco y su deudor. Brick y Palia (2007:472) mencionan que los investigadores, con resultados mixtos, han probado la hipótesis de que la duración de una relación de préstamo reduce significativamente la tasa de interés cargada en los préstamos. Ellos encuentran que "la duración de la relación impacta sobre el nivel de la tasas de interés del préstamo". Evidencia encontrada indica que las relaciones tienen valor, incrementan la 
disponibilidad de crédito y reducen las tasas de interés (Elyasiani y Goldberg, 2004).

También Bodenhorn (2003) en tests empíricos proveen información sobre la hipótesis de que las relaciones de largo plazo entre bancos y prestatarios son valiosas. Esta evidencia indica que las pequeñas empresas encuentran ventajas de tener relaciones extensas y largas con los bancos, además de que los préstamos sobre largos períodos produce menores costos de interés. En una muestra de préstamos de bancos a pequeñas empresas, Blackwell y Winters (1997) observan una relación inversa entre la estrechez de las relaciones bancarias y las tasas de interés, concluyen que las relaciones pueden ser valiosas por que las empresas pueden reducir significativamente los costos del crédito, mediante el establecimiento y el mantenimiento de relaciones cercanas con el banco.

Analizando el costo de financiamiento externo, Harhoff y Körting (1998:1348) encuentran que "hay una esperada dependencia de las tasas de interés sobre el tamaño y la edad de la empresa, pero no sobre la duración de la relación de préstamo". Por otro lado, encuentran que habiendo una confianza mutua entre el banco y la empresa (percibida así por los empresarios) parece tener un efecto fuerte en beneficio de las tasas de interés. Degryse y Van Cayseele (2000) analizando información de casi 18 mil préstamos bancarios a pymes belgas encuentran dos efectos contrarios. Por una parte, las tasas del préstamo aumentan con la duración de la relación de préstamo, y por otra parte, el ámbito de una relación, que definen como la compra de otros productos de información sensible del banco, disminuye la tasa de interés del préstamo sustancialmente. 
Utilizando una encuesta realizada a poco más de 4,000 empresas en 54 países Beck et al. (2005) tratan de identificar los obstáculos que la empresa puede tener que afecten su rendimiento y crecimiento, dentro de la encuesta se encuentran empresas pequeñas, medianas y grandes. Dentro de sus hallazgos se encuentra el que las empresas consideran el obstáculo de financiamiento como el principal obstáculo para crecer, haciendo notar que son menores en países desarrollados respecto a países en vías de desarrollo. Uno de dichos obstáculos son las altas tasa de interés. Además señalan que en promedio, las pequeñas empresas reportaron mayores obstáculos para la obtención de dicho financiamiento.

En base a lo analizado en el apartado de esta hipótesis, vemos que el obtener el crédito está muy relacionado con el concepto de la tasa de interés que se fijará en el mismo, antes ya habíamos hablado de las variables que repercuten en "la obtención de crédito" como variable endógena, ahora analizaremos la influencia que esta variable tiene sobre la tasa de interés; de ahí que se defina la décima y última hipótesis de este modelo de la siguiente manera:

Hipótesis H10: La facilidad de obtener crédito incide en la tasa de interés cobrada por la institución financiera, así, las empresas con menor posibilidad de crédito contratarán con una tasa más alta.

A lo largo de este capitulo se han establecido las hipótesis emanadas de nuestro modelo teórico, aquellas que intentaremos probar una vez realizado nuestro análisis empírico. Se ha establecido la incidencia que tienen conceptos como la opacidad, la relación de préstamo, la garantía, la 
antigüedad de la empresa en la obtención del crédito. Las características de dichas variables y como repercuten en una pyme para acceder al mismo.

Se ha comentado sobre el costo del crédito, y como es influenciado por determinados factores como la información financiera, la garantía y el tamaño de la empresa. Nuestras hipótesis están formuladas considerando la facilidad que tienen las empresas para obtener el crédito cuando reúnen alguna característica de dichas variables.

Además se ha fijado la tasa de interés en dos hipótesis, considerando el efecto del costo del crédito y la obtención del crédito en la misma. Algo que no ha sido tan explorado en la literatura actual. Y que tratamos de confirmar mediante el estudio de dichas hipótesis. El modelo teórico señalando las hipótesis formuladas queda de la siguiente manera: 
Figura 3.12.

Hipótesis en modelo teórico

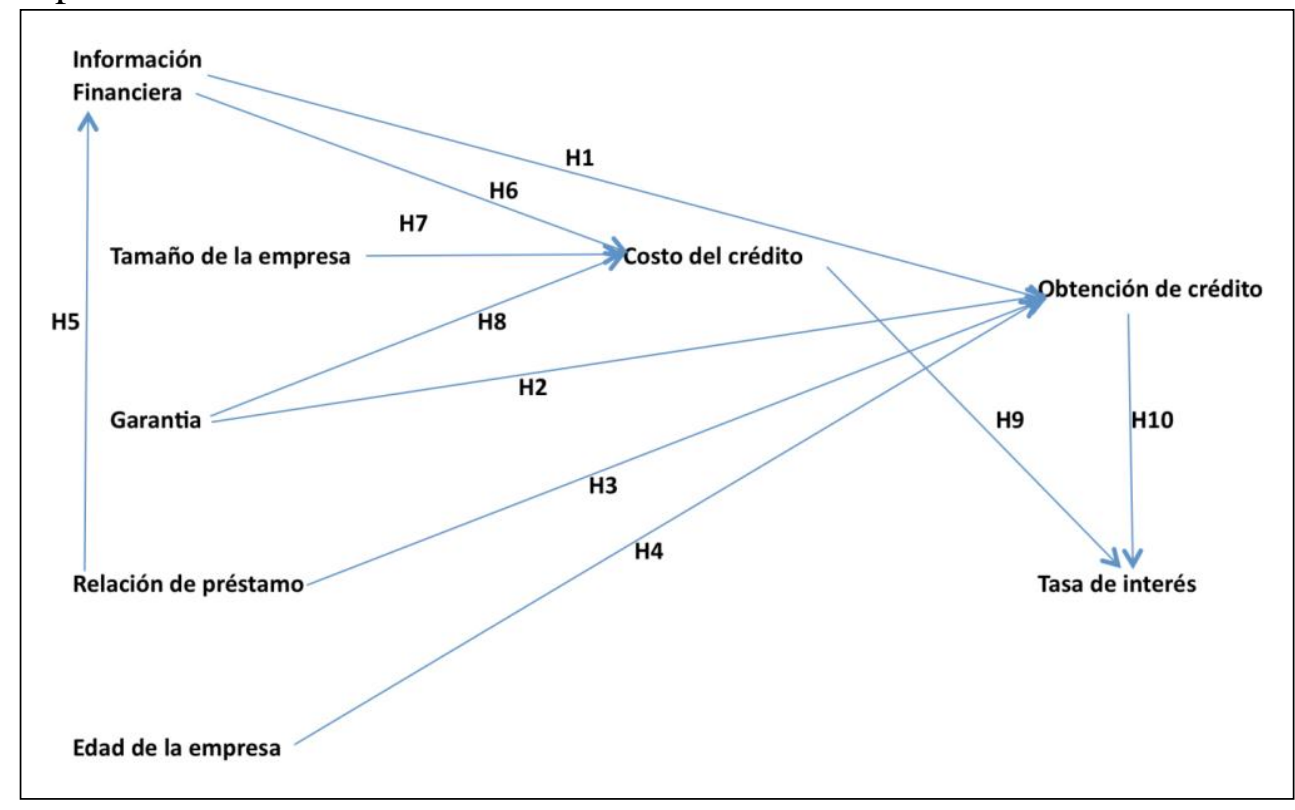

El siguiente capítulo definirá la metodología a seguir para la realización del estudio empírico, a fin de contrastar estas hipótesis con los resultados obtenidos. 


\section{Metodología}


"No duermas para descansar, duerme para soñar. Porque los sueños están para cumplirse" Walt Disney 


\subsection{Introducción}

De acuerdo a lo que se ha visto sobre las teorías de financiamiento y las hipótesis establecidas, y las afectaciones que pueden llegar a tener las pymes para la obtención del crédito, se puede continuar con el desarrollo de la metodología a seguir para evaluar los planteamientos realizados sobre los diferentes obstáculos y herramientas que pueden encontrar las empresas en su tramitación de financiamiento.

La forma del diseño de la investigación hace posible la obtención de información empírica para la validación del modelo. Por lo cual se describirá la fuente de información, las escalas utilizadas, técnicas de análisis y los pasos del trabajo empírico. Hablaremos sobre las variables que estudiaremos mediante la aplicación de un cuestionario.

Además se comentará el modelo de cuestionario que se utilizo, los indicadores que se consideraron dentro del mismo, las partes en las que se dividió el cuestionario, la población a la que fue dirigido así como la determinación de la muestra, el método que se siguió para obtener respuesta de las empresas y el período durante el cual se desarrollo esta actividad.

Se comentará la ficha técnica del cuestionario, las características de la muestra, además se darán a conocer algunos datos que se obtuvieron de las respuestas dadas por los encuestados, indicadores que nos darán una idea sobre la aspectos específicos de la población muestreada. 


\subsection{Análisis documental}

El análisis documental se realizará principalmente de Journals científicos internacionales, haciendo énfasis en los de mayor impacto.

Entre las principales fuentes bibliográficas que serán utilizadas en el desarrollo de la tesis se cuenta de Journals especializados como: Journal of Banking and Finance, Journal of Finance, Journal of Finacial Economics, Journal of Small Business Economics

\subsection{Variables utilizadas}

Estas se definen como aquellos obstáculos que encuentras las pymes para la obtención de financiamiento, para ello se han establecido ciertos indicadores realizando una investigación sobre los ítems que autores han preguntado en estudios anteriores. Las variables se presentan más adelante detallando un autor que haya utilizando los indicadores considerados anteriormente.

Algunos indicadores adicionales se presentan antes de los grupos de preguntas relativas a las variables principales motivos del estudio a fin de tener características específicas de la muestra. Lehmann et al. (2004), al analizar la información de empresas alemanas relativas al grupo que denominan variables de control, incluyen datos como el tipo de banco, el uso del crédito y el tipo de industria de la empresa solicitante. Beck et al. (2005) analizan información obtenida de 54 países de la Encuesta mundial de medio ambiente de negocios conducida por el Banco Mundial, en las cuales preguntan sobre los siguientes conceptos: requerimiento de garantía, 
burocracia y papeleo solicitado por bancos, altas tasas de interés, necesidad de contactos especiales con bancos, las cuales puedan ser consideradas como dificultades financieras para crecer.

Una de las preguntas específicas refiere a que tan problemático es el financiamiento para la operación y crecimiento, no solo esto sino también los conceptos anunciado si representan un obstáculo, en qué proporción para la continuidad de la operación. Después hacen referencia a los distintos tipos de financiamiento si es difícil acceder a ellos o no, o en qué medida, si la falta de información o cuando esta es inadecuada si afecta a la compañía.

\subsection{Características del cuestionario}

El cuestionario se dividió en 7 partes. La primera parte se preguntaron datos generales como: nombre de la empresa, domicilio y nombre del entrevistado, esto para soportar la información obtenida además de identificar el sector específico del área industrial manufacturera al que pertenece la empresa encuestada.

La segunda parte que se tituló "Información General" se utilizó para obtener información sobre las primeras variables, el número de empleados para conocer e identificar el tamaño de la empresa, así como la antigüedad de la misma en número de años para determinar que tan joven o madura es la compañía. Aquí también se establecieron algunas preguntas sobre las que gira el modelo, preguntas sobre la obtención del crédito, como que tipo de institución financiera es con la que se relaciona, duración del crédito, el uso del mismo. 
Se anexaron algunas preguntas cuantitativas, que fue de la parte que limitó en mayor medida la participación del empresario por lo antes expuesto, pero que varias de ellas cooperaron con la información, tales como: ventas, utilidad de operación y activos totales.

La tercera parte se establecieron 7 ítems para conocer específicamente la información sobre la variable independientes que se desea estudiar, si había tramitado un crédito, si se lo autorizaron o rechazaron, si nunca ha solicitado; 5 de las preguntas eran en escala 5 likert mientras 2 preguntas eran abiertas.

La cuarta parte hace referencia a la "Información", esto para conocer lo referente al constructor de información financiera, para ello se ocuparon 8 preguntas en escala 5 likert, lo cual de la idea sobre la generación de información.

La quinta parte se enfoca en la "Tasa de interés", 2 preguntas sobre el nivel y el tipo de tasa, además de 5 preguntas en escala 5 likert para conocer el impacto que tiene sobre el crédito este costo en las empresas.

La sexta parte del cuestionario habla sobre la "Relación de préstamo", un total de 17 preguntas buscando entender cuál es la relación entre el banco y la empresa, así como su utilidad para el tema de créditos, la mayoría en escala 5 likert, 12 de ellas, mientras que las otras se desea conocer la antigüedad de la relación, el número de relaciones, los servicios utilizados en dicha relación, entre otros. 
La última parte se establece para conocer lo relativo a la "Garantía", los bienes que la compañía otorga para dar seguridad a la institución financiera sobre la liquidación del crédito, un total de 14 ítems, de los cuales 13 de ellos son en escala 5 likert.

En total, este cuestionario se conformó por un total de 70 indicadores, de los cuales 46 correspondían a una escala 5 likert.

Como se estableció anteriormente en la descripción de cada uno de los indicadores incluidos, así como autores que han tomado dichos ítems para análisis anteriores, algunos de estos ítems son recogidos de encuestas internacionales como: del Banco Mundial la encuesta mundial del medio ambiente de negocios (The World Business Environment Survey), la encuesta financiera de las pequeñas empresas aplicada por la reserva federal de los Estados Unidos de Norteamérica (Survey of Small Business Finances), encuesta de negocios del Banco Mundial, entre otras encuestas elaboradas por autores en el área específica de los constructos establecidos en el modelo.

Dentro de los aspectos generales que se le preguntan al encuestado vienen las preguntas que nos indicarán la medida de dos constructos, el tamaño y la antigüedad de la empresa.

\subsubsection{Tamaño de la Empresa}

Esta se medirá de acuerdo al número de empleados, en México, de acuerdo a la Secretaría de Economía, la clasificación por sector y tamaño en 
publicación del 30 de diciembre de 2002 en el Diario Oficial de la Federación queda de la siguiente manera:

Tabla 4.1.

Clasificación de tamaño de empresa

\begin{tabular}{|l|l|}
\hline \multicolumn{1}{|c|}{ Tamaño } & Industria \\
\hline Micro & $0-10$ \\
\hline Pequeña & $11-50$ \\
\hline Mediana & $51-250$ \\
\hline Grande & Mayor a 250 \\
\hline
\end{tabular}

Fuente: Diario Oficial de la Federación (2002)

Con esta clasificación agruparemos los resultados de las encuestas para poder ubicar a las pymes, objetivo de esta tesis.

A nivel mundial, se ha comentado, las pymes representan una gran mayoría en cada país. Nuestro estudio se centra en el sector industrial manufacturero, Ayyagari et al. (2007) hacen un estudio de la proporción de pymes del sector manufacturero en varios países, consideran para este estudio a una pyme que cuente hasta con 250 trabajadores, al igual que la clasificación que hemos considerado para nuestro estudio en México. En la siguiente figura se muestran algunos de los países considerados, incluyendo por supuesto a México.

Analizando la figura 4.1., considerando precisamente el sector industrial manufacturero, vemos que la proporción de México en este número de pymes es importante. Un poco debajo de la proporción de Brasil, Japón e Italia. Pero nos muestra la importancia de las pymes en este sector, 
era interesante mostrar esta gráfica para comentar la importancia de nuestro estudio, al analizar la forma de financiamiento de las mismas, de acuerdo a lo que analizaremos en nuestros resultados.

Figura 4.1.

Participación de pymes en el sector industrial manufacturero

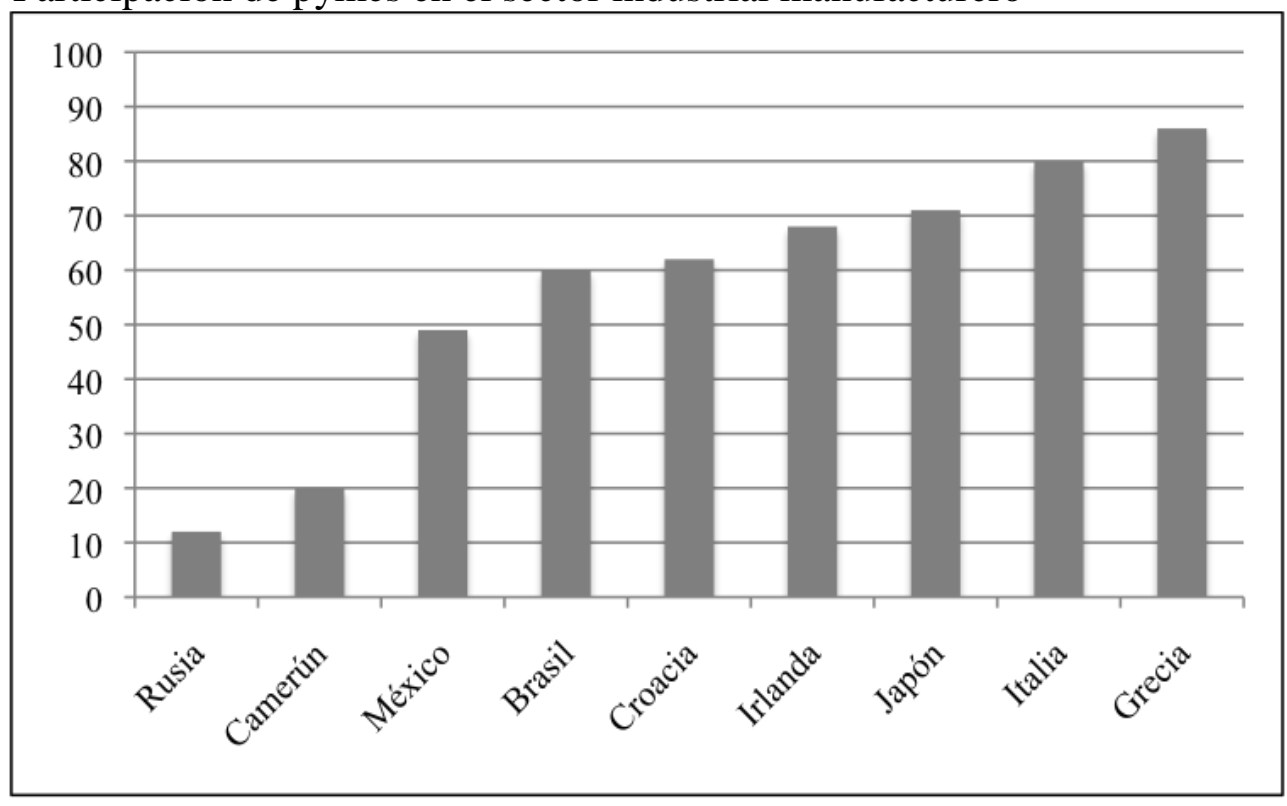

Fuente: Ayyagari et al. (2007)

\subsubsection{Edad de la Empresa}

Se utiliza dentro del cuestionario un indicador directo para que la empresa señale cuantos años tiene desde su creación, es decir, su antigüedad. Vickery (2008), utilizando información de la encuesta de la pequeña empresa y finanzas llevada a cabo por el comité de la reserva federal, señala en su hipótesis varias de las limitantes de las empresas para obtener crédito, como tamaño, edad y relaciones de préstamo. Una de las 
preguntas hace referencia a la antigüedad. Berger y Udell (1995) analizan información de la encuesta nacional de la pequeña empresa, en la cual se pide también reflejar los años de experiencia, que traducimos a la antigüedad de la empresa.

En nuestro modelo hemos establecido la relación entre la edad de la empresa y la facilidad para obtener crédito. Aunque otras variables dentro del modelo hacen mención del costo del crédito. Aunque no tratamos de forma directa una relación entre la edad y el costo, indudablemente las pymes, como se ha comentado en las hipótesis pueden tener un costo significativo. De acuerdo a un estudio realizado por Sakai et al. (2010) encuentran que la edad influye en el costo. Como se muestra en la figura 4.2.

Figura 4.2.

Perfil de edad de los costos de endeudamiento

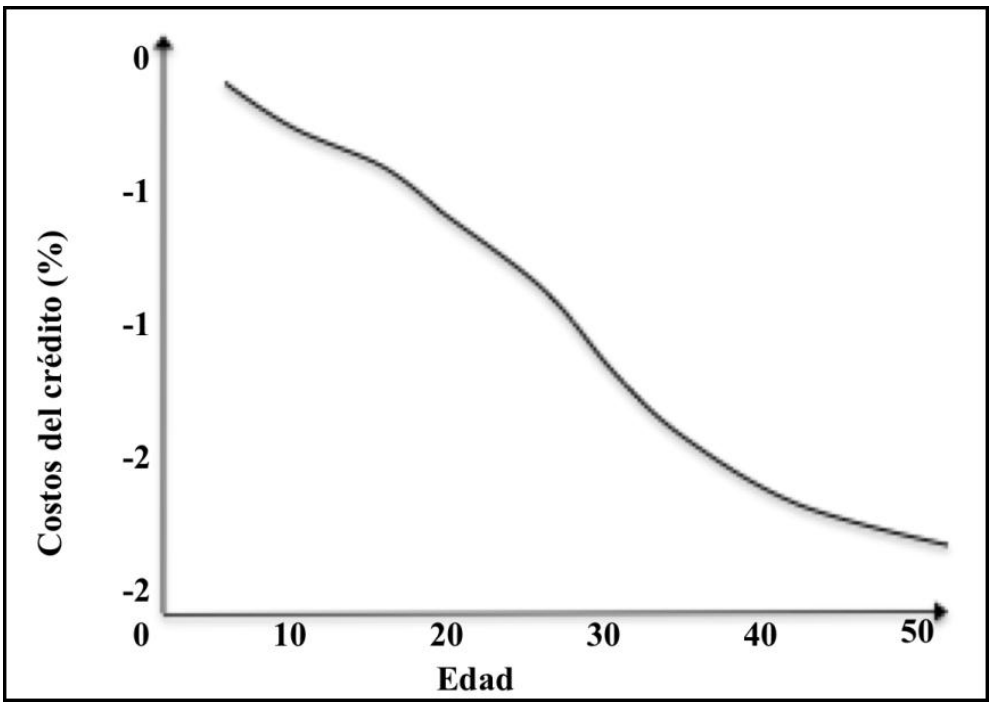

Fuente: Sakai et al. (2010) 
En la figura anterior, mostrando la edad de la empresa de 0 a 50 años, consideran que la diferencia representa alrededor de una base de 180 puntos. Ellos comentan que entre más antigua sea la empresa, el costo irá disminuyendo. La ventaja puede residir en que, muchas de las carencias que tienen una empresa nueva, la antigüedad las va cubriendo; el historial de crédito, los sistemas de información, la habilidad para la negociación, en algunos casos el tamaño de la misma. Esto hace que pueda llegar a obtener mejores condiciones de los bancos, considerando que le será otorgado el crédito correspondiente.

\subsubsection{Información}

Este constructo nos indica si la empresa obtiene $\mathrm{u}$ otorga información financiera con motivo de su operación, algunos de los indicadores que se establecen en el cuestionario para medir esta variable son: si cuenta con un contador, si puede proporcionar una proyección financiera, si ha sido investigado en el buró de crédito. La idea es determinar si la empresa es opaca o tiene asimetría en la información; específicamente, los indicadores utilizados en la encuesta se describen, así como las fuentes utilizadas para ello.

Miembro de cámara

Haciendo referencia como capital social a los contactos que se pueden tener en el medio empresarial o las diferentes relaciones, Ferrari (2003:673) hace referencia a que "el banco cuando realiza un préstamo, confía en que el deudor devolverá el crédito con los respectivo costos que se 
acuerden”, menciona que para eliminar la asimetría en la información, algunos bancos pueden establecer redes sociales para crear lazos de confianza, pues si no hubiera información formal o blanda, estas se podrían basar en aquellas redes que puedan dar confianza al banco. Una forma de hacerse llegar de esta información es de las organizaciones o cámaras a las que pueda estar adherida la empresa, de ahí que se pregunte si está inscrito en alguna cámara empresarial.

\section{Contador contratado}

Collis y Jarvis (2002) analizan si la empresa cuenta con un contador propio o algún contralor que se encargue de obtener la información, derivando en la importancia que pone la empresa en este tema. De ahí que se incluya en el cuestionario el conocer si es factible para las pymes encuestadas el contar con una persona que obtenga la información financieras así como la elaboración de estados y reportes relativos. Realiza la encuesta en empresas del Reino Unido. Además se busca el identificar el nivel de conocimiento contable de la empresa de acuerdo al sistema de información implementado. Por ello, se trata de identificar si establecer un sistema es factible en estas empresas. Dentro de las preguntas de la encuesta fueron referidas para identificar las fuentes de información y el uso de la misma.

Auditor certificado

Van Campenhout y Van Caneghem (2009) analizando empresas belgas quieren probar la hipótesis si hay una relación entre estados financieros dictaminados por auditor externo y el endeudamiento, para lo 
cual investigan si la información de la empresa está dictaminada y ello deriva en información de calidad y confiable. Una situación importante en la evaluación de la información financiera cuando la analizan los bancos es si los estados financieros se encuentran revisados por un auditor externo, la seguridad de una opinión de un externo especialista calificado da un voto de confianza a los resultados presentados por la compañía, de ahí que se trate de conocer si la información de las empresas está dictaminada. Pittman y Fortin (2004), hacen un análisis sobre la elección del auditor y el costo de la deuda para nuevas empresas públicas, la evidencia sugiere que utilizando una de las 6 principales firmas de auditores (4 en la actualidad), se pueden reducir los costos de monitoreo de deuda al aumentar la credibilidad en la información financiera lo que ayuda a reducir los costos de préstamos en las empresas jóvenes.

Proyección financiera

Fazzari y Athey (1987) analizan el comentario de que un flujo de efectivo y otras variables financieras no tienen lugar en la inversión, pero las empresas requieren de este tipo de estados para permitir a los comités de crédito la evaluación de sus proyectos, por ello se considera en el cuestionario si a falta de información, una proyección estimada de lo que tendrá la empresa como consecuencia de la obtención de recursos puede disminuir la opacidad o la asimetría de la información de la compañía.

Facilidad del trámite

Ayyagari et al. (2008) analizando la encuesta global del banco mundial sobre el ambiente de negocios, preguntan a los empresarios si el 
crecimiento de su empresa se ve limitado o hay obstáculos financieros dados por: garantía requerida por los bancos, el papeleo y burocracia de los mismos, altas tasas de interés. De ahí que se considere verificar que tan complicado o sencillo le resulte al empresario toda la tramitación de un crédito.

Percepción del negocio

Hogan y Hutson (2005) analizan la estructura de capital de empresas irlandesas, utilizando encuestas para la obtención de la información, en un espacio dedicado a la percepción de los bancos y de inversionistas, preguntan si el banco entiende el negocio, es decir, si el conocimiento de la institución financiera es suficiente para que pueda con mayor base tomar la decisión de financiar o no el proyecto de la empresa.

Conocimiento del cliente

Berger y Udell (2002) analizan información basada en la encuesta nacional de pymes y finanzas, con la cual identificando la fuente de financiamiento, establecen que el no contar con información de la empresa dificulta el acceder a créditos con terceros, con lo cual se prefiere el uso de recursos internos. Pero cultivando una relación los resultados de su análisis muestran que tan efectiva puede ser la información suave generada con esta relación. Este análisis respecto a la información "suave" que puede darse con el conocimiento entre el banco y la empresa por la relación misma pudiera subsanar la información cuantitativa requerida, de ahí que se incluya esta pregunta para saber la percepción sobre el conocimiento de la empresa. 
Buró de crédito

Lehmann et al. (2004), comentan sobre la teoría de la intermediación financiera que los bancos se especializan en la producción de información y diseño de los contratos de préstamo para resolver problemas de racionamiento de crédito a pymes que tienen problemas de asimetría en la información. Además señalan que los bancos reúnen información sobre los deudores y miden su riesgo mediante niveles de riesgo interno o calificaciones de los deudores. Una forma de investigar sobre sus antecedentes es un reporte del buró de crédito, lo cual genera información sobre su comportamiento crediticio.

\subsubsection{Tasa de Interés}

Se ha comentado del costo de financiamiento y como el interés resulta ser el más representativo. Para ello se pregunta directamente la tasa que le cobran, si es que tiene o ha tenido crédito al empresa encuestada, algunos otros indicadores son: si considera la tasa de interés alta, si los intereses representan un porcentaje significativo de sus ventas y utilidad de operación. A continuación se expresan los distintos indicadores que se preguntaron, citando algún autor que los haya manejado o comentado en su estudio correspondiente.

Nivel de tasa de interés

Vickery (2008) utilizando información de la encuesta de la pequeña empresa y finanzas llevada a cabo por el comité de la reserva federal, 
encuentra varios puntos respecto a los créditos obtenidos, como duración del mismo y la tasa de interés cobrada. Muchos autores hacen referencia o preguntan la tasa de interés del crédito, por supuesto es parte de las preguntas incluidas en este cuestionario. En su hipótesis señala varias de las limitantes de las empresas para obtener crédito, como tamaño, edad y relaciones de préstamo.

Binks y Ennew (1997) analizan información de empresas del Reino Unido, en el cual una de las consideraciones es la dificultad que presupone la tasa de interés para la obtención del crédito, obteniendo el resultado de que el mayor porcentaje de los encuestados lo considera el mayor obstáculo; cabe mencionar también que la garantía es uno de los principales factores señalados en esta encuesta. Esto apoya la hipótesis de que es un obstáculo, aun cuando no se establece al pregunta como tal.

Tasa alta de interés

Hashi y Toci (2010) utilizan la encuesta de ambiente de negocios y desempeño de empresas conducidas por el banco mundial (BEEPS) para analizar algunas cuestiones de los créditos, tales como: altas tasas de interés, requerimiento de garantía, si las empresas usan reglas estándar de contabilidad para la información. Considerando que la tasa de interés es de los principales costos de un préstamos, establecemos en el cuestionario un apartado para conocer la opinión de las pymes respecto a este tema o también saber si no es relevante, independientemente del costo, con tal de obtener recursos. Partiendo de que las empresas pudieran tener acceso al crédito, esto no significaría que no están pagando algo adicional, vía la tasa de interés, asociado a la falta de información y otras diferencias en el 
crédito. Además evalúan como puede afectar el crecimiento de la empresa con estos niveles altos de interés aunado al tamaño y edad de las pymes. Una pregunta específica es si consideran que la tasa de interés es tan alta que prefieren no tramitar ningún crédito.

Importe interés respecto a ingresos y utilidades

Dhanani et al. (2007) se enfocan en la administración del riesgo que supone la tasa de interés, esto particularmente en empresas del Reino Unido. Realizando una encuesta tratan de identificar las diferentes razones por las cuales se realizaría esta actividad; siendo que una parte importante de la hipótesis es la influencia de la tasa de interés en la obtención del crédito, parece pertinente el conocer si influye la decisión de la empresa sobre el monto de la tasa la manera en que se manifiesta ante el nivel de la misma. Entre muchas razones, alrededor de 20 situaciones encuestadas, las que parecen más adecuadas para este cuestionario son las que se refieren a la disminución del riesgo de crédito, una tasa baja de repago de la deuda, un alto nivel de préstamo, entre otras, eligiendo el nivel de préstamo. Además, determina que importancia tiene el pago de interés respecto a la utilidad de operación, la utilidad antes de impuestos y depreciación, que impacto tiene en los resultados del negocio. Considerando estas variables se evalúa si el monto solicitado influiría en el nivel de la tasa de interés.

Tasa fija de interés

Hablar sobre la variabilidad de la tasa es un tema importante, pues esto puede incidir en el costo del financiamiento. Scott (1997) analiza la variabilidad de las tasas de interés en precio de opciones, examina el efecto 
de la volatilidad y como afecta la rentabilidad, esto asimilándolo a las cuestiones de los créditos nos indica el efecto que puede tener al contratar el crédito.

Usando aproximadamente 18,000 observaciones en bancos de la zona euro por el período 2001 - 2008, Delis y Kouretas (2011:840), presentan una "fuerte evidencia empírica de que las tasas bajas de interés incrementan sustancialmente la toma de riesgo del banco". Utilizando varias tasas de interés, tasas de corto plazo, tasas de largo plazo, la tasa del banco central y tasa de crédito bancario. Como se muestra en la figura 4.3., esta reporta la regresión no paramétrica entre el riesgo tomado por el banco, medido por la razón de los activos de riesgo entre el total de activos, y el nivel de tasa de préstamo del banco, medida por la razón de ingresos por intereses entre el total de préstamos. La gráfica superior considera valores de la tasa de interés de hasta 0.25 , además de utilizar prácticamente todas las observaciones; y, la gráfica de abajo valores de hasta 0.15 , utilizando solo valores de las variables comentadas.

La regresión lineal refleja una relación negativa entre los activos de riesgo y la tasa de interés. Haciendo referencia a la crisis de 2008, comentan que la función efectiva del sistema bancario, no es solo tema de liberalización e integración, sino que también requiere una evaluación integral del riesgo bancario. Este análisis nos muestra el enfoque de las tasas de interés desde el punto de vista bancario. 
Figura 4.3.

Nivel de tasas de interés bancarias y riesgo tomado.
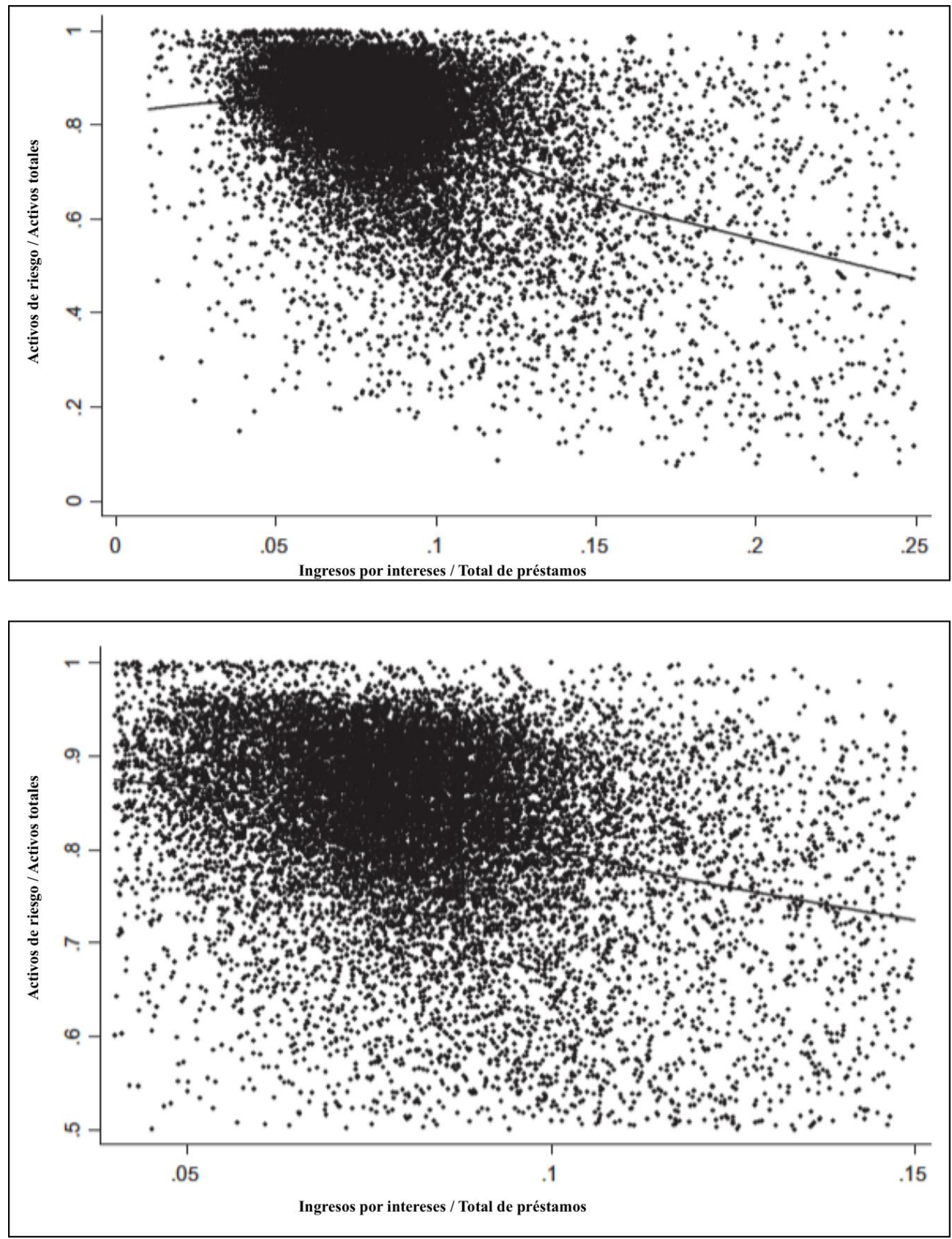

Fuente: Delis y Kouretas (2011) 


\subsubsection{Relación de Préstamo}

Hay 2 variables presentadas en el modelo que pueden atenuar el efecto de 2 variables exógenas con la variable endógena. La relación de préstamo y la garantía, partiendo de la idea de que la empresa al contar con alguno de estos constructos o los 2 para la obtención del crédito pudiera ayudarlo para suavizar o cubrir las variables de la "información financiera" y la "tasa de interés".

La relación de préstamo se medirá con algunos indicadores establecidos en el cuestionario como son: años de relación con su banco principal, confianza entre la empresa y el banco, número de reuniones con el banco, cantidad de servicios que ocupa la empresa. Con estos indicadores queremos encontrar si las empresas cultivan esta relación de préstamo, o si no cuentan con ello, tratando de identificar las razones.

Brick y Palia (2007), usando la encuesta nacional de finanzas de empresas coordinada por el comité del sistema de la reserva federal y administración de pequeñas empresas, encuentran que la duración de la relación de préstamos impacta tanto en la garantía a otorgar como el nivel de la tasa de interés. Machauer y Weber (1998) analizan preguntas como si el banco se siente como el banco de casa para la empresa, número de bancos con los cuales la empresa ha solicitado préstamo, y la duración en años de la relación bancaria. Analizando información de empresas alemanas Harhoff y Körting (1998) encuentran analizando información de cartas de crédito, que el costo de la tasa de interés depende más del tamaño y la edad de la empresa, más que la relación de préstamo. 
Duración de la relación de préstamo

Kano et al. (2006) analizan para determinar la fortaleza de una relación de préstamo el usar variables como la duración de la relación, el número de servicios usados del banco por la pyme y el número de bancos que prestan. Blackwell y Winters (1997) analizan una muestra de préstamos bancarios, relacionando también la relación de préstamo con la tasa de interés, preguntan los años que la empresa ha sido cliente del banco, así como los años de experiencia en el negocio, en particular encuentran que si la relación es más concentrada, es decir, con menores bancos o uno solo, la tasa tiende a ser menor. Una de sus hipótesis parte de los beneficios que una relación de préstamo puede general al no contar con información financiera auditada, con lo cual el análisis de las variables expuestas les puede ayudar a validar. Con la Encuesta del medio ambiente financiero realizada por la agencia Pyme se obtiene la relación mediante la pregunta de los años que lleva de relación la empresa con el banco, que servicios ha recibido del banco; además derivada de la relación analizan las variables de tasa de interés y garantía para verificar si hay un efecto positivo con la relación establecida.

Interés por relacionarse

Binks y Ennew (1997) al estudiar las relaciones bancarias de empresas inglesas, tratan de identificar 3 situaciones en las encuestas analizadas, que la empresa considera importante el proporcionar información al ejecutivo del banco en forma regular, que la empresa o dueño prefiere evitar el contacto con el banco, y si es importante discutir los 
excesos de crédito con el ejecutivo. De ahí que se busque el saber si a la empresa le guste relacionarse.

Degryse y Ongena (2005) estudian los efectos de las condiciones del préstamo de acuerdo a las condiciones de distancia entre la empresa, su banco y los bancos competidores, consideran que las tasas del préstamo pudieran variar de acuerdo a estas condiciones; la distancia pudiera influir en las veces que el empresario o gerente se reúne con el banco, de aquí se parte para conocer que tanta participación hay entre ellos.

Contacto especial

Ayyagari et al. (2008) en la encuesta mundial del ambiente de negocios del banco mundial analizada preguntan a los empresarios si el crecimiento de su empresa se ve limitado o hay obstáculos financieros dados por: necesidad de contactos especiales en bancos, acceso a créditos a largo plazo. En particular se extrae de este análisis el saber respecto a si se necesita algún conocido o contacto en el banco, pues se estima que en ocasiones el empresario cree que solo de esta forma se puede obtener financiamiento.

Acercamiento del banco

Howorth y Moro (2010) utilizando una encuesta de administradores de bancos que prestan en Italia, manejan algunas cuestiones para establecer la relación con sus deudores como frecuencia de reuniones por año, de revisiones por año, número de bancos con los que se relaciona, cuantos ejecutivos del banco son con los que tiene trato, así como algunas variables 
para determinar la confianza que se le tiene a la empresa por parte del banco. Una de ellas que se considera es saber si la gente del banco se acerca al empresario para conocerlo, sus necesidades, como es atendido.

Servicios bancarios

Degryse y Van Cayseele (2000) analizan el efecto de las relaciones de préstamo en la tasa de interés y la garantía, encontrando que entre más larga la relación más cara la tasa de interés, aunque analizando también el alcance o ámbito de dicha relación encuentras que la tasa disminuye cuando la empresa ocupa otros productos o servicios del banco y realiza la mayoría de sus pagos también a través de dicha institución.

Banco principal

Lehmann et al. (2004), al analizar la información de empresas alemanas; relativas a las variables que determinan respectos a las características de la relación, se enfocan en la duración de la relación y lo llamado "banco de casa", se toma esta última pero en sentido contrario, ya que se preguntó al gerente bancario, en este caso se preguntará al encuestado si el banco se considera el banco de casa de la empresa encuestada.

Confianza en la relación

Binks y Ennew (1997) establecen parámetros respecto a que si existe confianza entre la empresa y el banco a través de una escala likert con definiciones como: si el banco siempre está dispuesto a ayudar en tiempos 
de crisis, si se acerca de manera positiva para hacer sugerencias en el negocio, si el empresario tiene confianza de esos consejos, además de confiar en el ejecutivo respecto al entendimiento de sus necesidades financieras. Harhoff y Körting (1998) también evalúan la confianza entre el banco y la empresa, preguntando al encuestado si considera que la confianza entre su empresa y la institución financiera principal es mucha. Por ello se trata de establecer que tipo de confianza existe con el banco y el cliente, redactándola negativa para no inducir la respuesta.

Cantidad de relaciones

Angelini et al. (1998) preguntan a sus encuestados si una vez que ya obtienen crédito, desean tramitar préstamo adicional, si lo tramitarían aunque hubiera cambios a la alza tanto de la tasa de interés como de la garantía o si estas permanecieran igual o bajaran, de ahí que pueda establecerse si las pymes desearían obtener crédito sin importar cual sea el costo. D' Auria et al. (1999) utilizando información del banco central de Italia y de los bancos más grandes, analizan el efecto de las relaciones en la tasa de interés, considerando que varias relaciones disminuirán este problema, pero la alta concentración en uno con lo cual no hay competencia elevaría las tasas, con lo cual se busca conocer si las múltiples relaciones tienen un efecto positivo en la tasa. Ello indica nuevamente el revisar si hay un solo banco para la empresa o si se relaciona con varios que puedan competir para otorgar el crédito. Berger y Udell (1995) analizando información de la encuesta nacional de la pequeña empresa, encuentran que las pymes con relaciones de préstamo más largas cuentan con tasas de interés más bajas en sus créditos. 
Berger et al. (2001) prueban la relación con varios bancos preguntando si se tienen préstamos con más de un banco. Se toma esta pregunta en el cuestionario, además de verificar si la empresa que tuviera solo un banco, pudiera acceder a relacionarse con más aunque por el momento no haya explorado esa posibilidad.

Asignado un ejecutivo

Harhoff y Körting (1998) dentro de su modelo y análisis empírico usan la duración de la relación como un indicador de la calidad de la relación. Aunque la relación se cultiva a través del tiempo también es importante saber si esta se desarrolla con un ejecutivo o algunos ejecutivos en particular de la institución financiera, pues de otra manera se puede diluir la relación o no fortalecerse.

Relación fuerte

Behr et al. (2011) realizando un análisis de aplicaciones de préstamos de empresas de Mozambique investigan el efecto de la fortaleza o intensidad de las relaciones tiene un efecto sobre algunas variables del crédito, entre ellas la tasa de interés; aunque este se da de acuerdo a sus resultados hasta el tercer o cuarto préstamo encuentran una influencia positiva en la tasa. Además señala el efecto de que empresas que son opacas se benefician de la intensidad de estas relaciones. Cole (1998) analiza el efecto de las relaciones para obtener crédito, encontrando que más que la duración de la misma es más relevante que exista una relación antes del crédito con el banco. 
Experiencia con bancos

Pissarides (1999) utiliza la encuesta del Banco europeo para la reconstrucción y el desarrollo llamada Encuesta del ambiente de negocios y desempeño de las empresa, algunas preguntas evaluadas se refieren a: si la tasa de interés o el requerimiento de garantía han sufrido modificaciones en los últimos créditos contratados (esta evaluación se toma para saber si aquellas empresas que ya han contratado más de un crédito han tenido alguna mejora en las condiciones de tasa), cuales son los servicios que recibe de su banco o cuentas que tiene aperturadas en el mismo. En síntesis, se plantea si la experiencia con los bancos puede influir en el nivel de tasa.

Experiencias negativas

Lehmann y Neuberger (2001) analizan información de empresas alemanas, el cuestionario ocupa una escala likert de 5 puntos, en las cuales tratan de identificar los aspectos favorables o desfavorables de una relación de préstamo, indicadores como experiencias pasadas, disponibilidad para informar sobre problemas o estabilidad de la relación, son algunos de los conceptos considerados. Incluyo la pregunta sobre el conocer si hay experiencias negativas de la pyme, considerando que esto pueda limitar el interés de contar con una relación de préstamo e indirectamente la falta de crédito.

Operaciones con banco principal

Elyasiani y Goldberg (2004) analizan el efecto de las relaciones desde diferentes ángulos, uno de ellos sobre la disponibilidad de crédito, 
tasas y requerimiento de garantía, además de el impacto de la duración de la relación, múltiples relaciones y la distancia geográfica del deudor con el banco, sugieren que los bancos pequeños enfatizan este tipo de técnicas de préstamo. Ferri y Messori (2000) analizando información de empresas en Italia, encuentran que el norte del país con mayor antigüedad de industrialización tiene a los bancos más grandes al igual que empresas grandes, por otro lado, relaciones de préstamo más cercanas y de mayor duración prevalecen en el sur donde hay bancos y empresas más pequeños; aunque esto también al no contar con la oferta o competencia de bancos que se da en el norte puede ser una desventaja.

Obligación de informar

Parte de la situación que envuelve a la relación de préstamo es la confianza, y a su vez la obligación de informar acerca de cualquier situación que afecte a la empresa, Lehmann y Neuberger (2001:346) a fin de poder capturar los aspectos sociales de la relación, siguen algunas direcciones en su cuestionario: "experiencias positivas en el pasado, obligación con el socio, voluntad del prestatario de informar acerca de problemas y la estabilidad de la relación"; la voluntad del deudor de proporcionar información fue medida en una escala de 5 puntos, y poder comparar a una empresa si es mejor o peor que el promedio de las demás empresas.

Reunión para revisar la situación

La interacción entre el banco y la empresa puede ser una forma de fortalecer la relación, la buena comunicación y el conocimiento entre ambos provoca una relación más duradera y profunda, en comentario de Steijvers y 
Voordeckers (2009), la exclusividad o el enfoque de la relación puede ser también considerada como la fortaleza de la relación. Un banco puede ser considerado el principal si la empresa usa varios productos financieros de este, y mayormente se comunica con este banco. Esta interacción e intercambio de información reduce los problemas de asimetría y el riesgo.

Relación por los últimos 5 años

Ongena y Smith (2002) analizando lo relativo a la duración de las relaciones bancarias, comentan dentro de sus conclusiones que las empresas son más propensas a terminar la relación con un banco cuando la relación ya ha madurado o es larga, lo que sugiere que con el paso del tiempo la calidad de la misma puede ir disminuyendo. Comentan además de que aunque las empresas con múltiples relaciones bancarias terminan estas frecuentemente, lo hacen terminando relaciones nuevas y manteniendo las más antiguas. Además que las empresas al crecer tienden a cambiar de bancos pequeños a bancos grandes. Para entender el cambio que puedan hacer las empresas se adiciona la pregunta relativa a si la empresa ha cambiado de banco principal en los últimos años.

Intentamos establecer la importancia de las relaciones entre la empresa y la institución financiera, y las ventajas de cultivarla. Han et al. (2009) distinguen lo que sucede cuando el banco trata con buenos y malos deudores; además de la duración de la relación y la concentración del mercado. En la figura 4.4., se muestra esta relación. 
Figura 4.4.

Probabilidad estimada de ser desanimado: deudores de riesgo promedio.

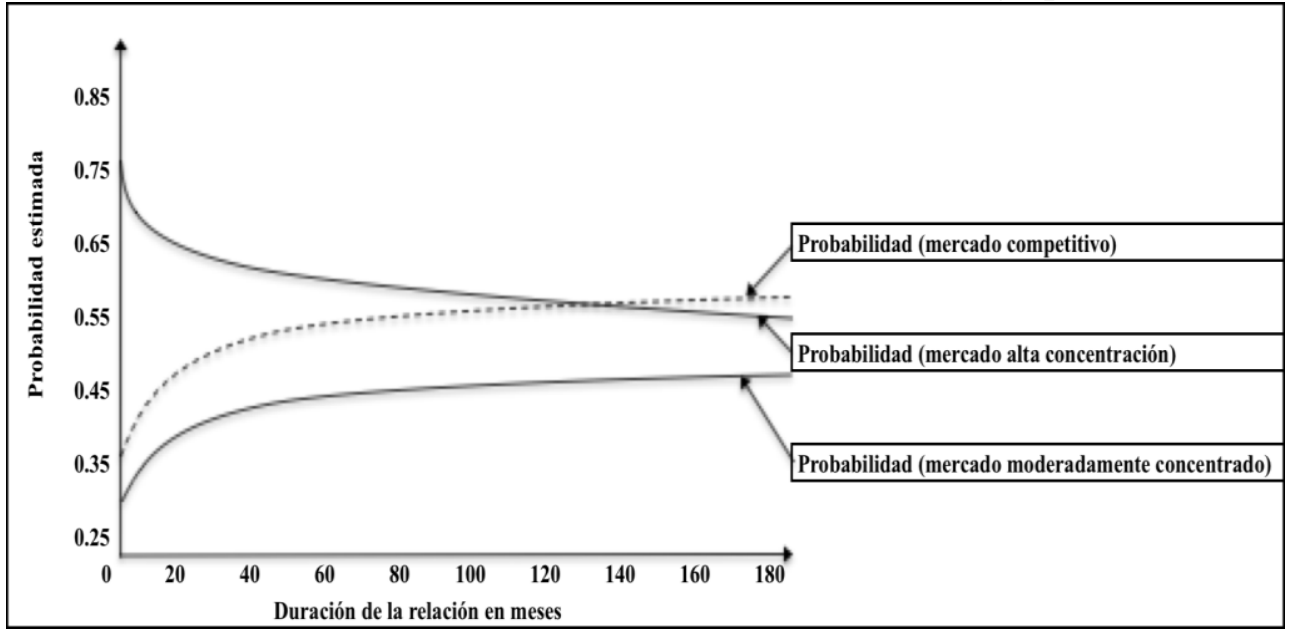

Fuente: Han et al. (2009)

Esta figura nos muestra que la posibilidad de ser desalentado por el banco entre deudores de riesgo promedio varia conforme a la duración de la relación. En un mercado competitivo, la relación de préstamo reduce la posibilidad de desaliento, pero esta se incrementa en un mercado concentrado. Esto sugiere que los bancos en un mercado competitivo no invierten lo suficiente en relaciones para ser capaces de distinguir a las empresas deudoras promedio de las que son mejores, hablando del compromiso de pago. No obstante, los bancos en mercados concentrados tiene gran incentivo de invertir en las relaciones, de tal manera que aquellas empresas con mal historial tendrán más posibilidad de que se les rechace su solicitud de crédito.

La relación de préstamo, siendo una de las técnicas más aplicadas y estudiadas en la literatura, cuenta con varias ventajas para que la pyme pueda tener acceso al crédito. Indicadores que mencionan tanto la duración de la relación, como la concentración de la misma, ya sea individual o 
múltiple. Además, como señala nuestro modelo, puede tener un efecto en la información financiera. Algunos autores han estudiado el efecto sobre algunos obstáculos de las empresas para financiamiento vía deuda. En la tabla 4.2., se ejemplifican los resultados empíricos de algunos autores.

Tabla 4.2.

Evidencia empírica sobre relación de préstamo

\begin{tabular}{|c|c|c|c|c|}
\hline Autores & $\begin{array}{c}\text { Indicador de la } \\
\text { relación }\end{array}$ & $\frac{\text { Resultados }}{\text { Disponibilidad }}$ & $\begin{array}{l}\text { Tasa de } \\
\text { interés }\end{array}$ & Garantía \\
\hline $\begin{array}{l}\text { Angelini et al. } \\
(1998)\end{array}$ & Duración & Aumenta & Aumenta & \\
\hline $\begin{array}{lll}\text { Berger y } & \text { Udell } \\
(1995) & \end{array}$ & Duración & & Disminuye & Disminuye \\
\hline Cole (1998) & $\begin{array}{l}\text { Duración } \\
\text { Concentración }\end{array}$ & $\begin{array}{l}\text { Aumenta } \\
\text { Aumenta }\end{array}$ & & \\
\hline $\begin{array}{lll}\text { Degryse y Van } \\
\text { Cayseele } & \\
(2005) & \\
\end{array}$ & Duración & & Aumenta & Disminuye \\
\hline $\begin{array}{l}\text { Elsas y Krahnen } \\
\text { (1998) }\end{array}$ & Duración & & Sin efecto & \\
\hline $\begin{array}{l}\text { Harhoff y Körting } \\
\text { (1998) }\end{array}$ & $\begin{array}{l}\text { Duración } \\
\text { Concentración }\end{array}$ & $\begin{array}{l}\text { Sin efecto } \\
\text { Aumenta }\end{array}$ & $\begin{array}{l}\text { Sin efecto } \\
\text { Sin efecto }\end{array}$ & $\begin{array}{l}\text { Disminuye } \\
\text { Disminuye }\end{array}$ \\
\hline $\begin{array}{l}\text { Lehmann } \quad y \\
\text { Neuberger } \\
(2001)\end{array}$ & $\begin{array}{l}\text { Duración } \\
\text { Confianza }\end{array}$ & $\begin{array}{l}\text { Aumenta } \\
\text { Aumenta }\end{array}$ & $\begin{array}{l}\text { Sin efecto } \\
\text { Disminuye }\end{array}$ & $\begin{array}{l}\text { Disminuye } \\
\text { Sin efecto }\end{array}$ \\
\hline $\begin{array}{l}\text { Machauer y Weber } \\
\text { (1998) }\end{array}$ & $\begin{array}{l}\text { Duración } \\
\text { Concentración }\end{array}$ & $\begin{array}{l}\text { Sin efecto } \\
\text { Aumenta }\end{array}$ & $\begin{array}{l}\text { Sin efecto } \\
\text { Sin efecto }\end{array}$ & $\begin{array}{l}\text { Sin efecto } \\
\text { Aumenta }\end{array}$ \\
\hline $\begin{array}{l}\text { Petersen y Rajan } \\
\text { (1994) }\end{array}$ & $\begin{array}{l}\text { Duración } \\
\text { Concentración }\end{array}$ & $\begin{array}{l}\text { Aumenta } \\
\text { Aumenta }\end{array}$ & & \\
\hline
\end{tabular}

Podemos apreciar que en cuanto a disposición del crédito, generalmente los resultados han mostrado que aumenta al tener una relación 
de préstamo de cierto tiempo con los bancos; por otro lado, es heterogéneo el impacto sobre la tasa de interés; $y$, en cuanto a la garantía, por lo general esta tiende a disminuir. Nuestros resultados arrojarán el efecto sobre la facilidad del crédito, como puede mostrarse en la disponibilidad de esta tabla; además de el efecto sobre la opacidad de la empresa, la información con que cuenta la misma.

\subsubsection{Garantía}

El uso de una garantía u otorgamiento de colateral es requerido por muchas instituciones financieras, tal como se ha comentado, en ocasiones, el que la empresa la otorgue consideramos que puede beneficiar en el trámite del financiamiento. Para ello también se establecen algunos otros indicadores, tales como: proporción de garantía otorgada respecto al crédito, facilidad que se tiene para otorgarla, si es indispensable para la tramitación, riesgo que acarrea su otorgamiento.

Hashi y Toci (2010) encuestan sobre el obstáculo que representa la garantía en la obtención del crédito, preguntando hasta que medida representa un mayor obstáculo o no obstaculiza realmente. Coco (2000) analiza como la garantía podría servir de incentivo en proyectos cuando existe asimetría en la información.

Berger y Udell (1995) dentro del análisis de la información de la encuesta nacional de la pequeña empresa, encuentran que las empresas jóvenes al tener relaciones bancarias relativamente nuevas, estarían dispuestas a ofrecer una garantía para cubrir asimetrías en la información. 
Chan y Kanatas (1985) comentan en su análisis que cuando se da la asimetría en la información la garantía tiende a aumentar, y de hecho, los deudores como muestra de su confianza como acreditados aumentan la garantía. Jiménez y Saurina (2004) utilizando datos de la Central de información de riesgos de España, encontrando, entre otras cosas, que si no se conoce la calidad de la empresa se procede a solicitar una garantía, esto nos comenta sobre la opacidad de la misma.

Japelli et al. (2005) hace mención que las tasas de interés pueden incrementar o disminuir dependiendo de algunos factores, haciendo referencia a la garantía de la manera en que las reformas judiciales mejoren la habilidad del prestatario para otorgarla, para ello ocupa información del centro de registro de créditos de Italia.

Porcentaje de garantía

Kang y Heshmati (2008) evalúan algunas características referentes a la garantía, entre ellas el monto que se garantiza, la proporción de la garantía. Es importante saber si el banco se conforma con una garantía de 1 a 1 al valor del préstamo o requiere un valor mayor al del crédito, de ahí el análisis que se puede obtener al conocer esta proporción. Pissarides (1999) utiliza la encuesta del Banco europeo para la reconstrucción y el desarrollo llamada Encuesta del ambiente de negocios y desempeño de las empresas, una de las cuestiones es referida a cual es el aforo o valor de la garantía respecto al crédito solicitado o contratado. 
Tipo de garantía

Binks y Ennew (1997) analizan información de empresas del Reino Unido, dentro de las respuestas buscadas preguntan que tipo de garantía es requerida por el banco, pues esta puede ser de la empresa, personal o ambas. Es interesante saber con qué garantizan las pymes y se incluyen ambas preguntas en el cuestionario como lo analizan estos autores. También Hulburt y Scherr (2003) analizan respuestas de pequeñas empresas, en las cuales preguntan si la deuda se aseguró con activos de la empresa o con bienes personales. Wang (2010) hace mención en su estudio que si no existiera asimetría en la información, la garantía debiera ser cero, aunque eso con los créditos analizados de distintos lugares es más factible el requerimiento de la misma. Voordeckers y Steijvers (2006) analizando información de empresas belgas con préstamos contratados tratan de analizar el por qué el banco solicita o puede preferir una garantía personal a una de la empresa, además de en qué medida se puede requerir garantía, ya sea un solo banco o varios, y si la relación no es tan profunda.

Servicios contratados

Chakraborty y $\mathrm{Hu}$ (2006) analizan el efecto que puede tener la duración de la relación, la edad de la empresa y que tantas relaciones bancarias así como el número de servicios utilizados, todo ello que les determine cuál es la razón o qué tipo de empresas están más propensas a ser requeridas de una garantía. Ya se ha preguntado el número de bancos con que se trabaja, la edad de la empresa y la duración de la relación, así que ahora se preguntará el promedio de servicios utilizados de la institución financiera. 
Garantía inferior al monto del crédito

Lehmann et al. (2004) analizando datos de préstamos a pequeñas y medianas empresas en Alemania, al referirse a las características del crédito, toman en consideración datos como la garantía, tamaño y duración del crédito, de ahí que se desprenda el considerar de las pymes encuestadas si lo solicitado llega a ser el monto autorizado por parte de la institución financiera. Formulando la pregunta consideramos si en alguna ocasión se ha obtenido un monto autorizado aunque sea mayor al valor de la garantía.

Problemática de garantía

Como lo comentan Chan y Kanatas (1985), la garantía implica varios costos, documentación legar, monitoreo, aseguramiento, mantenimiento, de acuerdo a lo convenido con el prestamista, y por supuesto queda limitado su uso. Comentan en su modelo que debería ser que si la tasa de interés aumenta la garantía debiera bajar. Consideran que la garantía se exhibe con la finalidad de bajar la tasa de interés. Se desea identificar la problemática que supone para la empresa el estar garantizando el crédito.

Requisito para crédito

Bhattacharya y Thakor (1993:5) revisan el tema de la intermediación financiera, el por qué existe, la colocación del crédito y otros servicios, entre otros temas. Revisando en particular el tema de la colocación del crédito, hay preguntas claves que tratan, por ejemplo, ¿Cómo afecta la garantía al racionamiento del crédito?, para ellos "la garantía puede reducir pero no 
eliminar el racionamiento del crédito", utilizando esta pregunta, de acuerdo al tema revisado, sería enfocarla a si el monto a recibir o a autorizarse por parte de la institución financiera depende del valor de la garantía.

Garantía del total de activos

Analizando garantías en créditos de mercados emergentes Menkhoff y Neuberger (2006:7) definen a la garantía como "el porcentaje de la línea de crédito garantizada". Además un indicador analizado es el valor de los activos de la empresa antes de la decisión de crédito.

Quién asigna el valor de la garantía

Barro (1976) analiza el papel de la garantía en las tasas de interés de mercado. Así encuentra que hay cierta tasa de interés que espera la empresa, la que estima el banco y la que a final de cuentas se contrata. Señala que habiendo un equilibrio en el mercado entonces se podría determinar el monto de la garantía que derive en la tasa de interés fijada y el monto del préstamo. Esto nos indica un punto importante sobre quién determina el valor de la garantía, por lo cual se desea conocer de la empresa su opinión al respecto.

Riesgo de perder la garantía

Se ha visto la importancia de otorgar una garantía para facilitar la obtención del crédito cuando hay otros obstáculos como la opacidad o el costo de interés, aunque cuando se ofrece una garantía se tiene implícito el riesgo de quizás perderla. Steijvers y Voordeckers (2009:927) mencionan 
que "el riesgo de perder la garantía ofrecida prevendría cualquier riesgo de desplazamiento de la conducta (de alto riesgo) del empresario después de recibir el crédito". Ello implica una ventaja para el banco, pues es parte del riesgo que llevará la empresa.

Garantía de acuerdo al tipo de banco

Maeseneire y Claeys (2007) analizan la situación de las pymes ante la internacionalización, y su relación con bancos locales, extranjeros, pequeños y grandes y su impacto ante la inversión extranjera. Hablando del tema de la garantía, tratan de identificar si esta varía dependiendo de la naturaleza del banco, tamaño u origen del capital, por ello se incluye una pregunta que involucre estas características de la institución financiera.

Costo importante de utilidades

Booth y Booth (2006) analizando información de la comisión de bolsa y valores de USA relativa a préstamos realizados, estudian específicamente la relación entre la garantía y los costos del préstamo, asociando primero la garantía con préstamos riesgosos, aunque encuentran que las empresas prefieren otorgar una garantía con la finalidad de disminuir el costo del préstamo, cuyo concepto principal es la tasa de interés. Entre las cuestiones que analizan de los montos del crédito, las tasas de interés, tanto el tipo como el monto, y las comisiones cobradas a la empresa. García (2006) analiza información de productores de maíz en México, preguntando que tan factible es el otorgamiento de garantía, y si el productor está con la disposición de depositar su producción como la garantía que pide el banco para el crédito, este punto sobresale para analizar si desde un principio el 
empresario está dispuesto o no a otorgar una garantía aun cuando le facilite el crédito o las condiciones del mismo.

Machauer y Weber (1998) en un estudio de empresas con crédito examinan los términos del banco referidos a garantía, tasa de interés y línea de crédito; encontrando una relación positiva entre la tasa de interés y la garantía; para ello requieren conocer si la empresa otorga una garantía, y cual es la tasa de interés cobrada. Analizando información de aerolíneas Benmelech y Bergman (2009) y preguntando sobre monto de garantía, interés, línea de crédito, niveles de endeudamiento, determinan que la garantía tiene un efecto sobre el costo del crédito.

Marcas o patentes como garantía

Maeseneire y Claeys (2007) analizan que tipos de garantías pueden ser aceptadas por los bancos y ofrecidas por la empresa, encontrando que son activos fijos más importantes para servir de garantía, pero tal vez algunos intangibles como marcas o patentes pudieran servir para dichos efectos. Se establece la pregunta correspondiente para saber si en determinado momento un activo intangible es atrayente para los bancos.

Hemos podido apreciar diferentes indicadores que nos muestren aquellos conceptos que significan obstáculos para las pymes o faciliten el crédito, de acuerdo a los constructos establecidos. En un estudio realizado en la República Checa sobre la historia de las pymes en ese país, Bohatá y Mládek (1999) obtienen resultados sobre los principales factores que bloquean el acceso al crédito. En la tabla 4.3., se muestran estos factores. 
Tabla 4.3.

Factores que bloquean el acceso al crédito

\begin{tabular}{|l|}
\hline \multicolumn{1}{|c|}{ Factores } \\
\hline Requerimiento de garantía \\
\hline Costo del crédito (tasas de interés) \\
\hline Larga espera en procesar la solicitud de crédito \\
\hline Procedimiento complejos en la solicitud \\
\hline La necesidad de contar con historial de registros \\
\hline La necesidad de conexiones con los gerentes del banco \\
\hline
\end{tabular}

Fuente: Bohatá y Mládek (1999)

Vemos la tendencia de las limitantes que tienen las pymes cuando requieren un crédito. Se ha descrito la composición del cuestionario diseñado para obtener la información empírica de nuestro estudio, a continuación se describirá como se obtendrá la información y la población objeto de estudio.

\subsection{Base de datos}

La información empírica se recoge a través de la aplicación de cuestionarios a empresas del sector industrial manufacturero, esta es la fuente a través de la cual se examinan las hipótesis establecidas de acuerdo al modelo teórico. Para su análisis se ha utilizado diverso software, los programas aplicados son: EQS 6.1 statistical software, SPSS y Excel. 


\subsection{Fuentes de información}

Será a través de una fuente primaria, la cual se desprenderá de la aplicación de cuestionarios a empresas, la cual conlleva la mayoría de preguntas en escalas multi-ítems de medida tipo Likert 5 puntos donde $1=$ Totalmente en desacuerdo y $5=$ Totalmente de acuerdo. Las escalas Likert “tienen ventajas asociadas a la facilidad de respuesta y administración, además de otras relacionadas con la validez y fiabilidad de las escalas" (Harris, 2001:26).

El total de empresas que respondieron y fueron considerados para el análisis ascendió a 208, se obtuvo un número un poco mayor pero se desecharon algunos por no ser del sector estudiado o por qué las preguntas contestadas eran un mínimo del total del cuestionario. La aplicación de cuestionarios se llevó a cabo de Junio a Diciembre de 2011.

\subsubsection{Población objeto de estudio}

Dentro de las distintas empresas que existen en el país, y en la vida económica de cualquier nación, podemos distinguir 3 grupos principales de acuerdo a su actividad: comercial, servicios e industrial. Para poder acotar la población de estudio he decidido aplicar las encuestas sobre el sector industrial. La base oficial de las empresas a encuestar se toma del SIEM (Sistema de información empresarial mexicano). La Subsecretaría de Promoción de la Industria y el Comercio Exterior (hoy Subsecretaría para la Pequeña y Mediana Empresa) a inicios de 1996 se dio a la tarea de 
instrumentar y desarrollar un sistema de información empresarial denominado SIEM.

El SIEM es el Sistema de Información Empresarial Mexicano el cual integra un registro completo de las empresa existentes desde una perspectiva pragmática y de promoción, accesible a confederaciones, autoridades, empresas y público en general, vía internet.

De dicha base se obtuvo el censo de las empresas del sector industrial a nivel nacional, de las cuales se obtuviera la muestra para la aplicación de cuestionarios.

\subsubsection{Determinación de la muestra}

De acuerdo al SIEM, a la fecha de obtención del censo la base de datos mostraba un total de 28,053 empresas registradas a nivel nacional. La intención de enviarlo mediante un correo electrónico fue la primera depuración para acelerar el proceso de obtención de la información empírica.

Al eliminar las empresas que no contaban con dirección de correo electrónico la población se redujo a 12,309 empresas. Analizando esta última base de datos se pudo apreciar que se repetía el nombre de algunas empresas, ya sea porque se trataba de la misma con diversas sucursales o que había más de un contacto para ciertas empresas, además de otras empresas de diferente nombre pero que tenían un contacto (persona) en común; por lo que se procedió a identificar a dichas empresas para no 
repetir la información o hacerles llegar el cuestionario en más de una ocasión.

Con este análisis se obtuvieron 10,351 empresas con datos completos para realizar el muestreo, esto es, principalmente con una dirección de correo electrónico para facilitar el requerimiento de información a empresas de todo el país. Además de contar con domicilio y un contacto.

Inicialmente procedí a enviar una solicitud vía correo electrónico a las 10,351 empresas, esto para asegurar el obtener el número mínimo de contestaciones base para el análisis. La respuesta fue mínima, dicho proceso inició en el mes de Junio de 2011, además de ello alrededor de un 20\% de los correos se recibía un mensaje de rechazo por que el correo no existía o alguna otra causa desconocida, por lo cual se tuvo que proceder a revisar empresas de manera más directa sin considerar estuvieran incluidas o no en el censo del SIEM; el cual era una referencia pero que no forzosamente incluía a todas las empresas del sector estudiado.

Se procedió a buscar contacto con empresas del sector que cotizaran en bolsa, considerando que al tratarse de información pública no habría gran inconveniente en participar en este estudio, se envió el cuestionario a alrededor de 35 empresas, solo alrededor de un $10 \%$ contestó.

La situación en general del país, de seguridad y confidencialidad, fue una de las características o respuestas comunes del empresario para negarse a participar en este proyecto, la confianza del empresario era mínima, aun con la explicación del motivo del cuestionario y el objetivo del estudio; se 
intento dar mayor confianza mediante la entrega de una carta constancia de la Universidad de Guanajuato y una prueba como estudiante de doctorado en el cual se constara que el fin era para una tesis de posgrado, no obstante, la mayoría declinaba el participar.

Parte del cuestionario era conocer la opinión de empresas que anteriormente no se les había otorgado crédito o que nunca habían solicitado, aun cuando no estuvieron en condiciones de contestar el $100 \%$ por dicha razón, pero era muy importante el conocer la opinión y experiencia de la empresas ante esta situación.

Por ello, se procedió a enviar correos electrónicos o solicitar de manera directa personalmente o vía telefónica a empresarios y gente del medio, explicando el objetivo del cuestionario y la utilidad del mismo. Además se solicitó apoyo indirecto a gente que tenía contacto con empresarios o gente que pudiera apoyar en el requerimiento a empresas de la actividad seleccionada.

De esta manera, se empezó a obtener una mayor cantidad de cuestionarios, desde microempresas, hasta empresas grandes internacionales. El proceso continuó hasta el mes de diciembre de 2011, en el cual se reunió el número que pudiera dar una base firme a las respuestas del modelo que se había construido y la validación de las hipótesis establecidas.

Como se comentaba, se logró la obtención de un total de 208 cuestionarios, y en la tabla 4.4. se muestra la ficha técnica de la información obtenida. Posteriormente se hace mención de las características de la 
muestra en la tabla 4.5., específicamente de la gente entrevistada, y en la tabla 4.6. sobre las empresas.

Tabla 4.4.

Ficha técnica del cuestionario

\begin{tabular}{|l|l|}
\hline $\begin{array}{l}\text { Universo de medida y ámbito } \\
\text { de estudios }\end{array}$ & $\begin{array}{l}\text { Empresas del sector industrial } \\
\text { manufacturero en México, con correo } \\
\text { electrónico. }\end{array}$ \\
\hline Tamaño de la muestra & 208 \\
\hline Fecha de trabajo empírico & Junio a Diciembre 2011 \\
\hline Tipo de estudio & $\begin{array}{l}\text { Cuestionario estructurado enviado por } \\
\text { correo electrónico. }\end{array}$ \\
\hline Error de la muestra & $\pm 5.48 \%$ \\
\hline Nivel de confianza & $\begin{array}{l}95 \% \text { para el caso más desfavorable } \\
(\mathrm{p}=\mathrm{q}=50 \%)\end{array}$ \\
\hline
\end{tabular}

Tabla 4.5.

Características de la muestra (entrevistados)

\begin{tabular}{|l|l|c|}
\hline Características Demográficas & & $\begin{array}{c}\text { Frecuencia } \\
\%\end{array}$ \\
\hline Sexo de la persona entrevistada & Masculino & 72.11 \\
& Femenino & 27.89 \\
\hline Edad de la persona entrevistada & $18-24$ años & 5.39 \\
& $25-34$ & 21.08 \\
& $35-44$ & 33.82 \\
& $45-54$ & 24.02 \\
& $55-64$ & 12.25 \\
& 65 y mayores & 3.44 \\
\hline
\end{tabular}


Tabla 4.6.

Características de la muestra (empresas)

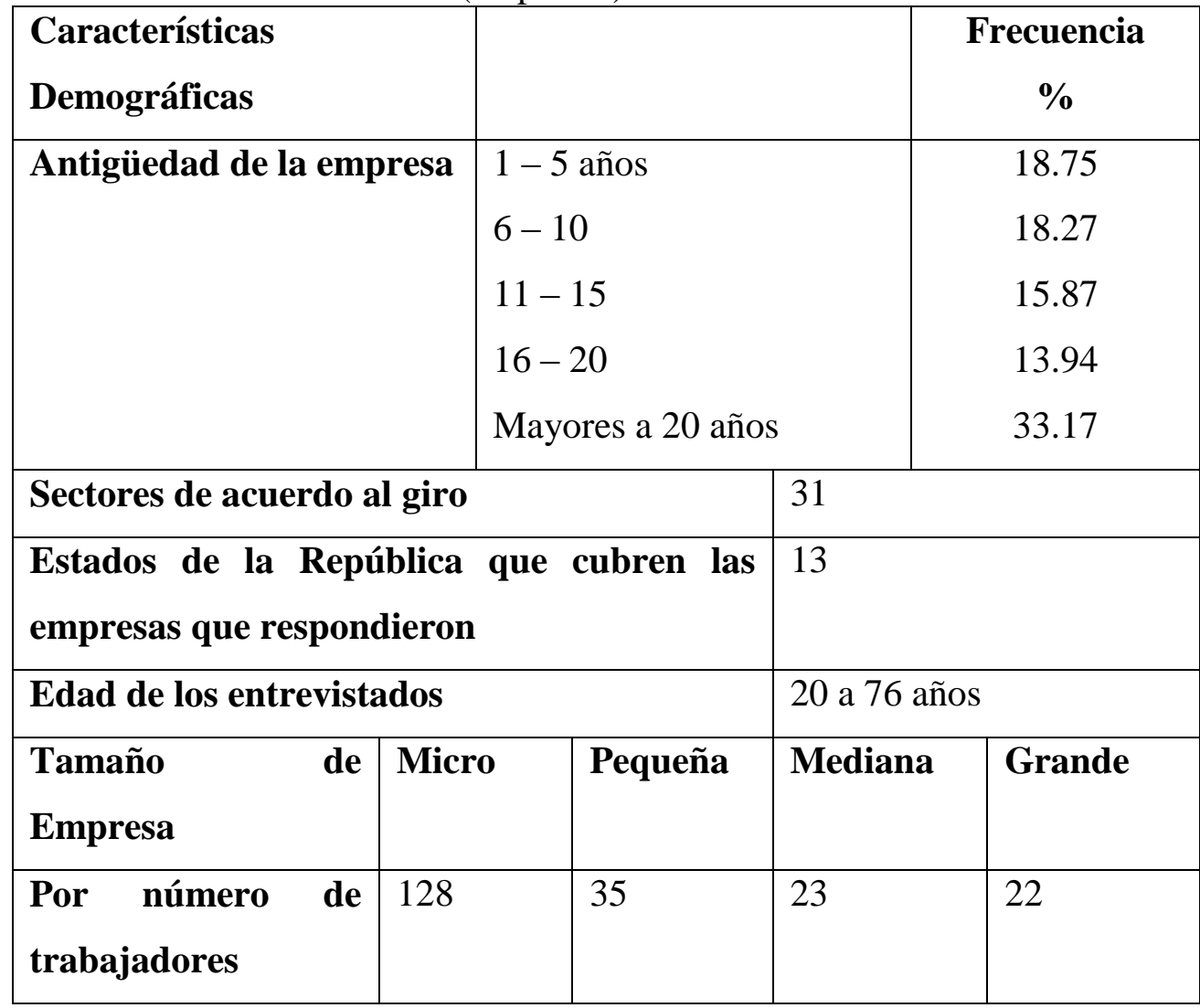

Encontramos que está ligeramente homogénea la proporción de empresas, dividiendo la antigüedad cada 5 años, así las más jóvenes que respondieron representan casi una quinta parte del total, se nota una ligera baja en los siguientes 3 grupos de 5 años, el resto que se muestra a mayores de 20 años, nos indica que una tercera parte de las empresas encuestadas ya tiene un historial importante de operaciones, lo cual indicaría a las instituciones de financiamiento la perduración de estas empresas, de acuerdo a la población objeto de estudio. 
Como se puede apreciar en la tabla 4.6., el porcentaje preponderante, más de la mitad de las empresas encuestadas son microempresas (hasta 10 trabajadores), lo cual sigue una tendencia del volumen de empresas a nivel mundial. De hecho, las pymes en estas encuestas abarcan el $89 \%$ de la muestra, lo cual nos confirma el volumen de empresas que abarcan el mayor número de requerimientos de crédito.

En su estudio empírico de empresas portuguesas Serrasqueiro y Nunes (2011) se preguntan si la antigüedad de las empresas es determinante para las decisiones de financiamiento, muestran que los resultados para pymes jóvenes y maduras sugieren que la teoría de la compensación y la teoría de la selección jerárquica no debieran ser mutualmente excluyentes; puesto que ambas son necesarias para entender las decisiones de estructura de capital de las pymes.

\subsection{Información de indicadores del cuestionario}

A continuación se presentarán algunos de los principales indicadores que se hicieron a pregunta abierta en relación a las distintas variables del modelo.

\subsubsection{Fuente de financiamiento}

Aun cuando los bancos se considerarían la principal fuente de financiamiento, en México existen diversas instituciones financieras de las cuales podrían obtenerse recursos vía crédito, a partir de las encuestas las principales fuentes de financiamiento reflejadas son las siguientes: 
Figura 4.5.

Fuentes de financiamiento

\section{Fuentes de Financiamiento}

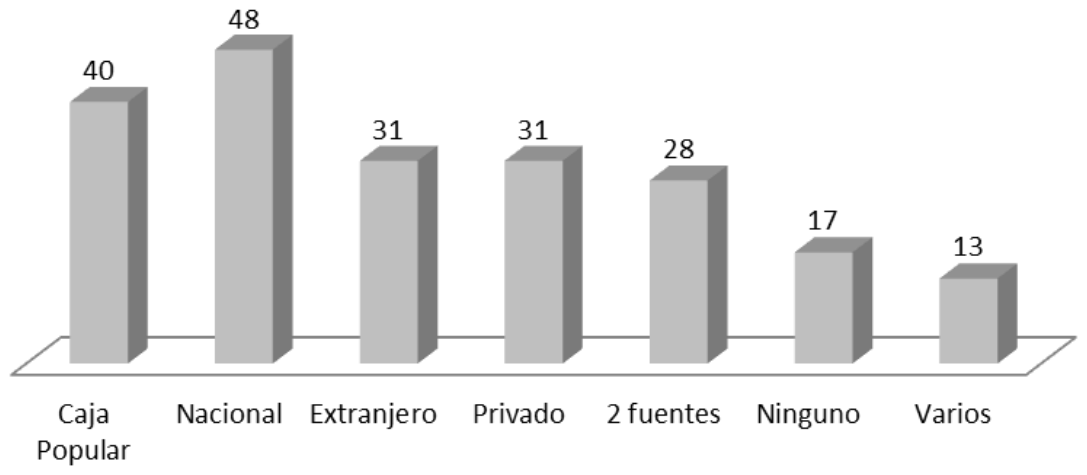

A la gente se le pidió mencionar, al tratarse de banca privada, si se trataba de bancos nacionales o extranjeros, la realidad es que la mayoría de bancos establecidos en territorio nacional pertenecen a algún banco de origen extranjero, principalmente españoles y estadounidenses. Algunas personas solo hicieron mención de que se trataba de banca privada, separando esto de las instituciones gubernamentales. Ello implica que del total de la banca se tienen 110 empresas que utilizan este medio para tramitar créditos, esto significa alrededor del 53\% de las empresas encuestadas. Se puede ver que las Cajas Populares representan un porcentaje importante, 40 empresas usaron esta vía. Ello puede comprenderse por los menores requisitos solicitados por estas instituciones, aunque regularmente con un costo mayor.

También hubo empresas que contaban con más de una fuente de financiamiento, estas 28 empresas contaban entre sus fuentes a bancos, cajas populares e instituciones gubernamentales. 
Otro aspecto reflejado es el que 17 empresas no tienen relación con institución financiera alguna, encontrando este principalmente en las micro empresas.

Un estudio interesante es realizado por Beck et al. (2008), en el que considerando alrededor de 50 países a nivel mundial, presenta las principales fuentes de financiamiento, dividiendo por tamaño de empresa; de una regresión de la parte de financiamiento correspondiente considerando el tamaño y otras características del país. La figura 4.6. muestra esta agrupación.

Figura 4.6.

Fuentes de financiamiento de acuerdo al tamaño de empresa

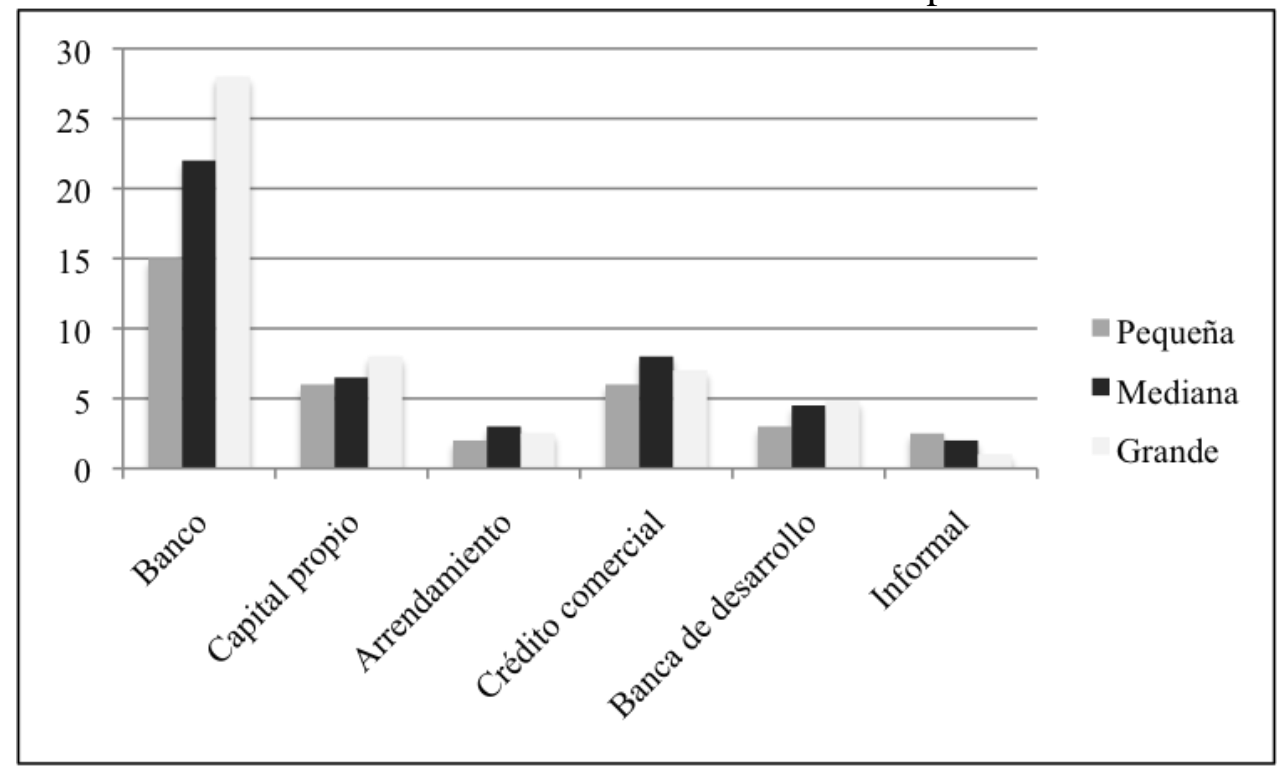

Fuente: Beck et al. (2008)

Si lo comparamos con nuestro estudio, vemos que concuerdan en que la banca es la principal fuente de recursos externos, también nos llama la atención que la diferencia respecto a las empresa grandes en 
financiamiento vía bancos es la mayor entre todas las fuentes de recursos. Vemos que en el aspecto informal la pequeña empresa es quién más lo usa. Otro aspecto interesante es que la banca gubernamental, mostrada en la tabla como banca de desarrollo es todavía más utilizada por las empresas grandes, cuando el fin de muchos programas, en México, es apoyar a la pyme.

\subsubsection{Plazo del crédito}

Un indicador solicitado a las empresas que contrataron un crédito es el conocer el tiempo por el cual se había otorgado el mismo, esto fue lo que se encontró:

Tabla 4.7.

Plazo del Crédito Obtenido

\begin{tabular}{|l|c|}
\hline \multicolumn{1}{|c|}{ Plazo del crédito } & $\begin{array}{c}\text { Frecuencia } \\
\%\end{array}$ \\
\hline Menor a 1 año & 5.77 \\
\hline 1 año & 14.42 \\
\hline $2-3$ años & 35.10 \\
\hline $4-5$ años & 20.67 \\
\hline $6-10$ años & 3.85 \\
\hline Mayor a 10 años & 0.48 \\
\hline Sin crédito & 19.71 \\
\hline & 100.00 \\
\hline
\end{tabular}

Del total de empresas un $80 \%$ de las mismas ha tenido algún crédito, de estas se aprecia que la mayoría lo han obtenido de un rango de 1 a 3 años de plazo, y va disminuyendo a mayor plazo, aunque es preciso señalar que aquellos que pidieron crédito con plazo de hasta un año fue un $14 \%$ del total de empresas encuestadas. 
Otro indicador, para conocer la facilidad en los trámites, esto independiente a los requisitos solicitados, es conocer el tiempo que tarda la empresa en dicho trámite, y las respuestas que se muestran en la figura 4.7.:

De acuerdo a las respuestas obtenidas, la mayoría empresas solo ocupó una semana en la obtención del crédito, la mayoría dentro del mes pudo completar su trámite, es interesante ver que 24 empresas duraron más de 2 meses para su obtención.

Figura 4.7.

Tiempo de Tramitación del Crédito

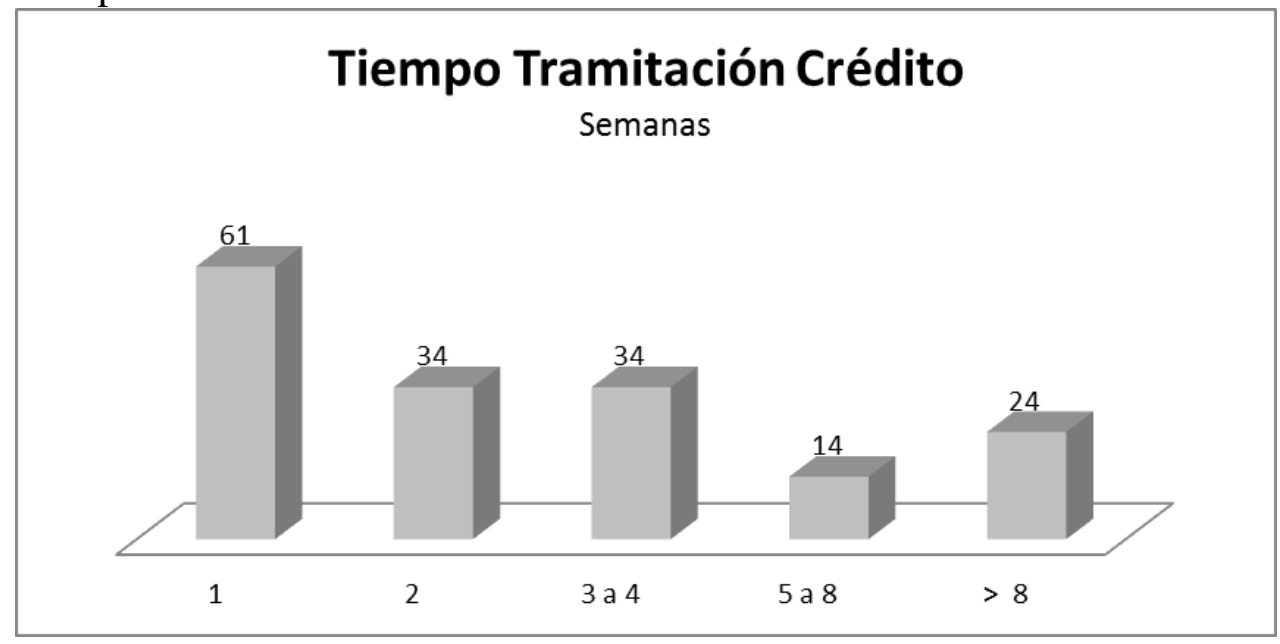

\subsubsection{Destino del crédito}

Es importante conocer en qué utilizaron las empresas los recursos obtenidos, dentro del indicador del cuestionario se pusieron varias opciones al encuestado, los resultados arrojados son los siguientes: 
Tabla 4.8.

Destino u ocupación del crédito

\begin{tabular}{|l|c|}
\hline \multicolumn{1}{|c|}{ Destino } & $\begin{array}{c}\text { Frecuencia } \\
\%\end{array}$ \\
\hline Capital de trabajo & 42.86 \\
\hline Nuevas inversiones & 32.14 \\
\hline Remplazar equipo & 6.55 \\
\hline Doble destino & 9.52 \\
\hline Otros usos & 8.93 \\
\hline & 100.00 \\
\hline
\end{tabular}

Del total de empresas encuestadas (208), 168 empresas que han obtenido crédito responden que principalmente lo ocupan para capital de trabajo y realización de nuevas inversiones, esto con el $43 \%$ y $32 \%$, respectivamente. Esto nos indica que las empresas ocupan mayormente sus necesidades de recursos para seguir operando, lo cual podría derivar en que si no cuentan con medios para operar estarían destinadas a cerrar. Lo cual contribuye al conocimiento de que se tiene de que un porcentaje menor de las pymes de nueva creación tienen larga vida.

Derivado de la crisis financiera del 2008, como se ha comentado, el crédito se restringió inicialmente, Ivashina y Scharfstein (2010) hacen un análisis de los 8 trimestres del 2007 y 2008, considerando qué tipo de créditos eran, en donde estaban dirigidos. Esta comparación muestra lo que se dio en el punto más crítico de la crisis acaecido en el cuarto trimestre de 2008, y se puede comparar contra el boom que se tuvo en crédito en el segundo trimestre de 2007. Los datos los obtuvieron de la base de datos de préstamos de bancos grandes “Reuters' DealScan”, en los Estados Unidos. 
Figura 4.8.

Préstamos para inversiones vs. Préstamos para reestructurar.

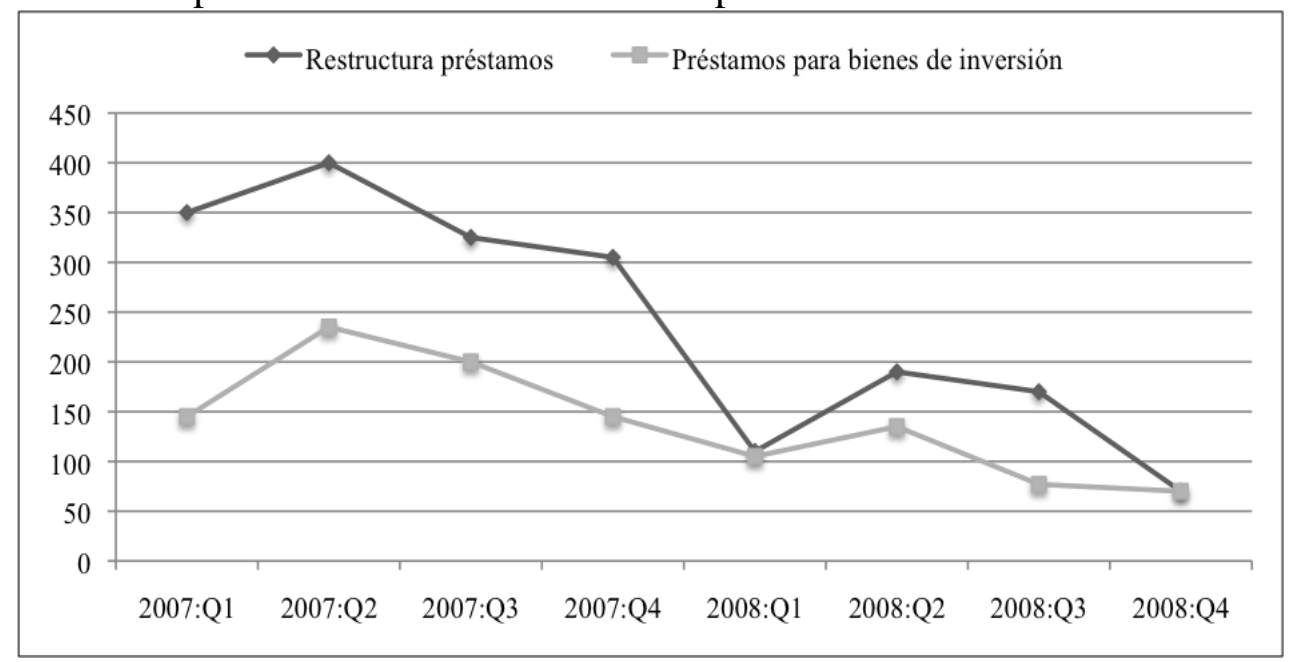

Fuente: Ivashina y Scharfstein (2010)

Como se ve en la figura 4.8., los créditos cayeron estrepitosamente, tanto para reestructura de préstamos como para nuevas inversiones. Hablábamos de la dificultad que supone para las pymes la obtención de crédito, y aun cuando son datos de Estados Unidos, el sentir de esta tendencia fue de impacto también el México. Pero, además de esto, en relación con la información obtenida en nuestro estudio sobre el destino del crédito. Se presenta la siguiente figura 4.9.: 
Figura 4.9.

Emisión total de líneas de crédito renovables frente a préstamos a largo plazo

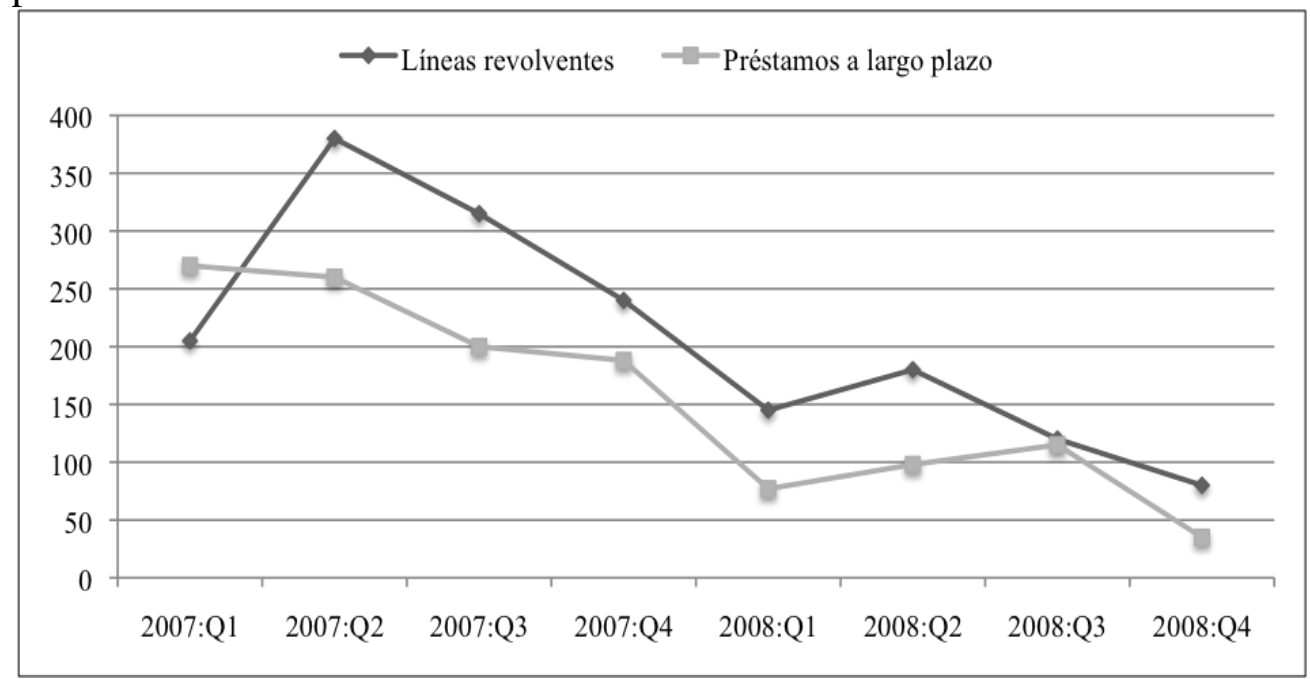

Fuente: Ivashina y Scharfstein (2010)

El impacto de la crisis, se muestra también en la figura 4.9, tanto las líneas revolvente, usadas para capital de trabajo; como los préstamos a largo plazo, que normalmente se ocupan para inversiones; cayeron de 2007 a 2008. Lo que apreciamos respecto a nuestros resultados, es de que son más requeridos los créditos para capital de trabajo, esto es similar a nuestro estudio. El capital de trabajo utilizado para compra de inventarios, para financiar a clientes, para pago a proveedores, es de los más necesitados para las pymes. Aunque, como se ha señalado, el crecimiento se da a través de las nuevas inversiones, principalmente.

Haciendo referencia también a los efectos de esta crisis del 2008, Campello et al. (2010) hacen una encuesta entre 1,050 directores financieros de Estados Unidos, Europa y Asia para que de manera directa indiquen si sus empresas tienes restricciones de crédito durante dicha crisis financiera. 
Estudian si las empresas cambian sus planes derivado de la crisis, basándose en los obstáculos financieros. La figura 4.10, muestra la comparación entre las empresas con limitaciones de crédito y las que no tienen limitaciones.

Figura 4.10.

Cambio de planes de empresas limitadas y no limitadas de financiamiento.

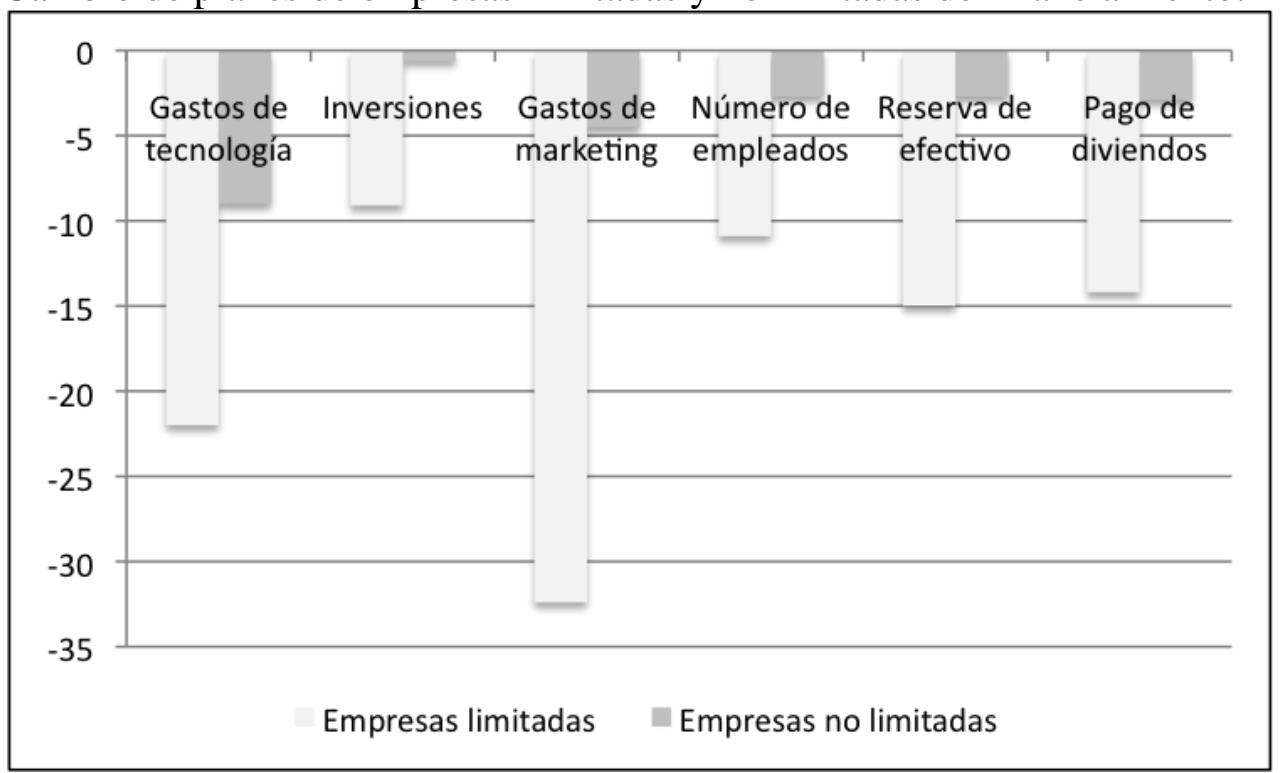

Fuente: Campello et al. (2010)

En la figura anterior podemos ver que la empresas que no tienen limitación o restricción en cuanto a financiamiento, sus planes se redujeron en mucho menor porcentaje respecto a aquellas empresas con restricción al crédito. Pensaban disminuir mucho más su gasto en tecnología, marketing e inversiones. De hecho, tendrían que contraer su tamaño en mayo medida, pues vemos una reducción mayor al $10 \%$ en el número de empleados. Nos indica, entonces, la problemática que se agudiza para las empresas cuando no pueden acceder al financiamiento con instituciones financieras. 


\subsubsection{Rechazo de solicitud de crédito}

Dentro de los indicadores para validar el modelo se planteó el conocer las causas de rechazo que habían encontrado las empresas, en su caso, así como el por qué prefieren no solicitar crédito. De las empresas encuestadas 17 señalaron diversas causas por las cuales la institución financiera no les otorgó el crédito solicitado, estas se resumen en la siguiente tabla.

\section{Tabla 4.9.}

Causas de Rechazo de Créditos

\begin{tabular}{|lc|}
\hline Causa de Rechazo & Cantidad \\
\hline Falta de garantía & 4 \\
Falta de aval & 2 \\
Muró de crédito & 2 \\
Incapacidad de pago & 2 \\
Requisitos del banco & 2 \\
Empresa menor 3 años & 2 \\
Otros & 1 \\
\hline
\end{tabular}

Se puede apreciar que la falta de garantía fue la predominante, esto por no contar con la misma o ser insuficiente para cubrir el aforo requerido. La falta de aval también puede asimilarse a la causa preponderante, pues se trata de un tercero que garantice el pago del crédito. Dentro del buró de crédito se indica tanto una empresa que no tenía un correcto historial así 
como otra que no contaba con historial alguno. El monto de ingresos también es causa de rechazo, el monto de ingresos también se puede hacer referencia para conocer el tamaño de la empresa, ello indicaría que no se trata de una empresa grande. Otras causas se encuentran en la incapacidad de pago de la empresa solicitante, los diversos requisitos solicitados y el tratarse de una empresa joven.

Dentro de las causas por las cuales no se ha solicitado crédito alguno, solo una empresa señaló que no lo ha hecho por que "las instituciones no apoyan a pequeñas empresas”.

\subsubsection{Tasa de Interés}

Uno de los constructos establecidos es la tasa de interés, la cual consideramos el costo principal de un crédito. Para evaluar la magnitud de este costo que cargan a las empresas se les preguntó tanto si el crédito se había contratado con una tasa fija o variable, así como la tasa anual cobrada por la institución financiera, del total de empresas encuestadas el $71 \%$ ha contratado su crédito con una tasa fija mientras que el $29 \%$ restante señaló una tasa variable.

Se entiende que la gente prefiere no correr el riesgo de un alza inesperada durante el plazo del crédito y que le afecte mayormente, aun cuando la tasa variable al momento de contratar pueda ser menor a una tasa fija. Pero el pasado indica una idea generalizada de que no es bueno el contratar tasas variables, aun cuando en el mercado existan instrumentos para protegerse a ciertos niveles de un alza, pero que tal vez las empresas 
pequeñas no conozcan o no puedan costearla en el momento de contratación.

El nivel de tasas fijas referidas se muestra en la figura 4.11.

Figura 4.11.

Niveles de Tasa Fija

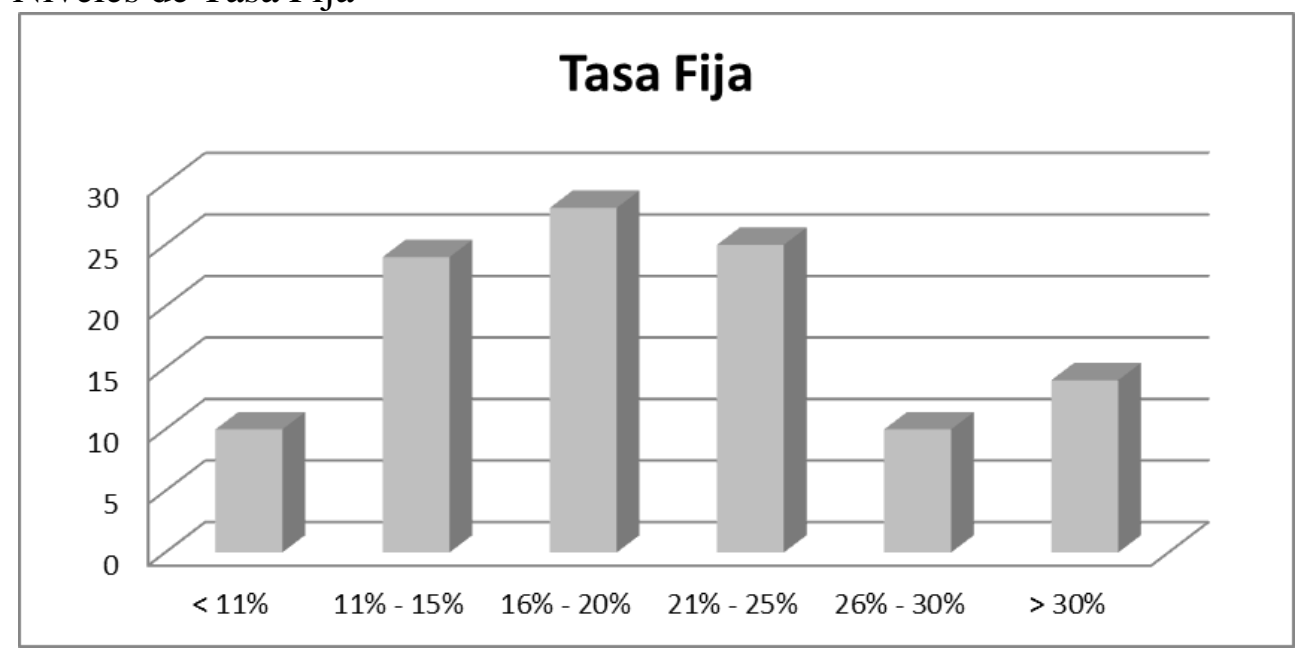

Como se aprecia en la tabla anterior, globalmente las tasas se centran en un rango del $11 \%$ al $25 \%$, siendo principalmente entre un $16 \%-20 \%$. Un mínimo de empresas cuenta con una tasa preferente menor al $11 \%$. Aunque también se aprecia que más de 10 empresas han contrato créditos con tasas superiores al $30 \%$, lo cual representa un costo significativo.

En cuanto a tasas variables los resultados encontrados se muestran en la siguiente figura. 
Figura 4.12.

Niveles de Tasa Variable

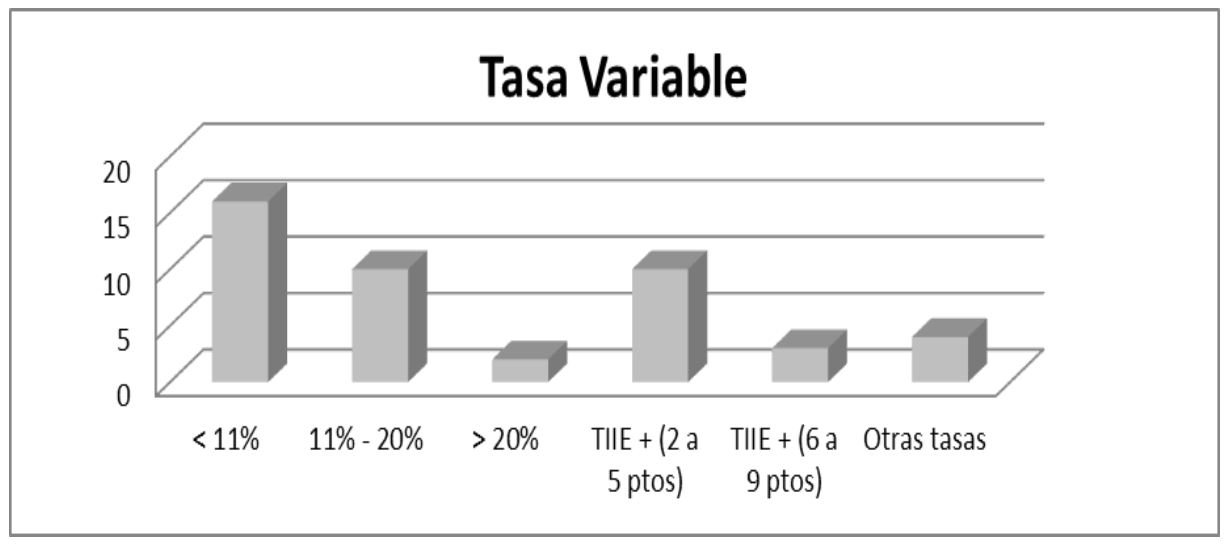

Algunas empresas señalaron la tasa total, algunas otras mencionaron los puntos adicionales que cobra la institución a la tasa base que en México es la TIIE (Tasa de interés interbancaria de equilibrio). Así, podemos ver que la mayor parte de las empresas en los diferentes rangos mostrados se encuentra en un nivel menor al 10\% de tasa anual; además, considerando que a Enero 2012 la TIIE aproximada es de 4.80\%, las empresas que mencionaron TIIE más " $x$ " número de puntos también son más las que se encontrarían en un rango menor al 11\%. Esto nos confirma que una tasa variable es más barata que las mostradas en la tabla de tasas fijas.

\subsubsection{Relación de Préstamo}

Una de las variables establecidas es la "relación de préstamo", la cual se presenta como un constructo que puede ayudar a obtener el crédito, así como tener una influencia positiva en la información. 
Uno de los indicadores preguntados en los cuestionarios fue el saber el número de años de relación que tiene la empresa con su principal institución financiera:

Figura 4.13.

Años de Relación con el Banco Principal

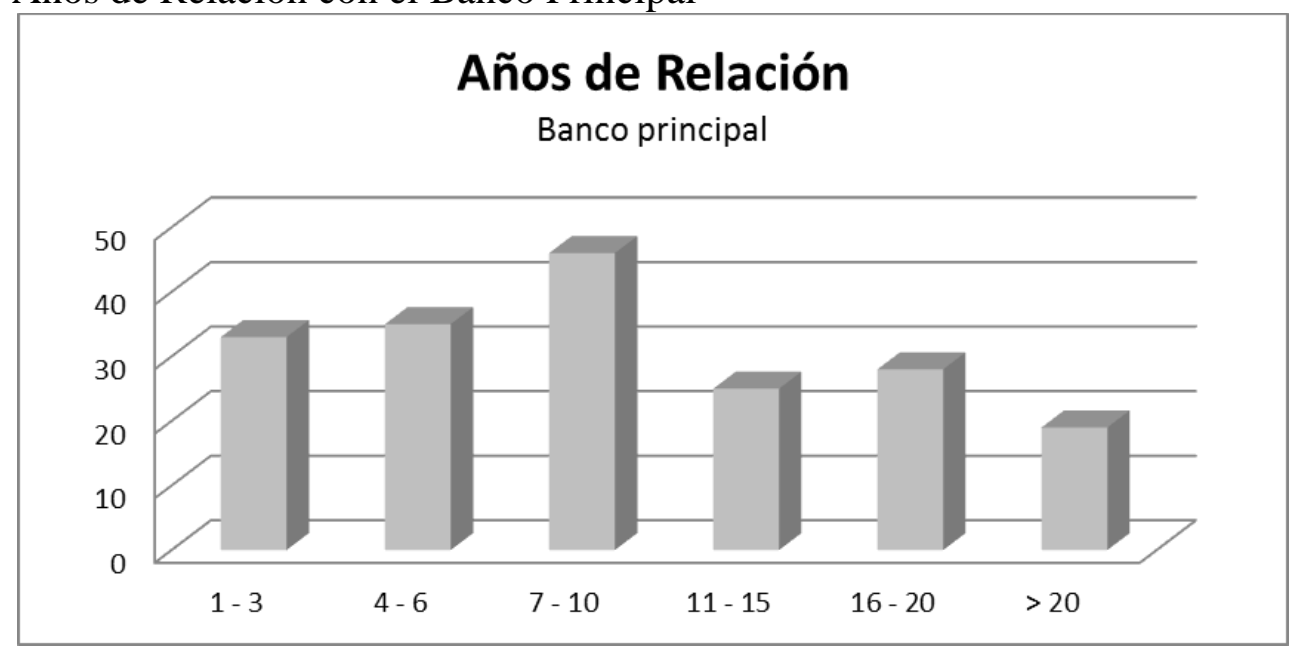

Esta tabla nos muestra la heterogeneidad en los años de relación de las empresas, de las 186 empresas que cuentas con alguna relación, más de 30 tienen tanto de $1-3$ años como de $4-6$ años, y podemos ver que un número importante tiene hasta 10 años de relación. Esto nos indica que muchas de las empresas llevan un tiempo importante de relación con su institución financiera.

Otro de los indicadores que se deseaba encontrar era saber que tan concentrada estaba la relación empresa con instituciones financieras, para lo cual se preguntó con cuantos bancos trabaja, obteniendo los siguientes resultados: 
Figura 4.14.

Número de bancos con los que trabaja la empresa

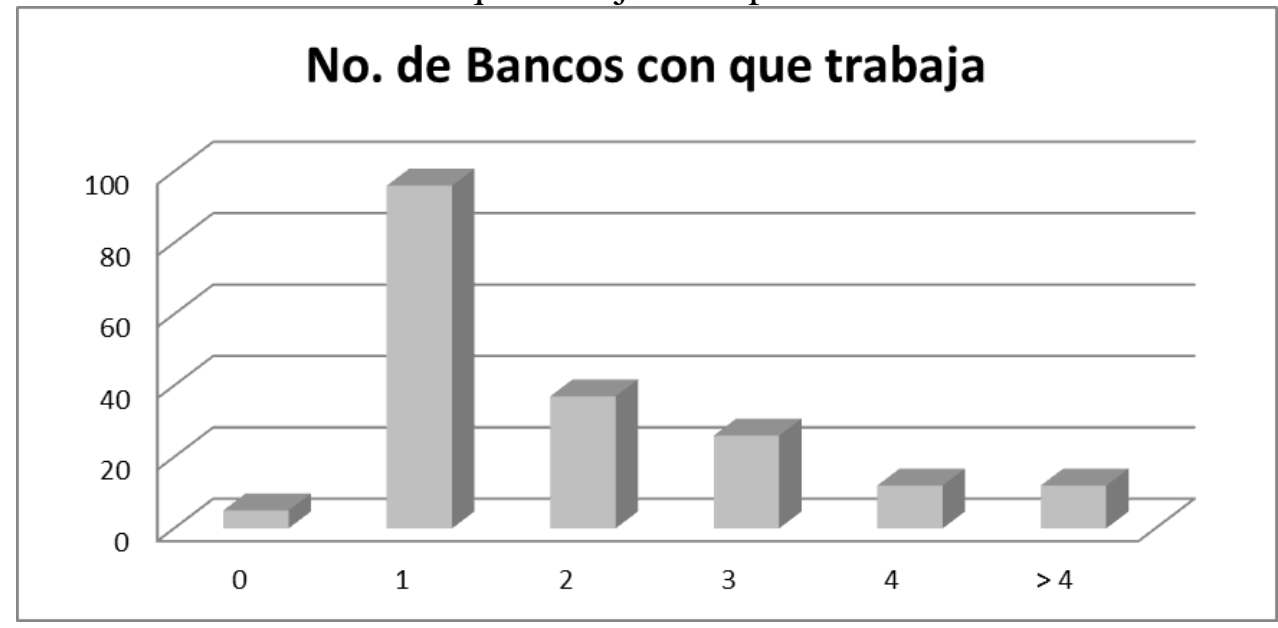

Aquí vemos que la gran mayoría, alrededor de un 51\% trabaja con solo una institución, este porcentaje disminuye dramáticamente de las empresas que trabajan con 2 o más bancos. Así, tenemos que menos de 40 empresas trabajan con 2 instituciones a la vez, y esto sigue disminuyendo en 3 o 4 relaciones bancarias. Un 6\% de las empresas encuestadas maneja más de 4 bancos.

Además de conocer los años de relación y la cantidad de relaciones de las empresas, es interesante conocer cuantas veces se reúne la empresa con el banco, para ello se tiene otro indicador que se resumen en la figura 4.15.

Aproximadamente una tercera parte de las empresas que tienen relación se reúnen más de 4 veces al año con gente de su banco, aunque podemos ver que las dos terceras partes restantes van desde ninguna reunión hasta solo 4 (el mínimo de estas empresas), lo cual no resulta positivo en 
cultivar una buena "relación de préstamo" de la cual se pueda valer la empresa en un momento dado para el requerimiento de crédito.

Figura 4.15.

Número de reuniones al año con su ejecutivo del banco

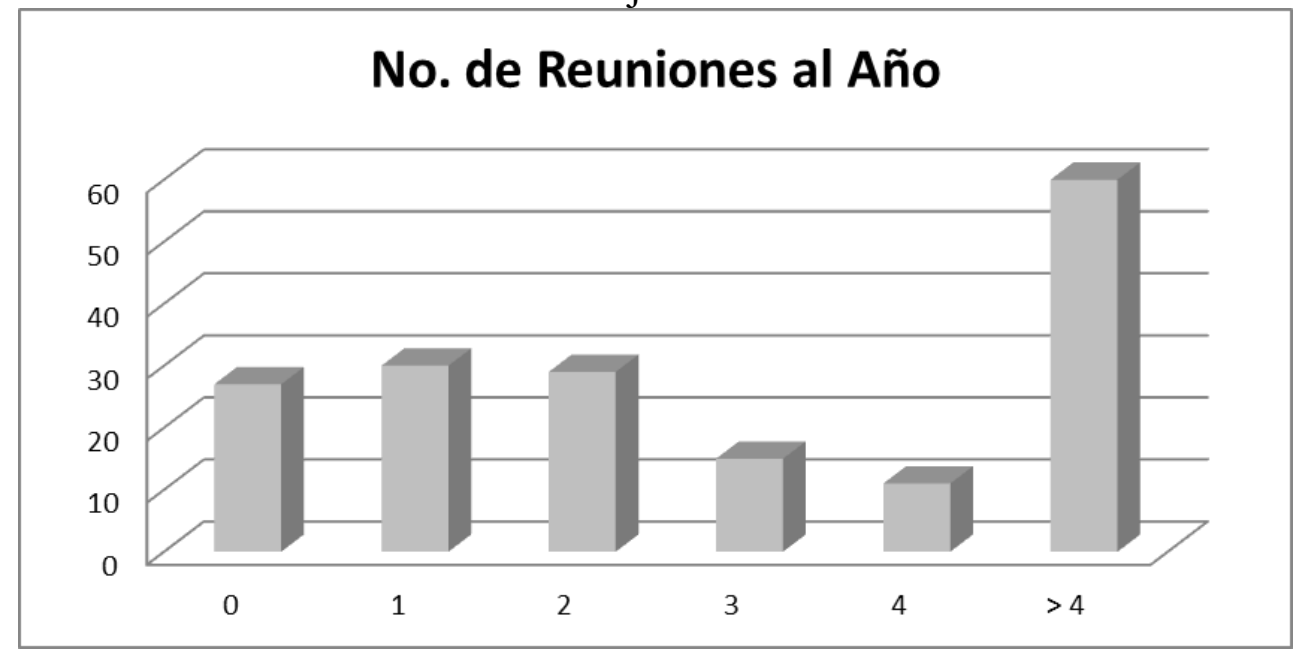

Dada la concentración en una relación múltiple de la empresa, quisimos conocer el porcentaje de operaciones con el banco principal, aquellas empresas que trabajan con solo una institución por supuesto tienen el $100 \%$ de operaciones con el mismo, pero resulta interesante el ver la distribución de aquellas con más de una relación. 
Figura 4.16.

Porcentaje de operaciones que realiza con su banco principal

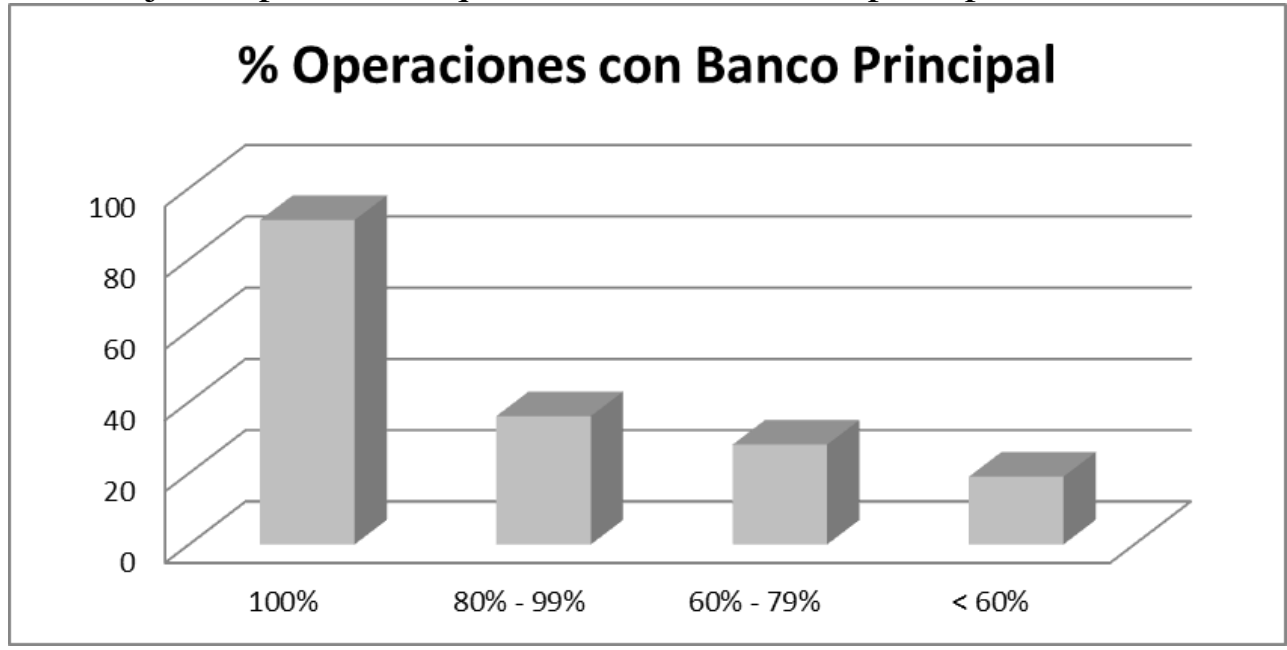

Como se comentaba, la mayor parte de empresas maneja el 100\% de sus operaciones con una institución, esto puede favorecer el conocimiento que la institución financiera desarrolle de la empresa y obtener una buena relación de préstamo, aunque limita la oferta y la posible negociación de la empresa. Alrededor de 30 empresas distribuyen sus operaciones entre un $80 \%$ - 99\%, y poco más de 20 empresas reducen este porcentaje entre un $60 \%-79 \%$. Se marca como 19 empresas concentran menos del $60 \%$ con su banco principal.

Además del porcentaje de operaciones, el número de servicios utilizados por la empresa nos pueda dar otra idea de que tan fuerte es la relación con el banco, o si se ocupa para lo mínimo necesario con motivo de un crédito, los resultados arrojados de las encuestas son los siguientes: 
Figura 4.17.

Cantidad de servicios utilizados por la empresa de su banco principal.

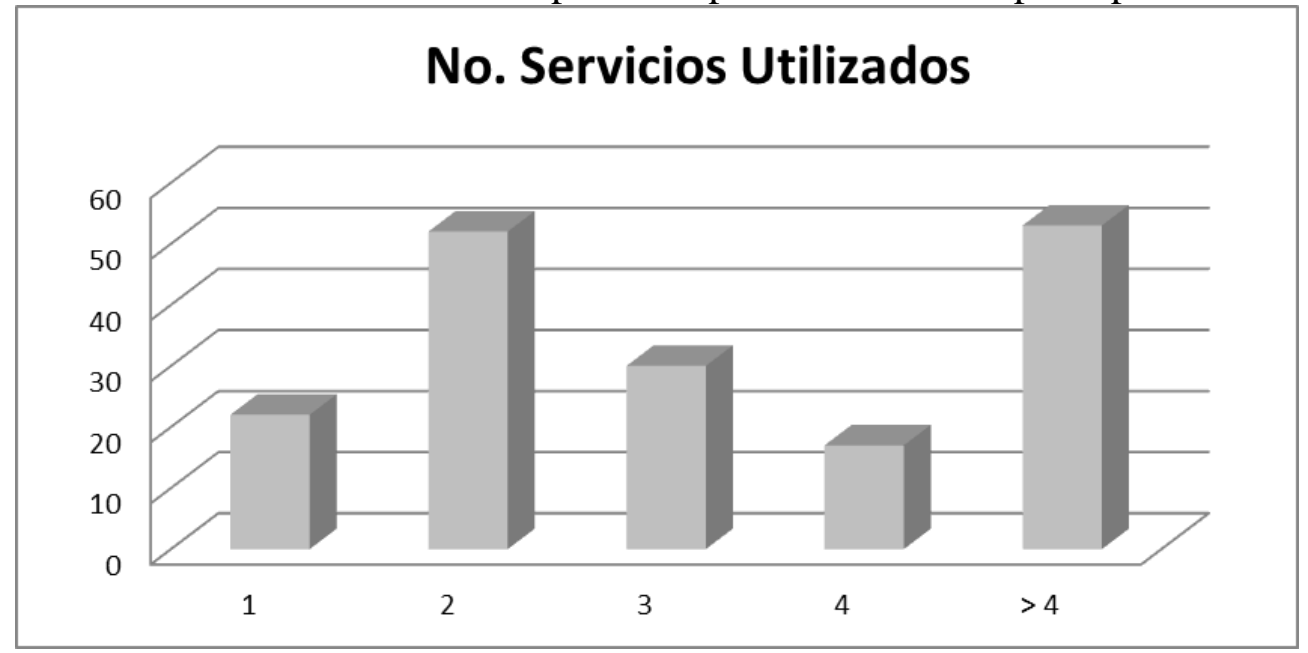

La mayor parte de las empresas encuestadas se centra en 2 servicios utilizados o más de 4, alrededor de 50 personas en ambos rangos son las que mencionaron esta cantidad de servicios. Se encuentra que aproximadamente 20 empresas solo ocupan un servicio de las instituciones.

\subsubsection{Garantía}

Otro de los constructos considerados en el modelo es la garantía. Uno de los indicadores incluidos fue sobre el aforo que requieren los bancos para otorgar el crédito, esto es, la proporción de valor entre la garantía y el monto solicitado, obteniendo lo siguiente: 
Figura 4.18.

Proporción entre el valor de la garantía y el monto del crédito.

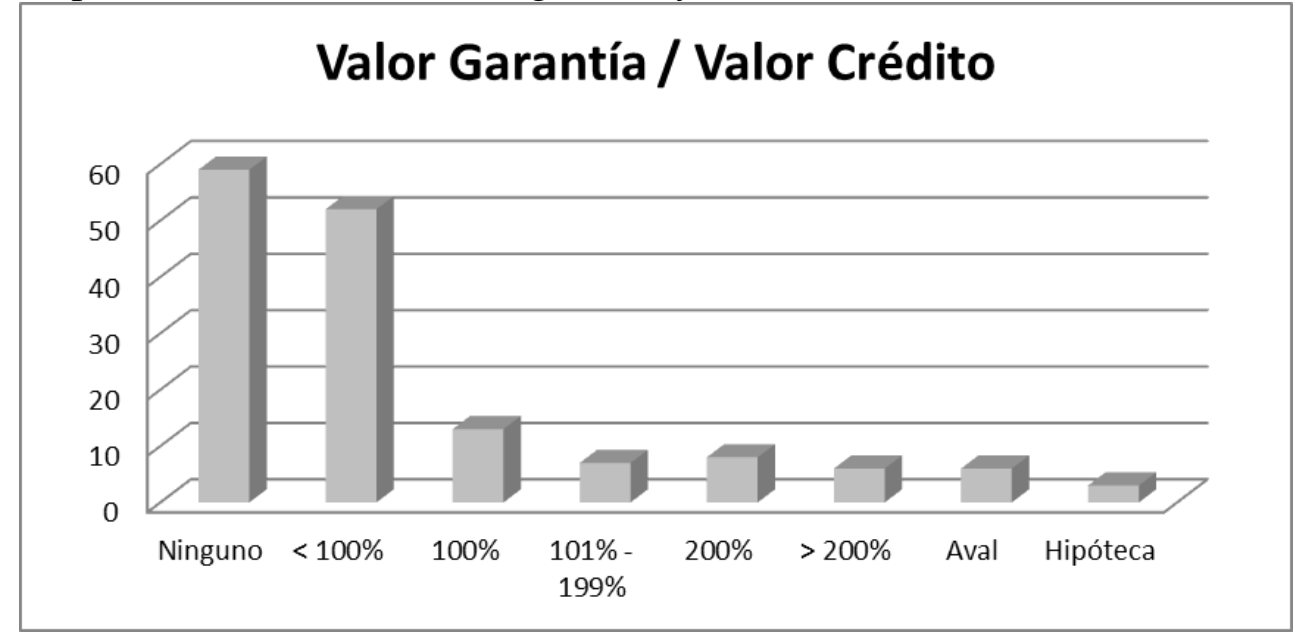

Como se muestra en la figura, de acuerdo a la información obtenida se muestra que más de 50 empresas no otorgaron ningún tipo de garantía; de aquellas que tuvieron que ofrecer algún tipo de garantía se tiene que aproximadamente 50 empresas (34\%) ofreció un bien con un valor inferior al monto solicitado. 13 empresas tuvieron que garantizar con un valor igual al monto solicitado, se reduce aun más el número de aquellas empresas que debieron garantizar con bienes cuyo valor excediera el monto del crédito. También se encontró que algunas empresas tuvieron que hacer uso de un aval para garantizar (4\%) el crédito.

Harhoff y Körting (1998) manejan como variables endógenas en su modelo las siguientes: "Garantía", el cual explican que es una variable Dummy indicando si la garantía o colateral fue requerida para obtener la línea de crédito más importante, "Interés" y "porcentaje de crédito comercial con descuentos tomados". Situación similar a los constructos que hemos explicado en nuestro modelo, hablando de garantía e interés. 
Hemos visto algunas características de la muestra sujeta de nuestro estudio, parte de estos indicadores son mostrados en un estudio realizado a pymes en Italia por Angelini et al. (2008), como se muestra en la figura 4.19., la mayoría de las empresas les gustaría tener un crédito adicional, aunque, las 3 cuartas partes lo harían solo si las condiciones actuales no aumentaran. Es curioso que de la muestra el 10\% estaría dispuesta a pagar un costo más alto o dejar una garantía mayor, con tal de obtener más crédito. Como en nuestro estudio, vemos que hay parte de las empresas encuestadas que no han solicitado crédito, y una mínima parte, pero también con ejemplos como el de nuestros resultados, indica que ya le ha sido negado el crédito, o que como estima que no le será autorizado prefiere no solicitarlo.

Figura 4.19.

Demanda de préstamos por pymes en Italia

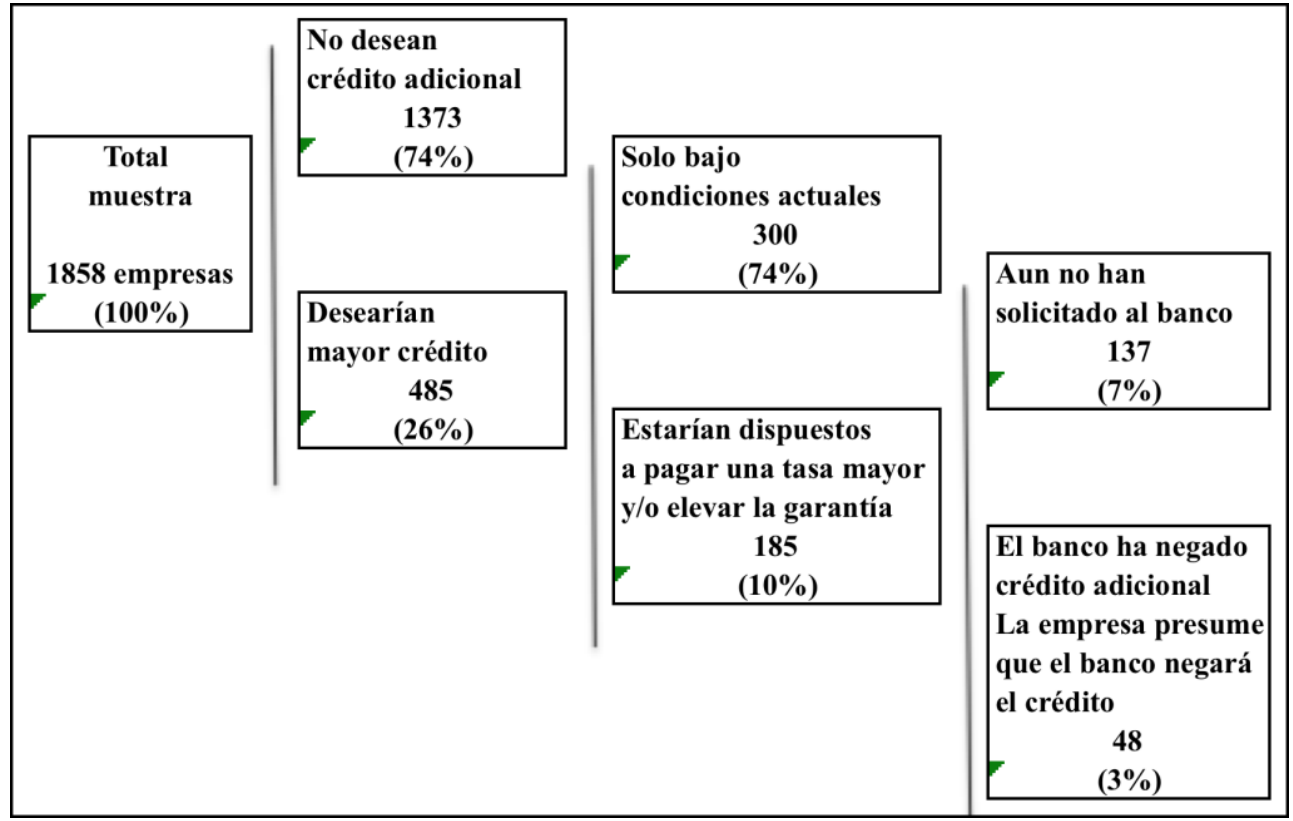

Fuente: Angelini et al. (1998) 
Hemos analizado como se ha determinado nuestra muestra, como diseñamos el cuestionario aplicado, los indicadores incluidos, y algunas de las características de la muestra obtenida con la aplicación de las encuestas. A continuación se describirán las técnicas de análisis a aplicar para la interpretación de los resultados obtenidos.

\subsection{Técnicas de análisis}

Una vez obtenidos los resultados de las encuestas y realizado la base de datos correspondiente, el trabajo empírico se ha desarrollado utilizando la metodología de las ecuaciones estructurales. "Una fortaleza importante de este método es la habilidad de mostrar análisis psicométricos y econométricos de manera conjunta de manera que algunas de las mejores características de ambos pueden ser explotados" (Fornell y Larcker, 1981:39). Es posible elaborar modelos de ecuaciones estructurales que incorporan la noción psicométrica de variables no observadas (constructos) y error de medición en el procedimiento de estimación.

Los modelos fueron estimados de las matrices de varianzas y covarianzas obtenidas mediante la aplicación del programa EQS 6.1 software estadístico (Bentler, 1995). Autores como Bollen (1989) manifiestan que este método ofrece estimadores consistentes para muestras grandes, cuando utilizamos variables continuas con una función de distribución multinormal. Otros autores también recomiendan dicho método en pequeñas muestras, siempre que sea plausible la asunción de normalidad e independencia. 


\subsubsection{Metodología de ecuaciones estructurales}

De acuerdo a Bollen (1989), en los análisis de regresión múltiple o ANOVA (análisis de la varianza) los coeficientes de regresión o el error de la varianza de los estimadores deriva de la minimización de la suma de las diferencias al cuadrado de la variable dependiente observada y de la predicha para cada caso. La metodología de los modelos de ecuaciones estructurales es diferente; esta pone énfasis en la covarianza más que en los casos, además, en lugar de minimizar las funciones de los valores individuales observados, minimiza la diferencia entre la muestra de covarianzas y las covarianzas pre establecidas en el modelo.

Siguiendo a Luque (2000:492), los modelos de ecuaciones estructurales "son una poderosa herramienta de análisis, cuyo verdadero valor está en usar simultáneamente variables observadas y latentes jugando diferentes papeles dentro del análisis general". Estos modelos son recomendables frente a otros métodos estadísticos convencionales cuando nos encontramos en situaciones con varias variables dependientes e independientes, en donde determinadas variables dependientes puedan establecer relaciones causales entre sí de forma simultánea (Reisinger y Turner, 1999). Además, como comentan Kristof-Brown et al. (2002), su utilización es muy apropiada porque nos permite tener en cuenta el error de medida, estimando simultáneamente todos los coeficientes, y evaluando el ajuste de todo el modelo con los datos en general.

En resumen, como resalta Luque (2000), con estos métodos se trata de integrar simultáneamente una serie de ecuaciones de regresión múltiple diferentes pero a la vez interdependientes, ya que las variables que son 
dependientes en una relación pueden ser independientes en otra relación dentro del mismo modelo. Además, estos modelos "constituyen una de las herramientas más potentes para el estudio de relaciones causales sobre datos no experimentales cuando estas relaciones son de tipo lineal" (Batista y Coenders, 2000:12).

\subsubsection{Modelo de ecuaciones estructurales}

El modelo de ecuaciones estructurales (SEM por sus siglas en inglés), conlleva un análisis multivariante (Fornell et al. 1987). El SEM toma lo mejor de técnicas de reducción de datos como el análisis de componentes principales y técnicas que estudian la relación entre variables, como la regresión multivariante. El SEM permite modelizar complejas relaciones entre variables observables y variables latentes de manera precisa.

La ventaja de este tipo de modelos es que permiten proponer tipo y dirección de las relaciones, como comentan Ruiz et al. (2010:34), "se espera encontrar la relación entre las diversas variables contenidas en él modelo, para pasar posteriormente a estimar los parámetros que viene especificados por las relaciones propuestas a nivel teórico". También señalan que se llaman modelos confirmatorios, derivado de que se desea "confirmar" mediante el análisis de la muestra las relaciones propuestas.

Para el desarrollo de nuestro trabajo empírico hemos utilizado un modelo de ecuaciones estructurales de dos etapas (Anderson y Gerbing, 
1998). Estas fases consisten básicamente en un análisis de medida de las variables latentes y la relación entre ellas mediante un modelo estructural.

Análisis de las propiedades sociométricas

El modelo en dos etapas consiste en primer lugar en un análisis de las propiedades sociométricas de las escalas utilizadas. En nuestro caso validaremos tanto las escalas utilizadas ya validadas por otros autores, como las construidas expresamente para observar nuestras variables. Con ello, estos indicadores servirán como medidas de las variables latentes.

De acuerdo a Bagozzi (1981), al introducir nuevas medidas es necesario observar su validez convergente, discriminante y de contenido, así como la consistencia interna como paso previo a la corroboración de las hipótesis sustantivas. Por ello se procedió al análisis de la dimensionalidad, fiabilidad y validez de las escala de valor percibido para asegurarnos que medimos el constructor que se intentaba medir. Este análisis nos permite refinar la escala, eliminando ítems no significativos.

En el caso de valor percibido, los ítems comparten la misma dimensión en las que fueron promediadas para determinar las medidas compuestas. Las medidas compuestas de valores percibidos son combinaciones de ítems para crear resultados agregados que son sujetos aun Análisis Factorial Confirmatorio (CFA por sus siglas en inglés) junto con el resto de las escalas consideradas en el estudio, con la finalidad de validarlas.

Dentro del AFC se someten a análisis medidas compuestas de valor percibido, las cuales son una combinación de ítems para crear puntuación 
agregadas, estas junto con el resto de las escalas consideradas en el estudio, para validarlas. El uso de medidas compuestas es útil por las siguientes razones, la primera que nos permite conocer mejor la distribución normal, además de resultar un modelo mas parsimonioso por que reduce el número de varianzas y covarianzas a ser estimadas, así que incrementa la estabilidad de los parámetros estimados, mejora la variable del tamaño de la muestra y reduce el error de muestreo en la estimación del proceso.

Para la percepción de la escala de valor de la invarianza el instrumento de medición fue verificado, por lo tanto asegura la comparabilidad entre los parámetros estimados tomando como entrada las medidas compuestas (Satorra, 2011). Así, una medida compuesta por cada dimensión del valor percibido fue introducido como un indicador variable en el análisis realizado para evaluar la dimensión, confianza y validez de las escalas.

Debemos primeramente establecer relaciones de dependencia entre las diversas variables atendiendo a razonamientos teóricos (Batista y Coenders, 2000). Una vez justificadas las variables a utilizar en el modelo, debemos construir un gráfico en el que se representen las relaciones expresadas; es el llamado diagrama de paso o de caminos o path diagram (Hair et al., 2006). Finalmente, una vez desarrollado el modelo causal y representado gráficamente, debemos convertirlo en un conjunto de ecuaciones que definan las relaciones entre los constructos (modelo estructural), la medida de dichos constructos a través de las variables observadas (modelo de medida), así como posibles correlaciones entre las diferentes variables (Luque, 2000). 
Cuando se realiza la identificación debemos asegurarnos que los parámetros del modelo puedan derivarse a partir de las varianzas y covarianzas entre las variables observables, con el fin de que el modelo sea estimable (Batista y Coenders, 2000). Una condición necesaria, pero no suficiente, consiste en que el número de ecuaciones o elementos distintos de la matriz de varianzas-covarianzas sea mayor que el número de parámetros a estimar; a esta diferencia se le denomina "grados de libertad". Esta condición no es suficiente, pero como indica Diamantopoulos (1994), no existen condiciones suficientes absolutas.

A lo largo de este capítulo se ha definido la forma en que será llevado a cabo el estudio empírico y análisis de los resultados. Hicimos una descripción detallada del cuestionario que se utilizará en la recolección de información, identificando las partes en que se divide así como los indicadores utilizados. En cuanto a los indicadores, se realizó una descripción de cada uno de ellos en los hicimos referencia a autores que los han considerado anteriormente o comentado en sus estudios.

Se comentó sobre la población a la cual aplicaremos nuestro estudio y como se determinó la muestra. Se hizo referencia a la fuente de información y el período en el cual se realizó la recopilación de información. Una vez hecho el estudio y obtenido la información, se reflejó la ficha técnica del cuestionario, así como las características de la muestra tanto de la gente encuestada como de las empresas.

Hay información importante que se obtuvo en la aplicación de los cuestionarios, por ello, parte de esa información se resumió en tablas y 
figuras, explicando algunas otras características de la muestra en cuanto a información relevante del tema de crédito.

El capítulo finaliza indicado las técnicas que utilizaremos para el análisis. Indicamos que el modelo de ecuaciones estructurales será la técnica principal en nuestra tesis, por lo cual explicamos el fundamento y conceptos que involucran esta técnica estadística. En el siguiente capítulo se mostrarán los resultados obtenidos de acuerdo a las variables establecidas en nuestro estudio. 
Análisis de Resultados 
"Cuando se logra un triunfo, creo que no es este lo que más se saborea; sino todo lo que se vivió para llegar a él” Juan Vaca Estrada 


\subsection{Introducción}

En este capítulo se analizarán los resultados obtenidos con el trabajo empírico efectuado, validar el modelo teórico establecido y contrastar las hipótesis, considerando la metodología de ecuaciones estructurales. En estos desarrollos se distinguirán las etapas de especificación, identificación, estimación, evaluación e interpretación, comunes a toda modelización con ecuaciones estructurales. Lo mostrado en este capítulo se tratará con la finalidad de comprobar la fiabilidad y validez de las diferentes escalas de medida, y posteriormente realizar el análisis de los modelos estructurales propuestos. Además, contrastaremos las hipótesis con los resultados obtenidos a fin de determinar si podemos confirmar o no si cumplimos las hipótesis propuestas en nuestro modelo.

\subsection{Validación de escalas y pruebas invariancia}

Los métodos de prueba para evaluar los modelos de ecuaciones estructurales con variables no observadas son una prueba t y una prueba chi cuadrada. La prueba t (el radio del parámetro estimado a su error estándar estimado) indica si los parámetros individuales estimados son estadísticamente diferente a cero. La estadística de chi cuadrada compara las bondades de ajuste entre la matriz de covarianza de los datos observados y la matriz de covarianza derivados de una estructura teórica especificada (modelo) (Fornell y Larcker, 1981).

Los indicadores utilizados para el análisis de las propiedad de los diferentes instrumentos de medida se describen a continuación. 
Dimensionalidad

Partimos de la premisa que el modelo estructural se basa en una definición teórica sólida que reflejen los constructos o relaciones que se desean medir. Por ello, es importante analizar la dimensionalidad o unidimensionalidad de todas y cada una de las escalas, mediante este análisis se espera comprobar la existencia de un único concepto en el conjunto de indicadores que indican un único constructor (Anderson y Gerbing, 1988). Esto, utilizando el Análisis Factorial Confirmatorio que se ha comentado en el capítulo anterior.

En los Análisis Factoriales Confirmatorios de cada una de las escalas debemos observar la calidad de ajuste de los modelos planteados. Es decir, previo al proceso de interpretación de los resultados es necesario determinar hasta qué punto los modelos asumidos se ajustan a los datos muestreados, por lo que es necesario observar la existencia de cualquier problema de ajuste.

Este proceso inicia con la observación de la existencia de suficientes grados de libertad para obtener modelos sobre identificados. Una vez comprobada la identificación, en las ecuaciones estructurales se distinguen tres tipos de medidas de ajuste global: medidas absolutas de ajuste, medidas incrementales, y medidas de parsimonia (Luque, 2000; Reisinger y Turner, 1999; Hair et al., 1998).

En la Tabla 5.1. presentamos una síntesis de los indicadores. Además de ellos, se utilizarán en nuestros modelos los grados de libertad, para observar que los modelos están sobre identificados. 
Tabla 5.1.

Medidas de bondad del ajuste del modelo de medida

\begin{tabular}{|l|l|}
\hline & Niveles de aceptación recomendados \\
\hline Medidas absolutas de ajuste & \\
\hline$\chi^{2} \mathbf{y}$ nivel de significación & Nivel de significación mayor de 0,05 \\
\hline GFI & Valores superiores a 0,90 \\
\hline RMSEA & Valores inferiores a 0,08 \\
\hline Medidas incrementales de ajuste & \\
\hline AGFI & Valores superiores a 0,90 \\
\hline
\end{tabular}

Fuente: Luque (2000)

Fiabilidad

Atendiendo a Hayes (1992:50), la fiabilidad puede ser definida como “el grado en que las mediciones están libres de desviaciones derivadas de errores causales". La fiabilidad nos asegura que el proceso de medida va a proporcionar siempre los mismos resultados, independientemente del modelo y la forma en que este se desarrolle. Al contrario del análisis de validez que se refiere a la bondad con que la medida definen un concepto, la fiabilidad se relaciona con la coherencia de la medida (Hair et al., 1998).

\section{Validez}

Es necesario observar la validez de las escalas y de todas las variables que conforman el modelo estructural. El análisis de validez intenta comprobar que lo que se está midiendo sea verdaderamente el constructo que se pretende valorar.

Estrechamente relacionada con la validez de constructo está la validez convergente y discriminante. Decimos que existe validez 
convergente, o validez interna cuando la medida utilizada se correlaciona fuertemente y de forma positiva con otras medidas del mismo constructo (Churchill, 1979).

Esta validez se puede contrastar también a través del análisis factorial, como se ha hecho en esta tesis. La utilización de medidas de ajuste incremental como el AGFI o la BBNFI, que hemos expuesto anteriormente, nos aseguran la validez convergente. Además, diversos autores sugieren estimar la validez de los indicadores a partir de las cargas factoriales (Bollen, 1989). Un Análisis Factorial exploratorio nos sirve para depurar las escalas iniciales y centrarnos en la información que proporcionan las cargas factoriales. De esta forma, y recurriendo al Análisis Factorial de Componentes Principales, nosotros podemos reducir el número de ítems con poco peso factorial $(\lambda<0,4)$. En el Análisis Factorial Confirmatorio debemos seguir el mismo proceso, de manera que la magnitud de los coeficientes de regresión lambda estimados por los modelos de medición superen idealmente el valor 0,4 planteado (Hair et al., 1998). Además, siguiendo a Luque (2000) y a Anderson y Gerbing (1982), debemos examinar la significación estadística de cada carga obtenida entre el indicador y la variable latente (valor t superior a 1.96 para $\alpha=0,05$ ).

En los modelos de ecuaciones estructurales existen otros procedimientos como el test de diferencias de la $\chi 2$. Este procedimiento consiste en evaluar la significatividad estadística de la diferencia entre los valores de la Chi-cuadrado de un modelo en el que se considera la correlación entre dos factores con otro en el que esta correlación se fija igual a la unidad (Jöreskog, 1971). 
Para validar la escala con nuestros datos, de acuerdo con los métodos anunciados previamente, hemos realizado los siguientes tests: 1) análisis de dimensionalidad mediante el procedimiento de Análisis Factoriales Confirmatorio y comprobación del ajuste del mismo; 2) análisis de fiabilidad de los parámetros estimados y las variables latentes; 3 ) análisis de validez de los instrumentos de medida.

Análisis de los modelos estructurales del modelo.

Una vez estimados y depurados los instrumentos de medida, debemos proceder a contrastar el grupo de hipótesis que engloban la serie de obstáculos que pueden encontrar las pymes cuando tramitan un crédito. La estimación de estos modelos estructurales pretende corroborar la consistencia de las relaciones causales de las variables latentes con los datos.

\subsection{Análisis de Resultados}

De acuerdo a los resultados obtenidos del estudio empírico, nuestro modelo quedaría de la siguiente manera, en el cual se indica la relación positiva o negativa de las relaciones causales entre las variables determinadas, como se muestra en la figura 5.1.: 
Figura 5.1.

Resultados obtenidos sobre el modelo teórico

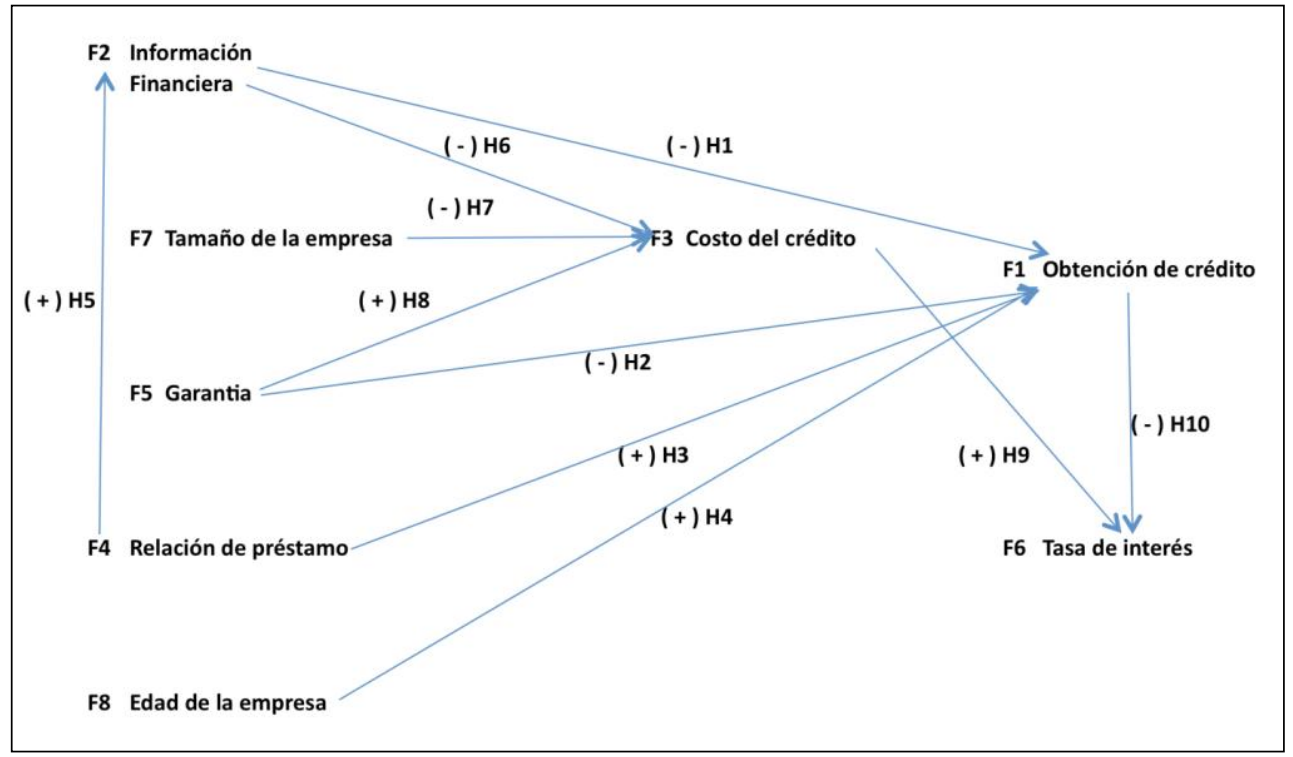

Primero se llevó a cabo un estudio de la dimensión, confianza y validez de la escala para asegurar que fue medido el constructor que se intentaba medir. Este análisis también permitió refinar la escala, eliminar ítems no significativos. El número final de ítems o indicadores considerados fue de 19 tal como se muestra en la tabla 5.2. 
Tabla 5.2.

Análisis de la dimensión, confianza y validez de la escala de valor percibido.

\begin{tabular}{|c|c|c|}
\hline Items & Factor & t-Valor \\
\hline \multicolumn{3}{|l|}{ F1 Obtención de crédito $(\mathrm{CR}=0,78 ; \mathrm{AVE}=, 68)$} \\
\hline Obtener el crédito solicitado le ha sido sencillo & 831 & 2,766 \\
\hline En general, le es fácil obtener créditos & ,770 & 3,074 \\
\hline \multicolumn{3}{|l|}{ F2 Información $(\mathrm{CR}=, 74 ; \mathrm{AVE}=, 56)$} \\
\hline $\begin{array}{l}\text { Cuenta con los servicios de un Contador que } \\
\text { elabore sus estados financieros }\end{array}$ & ,642 & 5,923 \\
\hline $\begin{array}{l}\text { Sus estados financieros se encuentran revisados y } \\
\text { certificados por un auditor externo }\end{array}$ & ,658 & 7,286 \\
\hline $\begin{array}{l}\text { El banco puede disponer con facilidad de una } \\
\text { proyección financiera de su empresa }\end{array}$ & ,785 & 3,978 \\
\hline \multicolumn{3}{|l|}{ F3 Costo del crédito $(\mathrm{CR}=, 79 ; \mathrm{AVE}=, 62)$} \\
\hline $\begin{array}{l}\text { Los intereses pagados por créditos representan un } \\
\text { porcentaje significativo de sus ventas }\end{array}$ & ,912 & 2,310 \\
\hline $\begin{array}{l}\text { Los intereses pagados por créditos representan un } \\
\text { porcentaje significativo de su utilidad de } \\
\text { operación }\end{array}$ & ,780 & 3,556 \\
\hline $\begin{array}{l}\text { La tasa de interés es relativamente alta por mi } \\
\text { poca experiencia con los bancos }\end{array}$ & ,505 & 7,879 \\
\hline \multicolumn{3}{|l|}{ F4 Relación de préstamo $(\mathrm{CR}=, 87 ; \mathrm{AVE}=, 63)$} \\
\hline $\begin{array}{l}\text { Se reune constantemente con el personal del } \\
\text { banco que le atiende }\end{array}$ & ,692 & 5,330 \\
\hline $\begin{array}{l}\text { Cuento con un contacto especial en el banco con } \\
\text { el que tramito los créditos }\end{array}$ & 807 & 5,036 \\
\hline $\begin{array}{l}\text { Los ejecutivos del banco se acercan a usted para } \\
\text { conocer sus necesidades, objetivos, } \\
\text { requerimientos. }\end{array}$ & ,693 & 5,286 \\
\hline $\begin{array}{l}\text { Tiene asignado un ejecutivo específico del banco } \\
\text { para atenderlo }\end{array}$ & ,742 & 5,232 \\
\hline Cuenta con una relación fuerte con su banco & ,809 & 4,820 \\
\hline \multicolumn{3}{|l|}{ F5 Garantía $(\mathrm{CR}=, 69 ; \mathrm{AVE}=, 52)$} \\
\hline $\begin{array}{l}\text { La garantía representa un porcentaje importante } \\
\text { del total de activos de su negocio }\end{array}$ & ,925 & 1,882 \\
\hline $\begin{array}{l}\text { El monto de la garantía es asignado o valuado por } \\
\text { la institución que le otorga el crédito }\end{array}$ & ,382 & 8,042 \\
\hline $\begin{array}{l}\text { Perder la garantía significa un riesgo para su } \\
\text { operación }\end{array}$ & ,614 & 5,333 \\
\hline F6 Tasa de interés & 1 & \\
\hline F7 Tamaño de la empresa & 1 & \\
\hline F8 Edad de la empresa & 1 & \\
\hline
\end{tabular}


Previamente a la estimación del modelo factorial en su conjunto, es necesario el análisis de unidimensionalidad de cada uno de los factores de primer orden que corresponden a las dimensiones individuales. En la Tabla 5.3. señalamos las medidas de bondad del ajuste de los modelos indicativos de las dimensiones individuales. En él se modificarán los modelos inicialmente propuestos, en función de la fiabilidad de los parámetros, las cargas individuales, o las correlaciones entre los residuos, obtenidas tras la aplicación del Test de Multiplicadores de Lagrange, conocido por sus iniciales inglesas como LMTEST.

Tabla 5.3.

Medidas de bondad de ajuste de valor percibido.

\begin{tabular}{|l|l|}
\hline Medidas de ajuste & Modelo \\
\hline Satorra-Bentler $\boldsymbol{\chi}^{\mathbf{2}}$ & 151.774 \\
\hline Grados de libertad & 127 \\
\hline Nivel de significación & 0.06620 \\
\hline RMSEA & 0.040 \\
\hline BBNNFI & 0.940 \\
\hline CFI & 0.956 \\
\hline IFI & 0.959 \\
\hline MFI & 0.902 \\
\hline GFI & 0.882 \\
\hline AGFI & 0.823 \\
\hline
\end{tabular}

Una vez realizada la unidimensionalidad de cada uno de los factores de primer orden estamos en condiciones de analizar el ajuste del modelo factorial de segundo orden.

Dentro del análisis, la primera fase en la cual nos enfocamos fue en el estudio de las propiedades psicométricas de la escala mostrada en la tabla 
5.2. para el total de la muestra. En relación a la medida del análisis del factor confirmatorio de los 19 ítems que finalmente se incluyeron en la escala, se obtuvieron 8 dimensiones: obtención de crédito, información, costo del crédito, relación de préstamo, garantía, tasa de interés, tamaño y edad de la empresa. En la tabla 5.3. se puede observar que la probabilidad asociada con chi-cuadrada alcanza un valor mayor a 0.05 (0.06620), con lo que nos indica en lo general un buen ajuste de la escala.

La validez convergente queda demostrada de dos formas, la primera es por que las cargas factoriales son significativas y mayores a 0.5 , y la segunda por que la varianza media extraída (AVE por sus siglas en inglés) para cada uno de los factores es también mayor a 0.5. La confianza en la escala queda demostrada por que los índices de confiabilidad compuestos de cada una de las dimensiones obtenidas son mayores a 0.5.

La tabla 5.4. muestra la validez discriminante de las escalas relacionadas con el valor percibido, evaluada a través de la varianza media extraída (AVE). Para esto un constructo debe compartir una mayor varianza con sus indicadores que con otros constructos del modelo. Esto sucede cuando la raíz cuadrada de AVE entre cada par de factores es mayor que la correlación estimada entre dichos factores. 
Tabla 5.4.

Validez discriminante de las escalas relacionadas con el valor percibido

\begin{tabular}{|c|c|c|c|c|c|c|c|c|}
\hline & 1 & 2 & 3 & 4 & 5 & 6 & 7 & 8 \\
\hline $\begin{array}{l}\text { F1. Obtención de } \\
\text { crédito }\end{array}$ & .825 & & & & & & & \\
\hline F2. Información & -.186 & .747 & & & & & & \\
\hline $\begin{array}{l}\text { F3. Costo del } \\
\text { crédito }\end{array}$ & -.089 & -.541 & .787 & & & & & \\
\hline $\begin{array}{l}\text { F4. Relación de } \\
\text { préstamo }\end{array}$ & .104 & .680 & -.451 & .796 & & & & \\
\hline F5. Garantía & -.241 & -.052 & .454 & - & .719 & & & \\
\hline F6. Tasa de interés & -.097 & -.257 & .188 & $\begin{array}{l}- \\
.267\end{array}$ & .035 & 1 & & \\
\hline $\begin{array}{l}\text { F7. Tamaño de la } \\
\text { empresa }\end{array}$ & -.015 & .238 & -.247 & .255 & $\begin{array}{l}- \\
.114\end{array}$ & -.180 & 1 & \\
\hline $\begin{array}{l}\text { F8. Edad de la } \\
\text { empresa }\end{array}$ & .217 & .365 & -.221 & .307 & $\begin{array}{l}- \\
.076\end{array}$ & -.047 & .122 & 1 \\
\hline
\end{tabular}

Una vez que las medidas compuestas se han formado de los ítems que comparten la misma dimensión en la escala de valor percibido, analizamos las propiedades psicométricas de las escalas que forman el modelo. Como se puede ver en la tabla 5.6., la probabilidad asociada con chi-cuadrada alcanza un valor mayor a 0.05 (0.06938), lo que indica un buen ajuste global de la escala.

La validez de convergencia es demostrada por un lado por que las cargas factoriales son significativas y mayores de 0.5 , y por otro lado, por que la varianza media extraída (AVE) para cada uno de los factores es mayor a 0.5. En lo que toca a la confianza de la escala, los índices de confianza compuesta de cada una de las dimensiones obtenidas son mayores a 0.6 . 
Tabla 5.5.

Análisis de la dimensión, confianza y validez de la medida de escalas.

\begin{tabular}{|c|c|c|}
\hline Items & Factor & $\mathrm{t}-\mathrm{Valor}$ \\
\hline \multicolumn{3}{|l|}{ F1 Obtención de crédito $(\mathrm{CR}=0,78 ; \mathrm{AVE}=, 68)$} \\
\hline Obtener el crédito le ha sido sencillo & ,804 & 3,503 \\
\hline En general, le es fácil obtener créditos & ,801 & 2,768 \\
\hline \multicolumn{3}{|l|}{ F2 Información (CR=,73 ;AVE=,55 ) } \\
\hline $\begin{array}{l}\text { Cuenta con los servicios de un Contador que elabore sus } \\
\text { estados financieros }\end{array}$ & ,637 & 5,983 \\
\hline $\begin{array}{l}\text { Sus estados financieros se encuentran revisados y certificados } \\
\text { por auditor externo }\end{array}$ & ,670 & 7,056 \\
\hline $\begin{array}{l}\text { El banco puede disponer con facilidad de una proyección } \\
\text { financiera de su empresa }\end{array}$ & ,766 & 4,390 \\
\hline \multicolumn{3}{|l|}{ F3 Costo del crédito $(\mathrm{CR}=, 78 ; \mathrm{AVE}=, 61)$} \\
\hline $\begin{array}{l}\text { Los intereses pagados por créditos representan un porcentaje } \\
\text { significativo de sus ventas }\end{array}$ & ,913 & 2,200 \\
\hline $\begin{array}{l}\text { Los intereses pagados por créditos representan un porcentaje } \\
\text { significativo de su utilidad de operación }\end{array}$ & ,773 & 3,602 \\
\hline $\begin{array}{l}\text { La tasa de interés es relativamente alta por mi poca experiencia } \\
\text { con los bancos }\end{array}$ & ,497 & 7,938 \\
\hline \multicolumn{3}{|l|}{ F4 Relación de préstamo $(\mathrm{CR}=, 86 ; \mathrm{AVE}=, 63)$} \\
\hline $\begin{array}{l}\text { Se reune constantemente con el personal del banco que le } \\
\text { atiende }\end{array}$ & ,691 & 5,350 \\
\hline $\begin{array}{l}\text { Cuenta con un contacto especial en el banco con el que tramito } \\
\text { los créditos }\end{array}$ & 807 & 4,986 \\
\hline $\begin{array}{l}\text { Los ejecutivos del banco se acercan a usted para conocer sus } \\
\text { necesidades, objetivos, requerimientos }\end{array}$ & ,689 & 5,314 \\
\hline $\begin{array}{l}\text { Tiene asignado un ejecutivo específico del banco para } \\
\text { atenderlo }\end{array}$ & ,744 & 5,149 \\
\hline Cuenta con una relación fuerte con su banco & ,806 & 4,750 \\
\hline \multicolumn{3}{|l|}{ F5 Garantía $(\mathrm{CR}=, 69$;AVE=, 51$)$} \\
\hline $\begin{array}{l}\text { La garantía representa un porcentaje importante del total de } \\
\text { activos de su negocio }\end{array}$ & ,850 & 2,090 \\
\hline $\begin{array}{l}\text { El monto de la garantía es asignado o valuado por la institución } \\
\text { que le otorga el crédito }\end{array}$ & ,424 & 7,609 \\
\hline Perder la garantía significa un riesgo para su operación & ,663 & 4,678 \\
\hline F6 Tasa de interés & 1 & \\
\hline F7 Tamaño de la empresa & 1 & \\
\hline F8 Edad de la empresa & 1 & \\
\hline
\end{tabular}

En la Tabla 5.6. se presentan los estimadores estandarizados de los parámetros principales del modelo final. Se puede corroborar cómo en este modelo todos los parámetros son estadísticamente significativos para un 
nivel de confianza del 95\%. Además, podemos observar que en la mayoría de los casos las cargas estadísticas son bastante elevadas.

Tabla 5.6.

Índices del ajuste del modelo factorial de segundo orden de la percepción de valor.

\begin{tabular}{|l|l|}
\hline & Escala final \\
\hline Medidas absolutas de ajuste & \\
\hline Satorra-Bentler $\boldsymbol{\chi}^{\mathbf{2}}$ & 167.6958 \\
\hline Grados de libertad & 142 \\
\hline Nivel de significación & 0.06938 \\
\hline GFI & 0.875 \\
\hline RMSEA & 0.046 \\
\hline Medidas incrementales de ajuste & \\
\hline BBNNFI & 0.801 \\
\hline CFI & 0.950 \\
\hline IFI & 0.952 \\
\hline MFI & 0.860 \\
\hline AGFI & 0.832 \\
\hline
\end{tabular}

La evaluación de la bondad del ajuste del modelo final viene relatada en la Tabla 5.6. En ella se observa como todos y cada uno de los índices comentados inicialmente alcanzan los valores deseados. Como se muestra en las medidas absolutas de ajuste, observamos que el estadístico sobre la $\chi^{2}$ de Satorra-Bentler nos indica que ésta es altamente significativa. Además, el GFI se sitúa por encima de 0.8 y el RMSEA por debajo de 0.05. Con relación a las medidas incrementales de ajuste, todas tienen un valor de 0.8 , además de que CFI y IFI superan el 0.9. 
Análisis de Validez

Como mencionamos anteriormente, la validez de contenido implica que los indicadores miden todo el concepto. En relación a la validez convergente, ésta indica si los diferentes ítems utilizados para medir el concepto están en realidad correlacionados entre si. Esta se asegura en primer lugar por el ajuste de los modelos, y en especial por la bondad de las medidas de ajuste incremental como el AGFI o la BBNFI. En segundo lugar, la magnitud de las cargas factoriales, con valores superiores o muy cerca de 0.4 (Hair et al., 1998), también nos asegura esta validez. Finalmente, señalar a su vez, la significación estadística de cada carga obtenida entre el indicador y la variable latente (valor t superior a 2.08 para $\alpha=0.05$ ), como apuntaron Luque (2000) y Anderson y Gerbing (1982).

De acuerdo a las variables anteriores, se establecieron las ecuaciones estructurales del modelo resultante a fin de aplicar las técnicas estadísticas comentadas.

Tabla 5.7.

Ecuaciones estructurales

\begin{tabular}{|l|l|l|l|l|l|l|l|}
\hline Constructo & F1 & F2 & F3 & F4 & F5 & F7 & F8 \\
\hline $\begin{array}{l}\text { F1. Obtención de } \\
\text { crédito }\end{array}$ & & -.559 & & .439 & -.278 & & .237 \\
\hline F2. Información & & & & .717 & & & \\
\hline F3. Costo del crédio & & -.529 & & & .435 & -.108 & \\
\hline F6. Tasa de interés & -.080 & & .195 & & & & \\
\hline
\end{tabular}




\subsubsection{Análisis de los modelos estructurales sobre la obtención del crédito}

Una vez estimados y depurados los instrumentos de medida, debemos proceder a contrastar las hipótesis establecidas. La estimación de estos modelos estructurales pretende corroborar la consistencia de las relaciones causales de las variables latentes con los datos.

Las hipótesis establecidas a partir del modelo teórico y que se intentan contrastar empíricamente ahora son las siguientes:

Hipótesis H1: Las empresas con menor requerimiento de información financiera por parte de los bancos tienen mayor oportunidad de conseguir financiamiento cuando lo solicitan.

Hipótesis H2: Las empresas con menor exigencia de garantía tienen mayor oportunidad de conseguir financiamiento cuando lo solicitan.

Hipótesis H3: Las empresas que mantienen una mayor relación con su banco tienen mayor posibilidad, que aquellas empresas carentes de relación, de conseguir financiamiento cuando lo soliciten.

Hipótesis H4: Las empresas con mayor edad o antigüedad tienen mayor oportunidad de conseguir financiamiento cuando lo solicitan.

Hipótesis H5: La relación establecida con el banco cubre la falta de información de la empresa, con ello puede superar su opacidad y conseguir financiamiento cuando lo soliciten. 


\subsubsection{Influencia directa de la información en la obtención del crédito (Hipótesis H1)}

Para la observación de las relaciones causales es necesario que planteemos las distintas fases de la modelización de los análisis estructurales. Para ello, en primer lugar, se realiza la identificación de un modelo donde el número de ecuaciones sea mayor que el número de parámetros. Seguidamente hemos utilizado el método de estimación por máxima verosimilitud pero con la obtención de estimadores robustos. De esta forma hemos modificado el modelo inicial iterativamente hasta alcanzar buenos ajustes.

Especificación

El objeto de esta fase es traducir las hipótesis teóricas en un sistema de ecuaciones. Este modelo inicial observa como variable latente exógena la información financiera $(\mathrm{P}=\xi 1)$, y como variable latente endógena la obtención del crédito tanto para las diferentes dimensiones de éstos como para los resultados globales $(\mathrm{Ri}=\eta 1 \mathrm{i})$.

La inclusión de todos los indicadores individuales en un modelo de ecuaciones estructurales completo, requiere de un elevado tamaño muestral. Para solucionar este problema de complejidad, muchos estudios han optado por la formación de variables compuestas, que utilizan agregados de los indicadores de medida para la modelización estructural. Con este procedimiento reducimos la complejidad del modelo, hecho que facilita su estimación. De hecho, existe controversia en la literatura entre utilizar la suma o la media como variable compuesta; nosotros hemos utilizado la 
suma, por ser éste el procedimiento más usual. De esta forma, para medir las dimensiones individuales de la información, se han considerado 3 diferentes indicadores de esta variable latente. A estos indicadores de la variable les llamaremos $(\mathrm{X} 1=\mathrm{SCONT})$, que indicará la utilización de servicios de un contador; (X2=EFCR), que nos señalará que los estados financieros se encuentran revisados y certificados por un auditor externo y, (X3=PFE), representativo de que el banco puede disponer de una proyección financiera de la empresa.

Figura 5.2.

Diagrama de pasos de los modelos estructurales de la hipótesis H1.

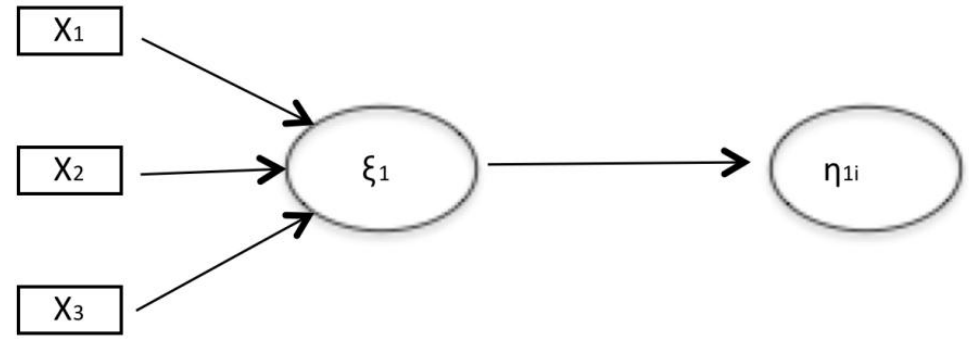

El diagrama de pasos que recoge estas relaciones viene expuesto en la Figura 5.2. Además, en la Figura 5.3. presentamos la traducción de este diagrama en las ecuaciones estructurales que definen el modelo estructural.

Figura 5.3.

Ecuaciones estructurales propuestas en la hipótesis H1.

$$
\begin{aligned}
\mathrm{X}_{1} & =\lambda_{\mathrm{xli}} \xi_{1}+\delta_{1 \mathrm{i}} \\
\mathrm{X}_{2} & =\lambda_{x 2 \mathrm{i}} \xi_{1}+\delta_{2 \mathrm{i}} \\
\mathrm{X}_{3} & =\lambda_{x 3 \mathrm{i}} \xi_{1}+\delta_{3 \mathrm{i}} \\
\eta_{1 \mathrm{i}} & =\beta_{1 \mathrm{i}} \xi_{1}+\xi_{1 \mathrm{i}}
\end{aligned}
$$




\section{Identificación}

La identificación implica que los parámetros del modelo puedan derivarse a partir de las varianzas y covarianzas entre las variables observables, con el fin de que el modelo sea estimable. La condición necesaria es que el número de parámetros sea menor que el número de ecuaciones o elementos distintos de la matriz de varianzas-covarianzas, con el fin de obtener grados de libertad mayores que 0. El programa EQS nos indica los grados de libertad, o la existencia de errores de identificación por la falta de estos.

Estimación

La estimación de los parámetros de un modelo de ecuaciones estructurales se realiza mediante la minimización de una función de discrepancia entre la matriz de varianzas-covarianzas obtenida en la muestra y la matriz de varianzas-covarianzas predicha por el modelo (Luque, 2000).

Una vez el modelo identificado y estimado debemos evaluar el ajuste de nuestros datos al modelo propuesto. El propio Luque recomienda tres niveles de evaluación: evaluación del ajuste del modelo global, evaluación del ajuste del modelo de medida y evaluación del ajuste del modelo estructural.

El ajuste global del modelo normalmente se evalúa mediante las medidas absolutas de ajuste, las medidas incrementales de ajuste, y las medidas de ajuste de parsimonia, tal como detallamos anteriormente, e igual 
que sucedía en los modelos de medida observados en los epígrafes anteriores.

Análisis de Fiabilidad

Tabla 5.8.

Fiabilidad de los segundos modelos de medida de la Hipótesis H1.

\begin{tabular}{|l|l|}
\hline \multicolumn{1}{|c|}{ Indicadores } & Carga Factorial \\
\hline F2 Información $(\mathrm{CR}=, 73 ; \mathrm{AVE}=, 55)$ & \\
\hline SCONT & .637 \\
\hline EFCR & .670 \\
\hline PFE & .766 \\
\hline
\end{tabular}

Una vez que las medidas compuestas han sido formadas de los ítems compartiendo la misma dimensión en la escala de valor percibido, analizamos las propiedad psicométricas de las escalas que forman el modelo. La validez convergente es demostrada en primer lugar por que las cargas factoriales son mayores a 0.5 (Bagozzi, 1980) y en segundo lugar, por que la varianza media extraída (AVE) del constructo es mayor a 0.5 (Fornell y Larcker, 1981). En cuanto a la fiabilidad de la escala, los índices de la fiabilidad compuesta (CR) del constructo es mayor a 0.6 (Bagozzi y Yi, 1988). Esto lo podemos observar en la tabla 5.8.

Dentro de la información financiera se pueden encontrar varios reportes, Collis y Jarvis (2002) mencionan tres fuentes principales de información en la administración de las pymes: las cuentas mensuales o trimestrales de la administración, el flujo de efectivo y los estados de cuenta del banco. Pudiéramos decir que las pymes por el hecho de tener una cuenta en el banco va a tener estos últimos, pero los primeros no se tendrán si no se generan y registran las operaciones. De ahí que hayamos considerado como 
un indicador el saber si la pyme cuenta con una persona que le prepare dicha información. Collis y Jarvis encuentran en su estudio evidencia que contradice a la generalidad de la literatura, pues encontraron en las pymes analizadas, que las practicas de administración financiera son relativamente sofisticadas. Además, encontraron que invariablemente las pymes confían en dos fuentes de información, el banco y un contador externo.

En un estudio de pymes belgas Van Campenhout y Van Caneghem (2009), sus resultados indican que tanto la calidad como la cantidad de información están relacionadas positivamente con el endeudamiento de las pymes. Indicando que su análisis soporta la idea de que la falta de información y la baja calidad de la información limita a las pymes del uso de recursos externos. También mencionan que aquellas empresas que no están obligadas a auditar su información, podrían optar por hacerlo con la finalidad de proporcionar mayor y mejor información. La falta de información verificable es un obstáculo para las pymes (Kano et al., 2006); esto lo podrían proporcionar a través de información auditada. Nosotros hemos mencionado en nuestra hipótesis que si la institución financiera solicita menor cantidad de información la pyme tendrá mayor posibilidad de obtener crédito.

Para Hyytinen y Pajarinen (2008) el estudio de la opacidad de las pymes no se ha ligado al uso de deuda externa, su estudio no confirma la situación de que las pymes opacas tengan mayor restricción de crédito. Internacionalmente, las pymes opacas tienden a recibir menor crédito de los bancos grandes y extranjeros. Dentro de nuestro estudio encontramos que el $15 \%$ de las empresas trabaja con un banco extranjero, aunque tal vez esta estadística sea mayor considerando que el capital de la mayoría de bancos 
en México es foráneo. Para tener información de mayor calidad, Sarapainavich y Kotey (2006) indican en su estudio que además de proporcionar mayor acceso de crédito a las pymes, el gobierno debiera implementar una ayuda para que la empresa pueda mantener sus registros adecuadamente. Haciendo referencia a la historia de México y el gobierno, Cull et al. (2006) indican que las barreras regulatorias pudieran prevenir a las instituciones financieras de países en desarrollo de apoyar a las pymes.

El contar con información dentro de las pymes, además con calidad, puede representar un costo para las empresas. Pero en ocasiones, algunas erogaciones se consideran gastos innecesarios. Hemos visto como varios autores hacen referencia a la importancia de contar con registros de las operaciones, de información confiable, verificable; y esto no solo ayuda a la administración del negocio sino también podrá ser requerimiento para acceder al crédito. Nuestro modelo estudia la influencia que tiene la información sobre la obtención del crédito, y encontramos que hay una relación negativa al respecto, es decir a menor información requerida más facilidad de obtener el crédito. Este hecho corrobora nuestra teoría, al indicar que la información es parte relevante para el otorgamiento de crédito y que entre mayor información proporcione la compañía más facilidad tendrá para recibir un crédito. De esta manera podemos concluir que se cumple esta hipótesis. 


\subsubsection{Influencia directa de la garantía en la obtención del crédito (Hipótesis H2)}

En este epígrafe, continuando con estructura mostrada, se contrasta el modelo teórico en su segunda hipótesis, la cual hace referencia a la influencia de la relación de préstamo de la empresa sobre la obtención del crédito.

\section{Especificación}

El objeto de esta fase es traducir las hipótesis teóricas en un sistema de ecuaciones. Este modelo inicial observa como variable latente exógena la garantía ( $\mathrm{P}=\xi 2)$, y como variable latente endógena la obtención del crédito tanto para las diferentes dimensiones de éstos como para los resultados globales $(\mathrm{Ri}=\eta 1 \mathrm{i})$.

La inclusión de todos los indicadores individuales en un modelo de ecuaciones estructurales completo, requiere de un elevado tamaño muestral. Para solucionar este problema de complejidad, muchos estudios han optado por la formación de variables compuestas, que utilizan agregados de los indicadores de medida para la modelización estructural. Con este procedimiento reducimos la complejidad del modelo, hecho que facilita su estimación. De esta forma, para medir las dimensiones individuales de la información, se han considerado 3 diferentes indicadores de esta variable latente. A estos indicadores de la variable les llamaremos (X4=GPIA), que indicará si la garantía representa un porcentaje importante del total de activos de su negocio; (X5=VGAB), que nos señalará si el valor de la garantía es asignado por el banco que otorga el crédito y, (X6=PGRO), 
representativo de que perder la garantía significa un riesgo para la operación de la empresa.

Figura 5.4.

Diagrama de pasos de los modelos estructurales de la hipótesis H2.

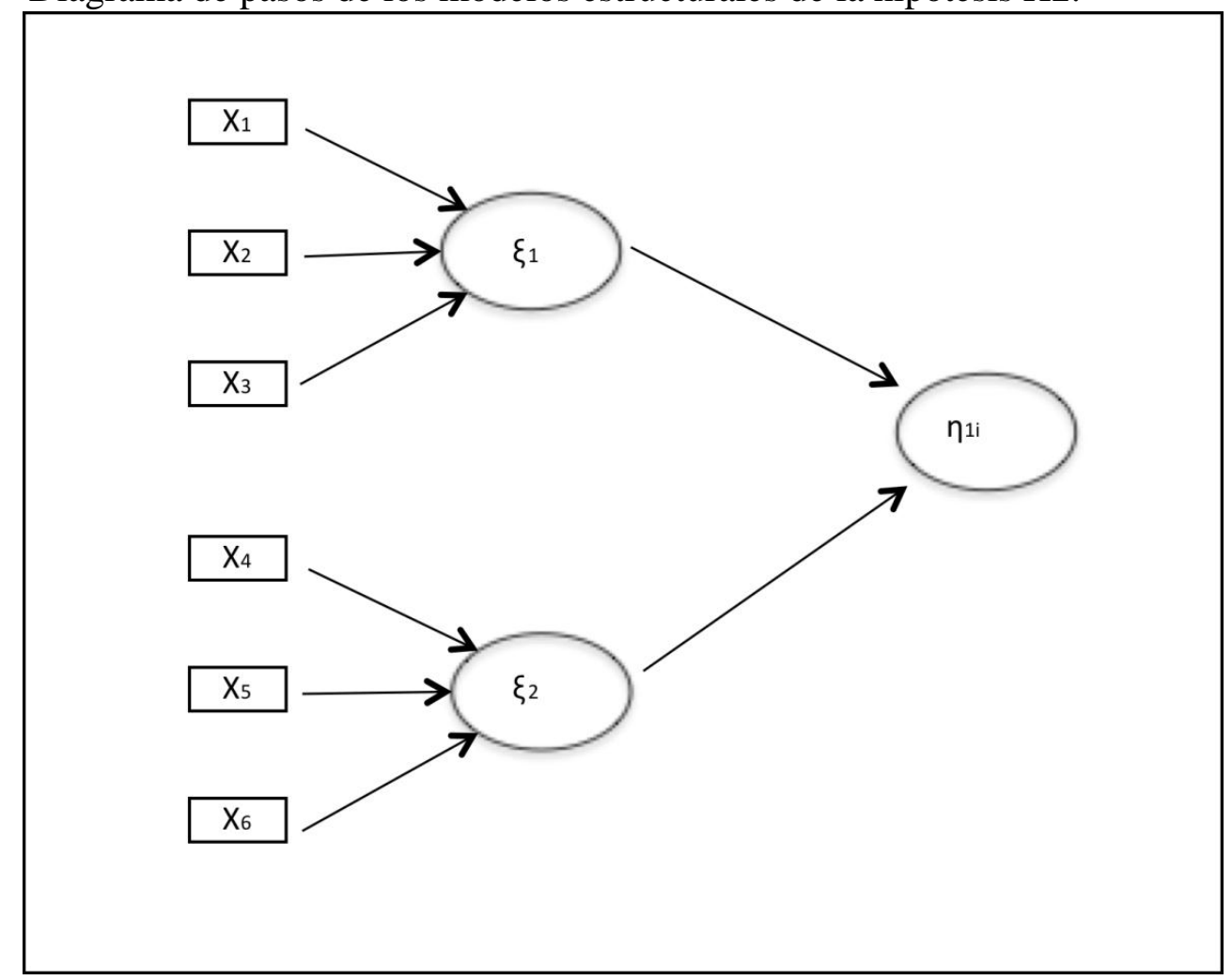

El diagrama de pasos que recoge estas relaciones viene expuesto en la Figura 5.4. Además, en la Figura 5.5. presentamos la traducción de este diagrama en las ecuaciones estructurales que definen el modelo estructural. 
Figura 5.5.

Ecuaciones estructurales propuestas en la hipótesis $\mathrm{H} 2$.

$$
\begin{aligned}
\mathrm{X}_{4} & =\lambda_{\mathrm{x} 4 \mathrm{i}} \xi_{2}+\delta_{4 \mathrm{i}} \\
\mathrm{X}_{5} & =\lambda_{\mathrm{x} 5 \mathrm{i}} \xi_{2}+\delta 5_{\mathrm{i}} \\
\mathrm{X}_{6} & =\lambda_{\mathrm{x} 6 \mathrm{i}} \xi_{2}+\delta 6_{\mathrm{i}} \\
\eta_{1 \mathrm{i}} & =\beta_{1 \mathrm{i}} \xi_{2}+\zeta_{1 \mathrm{i}}
\end{aligned}
$$

\section{Identificación}

La identificación implica que los parámetros del modelo puedan derivarse a partir de las varianzas y covarianzas entre las variables observables, con el fin de que el modelo sea estimable. La condición necesaria es que el número de parámetros sea menor que el número de ecuaciones o elementos distintos de la matriz de varianzas-covarianzas, con el fin de obtener grados de libertad mayores que 0. El programa EQS nos indica los grados de libertad, o la existencia de errores de identificación por la falta de estos.

\section{Estimación}

La estimación de los parámetros de un modelo de ecuaciones estructurales se realiza mediante la minimización de una función de discrepancia entre la matriz de varianzas-covarianzas obtenida en la muestra y la matriz de varianzas-covarianzas predicha por el modelo (Luque, 2000).

Una vez el modelo identificado y estimado debemos evaluar el ajuste de nuestros datos al modelo propuesto. El propio Luque recomienda tres 
niveles de evaluación: evaluación del ajuste del modelo global, evaluación del ajuste del modelo de medida y evaluación del ajuste del modelo estructural.

El ajuste global del modelo normalmente se evalúa mediante las medidas absolutas de ajuste, las medidas incrementales de ajuste, y las medidas de ajuste de parsimonia, tal como detallamos anteriormente, e igual que sucedía en los modelos de medida observados en los epígrafes anteriores.

Análisis de Fiabilidad

Tabla 5.9.

Fiabilidad de los segundos modelos de medida de la Hipótesis H2.

\begin{tabular}{|c|c|}
\hline \multicolumn{1}{|c|}{ Indicadores } & Carga Factorial \\
\hline F5 Garantía $(\mathrm{CR}=, 69 ; \mathrm{AVE}=, 51)$ & \\
\hline GPIA & .850 \\
\hline VGAB & .424 \\
\hline PGRO & .663 \\
\hline
\end{tabular}

Una vez que las medidas compuestas han sido formadas de los ítems compartiendo la misma dimensión en la escala de valor percibido, analizamos las propiedades psicométricas de las escalas que forman el modelo. La validez convergente es demostrada en primer lugar por que las cargas factoriales son mayores a 0.5 (Bagozzi, 1980), a excepción del indicador (valor de garantía asignado por el banco), los otros 2 indicadores son mayores, y en segundo lugar, por que la varianza media extraída (AVE) del constructo es mayor a 0.5 (Fornell y Larcker, 1981). En cuanto a la fiabilidad de la escala, los índices de la fiabilidad compuesta (CR) del 
constructo es mayor a 0.6 (Bagozzi y Yi, 1988). Esto lo podemos observar en la tabla 5.9.

La garantía ha sido requerida para empresas con poca capacidad de crédito (Berger y Udell, 1995). De ahí que ese riesgo supuesto, sea cubierto por los bancos de alguna manera, en este caso en particular con una garantía. En el estudio que realizan Jiménez et al. (2009), sus resultados confirman que la calidad del deudor es la primera determinante del uso de garantía en los préstamos analizados de empresas españolas. La garantía satisface parcialmente el objetivo de aliviar la dificultad de las pymes en cuestión del crédito, mencionan derivado de los resultados de su estudio Kang y Hesmatih (2008).

Cuando las pymes necesitan ofrecer una garantía, sus propias características, su nivel de activos que manejan, puede representar una limitante de no contar con algún bien para contratar el crédito. Así lo menciona Scholtens (1999), comenta que entre más joven y pequeña la empresa, menor capacidad tendrá para ofrecer una garantía Berger y Udell (2004) consideran que la garantía puede ser del negocio, del dueño o algún aval. El otorgar un bien personal puede limitar aún más a la empresa por el riesgo que representa para el dueño. De nuestro estudio algunas personas manifestaron que en lugar de garantía otorgaron un aval.

Nuestro estudio se refirió a determinar como facilita la garantía la obtención del crédito, y hemos visto en estudios anteriores, que para obtenerlo es necesario otorgarla. Coco (2000) comenta que el uso de garantía bajo ciertas condiciones eliminará el racionamiento de crédito y proporcionar el mejor nivel de endeudamiento e inversión. Avery et al. 
(1998) hacen mención que los préstamos recibidos por las pymes en su mayoría están realizados con compromisos personales, más que con bienes de la empresa. Estos resultados mencionan además que casi la mitad de las empresas estudiadas no cuentas con un préstamo y que de los que tienen, solo un $20 \%$ no están asociado con el alto compromiso personal. En nuestro estudio un indicador fue establecido para conocer si la empresa podría en determinado momento otorgar como garantía bienes personales. El estudio mencionado nos indica la relevancia que tiene para las pymes asegurar con bienes fuera del negocio.

Los resultados de nuestro estudio nos indican que la garantía tiene un efecto inverso sobre la obtención del crédito, es decir, a menor garantía requerida más facilidad de obtener el crédito. Situación que nos confirma nuestra hipótesis, aunque después de lo descrito en esta parte de los resultados obtenidos, debemos resaltar lo necesario que puede ser al requerir un crédito. No obstante, en la parte de nuestro modelo donde hacemos referencia a la garantía sobre el crédito podemos considerar que las propuesta se cumple.

\subsubsection{Influencia directa de la relación de préstamo en la obtención del crédito (Hipótesis H3)}

En este epígrafe, con la misma estructura del anterior, se contrasta el modelo teórico en su tercera hipótesis, la cual hace referencia a la influencia de la relación de préstamo de la empresa sobre la obtención del crédito. 
Especificación

El objeto de esta fase es traducir las hipótesis teóricas en un sistema de ecuaciones. Este modelo inicial observa como variable latente exógena la relación de préstamo $(\mathrm{P}=\xi 3)$, y como variable latente endógena la obtención del crédito tanto para las diferentes dimensiones de éstos como para los resultados globales $(\mathrm{Ri}=\eta 1 \mathrm{i})$.

La inclusión de todos los indicadores individuales en un modelo de ecuaciones estructurales completo, requiere de un elevado tamaño muestral. Para solucionar este problema de complejidad, muchos estudios han optado por la formación de variables compuestas, que utilizan agregados de los indicadores de medida para la modelización estructural. Con este procedimiento reducimos la complejidad del modelo, hecho que facilita su estimación. De esta forma, para medir las dimensiones individuales de la información, se han considerado 5 diferentes indicadores de esta variable latente. A estos indicadores de la variable les llamaremos (X7=RCPB), que indicará si la empresa se reúne constantemente con personal del banco que le atiende; (X8=CEB), que nos señalará si se cuenta con un contacto especial en el banco que se tramitan los créditos, (X9=EBAE), representativo de que los ejecutivos del banco se acercan a la empresa para conocer sus necesidades, objetivos, requerimientos, $(\mathrm{X} 10=\mathrm{AEB})$, mostrará si tiene asignado un ejecutivo específico del banco para atenderlo $\mathrm{y}$, (X11=RFB), indicativo de que la empresa cuenta con una relación fuerte con su banco. 
El diagrama de pasos que recoge estas relaciones viene expuesto en la Figura 5.6. Además, en la Figura 5.7. presentamos la traducción de este diagrama en las ecuaciones estructurales que definen el modelo estructural.

Figura 5.6.

Diagrama de pasos de los modelos estructurales de la hipótesis H3.

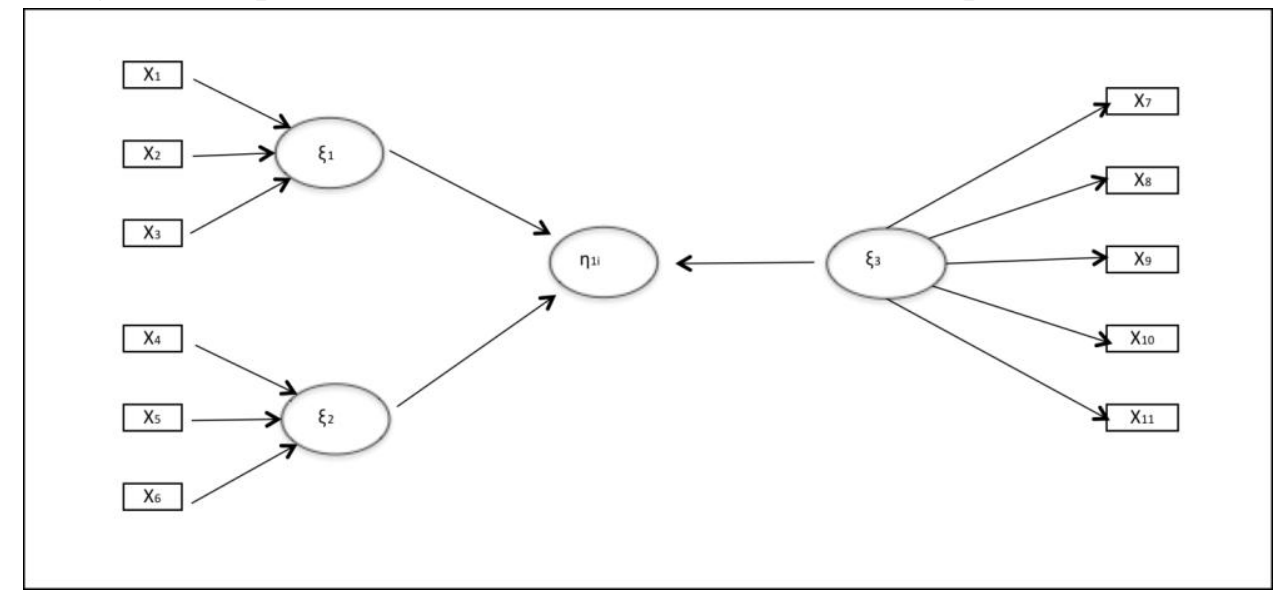

Figura 5.7.

Ecuaciones estructurales propuestas en la hipótesis H3.

$$
\begin{aligned}
\mathrm{X}_{7} & =\lambda_{\mathrm{x} 7 \mathrm{i}} \xi_{3}+\delta 7_{\mathrm{i}} \\
\mathrm{X}_{8} & =\lambda_{\mathrm{x} 8 \mathrm{i}} \xi_{3}+\delta 8_{\mathrm{i}} \\
\mathrm{X}_{9} & =\lambda_{\mathrm{x} 9 \mathrm{i}} \xi_{3}+\delta 9_{\mathrm{i}} \\
\mathrm{X}_{10} & =\lambda_{\mathrm{x} 10 \mathrm{i}} \xi_{3}+\delta_{10_{\mathrm{i}}} \\
\mathrm{X}_{11} & =\lambda_{x 11 \mathrm{i}} \xi_{3}+\delta_{11} \\
\eta_{1 \mathrm{i}} & =\beta_{1 \mathrm{i}} \xi_{3}+\xi_{1 \mathrm{i}}
\end{aligned}
$$




\section{Identificación}

La identificación implica que los parámetros del modelo puedan derivarse a partir de las varianzas y covarianzas entre las variables observables, con el fin de que el modelo sea estimable. La condición necesaria es que el número de parámetros sea menor que el número de ecuaciones o elementos distintos de la matriz de varianzas-covarianzas, con el fin de obtener grados de libertad mayores que 0. El programa EQS nos indica los grados de libertad, o la existencia de errores de identificación por la falta de estos.

Estimación

La estimación de los parámetros de un modelo de ecuaciones estructurales se realiza mediante la minimización de una función de discrepancia entre la matriz de varianzas-covarianzas obtenida en la muestra y la matriz de varianzas-covarianzas predicha por el modelo (Luque, 2000).

Una vez que el modelo se ha identificado y estimado debemos evaluar el ajuste de nuestros datos al modelo propuesto. El propio Luque recomienda tres niveles de evaluación: evaluación del ajuste del modelo global, evaluación del ajuste del modelo de medida y evaluación del ajuste del modelo estructural.

El ajuste global del modelo normalmente se evalúa mediante las medidas absolutas de ajuste, las medidas incrementales de ajuste, y las medidas de ajuste de parsimonia, tal como detallamos anteriormente, e igual 
que sucedía en los modelos de medida observados en los epígrafes anteriores.

Análisis de Fiabilidad

Tabla 5.10.

Fiabilidad de los segundos modelos de medida de la Hipótesis H3.

\begin{tabular}{|c|l|}
\hline \multicolumn{1}{|c|}{ Indicadores } & Carga Factorial \\
\hline F4 Relación de préstamo $(\mathrm{CR}=, 86 ; \mathrm{AVE}=, 63)$ & \\
\hline RCPB & .691 \\
\hline CEB & .807 \\
\hline EBAE & .689 \\
\hline AEB & .744 \\
\hline RFB & .806 \\
\hline
\end{tabular}

Una vez que las medidas compuestas han sido formadas de los ítems compartiendo la misma dimensión en la escala de valor percibido, analizamos las propiedades psicométricas de las escalas que forman el modelo. La validez convergente es demostrada en primer lugar por que las cargas factoriales son mayores a 0.5 (Bagozzi, 1980) y en segundo lugar, por que la varianza media extraída (AVE) del constructo es mayor a 0.5 (Fornell y Larcker, 1981). En cuanto a la fiabilidad de la escala, los índices de la fiabilidad compuesta (CR) del constructo es mayor a 0.6 (Bagozzi y Yi, 1988). Esto lo podemos observar en la tabla 5.10.

El incluir en nuestro modelo las principales variables que se manejan en la literatura sobre el crédito a pymes, por supuesto nos determinó tomar en cuenta a la relación de préstamo, una de las principales tecnologías de crédito. Usada esta variable tanto para ayudar a disminuir el costo del crédito, cubrir la opacidad de las empresas y sustituirse por el uso de la garantía, mencionada en la anterior hipótesis; nosotros en esta hipótesis H3 
la señalamos para determinar como influye directamente en la obtención del crédito.

La relación de préstamo se puede dar con un solo banco o ser múltiple, las características de una y otra pueden varias, pero en el fondo representan ambas una ventaja para la pyme. Por ejemplo, los resultados de Hernández-Cánovas y Martínez-Solano (2006) indican que las pymes que trabajan con menos bancos obtienen deuda a un menor costo. Varios indicadores fueron considerados en nuestra encuesta, y aunque al final los ítems considerados en nuestro estudio se enfocaron en el aspecto de la relación entre la empresa y el banco, un dato arrojado de dicho análisis nos señala que la mitad de las empresas trabajan con un solo banco, y esta proporción va disminuyendo respecto al número de bancos con los que se trabaja. Lo que indica que, de acuerdo a nuestra muestra, la relación múltiple no está arraigada en las empresas. En Suiza, por ejemplo, Neuberger et al. (2008) nos mencionan que las pymes cuentan con pocas relaciones bancarias, y el número de relaciones se incrementa con el tamaño.

El contar con información referente al contacto entre la empresa y el banco, el tener una persona en particular que atiende a la empresa por parte de la institución financiera, el saber si personal del banco para conocer nuestras necesidades y ayudarnos en cubrirlas, y determinar como considera la empresa su relación en cuestión de fortaleza; hizo conocer el impacto de este tipo de relaciones en su acceso al crédito. Estudiando el efecto de este tipo de relaciones en empresas españolas, Cardone et al. (2005) encuentran que las pymes que tienen varios bancos y largas relaciones con dichos bancos tiene mayor acceso al crédito. Los resultados de nuestro estudio 
arrojan que casi el $40 \%$ de las empresas cuenta con relaciones mayores a 10 años de antigüedad, y esto es una ventaja de acuerdo a estos estudios.

Algunos autores han encontrado que no siempre puede resultar una ventaja la relación de préstamo para las empresa. Otro estudio de Hernández-Cánovas y Martínez-Solano (2010) indica que las empresas con largas relaciones puede tener mayor acceso al crédito, pero también pueden tener altos costos financieros. Sus resultados muestran que hay un límite para el grado de concentración en las relaciones, así comentan que pymes con dos relaciones tienen menores cargos de intereses, seguidas por pymes con una sola relación, mientras que empresas con más de dos relaciones con bancos tiene la deuda más cara.

El fortalecimiento de una relación se puede dar a través de los servicios que la empresa utiliza del banco, los resultado de nuestro estudio nos indica que el 70\% de las empresas solo ocupa entre 1 y 3 servicios de la institución financiera, esto nos indica que las empresas utilizan lo mínimo indispensable de los servicios bancarios; esto pudiera interpretarse como hacerlo exclusivamente por necesidad o lo mínimo que se requiera. Binks y Ennew (1997), hacen una observación interesante a este respecto, mencionan que la mayoría de pymes no necesitan una relación cercana con sus bancos por que los servicios que requieren son simples. Pero, haciendo referencia a nuestro tema, vemos la importancia que refiere para el acceso al crédito.

Vickery (2008) menciona que los bancos con la relación a través del tiempo se vuelven más eficientes al supervisar la información privada, con lo cual aquellas empresas con fuertes relaciones con su banco tienen mayor 
acceso a financiamiento. Aunque también encontramos estudios con resultados diferente, como el de Cole (1998), en el cual encuentra que un potencial prestamista otorgará crédito a una empresa con la cual tiene una relación preexistente, pero que la duración de esta relación no es importante. Si nos referimos al banco, la relación puede ser una ventaja para los más pequeños frente a los grandes, como muestra un estudio de Elyasiani y Goldberg (2004), lo cual puede servir como ventaja para la pyme también.

Nuestro modelo deriva la influencia que tiene la relación de préstamo sobre la obtención del crédito, y obtenemos un resultado positivo, entre mayor sea la relación existente entre la empresa y su banco mayor facilidad tendrá para obtener el crédito. Como hemos planteado desde un principio, consideramos que la relación de préstamo es fundamental en el tema de deuda vía financiamiento; esto abre una oportunidad para las pymes, que normalmente no la ven como una oportunidad pero sí como una carga en sus operaciones. La competencia en México de los servicios bancarios se traduce en un oferta alta, con lo cual las pymes pueden tomar ventaja de este respecto y buscar las alternativas que puedan lograrse un mejor beneficio, ya sea mediante un solo banco o mediante múltiples relaciones.

\subsubsection{Influencia directa de la antigüedad de la empresa en la obtención del crédito (Hipótesis H4)}

En este epígrafe, continuando con estructura mostrada, se contrasta el modelo teórico en su cuarta hipótesis, la cual hace referencia a la 
influencia de la relación de préstamo de la empresa sobre la obtención del crédito.

Especificación

El objeto de esta fase es traducir las hipótesis teóricas en un sistema de ecuaciones. Este modelo inicial observa como variable latente exógena la edad de la empresa $(\mathrm{P}=\xi 4)$, y como variable latente endógena la obtención del crédito tanto para las diferentes dimensiones de éstos como para los resultados globales $(\mathrm{Ri}=\eta 1 \mathrm{i})$.

La inclusión de todos los indicadores individuales en un modelo de ecuaciones estructurales completo, requiere de un elevado tamaño muestral. Para solucionar este problema de complejidad, muchos estudios han optado por la formación de variables compuestas, que utilizan agregados de los indicadores de medida para la modelización estructural. Con este procedimiento reducimos la complejidad del modelo, hecho que facilita su estimación. A diferencia de las otras variables exógenas descritas hasta el momento, para la antigüedad de la empresa se cuenta con solo un indicador, a este indicador de la variable le llamaremos (X12=AE), que indicará la antigüedad o años de operación de la empresa. El diagrama de pasos que recoge estas relaciones viene expuesto en la Figura 5.8. La cual adiciona el efecto que tiene la antigüedad de la empresa en la obtención de crédito. 
Figura 5.8.

Diagrama de pasos de los modelos estructurales de la hipótesis H4.

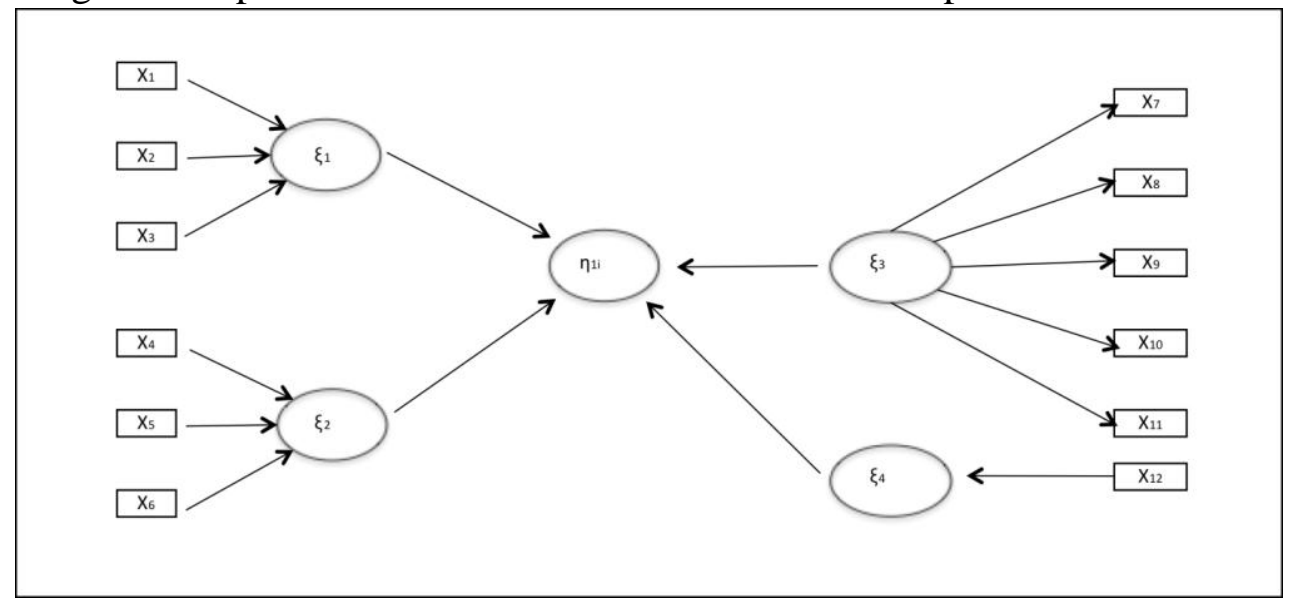

Identificación

La identificación implica que los parámetros del modelo puedan derivarse a partir de las varianzas y covarianzas entre las variables observables, con el fin de que el modelo sea estimable. La condición necesaria es que el número de parámetros sea menor que el número de ecuaciones o elementos distintos de la matriz de varianzas-covarianzas, con el fin de obtener grados de libertad mayores que 0. El programa EQS nos indica los grados de libertad, o la existencia de errores de identificación por la falta de estos.

Estimación

La estimación de los parámetros de un modelo de ecuaciones estructurales se realiza mediante la minimización de una función de discrepancia entre la matriz de varianzas-covarianzas obtenida en la muestra y la matriz de varianzas-covarianzas predicha por el modelo (Luque, 2000). 
Una vez que el modelo se ha identificado y estimado debemos evaluar el ajuste de nuestros datos al modelo propuesto. El propio Luque recomienda tres niveles de evaluación: evaluación del ajuste del modelo global, evaluación del ajuste del modelo de medida y evaluación del ajuste del modelo estructural.

El ajuste global del modelo normalmente se evalúa mediante las medidas absolutas de ajuste, las medidas incrementales de ajuste, y las medidas de ajuste de parsimonia, tal como detallamos anteriormente, e igual que sucedía en los modelos de medida observados en los epígrafes anteriores.

Análisis de Fiabilidad

Tabla 5.11.

Fiabilidad de los segundos modelos de medida de la Hipótesis H4.

\begin{tabular}{|c|}
\hline \multicolumn{1}{|c|}{ Indicadores } \\
\hline F8 Edad de la empresa \\
\hline $\mathrm{AE}$ \\
\hline
\end{tabular}

Una vez que las medidas compuestas han sido formadas de los ítems compartiendo la misma dimensión en la escala de valor percibido, analizamos las propiedades psicométricas de las escalas que forman el modelo. La varianza media extraída (AVE) del constructo es medida con un solo indicador y no tenemos problema con su valor. Dicho indicador se presenta para efectos de presentación Tabla 5.11.

Hemos aprendido que uno de los obstáculos que encuentran las empresas para obtener el crédito es respecto a su antiguiedad. Como lo han comentado diversos autores analizados, estas empresas no suelen contar con 
historial de crédito, tal vez no tienen nombre reconocido en el medio, o no cuentan con referencias comerciales. Esto pudiera cubrirse en el mediano plazo, pero las pymes pueden llegar a tener problemas de supervivencia en este tiempo. Love y Mylenko (2003) al evaluar una base datos sobre historial de las empresas en temas crediticios, revisan si tiene algún efecto en empresas jóvenes y antiguas. Las empresas más jóvenes normalmente no cuentan con historial.

Gregory et al. (2005), señala que las empresas antiguas, por definición han tenido mayor oportunidad para acumular utilidades que las empresas jóvenes, y así más fondos que están disponibles para financiar las operaciones de crecimiento. Esto hace más necesario que las jóvenes utilicen fondos externos. Gregory et al., (2005) elaboran un estudio que analiza el modelo del ciclo de crecimiento financiero de las pymes, el cual postula que las empresas cuando se hacen más grandes, más antiguas y con mayor información encuentran opciones de financiamiento más atractivas.

Este obstáculo de la edad de la empresa puede generar otros obstáculos, así lo comentan Hyytinen y Pajarinen (2008) en cuyo estudio sus resultados muestran un efecto negativo a la edad de la empresa, lo cual sugiere que mientras más joven la empresa más opaca es. Beck (2007) analiza encuestas realizadas por el Banco Mundial, en el cual encuentra que las pymes tienen mayor dificultad para recibir financiamiento que las empresas grandes, y además, las más jóvenes y nacionales reportaron mayores obstáculos. Klapper et al. (2002) identifican la afectación en cuanto al financiamiento de acuerdo a la edad de las empresas. Muestran que dentro de los primeros 3 años de operación el $85 \%$ son pymes, porcentaje que se ve reducido en las empresas mayores a 10 años cuyas pymes abarcan el 59\% en 
este análisis. Nuestro estudio indica que el $37 \%$ de la muestra encuestada tiene hasta 10 años de antigüedad.

Si esta es la misma tendencia que encontramos al día de hoy, podemos estimar que la mayoría de empresas de nueva creación se enfrentarán al problema de financiamiento, de obtener crédito. Si no cuentan con el capital suficiente en un inicio, o alternativas de financiamiento como amigos, familiares o fuentes con costos muy caros,; así como señala Vos et al., (2007), los negocios más nuevos (menores a 3 años) son más propensos a usar "ahorros personales, familiares, amigos y tarjetas de crédito. Por ello deben considerar que mientras no acumulen la experiencia, antigüedad e historial suficiente, no tendrán mayor acceso al crédito.

Los resultados de nuestro estudio corroboran la hipótesis establecida sobre la edad de la empresa. La antigüedad de la empresa tiene un efecto directo positivo sobre la obtención del crédito, es decir, a mayor antigüedad mayor facilidad de obtener el crédito. Este hecho corrobora nuestra teoría, al indicar que la edad de la empresa puede influir positivamente para la obtención de préstamos. Una empresa entre más antigua, cuenta ya con un historial importante, si no de créditos, si en cuanto a referencias comerciales, disminuye el riesgo de permanencia, al hacer constatar que ya ha operado en el mercado por cierto tiempo, y ayudará a la compañía a cultivar una relación con sus bancos. 


\subsubsection{Influencia directa de la relación de préstamo sobre la información de la empresa (Hipótesis H5)}

En este epígrafe se hace referencia a la quinta hipótesis del modelo, en la cual la relación de préstamo y la información se conjuntan, mostrando la influencia de la relación de préstamo sobre la información generada por la empresa cuando tramita un crédito.

Especificación

El objeto de esta fase es traducir las hipótesis teóricas en un sistema de ecuaciones. Este modelo inicial observa como variable latente exógena la relación de empresa $(\mathrm{P}=\xi 5)$, y como variable latente endógena la información financiera tanto para las diferentes dimensiones de éstos como para los resultados globales $(\mathrm{Ri}=\eta 2 \mathrm{i})$.

La inclusión de todos los indicadores individuales en un modelo de ecuaciones estructurales completo, requiere de un elevado tamaño muestral. Para solucionar este problema de complejidad, muchos estudios han optado por la formación de variables compuestas, que utilizan agregados de los indicadores de medida para la modelización estructural. Con este procedimiento reducimos la complejidad del modelo, hecho que facilita su estimación. 
Figura 5.9.

Diagrama de pasos de los modelos estructurales de la hipótesis H5.

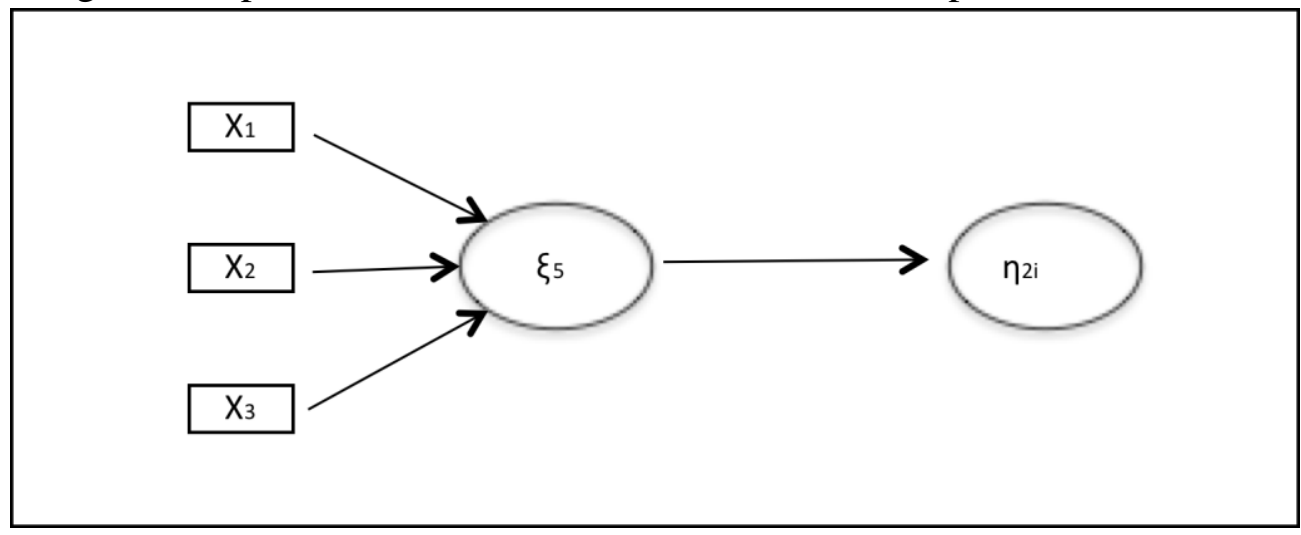

El diagrama de pasos que recoge estas relaciones viene expuesto en la Figura 5.9. La cual muestra el efecto que tiene la relación de préstamo en la información de la empresa en la obtención de crédito.

\section{Identificación}

La identificación implica que los parámetros del modelo puedan derivarse a partir de las varianzas y covarianzas entre las variables observables, con el fin de que el modelo sea estimable. La condición necesaria es que el número de parámetros sea menor que el número de ecuaciones o elementos distintos de la matriz de varianzas-covarianzas, con el fin de obtener grados de libertad mayores que 0. El programa EQS nos indica los grados de libertad, o la existencia de errores de identificación por la falta de estos. 


\section{Estimación}

La estimación de los parámetros de un modelo de ecuaciones estructurales se realiza mediante la minimización de una función de discrepancia entre la matriz de varianzas-covarianzas obtenida en la muestra y la matriz de varianzas-covarianzas predicha por el modelo (Luque, 2000).

Una vez que el modelo se ha identificado y estimado debemos evaluar el ajuste de nuestros datos al modelo propuesto. El propio Luque recomienda tres niveles de evaluación: evaluación del ajuste del modelo global, evaluación del ajuste del modelo de medida y evaluación del ajuste del modelo estructural.

El ajuste global del modelo normalmente se evalúa mediante las medidas absolutas de ajuste, las medidas incrementales de ajuste, y las medidas de ajuste de parsimonia, tal como detallamos anteriormente, e igual que sucedía en los modelos de medida observados en los epígrafes anteriores.

\section{Análisis de Fiabilidad}

Tabla 5.12.

Fiabilidad de los segundos modelos de medida de la Hipótesis H5.

\begin{tabular}{|l|l|}
\hline \multicolumn{1}{|c|}{ Indicadores } & Carga Factorial \\
\hline F4 Relación de préstamo $(\mathrm{CR}=, 86 ; \mathrm{AVE}=, 63)$ & \\
\hline RCPB & .691 \\
\hline CEB & .807 \\
\hline EBAE & .689 \\
\hline AEB & .744 \\
\hline RFB & .806 \\
\hline
\end{tabular}


Una vez que las medidas compuestas han sido formadas de los ítems compartiendo la misma dimensión en la escala de valor percibido, analizamos las propiedades psicométricas de las escalas que forman el modelo. La validez convergente es demostrada en primer lugar por que las cargas factoriales son mayores a 0.5 (Bagozzi, 1980) y en segundo lugar, por que la varianza media extraída (AVE) del constructo es mayor a 0.5 (Fornell y Larcker, 1981). En cuanto a la fiabilidad de la escala, los índices de la fiabilidad compuesta (CR) del constructo es mayor a 0.6 (Bagozzi y Yi, 1988). Esto lo podemos observar en la tabla 5.12.

Así como analizamos la relación de préstamo en cuanto al beneficio que tiene la empresa de contar con esta técnica para obtener crédito. Comentamos que puede ayudar también respecto a otras restricciones que le puede surgir a la pyme. Una de ellas analizadas en la primera hipótesis es la opacidad. La falta de información que hace que la empresa no pueda justificar a la institución financiera su capacidad para cumplir el compromiso que contraiga. Señalamos en nuestro modelo que la relación de préstamo puede tener una influencia sobre la información.

Hay un estudio realizado por Behr et al. (2011), en el cual mencionan que los deudores deben hacer un gran esfuerzo la primera vez que tramitan un crédito, pero que el esfuerzo se reduce en los siguientes préstamos. Señalan que es de considerar pues el grado de asimetría en la información debiera ser mayor cuando existe el primer contacto entre la empresa y el banco.

Habíamos comentado que la relación de préstamo se puede dar entre uno o más bancos. Berger et al. (2001) contrastando una hipótesis, 
mencionan que las empresas opacas tienden a contar con una sola relación de préstamo, mientras que el tener más relaciones dependerá de las condiciones financieras de la empresa, además de que esta se asegura de contar con más opciones en caso de que su banco principal se encuentre en dificultades financieras. Nuestros resultados arrojan, sobre las operaciones entre la empresa y los bancos, que más del $50 \%$ de las empresas cuentan con una sola relación, y en consecuencia, representan el $100 \%$ de sus operaciones, mientras que el $37 \%$ de empresas con varias relaciones concentra entre el $60 \%$ y el $99 \%$ de operaciones con su banco principal. Petersen y Rajan (1994) hacen mención que las pymes tiene gran parte de su deuda de aquellos bancos que les proporcionan servicios financieros informacionalmente intensivos.

La relación se inicia precisamente desde los servicios que empieza a usar la empresa de las instituciones financieras. Así nos comenta Cole (1998), quien indica en su estudio que el uso de diferentes servicios financieros afecta la disponibilidad del crédito, considerando que un banco le extenderá crédito a quién ya cuenta con una cuenta de ahorro y servicios financieros. Y comenta que el banco genera información privada valiosa rápidamente de estas relaciones. También De la Torre et al. (2010), coinciden en que los bancos pequeños puedan superar la opacidad mediante la relación con las empresas. Y se da por lo general, pues la atención suele ser más personalizada, la posición de un banco más grande en cuanto a la asignación de un ejecutivo en particular no es tanta como la de un banco más pequeño.

La hipótesis formulada indicaba que la relación de préstamo tiene un efecto directo sobre la información, un efecto positivo. Los resultados 
indican que se corrobora esta aseveración, la relación de préstamo puede subsanar la poca información que tenga la empresa y que deba ser sujeta de análisis para el crédito, es así que la relación de préstamo atenúa o elimina este obstáculo que suelen tener las pymes. Así que podemos concluir que se recomienda a las pymes el contar con una relación, sea esta única o múltiple, pues si es opaca, podrá beneficiarse, mientras se encarga de corregir su opacidad.

\subsubsection{Análisis de los modelos estructurales que indican la influencia de variables sobre el costo del crédito.}

Una vez estimados y depurados los instrumentos de medida indicativos de las variables endógenas que influyen en la variable exógena "obtención de crédito", , vamos a proceder a contrastar las hipótesis que señalan la influencia de algunas variables en el costo del crédito. La estimación de estos modelos estructurales pretende corroborar la consistencia de las relaciones causales de las variables con los datos. En concreto, las hipótesis que se deducen del modelo teórico:

H6: El costo del crédito se ve afectado por la información financiera otorgada por la empresa, a menor información financiera otorgada por la empresa el costo del crédito será más alto.

H7: El costo del crédito se ve afectado por el tamaño de la empresa, a menor tamaño de la misma el costo del crédito será más alto. 
H8: El costo del crédito varía en función del nivel de la garantía otorgada por la empresa, así, las empresas obtienen un menor costo de crédito cuando otorgan una mayor garantía.

Para la observación de las relaciones causales es necesario que planteemos las distintas fases de la modelización de los análisis estructurales. En estas etapas vamos a seguir los mismos procedimientos observados en las anteriores modelizaciones estructurales. Estas se concretan en primer lugar en la identificación de un modelo donde el número de ecuaciones sea mayor que el número de parámetros. Seguidamente hemos utilizado el método de estimación por máxima verosimilitud pero con la obtención de estimadores robustos.

\section{Especificación}

El objeto de esta fase es el traducir las hipótesis teóricas en un sistema de ecuaciones. Este modelo inicial observa como variables latentes exógenas la información financiera $(\mathrm{IF}=\xi 1)$, el tamaño de la empresa $(\mathrm{TE}=$ $\xi 2)$ y la garantía $(\mathrm{G}=\xi 3)$. Como variable latente endógena se incluye el costo del crédito, medida por un agregado que recoge las diferentes dimensiones planteadas anteriormente $(\mathrm{CI}=\eta 1)$.

En los epígrafes anteriores hemos comprobado la bondad de los modelos de medida para observar como ciertas variables exógenas influyen en la obtención de crédito. La inclusión de todos los indicadores individuales en un modelo de ecuaciones estructurales completo requiere de un elevado tamaño muestral y de unos medios técnicos más potentes de los que disponemos con nuestro programa y nuestro ordenador. Para solucionar 
este problema de complejidad muchos estudios han optado por la formación de variables compuestas, que utilizan agregados de los indicadores de medida para la modelización estructural. Este procedimiento reduce la complejidad y facilita la estimación, como hemos relatado anteriormente, hecho que justifica su utilización en la presente tesis.

De esta forma, para medir las dimensiones individuales de las diferentes variables se han utilizado tres, uno y tres indicadores, respectivamente, de cada una de las variables latentes de primer orden. A estos indicadores les llamaremos: $(\mathrm{X} 1=\mathrm{SCONT})$, que indicará la utilización de servicios de un contador; (X2=EFCR), que nos señalará que los estados financieros se encuentran revisados y certificados por un auditor externo, (X3=PFE), representativo de que el banco puede disponer de una proyección financiera de la empresa; (X4=TE), que indicará el tamaño de la empresa; (X5=GPIA), que indicará si la garantía representa un porcentaje importante del total de activos de su negocio; (X6=VGAB), que nos señalará si el valor de la garantía es asignado por el banco que otorga el crédito y, $(\mathrm{X} 7=\mathrm{PGRO})$, representativo de que perder la garantía significa un riesgo. No obstante, y como señalamos anteriormente, estos 7 indicadores se concretarán en tres variables latentes de segundo orden, que vendrán señaladas como $(\mathrm{IF}=\xi 1)$, que se referirá a la información financiara; (TE =

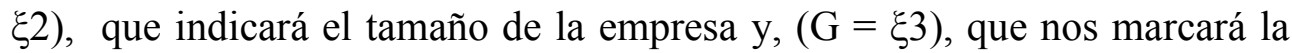
garantía. 
Figura 5.10.

Diagrama de pasos de los modelos estructurales de las hipótesis H6, H7 y H8.

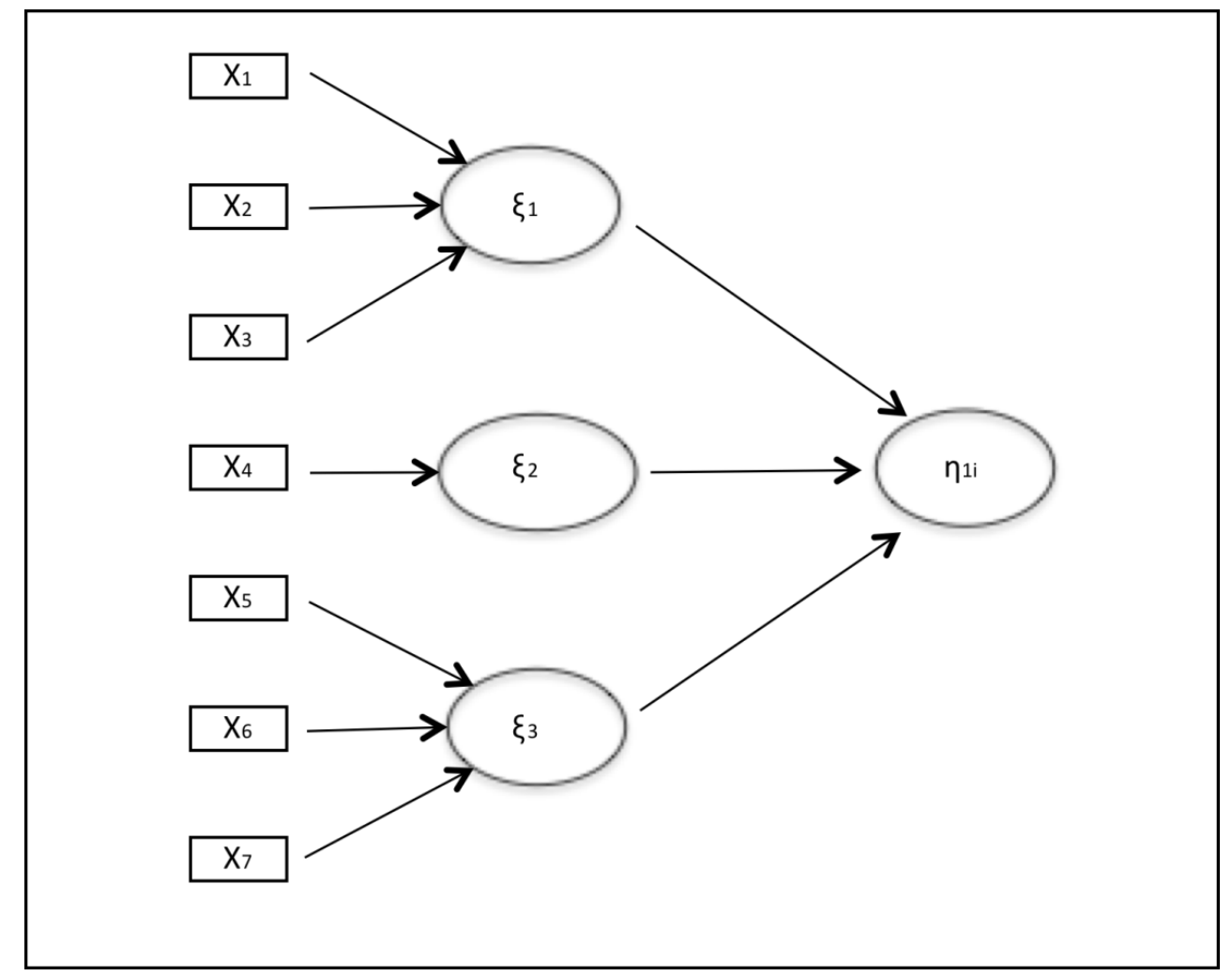

Con relación a la variables endógenas, hemos optado por una variable latente, denominada $(\mathrm{CI}=\eta 1)$. A su vez, esta variable endógena vendrá explicada por las tres variables latentes de segundo orden, las cuales, al representar entre sí un constructo común indicativo de las capacidades directivas, covariarán conjuntamente.

En el diagrama de pasos de la Figura 5.10. se recogen estas relaciones. Además, presentamos a continuación, en la Figura 5.11., la traducción de este diagrama en las ecuaciones estructurales que definen el modelo estructural. 
Figura 5.11.

Ecuaciones estructurales propuestas en las hipótesis H6, H7, H8.

$\mathrm{X}_{1}=\lambda_{\mathrm{x} 11} \xi_{1}+\delta_{1}$

$\mathrm{X}_{2}=\lambda_{\mathrm{x} 21} \xi_{1}+\delta_{2}$

$\mathrm{X}_{3}=\lambda_{\mathrm{x} 31} \xi_{1}+\delta_{3}$

$\mathrm{X}_{4}=\lambda_{\mathrm{xil}} \xi_{2}+\delta 4_{\mathrm{i}}$

$\mathrm{X}_{5}=\lambda_{\mathrm{x} 5 \mathrm{i}} \xi_{3}+\delta 5_{\mathrm{i}}$

$\mathrm{X}_{6}=\lambda_{\mathrm{x} 6 \mathrm{i}} \xi_{3}+\delta_{6 \mathrm{i}}$

$\mathrm{X}_{7}=\lambda_{\mathrm{x} 7 \mathrm{i}} \xi_{3}+\delta 7_{\mathrm{i}}$

$\eta_{1 \mathrm{i}}=\beta_{1} \xi_{1}+\beta_{2} \xi_{2}+\beta_{3} \xi_{3}+\xi_{1 \mathrm{i}}$

Identificación

La identificación implica que los parámetros del modelo puedan derivarse a partir de las varianzas y covarianzas entre las variables observables. La condición necesaria es que el número de parámetros sea menor que el número de ecuaciones, con el fin de obtener grados de libertad positivos. El programa EQS nos indica los grados de libertad, o la existencia de errores de identificación por la falta de estos.

Estimación

La estimación de los parámetros de un modelo de ecuaciones estructurales se realiza nuevamente aplicando el método de máxima verosimilitud con la obtención de estimadores robustos.

Procedamos ahora al ajuste del modelo de medida, para identificar si los parámetros estimados son o no significativos. En la tabla 5.13. se recogen las cargas factoriales, que indicarán la validez de cada indicador. En 
esta tabla se puede observar cómo todas las cargas factoriales de los modelos de medida superan el valor de 0.4 (Hair et al., 1998). Podemos además corroborar que todas las cargas factoriales son estadísticamente significativas. La conclusión de estos resultados implica que todos los indicadores utilizados tienen un peso importante sobre los conceptos teóricos que miden.

Tabla 5.13.

Parámetros estimados de las variables en el modelo estimado de las hipótesis H6, H7 y H8.

\begin{tabular}{|l|l|l|l|}
\hline & \multicolumn{3}{|c|}{ Modelos variables sobre costos de intereses } \\
\hline Medidas & \multicolumn{1}{|c|}{ IF } & TE & G \\
\hline Exógenas & & & \\
\hline $\mathrm{X}_{1}$ & .642 & & \\
\hline $\mathrm{X}_{2}$ & .658 & & \\
\hline $\mathrm{X}_{3}$ & .785 & & \\
\hline $\mathrm{X}_{4}$ & & & \\
\hline $\mathrm{X}_{5}$ & & & .925 \\
\hline $\mathrm{X}_{6}$ & & & .382 \\
\hline $\mathrm{X}_{7}$ & & & .614 \\
\hline
\end{tabular}

Observada la significación, debemos atender fiabilidad individual de los diferentes indicadores, es decir, la varianza que el indicador tiene en común con la variable latente a la que mide y la que se debe al error. Como observamos en los apartados anteriores nosotros mediremos esta fiabilidad con la carga factorial de los indicadores, que debía ser superior a 0.5.

Podemos constatar, como se muestra en la Tabla 5.14, que en la mayoría de los modelos se obtienen altas fiabilidades, tanto conjuntas como individuales. Una vez que las medidas compuestas han sido formadas de los 
ítems compartiendo la misma dimensión en la escala de valor percibido, analizamos las propiedades psicométricas de las escalas que forman el modelo. La validez convergente es demostrada en primer lugar por que las cargas factoriales son mayores a 0.5 (Bagozzi, 1980), a excepción del indicador $\mathrm{X}_{6}$ de la garantía; y en segundo lugar, por que la varianza media extraída (AVE) de cada constructo es mayor a 0.5 (Fornell y Larcker, 1981). En cuanto a la fiabilidad de la escala, los índices de la fiabilidad compuesta (CR) del constructo es mayor a 0,6 (Bagozzi y Yi, 1988).

Tabla 5.14.

Fiabilidad de los modelos de medida de las hipótesis H6, H7 y H8.

\begin{tabular}{|l|l|l|l|l|l|}
\hline & & \multicolumn{1}{|c|}{ CR } & AVE & Indicadores & $\begin{array}{c}\text { Carga } \\
\text { Factorial }\end{array}$ \\
\hline Modelo & Constructos & & & & \\
\hline $\begin{array}{l}\text { Modelo } \\
\text { Estructural }\end{array}$ & Información & 0.73 & 0.55 & $\mathrm{X}_{1}$ & 0.637 \\
& & & & $\mathrm{X}_{2}$ & 0.670 \\
& & & & $\mathrm{X}_{3}$ & 0.766 \\
\hline & Tamaño de la & & & $\mathrm{X}_{4}$ & \\
& empresa & & & & \\
\hline & Garantía & 0.69 & 0.51 & $\mathrm{X}_{5}$ & 0.850 \\
& & & & $\mathrm{X}_{6}$ & 0.424 \\
& & & & $\mathrm{X}_{7}$ & 0.663 \\
\hline
\end{tabular}

Corroborados los ajustes del modelo global y del modelo de medida, debemos prestar atención al ajuste del modelo estructural estimado. Para ello debemos observar el nivel de significación de los parámetros estimados y la fiabilidad de las ecuaciones estructurales, aspectos reflejados en la Tabla 5.15. 
Tabla 5.15.

Parámetros estimados en el modelo estructural de las hipótesis H6, H7 y H8.

\begin{tabular}{|l|l|l|}
\hline \multicolumn{1}{|c|}{ Variables } & \multicolumn{1}{|c|}{ Indicadores } & Valor t \\
\hline IF & $\mathrm{X}_{1}$ & 5.983 \\
& $\mathrm{X}_{2}$ & 7.056 \\
& $\mathrm{X}_{3}$ & 4.390 \\
\hline TE & $\mathrm{X}_{4}$ & \\
\hline $\mathrm{G}$ & $\mathrm{X}_{5}$ & 2.090 \\
& $\mathrm{X}_{6}$ & 7.609 \\
& $\mathrm{X}_{7}$ & 4.678 \\
\hline
\end{tabular}

De acuerdo a las hipótesis resultantes de la relación con los costos de intereses, observamos que todas y cada una de éstas se corroboran. En primer lugar se contrasta la relación que engloba la información financiera, el tamaño de empresa y la garantía con el costo del crédito. En este modelo se observa además como todos y cada uno de los factores explicativos de estas capacidades adquiridas son altamente significativos, y con cargas factoriales mayores a 0.4 , hecho que indica que todas las variables aportan información al modelo, y por tanto todos los indicadores tienen un peso importante sobre el concepto teórico indicativo del costo del crédito.

Puntualizando que no todos los valores de las cargas factoriales son mayores a 0.5 . Recordemos que el análisis del coeficiente de correlación al cuadrado señala la proporción de la varianza que tiene en común con el constructo, y no se debe al termino error. No obstante, en el análisis individual de cada una de estas variables obtuvimos fiabilidades de las escalas bastante apropiadas. 
Aunque podemos resumir los resultados, comentando cada una de las relaciones establecidas en esta parte de nuestro modelo que se centra en el costo del crédito. Como se ha señalado, el costo que cobran las instituciones financieras por otorgar financiamiento puede representar un obstáculo para las pymes, no suelen contar con alta solvencia, una rentabilidad acumulada relevante, y tampoco un historial crediticio de peso. Esto orilla a que la negociación no pueda tener impacto en las condiciones crediticias. Pero mostramos en nuestro modelo teórico, algunas de las variables que la pyme pudiera ocupar a fin de mejorar lo que para ellos resulta muy caro.

En la evaluación del crédito se tomó en cuenta el impacto que tienen los intereses pagados por la empresa, si estos representan un alto porcentaje de sus ventas, si representan un porcentaje considerable de su utilidad de operación y si cree que el tener que pagar una tasa elevada resulta por su poca experiencia con los bancos. Además de otros indicadores que consideramos relevantes darlos a conocer en esta parte del estudio.

La primera relación causal establecida en relación con el costo del crédito fue la información financiera de la empresa. Hemos hablado de la importancia que tiene el contar con suficiente información y además esta sea de calidad. Mencionamos que las pymes suelen considerarse opacas. Y que esto representa un obstáculo para las mismas, lo cual pudiera beneficiar al proporcionar información relevante y confiable. Así, establecimos en nuestra hipótesis que a menor información entregada por parte de la compañía el costo del crédito será mayor. 
Won y Heshmati (2008) argumentan que derivado de una falta de información y después de evaluar la solicitud de crédito de prestatarios riesgosos se dificulta la obtención del préstamo o el tenerlo con más altas tasas de interés, situación que va en concordancia que la hipótesis que tratamos de contrastar. Petersen y Rajan (1994) comentan que los altos costos interés pagados por las empresas puede llegar a reducir su confianza en el uso de recursos externos, situación que puede limitar el crecimiento de las pymes. Liu et al. (2011) al analizar información de Nueva Zelanda comparando los costos de las tasas promedio sobre hipotecas respecto a las tasas por préstamos a empresas, encuentran que los costos de crédito no son tan competitivos que los de hipotecas. Esto puede desalentar a las pymes de mejorar su opacidad si pueden obtener recursos más baratos mediante otro esquema.

Si hemos comentado que las pymes ante la falta de recursos pueden buscar en familiares o amigos algún crédito, que algunos de los encuestados en nuestro estudio señalaron esta fuente de financiamiento. El tener bloqueado el acceso al crédito bancario, orilla a buscar otras fuentes. Antes de voltear a disminuir el costo vía las alternativas como la presentación de información. Los diferenciales de tasas de préstamos entre empresas grandes y pequeñas son sorprendentes, comenta Dietrich (2010), inicialmente se da como resultado de la poca eficiencia en pequeñas empresas. Corroboramos entonces lo planteado en este párrafo, pues a mayor tamaño de empresa se suele tener mejores sistemas de información y control de la misma.

En un estudio en México, Maudos y Solís (2009) analizan los costos de interés por el período de 1993 - 2005, señalando que comparado con los estándares internacionales, México tiene altos márgenes bancarios que 
reflejan altos costos de intermediación, además, señalan que bancos con altos costos de operación los traspasan a sus clientes mediante altas tasas de interés en créditos y bajas tasas en depósitos. A nivel internacional la limitante del flujo de crédito se encuentra la asimetría en la información, comenta Ashta (2009), además de los costos de la operación para préstamos pequeños.

Tal como se muestra en nuestro modelo, hay una relación inversa entre la información y el costo del crédito. Y hemos podido corroborar en base a nuestros resultados, que las empresas que lleguen a proporcionar menos información financiera sobre su operación tendrán que compensarlo pagando altas tasas de interés, costo principal del crédito. Esto en un inicio es tema desalentador para las pymes, pero hace notar la obligación de estas para cumplir con requisitos mínimos, que de hecho, en parte legal y fiscal, se tiene como una obligación, dependiendo del tipo de empresa.

Otra variable que consideramos con influencia sobre el costo del crédito fue el tamaño de la empresa. Aquí consideramos un solo indicador y nos basamos en el número de empleados. Como se comentó en el capítulo de metodología, la base fue tomada de acuerdo a la clasificación realizada por la Secretaría de Economía, la cual tiene mucha similitud con otras clasificaciones alrededor del mundo. Por ejemplo, en la tabla 5.16., mostramos la proporción de pymes que existen en Centroamérica. 
Tabla 5.16.

Porcentaje de Pymes en Centroamérica

\begin{tabular}{|l|l|}
\hline País & Porcentaje de Empresas \\
\hline Costa Rica & $97.9 \%$ \\
\hline El Salvador & $99.7 \%$ \\
\hline Guatemala & $89.4 \%$ \\
\hline Honduras & $96.4 \%$ \\
\hline Nicaragua & $91.0 \%$ \\
\hline Panamá & $98.5 \%$ \\
\hline Región & $96.0 \%$ \\
\hline
\end{tabular}

Fuente: Banco Interamericano de Desarrollo (1999).

Los resultados de nuestro estudio muestran que un $89.4 \%$ de la muestra son pymes. Ello nos indica la relevancia del tema para este sector.

Un ejemplo de la falta de crédito es en Brasil, las restricciones de crédito son tan severas que solo cerca del $14 \%$ al $19 \%$ de las micro y pequeñas empresas - cerca de 6 millones - usan préstamos bancarios para fondear sus inversiones u obtener flujo de efectivo (Zambaldi et al., 2011). Las pymes encaran mayores obstáculos que las empresas grandes en cuanto a temas de financiamiento (Schiffer y Weder, 2001). Las pymes usan menor financiamiento externo, especialmente de bancos, así lo mencionan Beck et al. (2008), señala en su estudio que en México del 100\% de inversión realizada en las empresas, casi el $70 \%$ es en base a recursos internos, que agrupan las utilidades retenidas, así como préstamos de familiares y amigos. Si entonces vemos que las pymes adolecen del crédito, y de hecho, prefieren no hacerlo, es difícil que puedan tener una negociación que los beneficie con las instituciones. 
En otro estudio empírico, Beck (2007) nos muestra que los costos de la operación del crédito, son uno de los factores que explican el limitado acceso a financiamiento externo de gran número de pymes, tanto en países desarrollados como en desarrollo. Hashi y Toci (2010), también al analizar las principales restricciones financieras y obstáculos para el crédito, encuentran que las pequeñas empresas, aparte de los obstáculos generales de financiamiento, al pertenecer al grupo de pymes incrementa la posibilidad de reportar mayores obstáculos para operar y crecer debido a altas tasas de interés. Nuestro estudio corrobora que a menor tamaño de empresa, estas tendrán que pagar un costo más alto por su crédito.

Y esto pareciera una incongruencia, pues en teoría, la pequeña empresa tiene menor posibilidad de cubrir este tipo de costos respecto a una empresa grande. Pero la realidad nos muestra que al tener un mayor riesgo para los bancos, las pymes deben cubrir este riesgo mediante un costo más alto. Esto pudiera abrir una forma de innovar respecto a este tema, si tal vez la banca privada no puede hacerlo, el gobierno pueda implementar medios más efectivos para realizarlos, por qué aún cuando ya existen algunos programas de este tipo, el grueso de las empresas no se benefician de ellos.

Por último, hacemos referencia a un estudio que realizó Vickery (2008), encuentra evidencia que las pymes utilizan los contratos de préstamo para ajustar de forma sistemática su exposición a riesgo de la tasa de interés. Las empresas con restricciones de crédito tienen más probabilidades de tomar una tasa fija de interés, pues señalan que este tipo de empresas son más sensibles a los cambios en la política monetaria. Una parte de los resultados empíricos nos indica la alternativa que tienen las empresa entre tener una tasa fija o variable. De la muestra obtenida, el $71 \%$ 
de empresas ha contratado su crédito con una tasa fija, en tanto que el resto es una tasa variable; si comentamos que casi el $90 \%$ de la muestra son pymes, podemos observar proporcionalmente que la mayoría prefieren este tipo de tasa.

Al analizar nuestros resultados, encontramos que hay una relación negativa entre el tamaño de la empresa y el costo del crédito. Las más pequeñas pagan un costo mayor. Esto puede volverse un circulo vicioso, pues las pymes requieren crédito para crecer, pero requieren de recursos para ello, lo cual es limitado por su tamaño, y si lo obtienen tendrán que costearlo de manera significativa. Así que mientras no sean más grandes, debieran apoyarse en otras variables, como hemos señalado en el estudio, para disminuir el costo de esta deuda externa.

La última variable que consideramos en relación al costo del crédito es la garantía. Este constructo fue analizado de manera directa con la obtención del crédito y señalamos las características de dicha relación. Así como hemos señalado la posibilidad de que la información y el tamaño de la empresa pueda tener un efecto positivo en el costo del préstamo, manejamos en nuestro modelo que también la garantía pueda ayudar a mejorar dicho costo.

Hay otro estudio en el cual se analiza la incidencia el costo de la garantía sobre el costo de la deuda, este es llevado a cabo por Benmelech y Bergman (2009), encuentran una relación negativa, por tanto se asocia un costo más barato una vez que el riesgo del deudor se ha reducido con el otorgamiento de la garantía. Esta ventaja también es encontrada por Scholtens (1999) quién apoya la teoría de que la garantía tendrá un efecto 
positivo en la tasa de interés cargada por el banco. Además, una nueva forma que pueda disminuir la tasa de interés de los créditos mediante el ofrecimiento de una garantía parcial sobre el monto del mismo (Honohan, 2010). En nuestro estudio preguntamos cual era la proporción de la garantía cuando se requería alguna, siendo que el 55\% de las empresas que habían otorgado alguna, lo habían hecho por un valor inferior al monto del crédito, esto pudiera ser una ventaja para las pymes.

Wang (2010) muestra en sus resultados que los empresarios tienden a elegir una combinación de mayor garantía y menor tasa de interés. Booth y Booth (2006) examinan la relación entre los costos del crédito y la garantía del mismo. La evidencia es consistente con la elección de las empresas en el otorgamiento de garantía para disminuir los costos derivados del préstamo bancario. Benmelech y Bergman (2009) analizan el efecto de la garantía sobre el costo de la deuda. Comentan que la teoría indica que la garantía incrementa la disponibilidad de crédito y reduce su precio mediante la disminución del riesgo de los deudores

El resultado obtenido nos indica una relación negativa entre la garantía y el costo del crédito. El banco desea disminuir el riesgo cobrando un interés alto ó requiriendo una garantía que pueda cubrir la deuda en caso de falta de pago. En cuanto a las pymes, el temor de perder la garantía, puede ser otra limitante y preferir pagar un costo alto de intereses, sin evaluar el impacto que pueda tener en la operación del negocio. Es recomendable hacer una comparación entre el costo que representa otorgar la garantía y el costo que supone la contratación de un crédito, la pyme debe partir de la idea de que el otorgamiento de la garantía se dará para obtener un beneficio y acceder al crédito, y que el crédito se tomará al haber 
planeado que la operación en el mediano plazo o durante el plazo del crédito no tendrá algún riesgo. De ahí que pareciera una mejor opción el dar la garantía con la finalidad de bajar el costo de financiamiento.

Así concluimos que corroboramos todas y cada una de las hipótesis del modelo estructural presentado en este epígrafe, la información financiera y el tamaño de empresa tienen una influencia significativa y negativa en el costo del crédito, en tanto que la garantía tiene una influencia significativa y positiva en el costo del crédito.

\subsubsection{Análisis de los modelos estructurales que indican la influencia de variables sobre la Tasa de interés.}

Una vez estimados y depurados los instrumentos de medida indicativos de las variables endógenas que influyen en la variable exógena "obtención de crédito", así como las variables endógenas y su relación con la variable endógena "costo del crédito", vamos a proceder a contrastar las hipótesis que señalan la influencia de algunas variables sobre la tasa de interés. La estimación de estos modelos estructurales pretende corroborar la consistencia de las relaciones causales de las variables con los datos. En concreto, las hipótesis que se deducen del modelo teórico son:

Hipótesis H9: El costo del crédito pagado por la empresa se traduce en una de tasa de interés alta cuando dicho costo financiero representa un porcentaje importante de sus ingresos y utilidades. 
Hipótesis H10: La facilidad de obtener crédito incide en la tasa de interés cobrada por la institución financiera, así, las empresas con menor posibilidad de crédito contratarán con una tasa más alta.

Para la observación de las relaciones causales es necesario que planteemos las distintas fases de la modelización de los análisis estructurales. En estas etapas vamos a seguir los mismos procedimientos observados en las anteriores modelizaciones estructurales. Estas se concretan en primer lugar en la identificación de un modelo donde el número de ecuaciones sea mayor que el número de parámetros. Seguidamente hemos utilizado el método de estimación por máxima verosimilitud pero con la obtención de estimadores robustos.

\section{Especificación}

El objeto de esta fase es el traducir las hipótesis teóricas en un sistema de ecuaciones. Este modelo inicial observa como variables latentes exógenas el costo del crédito $(\mathrm{CI}=\xi 1)$ y la obtención del crédito $(\mathrm{OC}=\xi 2)$. Como variable latente endógena se tiene la tasa de interés, medida por un agregado que recoge las diferentes dimensiones planteadas anteriormente $(\mathrm{TI}=\eta 1)$.

En los epígrafes anteriores hemos comprobado la bondad de los modelos de medida para observar como ciertas variables exógenas influyen en la obtención de crédito. La inclusión de todos los indicadores individuales en un modelo de ecuaciones estructurales completo requiere de un elevado tamaño muestral y de unos medios técnicos más potentes de los que disponemos con nuestro programa y nuestro ordenador. Para solucionar 
este problema de complejidad muchos estudios han optado por la formación de variables compuestas, que utilizan agregados de los indicadores de medida para la modelización estructural. Este procedimiento reduce la complejidad y facilita la estimación, como hemos relatado anteriormente, hecho que justifica su utilización en la presente tesis.

De esta forma, para medir las dimensiones individuales de las diferentes variables se han utilizado tres y dos indicadores, respectivamente, de cada una de las variables latentes de primer orden. A estos indicadores les llamaremos: (X1=OCHSS), que indicará que obtener el crédito le ha sido sencillo a la empresa; (X2=FOC), que nos señalará si en general, le es fácil obtener créditos a la empresa, $(\mathrm{X} 3=\mathrm{IPPRV})$, representativo de que los intereses pagados por créditos representan un porcentaje significativo de las ventas de la empresa; (X4=IPPRUO), que indicará si los intereses pagados por créditos representan un porcentaje significativo de las ventas de la empresa y, (X5=TIAPE), que mostrará si la tasa de interés es relativamente alta por la poca experiencia de la empresa con los bancos. No obstante, y como señalamos anteriormente, estos 5 indicadores se concretarán en dos variables latentes de segundo orden, que vendrán señaladas como (OC = $\xi 1)$, que se referirá a la obtención del crédito $\mathrm{y},(\mathrm{CI}=\xi 2)$, que indicará el costo del crédito. 
Figura 5.12.

Diagrama de pasos de los modelos estructurales de las hipótesis H9 y H10.

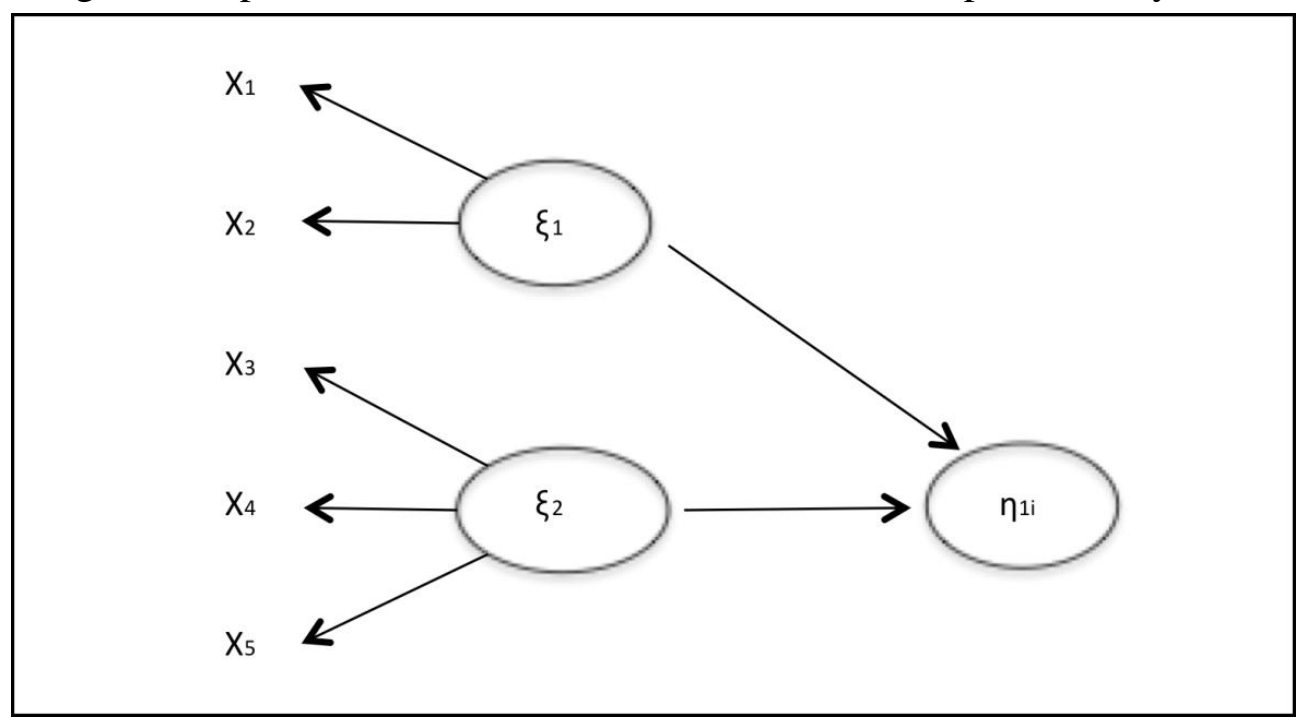

Con relación a la variables endógenas, hemos optado por una variable latente, denominada $(\mathrm{TI}=\eta 1)$. A su vez, esta variable endógena vendrá explicada por las dos variables latentes de segundo orden, las cuales, al representar entre sí un constructo común indicativo de las capacidades directivas, covariarán conjuntamente

En el diagrama de pasos de la Figura 5.12. se recogen estas relaciones. Además, presentamos a continuación, en la Figura 5.13., la traducción de este diagrama en las ecuaciones estructurales que definen el modelo estructural . 
Figura 5.13.

Ecuaciones estructurales propuestas en las hipótesis H9 y H10.

$$
\begin{aligned}
& \mathrm{X}_{1}=\lambda_{\mathrm{x} 11} \xi_{1}+\delta_{1} \\
& \mathrm{X}_{2}=\lambda_{\mathrm{x} 21} \xi_{1}+\delta_{2} \\
& \mathrm{X}_{3}=\lambda_{\mathrm{x} 31} \xi_{2}+\delta_{3} \\
& \mathrm{X}_{4}=\lambda_{\mathrm{x} 4 \mathrm{i}} \xi_{2}+\delta_{4} \\
& \mathrm{X}_{5}=\lambda_{\mathrm{x} 5 \mathrm{i}} \xi_{2}+\delta_{\mathrm{i}} \\
& \eta_{1 \mathrm{i}}=\beta_{1} \xi_{1}+\beta_{2} \xi_{2}+\xi_{1 \mathrm{i}}
\end{aligned}
$$

\section{Identificación}

La identificación implica que los parámetros del modelo puedan derivarse a partir de las varianzas y covarianzas entre las variables observables. La condición necesaria es que el número de parámetros sea menor que el número de ecuaciones, con el fin de obtener grados de libertad positivos. El programa EQS nos indica los grados de libertad, o la existencia de errores de identificación por la falta de estos.

\section{Estimación}

La estimación de los parámetros de un modelo de ecuaciones estructurales se realiza nuevamente aplicando el método de máxima verosimilitud con la obtención de estimadores robustos.

Procedamos ahora al ajuste del modelo de medida, para identificar si los parámetros estimados son o no significativos. En la tabla 5.17. se recogen las cargas factoriales, que indicarán la validez de cada indicador. En esta tabla se puede observar cómo todas las cargas factoriales de los 
modelos de medida superan el valor de 0.4 (Hair et al., 1998). Podemos además corroborar que todas las cargas factoriales son estadísticamente significativas. La conclusión de estos resultados implica que todos los indicadores utilizados tienen un peso importante sobre los conceptos teóricos que miden.

Tabla 5.17.

Parámetros estimados de las variables en el modelo estimado de las hipótesis $\mathrm{H} 9$ y H10.

\begin{tabular}{|l|l|l|}
\hline & \multicolumn{2}{|c|}{ Modelos variables sobre Tasa de Interés } \\
\hline Medidas & \multicolumn{1}{|c|}{ OC } & CI \\
\hline Exógenas & & \\
\hline $\mathrm{X}_{1}$ & .831 & \\
\hline $\mathrm{X}_{2}$ & .770 & \\
\hline $\mathrm{X}_{3}$ & & .912 \\
\hline $\mathrm{X}_{4}$ & & .780 \\
\hline $\mathrm{X}_{5}$ & & .505 \\
\hline
\end{tabular}

Observada la significación, debemos atender fiabilidad individual de los diferentes indicadores, es decir, la varianza que el indicador tiene en común con la variable latente a la que mide y la que se debe al error. Como observamos en los apartados anteriores nosotros mediremos esta fiabilidad con el Factor de los indicadores, que debía ser superior a 0.5 .

Podemos constatar, como se muestra en la Tabla 5.18, que en la mayoría de los modelos se obtienen altas fiabilidades, tanto conjuntas como individuales. Una vez que las medidas compuestas han sido formadas de los ítems compartiendo la misma dimensión en la escala de valor percibido, analizamos las propiedades psicométricas de las escalas que forman el modelo. La validez convergente es demostrada en primer lugar por que las 
cargas factoriales son mayores a 0.5 (Bagozzi, 1980), y en segundo lugar, por que la varianza media extraída (AVE) de cada constructo es mayor a 0.5 (Fornell y Larcker, 1981). En cuanto a la fiabilidad de la escala, los índices de la fiabilidad compuesta (CR) del constructo es mayor a 0.6 (Bagozzi y Yi, 1988).

Tabla 5.18.

Fiabilidad de los modelos de medida de las hipótesis H9 y H10.

\begin{tabular}{|l|l|l|l|l|l|}
\hline & & CR & AVE & Indicadores & $\begin{array}{c}\text { Carga } \\
\text { Factorial }\end{array}$ \\
\hline Modelo & Constructos & & & & \\
\hline Modelo & Obtención de & 0.78 & 0.68 & $\mathrm{X}_{1}$ & 0.804 \\
Estructural & crédito & & & $\mathrm{X}_{2}$ & 0.801 \\
Final & & & & & \\
\hline & Costo del crédito & 0.78 & 0.61 & $\mathrm{X}_{3}$ & 0.913 \\
& & & & $\mathrm{X}_{4}$ & 0.773 \\
& & & & $\mathrm{X}_{5}$ & 0.497 \\
\hline
\end{tabular}

Corroborados los ajustes del modelo global y del modelo de medida, debemos prestar atención al ajuste del modelo estructural estimado. Para ello debemos observar el nivel de significación de los parámetros estimados y la fiabilidad de las ecuaciones estructurales, aspectos reflejados en la Tabla 5.19. 
Tabla 5.19.

Parámetros estimados en el modelo estructural de las hipótesis H9 y H10.

\begin{tabular}{|l|l|l|}
\hline \multicolumn{1}{|c|}{ Variables } & \multicolumn{1}{|c|}{ Indicadores } & Valor t \\
\hline OC & $\mathrm{X}_{1}$ & 3.503 \\
& $\mathrm{X}_{2}$ & 2.768 \\
\hline $\mathrm{CI}$ & $\mathrm{X}_{3}$ & 2.200 \\
& $\mathrm{X}_{4}$ & 3.602 \\
& $\mathrm{X}_{5}$ & 7.938 \\
\hline
\end{tabular}

De acuerdo a las hipótesis resultantes de la relación con la tasa de interés, observamos que una de las hipótesis no se corrobora. En primer lugar se contrasta la relación que engloba la obtención del crédito y el costo del crédito con la tasa de interés. En este modelo se observa además como todos y cada uno de los factores explicativos de estas capacidades adquiridas son altamente significativos, y con cargas factoriales mayores a 0.4, hecho que indica que todas las variables aportan información al modelo, $\mathrm{y}$ por tanto todos los indicadores tienen un peso importante sobre el concepto teórico indicativo de la tasa de interés. Puntualizando que no todas las R2 son mayores a 0.5. Recordemos que el análisis del coeficiente de correlación al cuadrado señala la proporción de la varianza que tiene en común con el constructo, y no se debe al termino error. No obstante, en el análisis individual de cada una de estas variables obtuvimos fiabilidades de las escalas bastante apropiadas.

Hemos comentado a lo largo de nuestro estudio que el costo del crédito puede ser un obstáculo importante para que las pymes obtengan un préstamo. El costo del crédito engloba varios conceptos. La comisión que cobra el banco por contratar el crédito. Los costos de avalúo si se ha requerido una garantía. Los costos del notario que habrá de protocolizar el 
contrato. Y, por supuesto, el costo de interés, que suele convertirse en lo más representativo del crédito. Para evaluar dicho costo se requirió conocer el impacto del pago de intereses sobre las ventas y sobre la utilidad de operación, además de conocer si la empresa cree tener una tasa alta por su poca expriencia con los bancos.

Para el constructo de la tasa de interés, se le preguntó a la empresa el porcentaje de tasa que le cobran en su crédito. Algunas empresas cuentan con tasas inferiores al $10 \%$ anual, mientras otras llegan a tener tasas anuales mayores a un $30 \%$. Podemos ver que existe una disparidad importante. La tasa de referencia en México para créditos es la TIIE (Tasa de interés interbancaria de equilibrio), la cual es calculada por el Banco de México en base a un promedio de varios bancos del país. Al 25 de octubre de 2012, la TIIE a 28 días es de $4.8262 \%$; el excedente sobre esta tasa se considera la utilidad para el banco. Entonces vemos ganancias bajas en algunos casos, pero en otras se carga mucho el costo a la empresa.

Las tasas que nos presentan las empresas se pueden contratar de forma fija o variable. En nuestro cuestionario agregamos dicho indicador, no tanto para ser objeto de estudio, pero para conocer la tendencia de la muestra. Así, la parte predominante por mucho es la contratación del crédito a tasa fija, el $71 \%$ de las empresas manejan este tipo de tasas. Si bien es cierto que la tasa variable al momento de concentración es más barata, esta conlleva un riesgo si las condiciones económicas provocan un alza en las mismas. Ceccetti (1995) menciona que cuando la política establecida incrementa las tasas de interés puede causar una afectación en la empresa que limite su capacidad de crédito y de pago y, en consecuencia, de contratación de crédito. 
Como traducir entonces que el costo del crédito tiene relación sobre la tasa de interés del crédito. Binks y Ennew (1997) utilizan una muestra de 6,000 pequeñas empresas de una encuesta privada de 1994 realizada en el Reino Unido, en ella encuentran que las principales barreras para el acceso del crédito se basan en dos conceptos, los cargos bancarios (costos o comisiones) y las tasas de interés. Además, Hashi y Toci (2010) analizando países del este de Europa, encuentran que las altas tasas de interés y requerimiento alto de colateral significan un gran obstáculo para la operación y crecimiento de las pymes, más que de las grandes.

Entendemos que el pagar un alto costo de interés, que es el principal componente del crédito, significa para la pyme una erogación muy fuerte; si lo traducimos en su estado de resultados, pueden afectar mucho su rentabilidad después de la utilidad de operación, ello significaría que la tasa de interés bajo la cual se contrató es muy alta. Una vez obtenidos los resultados empíricos, el análisis nos muestra que hay una relación positiva entre el costo del crédito y la tasa de interés, a mayor costo mayor tasa, y encontramos que es valida la hipótesis establecida en el modelo. Las pymes reflejan que esas altas tasas de interés representan un costo muy relevante tanto de sus ingresos como de sus utilidades operativas, lo cual mina su rentabilidad neta para su crecimiento y operación, tal como se ha expuesto.

La última relación establecida en nuestro modelo indica la relación entre la obtención del crédito y la tasa de interés. Antes de enfocarnos en los resultados de esta relación, es interesante analizar de las empresas que forman nuestra muestra, si todas han obtenido crédito. De las 208 empresas del estudio, alrededor del $30 \%$ no han solicitado crédito, y de las principales causas que externan son: se han utilizado recursos internos, no se ha 
necesitado y los intereses son altos. Esta última mención tiene conexión sobre nuestra última relación, ese costo implica una preocupación o limitante para las empresas de nuestro estudio.

Más allá de las empresas que si obtuvieron crédito y conocimos sus tasas de interés, y las que nombramos en el párrafo anterior que no han solicitado algún préstamo, encontramos un tercer grupo, empresas que han solicitado crédito pero les fue rechazado. Considerando interesante mostrar las causas de dicho rechazo, presentamos un resumen de lo que se encontró en nuestro estudio sobre 17 rechazos señalados, cuyo desglose se muestra en la tabla 5.20.:

Tabla 5.20.

Causas de rechazo en solicitudes de crédito

\begin{tabular}{|l|c|}
\hline Causa de Rechazo & Cantidad \\
\hline Falta de garantía & 4 \\
\hline Falta de aval & 2 \\
\hline Buró de crédito & 2 \\
\hline Monto de ingresos & 2 \\
\hline Incapacidad de pago & 2 \\
\hline Requisitos del banco & 2 \\
\hline Empresa menor a 3 años & 1 \\
\hline Otros & 2 \\
\hline
\end{tabular}

Es importante mencionar, aunque en esta parte hablamos de la facilidad del crédito y la tasa de interés, que varios de los obstáculos que hemos mencionado en los constructos de nuestro modelo han sido señalados por empresa que ya han vivido el rechazo a su solicitud. La falta de garantía 
o aval, los requisitos del banco que pudieran ser parte de información, el ser una empresa joven, el monto de ingresos puede asimilarse a otra clasificación de pymes.

El obtener crédito, después de ver esta tabla, nos deja claro, además de la literatura señalada sobre las diversas hipótesis; que el obtener crédito no es fácil. La empresa, en particular las pymes, encuentran muchos obstáculos, y al día de hoy parece que la tendencia en el corto plazo no cambia. La tasa de interés es otra parte que no precisamente facilitará la obtención del crédito, de hecho la relación establecida va en el sentido de que las empresas con menor facilidad en la obtención del crédito contratan a una tasa más alta. Sin embargo, y corroborando el modelo general estimado anteriormente, las variables indicativas de la obtención del crédito y la facilidad en la obtención de los mismos no son nada significativas, hecho que descarta la corroboración de las hipótesis aparejada a estas variables. Con lo cual no se cumple la décima hipótesis.

En resumen, en este capítulo se ha podido revisar y analizar los resultados obtenidos con el trabajo empírico, señalando la metodología para la interpretación del mismo. Se mostraron las ecuaciones y modelos estructurales obtenidos a partir del modelo teórico y la información obtenida. Se verificó la dimensionalidad, fiabilidad y validez de los indicadores y constructos, así como sus relaciones respectivas. Al contrastar las hipótesis pudimos corroborar 9 de las 10 hipótesis planteadas inicialmente, lo cual nos da una certeza bastante alta de nuestro modelo teórico establecido inicialmente. 


\section{Conclusiones}


“..... por que las personas que están lo suficientemente locas para pensar que pueden cambiar al mundo, son quienes lo logran". Apple, Inc. Think different Comercial, 1997 


\subsection{Conclusiones}

El propósito de la tesis fue identificar aquellos obstáculos que limitan a las pymes en obtener crédito. Además, mostrar los conceptos, que de acuerdo a la teoría, pueden ayudar a conseguir el préstamo, ya sea eliminando los obstáculos o coadyuvando en disminuirlos. Como se fue describiendo, el financiamiento vía deuda es uno de los conceptos principales que las empresas utilizan dentro de la configuración de su estructura de capital. Y aunque muchas empresas prefieren los recursos internos, como menciona la teoría de la selección jerárquica, hay otras empresas que no generan lo suficiente para mantenerse o crecer.

A través del estudio nos enfocamos en el crédito como la vía que las empresas requieren para su crecimiento y operación. El crédito es la nomenclatura más común cuando se pide financiamiento, las instituciones financieras analizan cada prestatario para saber si son sujetos o no, desde la perspectiva de que van a ser capaces de pagar las amortizaciones de capital e intereses derivadas del contrato de crédito; al solicitante se le requerirá un serie de requisitos para poder evaluar la decisión sobre el crédito, lo cual normalmente es realizado por un comité interno de la institución financiera, con personal diferente a quién ha tenido contacto con el empresario.

La decisión que toma la institución financiera se distingue dentro de la literatura entre dos tipos de procesos de decisión de préstamos, relación bancaria y estado de préstamo. La primera depende sobre información objetiva y subjetiva sobre el prestatario, a través de la relación de los bancos con él (Diamond, 1989), mientras que el préstamo sobre estados descansa en 
procedimientos objetivos como puntuación de crédito y seguridad del préstamo (Rauch y Hendrickson, 2004)

Cuando la oferta de crédito no es suficiente, vemos que las instituciones financieras lo dirigen a los que pueden considerar como clientes seguros. Pero este no sería solo el mayor problema, hay momentos en los que aun cuando se esté dispuesto a obtener financiamiento a costo alto se dificulta su contratación, de ahí conocimos el concepto de racionamiento de crédito, el cual es la situación en la cual un potencial prestatario carece de acceso al crédito, aunque acepte en pagar un alto precio (tasa de interés) que el prevaleciente en el mercado. (Jaffee y Russell, 1976)

Existen muchas instituciones conocidas como cajas de ahorro y préstamo o cajas populares, las cuales en México suelen tener un costo más alto que la banca comercial, u otras instituciones más pequeñas que se enfocan en préstamos de cantidades menores a plazos también menores pero cuya tasa actualizada es exorbitante. Aunque los resultados nos indican que en México las pymes la marcaron como la segunda fuente principal de créditos que utilizan.

Encontramos que las pymes representan una parte importante en la generación de recursos de los países. Como señalaban Beck y DemirgucKunt (2006), los esfuerzos dirigidos a las pymes están basados en dos premisas, 1) las pymes son el motor del desarrollo económico, pero 2) las fallas de mercado e institucionales impiden su crecimiento. De acuerdo a datos del Instituto Nacional de Estadística, Geografía e Informática (INEGI), se estima que las mipymes constituyen el $99 \%$ del total de 
unidades económicas del país, representan alrededor del 50\% del PIB y contribuyen a generar más del 70\% de los empleos en México.

El análisis de la literatura teórica, nos dio un conocimiento profundo de lo que las empresas experimentan para tomar decisiones respecto a su estructura de capital y, en consecuencia para fijar el nivel de endeudamiento vía crédito que requieren. Pero, no bastaba conocer que las pymes requieren de préstamos para cubrir sus necesidades, sino confirmar si realmente tienen mayor problema para obtener los créditos que las empresas grandes. Para ello contribuimos con un modelo financiero en el que pueda visualizarse la forma en que diferentes variables influyen en la facilidad o complicación del crédito.

Para obtener la información empírica utilizamos una muestra de empresas del sector industrial manufacturero a nivel nacional, después de la aplicación de encuestas, se obtuvieron 208, con lo cual se procedió a analizar la información mediante la técnica de ecuaciones estructurales. Los resultados en general fueron satisfactorios, pues gran parte de las relaciones establecidas pudieron verificarse al obtener los resultados.

Primero, verificamos cual es el efecto que tiene la información sobre la obtención de crédito. Para ello nos centramos en los indicadores obtenidos sobre el uso de un profesional que prepara información financiera de la empresa, un especialista que certifica dicha información y la posibilidad de hacer proyecciones financieras de la situación de la compañía. Habíamos revisado el impacto que tiene la opacidad en el acceso al crédito. Lo cual representa costos adicionales para la institución 
financiera, y, de cierto modo, un problema de asimetría entre el banco y la pyme.

La literatura nos indica que las pymes son opacas por naturaleza, en la mayoría de los casos. Los resultados encontrados por Hyytinen y Pajarinen (2008) indican que no forzosamente el tamaño de la empresa pudiera ser un indicador de opacidad. Los resultados de Kano et al. (2006) hacían referencia que anteriormente no se podía verificar que la información fuera confiable, esto es, la información que las empresas entregan a las instituciones financieras. Estudiando pymes japonesas resuelven esto indicando qué información verificable se entregue a los bancos, como información revisada por auditor externo, la cual puede convertirse en una técnica de préstamo para las pymes.

Nuestros resultados indican que cuando la empresa es requerida con menor nivel de información entonces se le facilita el crédito. Esta situación inversa nos hace dependientes, en cierta forma, de la bondad del banco hacia nosotros. Así que podemos indicar que cuando la empresa requiere de entregar una información más basta, estados financieros, reportes a detalle de las diferentes cuentas, o información revisada por auditor externo, si no cuenta con estos elementos se le complicará acceder al crédito.

Hemos confirmado que aquellas empresas con menor requerimiento de información han obtenido crédito, lo cual puede convertirse en obstáculo cuando el banco lo pide y asumimos que normalmente las pymes no cuentan con ello. Lo que significa que las empresas opacas tienen mayor complicación para obtener un crédito, puesto que las instituciones financieras no pueden evaluar el riesgo de la compañía, y el costo adicional 
que deben realizar los bancos no justifica la supervisión de las mismas. Por otro lado, si la empresa reportara mayor información, esta tendría un efecto positivo, además de facilitar el crédito, el disminuir el costo del mismo.

También Sarapaivanich y Kotey (2006) realzan la importancia de contar con información de calidad para acceder al crédito. Sus hallazgos soportan la idea de que el contar con información que los inversionistas puedan analizar, les abre mayor acceso al capital externo. A contrario censu, como se manejaba en nuestra hipótesis, aquellas empresas con menor requerimiento de información podrán también tener acceso. Pero, haciendo énfasis en esta situación, la mejor recomendación para la pyme es de que pudiera eliminar su opacidad, contar con su información, que esta pueda ser verificada por un auditor, y ello le facilite aun más el obtener recursos vía deuda.

La literatura también nos indicó que gran parte de las instituciones financieras requieren al deudor una garantía, aquella que minimice el riesgo para el acreedor y tenga un seguro para en caso de que la empresa no pague (Kon y Storey, 2003). Esto acarrea costos para la empresa, se tiene que realizar un avalúo del bien, se debe realizar una hipoteca en caso de tratarse de un bien inmueble. No solo esto, en ocasiones no hay bienes en la empresa y entonces el dueño debe utilizar sus bienes personales, así nos lo señalaron Avery et al. (1998) y Voordeckers y Steijvers (2006).

A final de cuentas, quisimos determinar el impacto o el costo que representa para la compañía el dejar un bien garantizando el crédito obtenido. Para ello nos apoyamos en indicadores que hablaban si la garantía representaba un porcentaje importante del total de activos del negocio, si el 
valor del bien con el que se garantizaba era fijado por el acreedor y si el llegar a perder la garantía ponía en riesgo la operación de la empresa. Por supuesto, la garantía tiene ventajas, algunas de ellas nos mostraban Steijvers et al. (2010), como el reducir costos de agencia y asimetrías en la información. Nuestro modelo señala directamente el impacto sobre la obtención del crédito.

De acuerdo a los resultados obtenidos, hay un influencia en la solicitud de la garantía, lo que encontramos nos señala que cuando a las empresas no se les exige garantía, estas tienen mayores posibilidad de recibir un crédito. Esto facilita a la pyme su acceso, pero al igual que comentábamos con la información financiera, deberá encontrar aquellas instituciones que no tengan como política estricta el depósito de una garantía para dar seguridad al contrato de préstamo. Esto nos deja con ciertas limitantes, pues podemos concluir que si representa un obstáculo, algunas instituciones la figura que utilizarán para garantizar el crédito será un aval o colateral, pero estos conceptos son similares en el contexto. Las pymes regularmente tienen mayor dificultad para otorgar una garantía, así lo encuentra Scholtens (1999).

Los resultados que obtienen Jiménez et al. (2009) sobre el uso de garantía en el trámite de créditos, como ellos lo mencionan, quedan un poco limitados por no tener la tasa de interés cobrada o el propósito del crédito. Situación que en nuestro estudio si se realiza, obteniendo una variable específica sobre la tasa, y también encontramos que casi la mitad de las empresas encuestadas utiliza los créditos para capital de trabajo, en tanto que otra tercera parte lo utiliza en nuevas inversiones. Esto expande un poco 
más la naturaleza de nuestro estudio y las herramientas para la comprobación de nuestro modelo.

Además, encontramos que alrededor de una tercera parte de las empresas estudiadas no ha tenido la necesidad de otorgar una garantía, lo cual apoya el contrastar nuestra hipótesis de que esto facilita la obtención del crédito. Más aún, en el medio financiero normalmente se solicita una garantía con valor mayor al monto del crédito solicitado, los resultados encontrados indican que, de las empresas que tuvieron que dar una garantía en su crédito, la mayoría dio un bien cuyo valor era menor al crédito, lo cual se contrapone a las estimaciones que se tienen en el mercado crediticio.

Una de las principales técnicas de préstamo que podemos encontrar en la literatura es la relación de préstamo. El contacto que se cultiva a lo largo del tiempo, el trato y la confianza entre la empresa y la institución financiera. De hecho, Howorth y Moro (2010) señalan a la confianza como un tipo de información que está otorgando la empresa. Muchos autores han resaltado las ventajas que conlleva el llevar una buena relación con el banco, más aún, el contar con múltiples relaciones que promuevan la competencia para un mayor beneficio de la compañía. Entre reconocidos autores que hablan sobre el tema tenemos a Berger y Udell (1995) que hacen referencia en particular a las empresas nuevas con relaciones recientes. Behr et al. (2011) hablan sobre el efecto positivo que tiene una relación intensa.

Así, en nuestro estudio encontramos que la relación de préstamo es una de las técnicas más relevantes con que puede auxiliarse la empresa en el crédito. De la información empírica recopilada, varios indicadores nos fueron útiles para validar nuestra hipótesis. El saber que tanto se reúne la 
empresa con el personal del banco, el conocer si cuenta con un contacto especial, darnos cuenta si los ejecutivos se acercan a la empresa para anticiparse a sus necesidades, si tenía asignado un ejecutivo en particular para atenderlo y si consideraba tener una relación fuerte con su banco; esta información fue de gran ayuda para verificar la fiabilidad de nuestro modelo.

Estos indicadores fueron de gran impacto en los resultados obtenidos, estos nos confirman la importancia de las relaciones en el tema del crédito. Pudimos corroborar que entre mayor sea la relación de la empresa con el banco, tiene mucha mayor facilidad de obtener crédito. Este resultado concuerda con el que encuentran Petersen y Rajan (1994) y Vickery (2008). Algunos autores han establecido en sus resultados que la relación de préstamo tiene un efecto positivo respecto a la opacidad, el costo del crédito y hasta la necesidad de garantía.

Encontramos también algunas formas de entender cuan intensa es la relación entre las empresas y sus bancos, así, encontramos, por ejemplo que casi el $50 \%$ de las empresas estudiadas trabaja con un solo banco, esto nos indica que carecen de las ventajas de la multirelación, pero por otro lado su relación es más fuerte. Para aquellas empresas que trabajan con más de un banco, encontramos que la mayoría cuenta con un banco de casa, es decir, el principal se lleva entre el $60 \%$ y el $90 \%$ de las operaciones de la empresa. Otra forma de ver que tan fuerte es la relación es a través de los años que se conocen, los datos nos reflejan que poco más de la mitad ya tiene una relación de 7 años o más. Lo cual nos dice que las empresas han cultivado una relación, y han obtenido beneficio de ella en la obtención de crédito. 
Definitivamente una de las principales restricciones que tiene las pymes cuando desean acceder al crédito es la antigüedad, que normalmente los bancos la asocian con la experiencia, historial y permanencia. Vos et al. (2007) nos señalaban que las empresas menores a 3 años utilizaban principalmente ahorros, o recurrían a familiares y amigos, con tendencia menor al crédito bancario (también lo señalan Binks y Ennew, 1997). Las empresas más antiguas cuentan con mayor disposición de préstamos (Gregory et al., 2005). Hyytinen y Pajarinen (2008) encuentran en su estudio que la edad de la empresa tiene un efecto negativo, pues entre más joven más opaca es la empresa.

Así que, siendo una característica común en las pymes, una menor antigüedad promedio respecto a las grandes, señalamos en nuestro modelo la relación con la obtención del crédito. Se le preguntó a las empresa los años de operación o de antigüedad, obteniendo resultados de empresas de 1 a 20 años en intervalos de 5 años, una tendencia a la baja, es decir, un porcentaje mayor en las más jóvenes que disminuía conforme se incrementaba la antigüedad. Aunque es preciso hacer notar que el rango de 1 a 5 años que representaba el 19\% de la muestra, era menor al de empresas con más de 20 años operando, encontrando un $33 \%$ de la muestra en este rango. No obstante, al contrastar la hipótesis, vemos que hay una relación positiva entre la edad y obtención del crédito, lo cual confirma la hipótesis establecida.

Cuando habla de ciertas restricciones de financiamiento, Beck (2007) hace un comentario sobre las instituciones que el gobierno mexicano ha impulsado como NAFIN (Nacional financiera) y FIRA (Fideicomiso instituido en relación con la agricultura) con la finalidad de incentivar a la 
banca privada en apoyar a las pymes con programas de financiamiento, tratando de equilibrar los costos y riesgos de los organismos de gobierno. Los resultados obtenidos, indican que la fuente de recursos que mayor ocupan las empresas son los bancos, alrededor de un 50\%, cuando si hablamos de organismos gubernamentales, no llega al 3\%. Aun con estos programas la penetración de estos apoyos crediticios no se han palpado en las pymes.

Nuestro modelo señala la influencia positiva que tiene la relación de préstamo en la obtención del crédito, también la influencia negativa de la información financiera respecta a la misma variable dependiente. Pero otra relación causal se da entre la relación y la información, reflejamos el aspecto positivo que puede tener el contar con una relación a falta de información generada en la empresa. Berger et al. (2001) han señalado la ventaja de empresas opacas de obtener crédito al tener una relación de préstamo. Lo mismo comenta De la Torre et al. (2010), en el estudio que realizan obtienen información acerca de la forma en que se relacionan las empresas con los bancos, uno de los indicadores muestra que en promedio un $88 \%$ de las empresas estudiadas utiliza los servicios tanto de crédito como de depósitos en los bancos, hablando en particular de México encuentra que en promedio la empresa ocupa 5.3 servicios; nuestro estudio indica que el $75 \%$ de las empresas utiliza 2 o más productos del banco.

Tal vez el número de servicios se vea afectado por el número de relaciones que tiene la empresa, de hecho, el conocimiento que el banco va a formarse de la pyme también variará si es el único banco con el que trabaja. El resultado que encuentra Berger et al. (2001) es de que las pymes opacas tienden a relacionarse con un solo banco, como hemos comentado nuestro 
estudio arroja también que alrededor del $50 \%$ de las empresas encuestadas solo tiene un banco.

Al contrastar nuestra hipótesis, vemos que el resultado es satisfactorio, es decir, cumplimos con la hipótesis al encontrar que la empresa al tener una relación con el banco se supera la opacidad que tenga, así le facilita el acceder al crédito. Así que el ver que una empresa opaca dependerá de que el banco no le requiera una cantidad relevante de información, esto podría superarse si la relación que se tiene es lo bastante fuerte y de confianza para poder superar el obstáculo. Esto significa que la relación de préstamo es una de las principales técnicas que las pymes pueden usar en la consecución del crédito. Y, en determinadas circunstancias puede ayudarlos en mejorar el costo del crédito o el requerimiento de garantía, situación que no hemos estudiado directamente en nuestro modelo pero puede ser sujeto de estudio en un análisis posterior.

Uno de los aspectos que mayor preocupación le causa a las empresa es el costo que tendrá el crédito. Cuestiones de comisiones al contratar, avalúos si hay garantía, costos del contrato, y lo principal que es el pago de intereses. De hecho, las altas tasas de interés son consideradas el principal obstáculo por parte de las pymes. Beck et al. (2006) muestra dicho resultado en una encuesta realizada a cerca de 10 mil empresas en 80 países. El pagar un interés elevado puede provocar que la empresa reduzca la utilización de financiamiento externo (Petersen y Rajan, 1994). Por si esto fuera poco, las pymes tienen mayores costos que las empresas grandes (Dietrich, 2010).

Aun cuando escuchamos en la actualidad que los países más desarrollados tienen fijadas tasas de interés muy bajas, en México los 
márgenes bancarios son altos (Maudos y Solís, 2009). Mencionan que los bancos con altos costos de operación traspasan dicho costo a sus cliente, lo que se traduce en una barrera al crédito y al crecimiento. Hashi y Toci (2010) en los resultados de su estudio muestran que las altas tasas de interés son un gran obstáculo para la operación y crecimiento de las pymes respecto a las empresas grandes. Usando resultados de la encuesta del banco mundial sobre ambiente de negocios Ayyagari et al. (2008) relacionan las altas tasas de interés con la falta de dinero de los bancos. Situación que pareciera ocurrir al día de hoy, pero también señalan la relación de dichos altos intereses con los requerimientos de documentación, situación que agudiza la posibilidad de la empresas de contratar crédito.

Analizando nuestros resultados vemos un efecto negativo entre la información y el costo, es decir, confirmamos la posición de que a menor información que entregue la compañía al banco, con lo cual se muestra como una empresa opaca y con el riesgo que significa, el banco cobrará un interés más alto para compensar dicho riesgo. Esta hipótesis queda demostrada con el análisis realizado.

El concepto de pymes separa a las empresas grandes, la literatura nos muestra el tamaño como un obstáculo más para el crédito, partiendo de la idea de que a los bancos no les interesa este mercado, entre otras causas, la opacidad ya comentada, los costos que generan atender a este grupo de empresas, la falta de gobierno corporativo. No obstante, en nuestro modelo lo indicamos con una relación directa con el costo del crédito. Comprobando que el tamaño de la empresa tiene un efecto inverso con el costo del crédito, es decir, a menor tamaño de empresa el costo del crédito será mayor. 
Cuando se supondría que una empresa grande tendría mayor capacidad para soportar cierto costo, son las pymes las que cubren mayores costos.

A efectos de agrupar a las empresas por tamaño en nuestro estudio se utilizó el número de trabajadores, que es uno de los indicadores más comunes a nivel mundial, y el cual fue más sencillo de proporcionar por las empresas. Algunas clasificaciones refieren al nivel de ingresos, pero, como se comentó en la parte de metodología, fue complicado el obtener ese tipo de información de las empresas.

Las pymes enfrentan no solo obstáculos financieros, también legales, económicos, institucionales (Pissarides, 1999), situación también mencionada por Schiffer y Weder (2001). En Europa, dentro de la comisión Europea existe una institución llamada Eurostat, este organismo menciona que de todas las empresas creadas en 2002 , el $81.20 \%$ no contaba con empleados al momento de su creación, solo el $1.50 \%$ tenía más de 10 empleados y el resto empleaba entre 1 y 9 personas. Al 2005, de las empresas que habían sobrevivido, el porcentaje de las empresas que contaban entre 1 y 9 empleados se había incrementado al $24.90 \%$, al igual que aquellas que contaban con más de 10 empleados con un $4.10 \%$.

En España, por ejemplo, según el Directorio Central de Empresas (DIRCE) al 1 de Enero de 2008 había 3’414,779 Pymes (empresas comprendidas entre 0 y 249 asalariados); lo cual representa el $99.86 \%$ de las empresas que comprenden el censo, excluidas la agricultura y pesca. Países vecinos del sur de México también reflejan la tendencia de las Pymes, las cuales representan el mayor porcentaje empresarial de unidades económicas, ello reafirma la relevancia que tienen este tipo de empresas en el desarrollo 
económico y por supuesto, en generación de empleos. SEBRAE (servicio de apoyo a la micro y pequeña empresas) de Brasil en el 2007 conduce una encuesta que muestra que el $22 \%$ de las micro y pequeñas empresas de Brasil terminan sus actividades antes de cumplir dos años de operación, significativamente debido a una falta de recursos para manejar su flujo de caja (Zambaldi et al., 2011).

En México la tendencia del número de pymes no cambia, la Secretaría de Economía menciona que las micro, pequeñas y medianas empresas representan el $99 \%$ del total de empresas en el país, aunque las empresas grandes cuentan con un $22 \%$ de empleos otorgados y un $31 \%$ del producto interno bruto. Aun así, las pymes son un generador de riqueza muy importante, pero el crédito se presenta como una limitante para ellos (Beck y Demirguc-Kunt, 2006; Rahaman, 2011; Beck, 2007). Algunos autores se refieren a la necesidad de reformas a los sistemas legal y financiero para mejorar esta problemática (Beck et al., 2008; Klapper et al., 2002).

Mostramos que los resultados de nuestro estudio arroja que el tamaño de la empresa influye de manera inversa negativamente en el costo del crédito. Las pymes van a tener un costo más elevado. Este resultado concuerda con el obtenido por Pissarides et al. (2003), analizando una muestra de empresas rusas y belgas encuentran que entre las 5 principales restricciones que manifiestan las pymes se encuentran la obtención de financiamiento y que la empresa enfrenta altos costos de intereses.

La garantía nos definió un aspecto relevante para la obtención de crédito, pero encontramos que puede tener un efecto positivo en el costo del mismo. Berger y Udell (1995) no encontraron una relación estadística entre 
la tasa de interés y la garantía establecida, sin embargo, tanto la tasa de interés como la garantía podrían disminuir ante una relación positiva de la empresa con el banco. Ellos no encontraron ninguna relación pero nuestro estudio nos muestra lo contrario. Una vez establecida la relación respectiva encontramos que el costo del crédito disminuye cuando la empresa ha otorgado una garantía. Se comentó la dificultad que puede tener la empresa para otorgarla, pero a su vez, encontramos que puede verse beneficiada con el otorgamiento de la misma. Brick y Palia (2007) encuentran en un estudio que la garantía tiene un impacto económico estadístico significativo sobre las tasas de interés de los préstamos.

Y aunque Berger y Udell no obtuvieron dicha relación, Wang (2010) muestra en sus resultados que los empresarios eligen una combinación de mayor garantía y menor tasa de interés. También Benmelech y Bergman (2009) encuentran en su estudio que el costo del financiamiento externo disminuye al ofrecer una garantía. El banco mismo considera que el riesgo disminuye y entonces la tasa de interés debiera bajar (Black et al., 1996). Chan y Kanatas (1985) comentan que la tasa de interés del préstamo dependerá, en parte, del valor de la garantía que la empresa ofrezca. Así que podemos confirmar la relación existente entre la garantía y el costo del crédito, tal como se expuso en nuestro modelo.

Se ha comentado que el también dejar una garantía tiene un costo, por el avalúo, los contratos, la hipoteca; pero el costo del crédito suele ser mucho mayor, así que la empresa debe comparar ambos costos para tomar la decisión. Si la institución financiera de cualquier manera solicita una garantía para avalar el crédito, y la pyme puede tomar ventaja de esta 
situación para mejorar el costo del mismo, creemos que se tendrá una ventaja adicional con el otorgamiento de la garantía.

El costo del crédito en sí pudiera considerarse como un obstáculo para las pymes, su rentabilidad, sus ingresos, no pueden compararse al de una empresa grande, regularmente sus costos no son tan variados y deben de cuidar al detalle sus erogaciones. Nuestro modelo muestra de manera innovadora la relación entre el costo de crédito y la tasa de interés. Se estableció la relación causal de algunos constructos sobre el costo del crédito. Para el análisis de esta variable se utilizaron los indicadores que muestran el impacto que tiene el interés pagado sobre los ingresos y utilidades operativas de la empresa, además de saber si la empresa considera el tener un alta tasa de interés por su falta de experiencia con los bancos.

Las empresas buscan el menor costo al endeudarse, la teoría de la jerarquía financiera nos indicó que antes de ello las empresas prefieren usar fondos internos. La teoría del equilibrio señalaba que la empresa al realizar el pago de intereses buscaba un beneficio mediante la deducción de los mismos para la disminución del pago de impuestos. Para una pyme, puede resultar bastante caro el costo del crédito, pero su crecimiento u operación se ve limitada sin recursos adicionales. Ello crea una disyuntiva, pero de acuerdo a nuestro estudio en el rango del $16 \%$ al $20 \%$ se encontró el grupo más numeroso de empresas. Encontramos algunas que tenían una tasa anualizada menor al 10\%, aunque esto se reflejaba en las más grande, no en las pymes. Pero, en rangos arriba del $20 \%$ anual de tasa encontramos a casi el $50 \%$ de las empresas. 
Ello nos ayuda a identificar el resultado de nuestra hipótesis. En esta señalamos que el costo de crédito al representar una parte relevante de sus ingresos y utilidades de operación se traduce en un alta tasa de interés. El estudio empírico nos contrasta dicha hipótesis, vemos que entre más alto el costo más alta la tasa; lo cual podemos traducir en que la carga de interés para las pymes es de alto impacto en su rentabilidad. Esto pareciera un problema conocido por todos, pero si el sistema financiero indica que para cubrir el riesgo por ciertos defectos que tienen las pymes estas tienen que pagar un mayor costo que las empresas grandes y sin riesgo, entonces hay mayor afectación a las empresas que en teoría requerirían de mayor apoyo.

Esta parte es muy importante, del poder establecer un método en el cual el costo pudiera cargarse en función de los resultados, esto hasta cierto límite y tal vez solo enfocándonos a las pymes. Es decir, de acuerdo a las posibilidades de las empresas en cuanto a ingresos y utilidades, una vez cubierto las preocupaciones del banco como opacidad o garantía; el fijar una tasa de interés que vaya a acorde a las capacidades de la empresa. Se han creado algunas instituciones financieras en las cuales, basado en la confianzas, se le presta a microempresarios sin aval, garantía, o información sobre la empresa, más aun nuevas. Pero han sido puntos aislados, en México algunas instituciones, atendiendo este mercado olvidado por los corporativos financieros más grandes, apoyan a las pequeñas empresas, pero en algunos casos las tasas anualizadas son bastante elevadas. Como se traducen en créditos a muy corto plazo (menor a un año), las empresas no ven el costo que representa, al facilitarse las condiciones del trámite y omitir algunos requerimientos las instituciones financieras elevan las tasas de interés. 
Claro que tratándose de un servicio oneroso, las instituciones financieras deben cubrir sus costos y obtener un beneficio por la operación. Esto no da lugar a discusiones. Pero, si no hay clientes no hay negocio. Si las empresas grandes por sus propias características ya tienen ciertas ventajas respecto a la tasa de interés y ya trabajan con las instituciones financieras; por que no voltear a ver a las pymes, que representan más del $90 \%$ de las empresas a nivel global. Se comentó que los bancos adicionalmente al crédito, pueden obtener provecho mediante la oferta de otros productos a estos clientes, en cuestión de depósitos, de nóminas a trabajadores, del manejo de tesorería, entre otros. Si de estos servicios ya existe un cargo, el hacerlos crecer originará más beneficios. Pero la empresa no ocupa muchos servicios de sus acreedores. El gobierno también limita de cierra manera esta situación al integrar al sistema financiero como regulador en algunos aspectos tributarios.

Ceccetti (1995) menciona que cuando la política establecida por el banco central del país de que se trate, incrementa las tasas de interés puede causar una afectación en la empresa que limite su capacidad de crédito y de pago y, en consecuencia, de contratación de crédito. Ayyagari et al. (2008) encuentran que las altas tasas de interés restringen el crecimiento de la empresa. El obstáculo del alta tasa de interés captura el costo del financiamiento y es en si misma una variable endógena que depende de la habilidad del sistema financiero para satisfacer la demanda de capital. Se mencionó que en México instituciones como NAFIN y FIRA tratan de apoyar el crédito a un costo menor, pero no alcanzan a cubrir la demanda. Berger y Udell (2006) remarcan una cadena causal de estructuras políticas a financieras, que afectan la viabilidad y rentabilidad de las diferentes tecnologías de crédito. 
Si la banca privada por si sola no ha podido mejorar esta falta o limitación de financiamiento a las pymes, y el gobierno con sus programas no realiza una oferta suficiente, se debiera hacer un trabajo conjunto para realizarlo. Nuestro modelo ha indicado cual es la influencia de estas variables que se manejan alrededor del crédito de pymes, muchos estudios no llegan a llevarse a campo, pero encontramos también instituciones que tratan de mejorar estas situaciones con el Banco Mundial. Es cuestión de acoplar el modelo donde ha sido exitoso en los lugares o países donde se carece pero de acuerdo a las características y necesidades del medio empresarial en particular.

La tasa de interés también se presentó en nuestro modelo influenciada por la obtención del crédito. Pueden intervenir muchas variables para facilitar el crédito, para superar los obstáculos que hemos planteado en nuestro modelo e hipótesis. Cuando la empresa no tiene oferta de deuda externa, no tiene poder de negociación y orilla a que tenga que aceptar las condiciones que las instituciones financieras le ofrecen. Por lo cual podemos pensar que cuando a la empresa le es fácil obtener crédito, podrá elegir una opción más económica, con tasas competitivas.

Al contrastar esta hipótesis no encontramos los elementos suficientes para poder validarla. Es decir, no encontramos que la facilidad que tiene la pyme pueda incidir en una tasa más baja de interés. No es significativo el resultado obtenido en esta relación, por lo cual nuestra hipótesis no se cumple, no pudimos corroborar la influencia en la tasa de interés.

Nuestro modelo mostró los principales obstáculos financieros que suelen tener las pymes para acceder al crédito. Obstáculos de financiamiento 
que se han tratado por varios autores, pero los mostramos en nuestro modelo teórico haciendo una relación específica de lo que consideramos influye y facilita el préstamo. Las restricciones de crédito en la actualidad después de las crisis financiera del 2008 aun se sienten en el mercado de crédito, pues la oferta no ha despegado a lo que había antes de esa fecha. Si bien es cierto que no se limitado al cien por ciento, las empresas que ya tenían dificultadas pueden encontrar más aún en la actualidad. Pero nuestro modelo sirve para que puedan sopesar las ventajas de implementar en sus empresas lo que las instituciones requieren para facilitarles la obtención del crédito.

El costo del mismo crédito ha sufrido un ligero incremento, pero esto afecta a las pymes. Siendo uno de los principales motores económicos, la ventaja que deben aprovechar este tipo de empresas es la aparición de nuevas instituciones o las ya existentes que generan programas en particular para este mercado. Pero se requiere un cambio de cultura respecto a la deuda. Si bien es cierto que experiencias anteriores en México limitan el hacer uso de recursos externos, también es cierto que las posibilidades de crecimiento y operación se reducen.

En resumen, podemos concluir que la mayor parte de nuestro modelo fue corroborado, dejando constancia de las situaciones por las que deben pasar las pymes cuando requieren un crédito. Además, nuestro estudio nos otorga un marco de referencia para lo que existe en México en materia de financiamiento, pero también puede servir de comparativo a otras economías de características similares, puesto que reflejamos variables que son comunes y han sido estudiadas en muchos países alrededor del mundo. 


\subsection{Limitaciones y Futuras líneas de investigación}

El trabajo desarrollado en esta tesis, como en lo general, adolece de algunas limitaciones, sea por acotar el campo del estudio, por enfocarse en algunos conceptos o por la dimensión que conlleva el tema.

Uno de las limitaciones es relativo a la influencia que puede tener la relación de préstamo sobre otras variables del modelo de financiamiento. La literatura nos indica que una relación de préstamo, además de facilitar el crédito o cubrir la opacidad como analizamos en nuestros resultados, puede incidir en el costo de crédito de manera positiva y, a su vez, en la garantía que es requerida por algunas instituciones para disminuir el riesgo. Indudablemente la relación de préstamo como tal tiene gran relevancia en el tema de financiamiento vía bancos, es por ello que al ser de gran relevancia pudiéramos haber analizado otras relaciones causales, pero se decidió en este sentido limitar el objeto de estudio a las relaciones ya planteadas.

Otra de las limitaciones que tuvo el estudio fue que el análisis empírico se centró en empresas del sector industrial, el sector comercial es otro de los sectores muy importantes no solo a nivel nacional, además del sector servicios. Pero con la finalidad de acotar la población objeto del estudio y obtener las características propias del tema de crédito en este sector es que se definió utilizar las empresas manufactureras para el desarrollo de esta tesis. Teniendo las bases del estudio y el cuestionario ya diseñado, se podría generar una nueva línea de investigación para otros sectores. 
Adicionalmente, como se menciona en la metodología de la tesis, la muestra sobre la que se aplicaron los cuestionarios solo abarcan 13 estados del país, con lo cual más de la mitad del país no fue considerado en el estudio. A pesar de la dificultad de contar con este tipo de información que hace referencia a la situación financiera de la compañía, lo mejor hubiera sido tener mayor presencia a nivel nacional en los resultados, no obstante que se considera un buen número de estados abarcados, se habría enriquecido aún más el contar con el total, con lo cual más adelante pudiera efectuarse un estudio aplicando a empresas residentes en estados de los cuales no se obtuvo información en este estudio.

Por último, otra limitación importante fue el no poder hacer un análisis cuantitativo sobre la información financiera de las empresas, inicialmente solo se solicitaron en el cuestionario 3 datos sobre balance y resultados de la empresa. Como se explicaba, el entorno en el país dificultó mucho la obtención de encuestas, de otra forma, hubiéramos podido adicionar otros indicadores que nos dieran información sobre la situación de la empresa que favorecieran o limitaran la concesión del crédito. Situación que han podido realizar otros autores teniendo acceso a información de este tipo.

Las conclusiones y limitaciones planteadas en nuestro estudio nos conducen a establecer futuras líneas de investigación con motivo de los resultados de nuestro trabajo.

Como se mencionaba, parte de la contribución de nuestro trabajo fue la relación existente entre algunos de los obstáculos financieros con el costo del crédito, y este a su vez con la tasa de interés que cobra el banco. Pero no 
analizamos la relación entre el costo del crédito y la obtención del crédito, de ahí que aquí surja una línea de investigación que determine la influencia que puede tener esta variable. Algunos de los autores señalan como obstáculo el costo que tiene el crédito para las pymes, se puede analizar en particular esta situación para determinar las causas y las características en esta relación.

Partiendo de los constructos establecidos en nuestro modelo, otra línea de investigación es el analizar la relación directa entre el tamaño de la empresa y la facilidad para obtener crédito. Nosotros analizamos la influencia sobre el costo del crédito, pero considerando que las pymes conllevan este obstáculo, será importante determinar si el tamaño como empresa influye directamente al solicitar un crédito y las condiciones del mismo.

El cuestionario que se diseñó a partir de diferentes estudios realizados anteriormente, incluía varios indicadores que no fueron utilizados en este estudio, pero estos pueden ocuparse para diferentes trabajos de investigación que incluyan el estudio de variables como la información, tasa de interés, relación de préstamo y garantía.

Hablando de la información financiera de las empresas, una línea posible de investigación residiría en agregar algunos indicadores cuantitativos dentro de las variables estudiadas para conocer la situación financiera de la compañía. No para hacer una evaluación financiera de la misma, si no para relacionar algunas razones financieras, como han hecho otros autores, dentro de las características de la muestra de empresas que se estudien. 


\section{Bibliografía}


Almeida, H., \& Philippon, T. (2007). The risk-adjusted cost of financial distress. The Journal of Finance, 62(6), 2557-2586.

Alti, A. (2006). How persistent is the impact of market timing on capital structure? The Journal of Finance, 61(4), 1681-1710. doi:10.1111/j.1540-6261.2006.00886.x

Altman, E. I., \& Sabato, G. (2007). Modelling credit risk for SMEs: Evidence from the U.S. market. Abacus, 43(3), 332-357.

Ameziane Lasfer, M., Sundarsanam, P. S., \& Taffler, R. J. (1996). Financial distress, asset sales and lender monitoring (25 (3) ed.) Financial Management.

Anderson, J.C. \& Gerbing, D.W. (1988). Structural equation modeling in practice: A review and recommended two-step approach. Psychological Bulletin, 103(3), 411-423.

Angelini, P., Di Salvo, R., \& Ferri, G. (1998). Availability and cost of credit for small businesses: Customer relationships and credit cooperatives. Journal of Banking \& Finance, 22(6-8), 925-954.

Antoniou, A., Guney, Y., \& Paudyal, K. (2006). The determinants of debt maturity structure: Evidence from france, germany and the UK. European Financial Management, 12(2), 161-194.

Ashta, A. (2009). Microcredit capital flows and interest rates: An alternative explanation. Journal of Economic Issues (M.E.Sharpe Inc.), 43(3), 661683. 
Asquith, P., \& Gertner, R. (1994). Anatomy of financial distress: An examination of junk-bond issuers. Quarterly Journal of Economics, 109(3), 625 .

Autore, D. M., \& Kovacs, T. (2010). Equity issues and temporal variation in information asymmetry. Journal of Banking \& Finance, 34(1), 12-23. doi:DOI: 10.1016/j.jbankfin.2009.06.016

Avery, R. B., Bostic, R. W., \& Samolyk, K. A. (1998). The role of personal wealth in small business finance. Journal of Banking \& Finance, 22(68), 1019-1061.

Ayyagari, M., Beck, T., \& Demirguc-Kunt, A. (2007). Small and medium enterprises across the globe. Small Business Economics, 29(4), 415434.

Ayyagari, M., Demirgüc-Kunt, A., \& Maksimovic, V. (2008). How important are financing constraints? the role of finance in the business environment. The World Bank Economic Review, 22(3), 483-516.

Baas, T., \& Schrooten, M. (2006). 'Relationship banking and SMEs: A theoretical analysis'. Small Business Economics, 27(2), 127-137.

Bagozzi, R. P. (1980). Causal models in marketing. New York: Wiley:

Bagozzi, R.P., \& Yi, T. (1988). On the evaluation of structural equation models. Journal of the Academy of Marketing Science, 16(1), 74-94. 
Bagozzi, R. P. (1981). Attitudes, intentions, and behavior: A test of some key hypotheses. Journal of Personality and Social Psychology, 41(4), 600-627.

Baker, M., \& Wurgler, J. (2002). Market timing and capital structure. The Journal of Finance, 57(1), 1-32. doi:10.1111/1540-6261.00414

Barro, R. J. (1976). The loan market, collateral, and rates of interest. Journal of Money, Credit \& Banking (Ohio State University Press), $8(4), 439-456$.

Batista, J.M. \& Coenders, G.G. (2000). Modelos de ecuaciones estructurales (modelos para el análisis de relaciones causales). Madrid, España: Hespérides.

Beck, T. (2007). Financing constraints of smes in developing countries: Evidence, determinants and solutions. Open Access Publications from Tilburg University,

Beck, T., \& Demirguc-Kunt, A. (2006). Small and medium-size enterprises: Access to finance as a growth constraint. Journal of Banking \& Finance, 30(11), 2931-2943. doi:DOI: 10.1016/j.jbankfin.2006.05.009

Beck, T., Demirgüç-Kunt, A., Laeven, L., \& Maksimovic, V. (2006). The determinants of financing obstacles. Journal of International Money and Finance, 25(6), 932-952. doi:DOI: 10.1016/j.jimonfin.2006.07.005

Beck, T., Demirgüc-Kunt, A., \& Maksimovic, V. (2005). Financial and legal constraints to growth: Does firm size matter? The Journal of Finance, 60(1), 137-177. 
Beck, T., Demirgüç-Kunt, A., \& Maksimovic, V. (2008). Financing patterns around the world: Are small firms different? Journal of Financial Economics, 89(3), 467-487. doi:DOI: 10.1016/j.jfineco.2007.10.005

Behr, P., Entzian, A., \& Güttler, A. (2011). How do lending relationships affect access to credit and loan conditions in microlending? Journal of Banking \& Finance, 35(8), 2169-2178.

Benmelech, E., \& Bergman, N. K. (2009). Collateral pricing. Journal of Financial Economics, 91(3), 339-360. doi:DOI: 10.1016/j.jfineco.2008.03.003

Bentler, P. M. (1995). EQS structural equationis program manual. Encino, CA.: Multivariate Software, Inc.

Berger, A. N., Espinosa-Vega, M. A., Frame, W. S., \& Miller, N. H. (2005). Debt maturity, risk, and asymmetric information. The Journal of Finance, 60(6), 2895-2923. doi:10.1111/j.1540-6261.2005.00820.x

Berger, A. N., \& Black, L. K. (2011). Bank size, lending technologies, and small business finance. Journal of Banking \& Finance, 35(3), 724-735.

Berger, A. N., \& Bonaccorsi di Patti, E. (2006). Capital structure and firm performance: A new approach to testing agency theory and an application to the banking industry. Journal of Banking \& Finance, 30(4), 1065-1102. doi:DOI: 10.1016/j.jbankfin.2005.05.015

Berger, A. N., Espinosa-Vega, M. A., Frame, W. S., \& Miller, N. H. Why do borrowers pledge collateral? new empirical evidence on the role of 
asymmetric information. Journal of Financial Intermediation, In Press, Corrected Proof doi:DOI: 10.1016/j.jfi.2010.01.001

Berger, A. N., Klapper, L. F., \& Udell, G. F. (2001). The ability of banks to lend to informationally opaque small businesses. Journal of Banking \& Finance, 25(12), 2127-2167.

Berger, A. N., \& Udell, G. F. (1995). Relationship lending and lines of credit in small firm finance. Journal of Business, 68(3), 351.

Berger, A. N., \& Udell, G. F. (1998). The economics of small business finance: The roles of private equity and debt markets in the financial growth cycle. Journal of Banking \& Finance, 22(6-8), 613-673. doi:DOI: 10.1016/S0378-4266(98)00038-7

Berger, A. N., \& Udell, G. F. (2002). SMALL BUSINESS CREDIT AVAILABILITY AND RELATIONSHIP LENDING: THE IMPORTANCE OF BANK ORGANISATIONAL STRUCTURE. The Economic Journal, 112(477), F32-F53.

Berger, A. N., \& Udell, G. F. (2004). The institutional memory hypothesis and the procyclicality of bank lending behavior. Journal of Financial Intermediation, 13(4), 458-495.

Berger, A. N., \& Udell, G. F. (2006). A more complete conceptual framework for SME finance. Journal of Banking \& Finance, 30(11), 2945-2966. doi:DOI: 10.1016/j.jbankfin.2006.05.008 
Berggren, B., Olofsson, C., \& Silver, L. (2000). Control aversion and the search for external financing in swedish SMEs. Small Business Economics, 15(3), 233-242.

Berlin, M., \& Mester, L. J. (1998). On the profitability and cost of relationship lending. Journal of Banking \& Finance, 22(6â€“8), 873897.

Bessler, W., Drobetz, W., \& Grüninger, M. C. (2011). Information asymmetry and financing decisions*. International Review of Finance, $11(1), 123-154$.

Bharath, S. T., Pasquariello, P., \& Wu, G. (2009). Does asymmetric information drive capital structure decisions? Review of Financial Studies, 22(8), 3211-3243.

Bharath, S., Dahiya, S., Saunders, A., \& Srinivasan, A. (2007). So what do I get? the bank's view of lending relationships. Journal of Financial Economics, 85(2), 368-419.

Bhattacharya, S., \& Thakor, A. V. (1993). Contemporary banking theory. Journal of Financial Intermediation, 3(1), 2-50.

Binks, M. R., \& Ennew, C. T. (1997). The relationship between U.K. banks and their small business customers. Small Business Economics, 9(2), 167-178.

Bitler, M. P., Moskowitz, T. J., \& Vissing-Jorgensen, A. (2005). Testing agency theory with entrepreneur effort and wealth. The Journal of Finance, 60(2), 539-576. doi:10.1111/j.1540-6261.2005.00739.x 
Black, J., de Meza, D., \& Jeffreys, D. (1996). House prices, the supply of collateral and the enterprise economy. Economic Journal, 106(434), 60-75.

Blackwell, D. W., \& Winters, D. B. (1997). Banking relationships and the effect of monitoring on loan pricing. Journal of Financial Research, 20(2), 275.

Blazenko, G. W. (1987). Managerial preference, asymmetric information, and financial structure. Journal of Finance, 42(4), 839-862.

Bodenhorn, H. (2003). State banking in early america: A new economic history. Oxford University Press,

Bohatá, M., \& Mládek, J. (1999). The development of the czech sme sector. Journal of Business Venturing, 14(5-6), 461-473.

Bollen, K. A. (1989). Structural equations with latent variables. New York: Wiley,

Boot, A. W. A., Thakor, A. V., \& Udell, G. F. (1991). Secured lending and default risk: Equilibrium analysis, policy implications and empirical results. Economic Journal, 101(406), 458-472.

Booth, J. R., \& Booth, L. C. (2006). Loan collateral decisions and corporate borrowing costs. Journal of Money, Credit \& Banking (Ohio State University Press), 38(1), 67-90. 
Bradley, M., Jarrell, G. A., \& Kim, E. H. (1984). On the existence of an optimal capital structure: Theory and evidence. Journal of Finance, 39(3), 857-878.

Brick, I. E., \& Palia, D. (2007). Evidence of jointness in the terms of relationship lending. Journal of Financial Intermediation, 16(3), 452476.

Brush, T. H., Bromiley, P., \& Hendrickx, M. (2000). The free cash flow hypothesis for sales growth and firm performance. Strategic Management Journal, 21(4), 455-472. doi:10.1002/(SICI)10970266(200004)21:4<455::AID-SMJ83>3.0.CO;2-P

Campello, M., Graham, J. R., \& Harvey, C. R. (2010). The real effects of financial constraints: Evidence from a financial crisis. Journal of Financial Economics, 97(3), 470-487.

Cardone, C., Casasola, M. J., \& Samartin, M. (2005). Do banking relationships improve credit conditions for spanish smes? Business Economic Working Papers, Universidad Carlos III, Departamento de Economía de la Empresa

Cecchetti, S. G. (1995). Distinguishing theories of the monetary transmission mechanism. Review (00149187), 77(3), 83.

Céspedes, J., González, M., \& Molina, C. A. (2010). Ownership and capital structure in latin america. Journal of Business Research, 63(3), 248254. doi:DOI: 10.1016/j.jbusres.2009.03.010 
Chakraborty, A., \& Hu, C. X. (2006). Lending relationships in line-of-credit and nonline-of-credit loans: Evidence from collateral use in small business. Journal of Financial Intermediation, 15(1), 86-107.

Chirinko, R. S., \& Singha, A. R. (2000). Testing static tradeoff against pecking order models of capital structure: A critical comment. Journal of Financial Economics, 58(3), 417-425. doi:DOI: 10.1016/S0304$405 X(00) 00078-7$

Churchill Jr., G. A. (1979). A paradigm for developing better measures of marketing constructs. Journal of Marketing Research (JMR), 16(1), 6473.

Coase, R. H. (1937). The nature of the firm. Economica, 4(16), 386-405. doi:10.1111/j.1468-0335.1937.tb00002.x

Cocco, J. F., Gomes, F. J., \& Martins, N. C. (2009). Lending relationships in the interbank market. Journal of Financial Intermediation, 18(1), 2448.

Coco, G. (2000). On the use of collateral. Journal of Economic Surveys, 14(2), 191-214.

Cole, R. A. (1998). The importance of relationships to the availability of credit. Journal of Banking \& Finance, 22(6-8), 959-977.

Collis, Jil. \& Jarvis, Robin. (2002). Financial information and the management of small private companies. Journal of Small Business and Enterprise Deveploment, 9(2), 100-110. 
Columba, F., Gambacorta, L., \& Mistrulli, P. E. (2010). Mutual guarantee institutions and small business finance. Journal of Financial Stability, 6(1), 45-54. doi:DOI: 10.1016/j.jfs.2009.12.002

Crutchley, C. E., \& Hansen, R. S. (1989). A test of the agency theory of managerial ownership, corporate leverage, and corporate dividends. FM: The Journal of the Financial Management Association, 18(4), 3646.

Cull, R., Davis, L. E., Lamoreaux, N. R., \& Rosenthal, J. (2006). Historical financing of small- and medium-size enterprises. Journal of Banking \& Finance, 30(11), 3017-3042.

D’Auria, C., Foglia, A., \& Reedtz, P. M. (1999). Bank interest rates and credit relationships in italy. Journal of Banking \& Finance, 23(7), 1067-1093. doi:DOI: 10.1016/S0378-4266(98)00131-9

De la Torre, Augusto, Martínez Pería, María Soledad, \& Schmukler, S. L. (2009). Drivers and obstacles to banking SMEs : The role of competition and the institutional framework. CESifo Working Paper.

De la Torre, A., Martínez Pería, M. S., \& Schmukler, S. L. (2010). Bank involvement with SMEs: Beyond relationship lending. Journal of Banking \& Finance, 34(9), 2280-2293.

De Maeseneire, W., \& Claeys, T. (2007). SMES, FDI and financial constraints (Erasmus University Rotterdam ed.)

Degryse, H., \& Ongena, S. (2005). Distance, lending relationships, and competition. The Journal of Finance, 60(1), 231-266. 
Degryse, H., \& Van Cayseele, P. (2000). Relationship lending within a bank-based system: Evidence from european small business data. Journal of Financial Intermediation, 9(1), 90-109.

Delis, M. D., \& Kouretas, G. P. (2011). Interest rates and bank risk-taking. Journal of Banking \& Finance, 35(4), 840-855.

Dell'Ariccia, G. (2001). Asymmetric information and the structure of the banking industry. European Economic Review, 45(10), 1957-1980. doi:DOI: 10.1016/S0014-2921(00)00085-4

Denis, D. J., Denis, D. K., \& Sarin, A. (1999). Agency theory and the influence of equity ownership structure on corporate diversification strategies. Strategic Management Journal, 20(11), 1071-1076. doi:10.1002/(SICI)1097-0266(199911)20:11<1071::AIDSMJ70>3.0.CO;2-G

Detragiache, E., Garella, P., \& Guiso, L. (2000). Multiple versus single banking relationships: Theory and evidence. The Journal of Finance, 55(3), 1133-1161.

Dhanani, A. V., Fifield, S., Helliar, C., \& Stevenson, L. (2007). Why UK companies hedge interest rate risk. Studies in Economics and Finance, 24(1), 72-90.

Dhumale, R. (1998). Earnings retention as a specification mechanism in logistic bankruptcy models: A test of the free cash flow theory. Journal of Business Finance \& Accounting, 25(7), 1005-1026. 
Diamantopoulos, A. (1994). Modelling with LISREL: A guide for the uninitiated. Journal of Marketing Management, 10(1-3), 105-136.

Diamond, D. W. (1989). Reputation acquisition in debt markets. Journal of Political Economy, 97(4), 828.

Dickinson, D., \& Villeval, M. (2008). Does monitoring decrease work effort?: The complementarity between agency and crowding-out theories. Games and Economic Behavior, 63(1), 56-76. doi:DOI: 10.1016/j.geb.2007.08.004

Dierkens, N. (1991). Information asymmetry and equity issues. Journal of Financial and Quantitative Analysis, 26(02), 181-199.

Dietrich, A. (2010). Explaining loan rate differentials between small and large companies: Evidence from switzerland. Small Business Economics, , 1-14.

Díez-Vial, I. (2007). Explaining vertical integration strategies: Market power, transactional attributes and capabilities. Journal of Management Studies, 44(6), 1017-1040.

Donaldson, G. (1961). Corporate debt capacity: A study of corporate debt policy and the determination of corporate debt capacity. Boston, Division of Research, Havard Graduate School of Business Administration,

Dybvig, P. H., Farnsworth, H. K., \& Carpenter, J. N. (2010). Portfolio performance and agency. Review of Financial Studies, 23(1), 1-23. doi:10.1093/rfs/hhp056 
Egeln, J., Licht, G., \& Steil, F. (1997). Firm foundations and the role of financing constraints. Small Business Economics, 9(2), 137-150.

Eisenhardt, K. M. (1989). Agency theory: An assessment and review. Academy of Management Review, 14(1), 57-74.

Elliott, W. B., Koëter-Kant, J., \& Warr, R. S. (2007). A valuation-based test of market timing. Journal of Corporate Finance, 13(1), 112-128. doi:DOI: 10.1016/j.jcorpfin.2006.12.001

Elliott, W. B., Koëter-Kant, J., \& Warr, R. S. (2008). Market timing and the debt-equity choice. Journal of Financial Intermediation, 17(2), 175197. doi:DOI: 10.1016/j.jfi.2007.05.002

Elsas, R. (2005). Empirical determinants of relationship lending. Journal of Financial Intermediation, 14(1), 32-57.

Elsas, Ralf \& Krahnen, Jan Pieter. (2002). Collateral, defalt risk and relationship lending: An empirical study on financial contracting. Center for Financial Studies, 17

Elsas, R., \& Krahnen, J. P. (1998). Is relationship lending special? evidence from credit-file data in germany. Journal of Banking \& Finance, 22(1011), 1283-1316.

Elsayed, K. (2007). Does CEO duality really affect corporate performance? Corporate Governance: An International Review, 15(6), 1203-1214. doi:10.1111/j.1467-8683.2007.00641.x 
Elyasiani, E., \& Goldberg, L. G. (2004). Relationship lending: A survey of the literature. Journal of Economics and Business, 56(4), 315-330.

Fama, E. F. (1980). Agency problems and the theory of the firm. Journal of Political Economy, 88(2), 288-307.

Fama,Eugene F., \& Jensen, Michael C. (1983). Separation of ownership and control. Journal of Law and Economics, 26(2), 301-325.

Fama, E. F., \& French, K. R. (2002). Testing trade-off and pecking order predictions about dividends and debt. Review of Financial Studies, 15(1), 1-33. doi:10.1093/rfs/15.1.1

Farinha, L. A., \& Santos, J. A. C. (2002). Switching from single to multiple bank lending relationships: Determinants and implications. Journal of Financial Intermediation, 11(2), 124-151.

Fazzari, S. M., \& Athey, M. J. (1987). Asymmetric information, financing constraints, and investment. Review of Economics \& Statistics, 69(3), 481.

Ferri, G., \& Messori, M. (2000). Bank-firm relationships and allocative efficiency in northeastern and central italy and in the south. Journal of Banking \& Finance, 24(6), 1067-1095.

Fisman, R., \& Love, I. (2003). Trade credit, financial intermediary development, and industry growth. Journal of Finance, 58(1), 353-374.

Flannery, M. J. (1986). Asymmetric information and risky debt maturity choice. Journal of Finance, 41(1), 19-37. 
Foglia, A., Laviola, S., \& Marullo Reedtz, P. (1998). Multiple banking relationships and the fragility of corporate borrowers. Journal of Banking \& Finance, 22(10-11), 1441-1456.

Fornell, C. (1987). A second generation of multivariate analysis : Classification of methods and implications for marketing research Chicago: American Marketing Association.

Fornell, C., \& Larcker, D. F. (1981). Evaluating structural equation models with unobservable variables and measurement error. Journal of Marketing Research (JMR), 18(1), 39-50.

Fosberg, R. H. (2008). Debt capacity and debt financing. Journal of Business \& Economic Research, 6(8), 21-26.

Frank, M. Z., \& Goyal, V.K. (2007). Trade-off and pecking order theories of debt. (E. B. Eckbo, Ed), Water, 2(6), 797-809-SSRN.

Frank, M. Z., \& Goyal, V. K. (2003). Testing the pecking order theory of capital structure. Journal of Financial Economics, 67(2), 217-248. doi:DOI: 10.1016/S0304-405X(02)00252-0

Frank, M. Z., \& Goyal, V. K. (2009). Capital structure decisions: Which factors are reliably important? Financial Management (Blackwell Publishing Limited), 38(1), 1-37.

Frankforter, S. A., Berman, S. L., \& Jones, T. M. (2000). Boards of directors and shark repellents: Assessing the value of an agency theory perspective. Journal of Management Studies, 37(3), 321-348. 
Franks, J., \& Sussman, O. (2005). Financial distress and bank restructuring of small to medium size UK companies. Review of Finance, 9(1), 6596.

Froot, K. A., Scharfstein, D. S., \& Stein, J. C. (1993). Risk management: Coordinating corporate investment and financing policies. Journal of Finance, 48(5), 1629-1658.

Galindo, A., \& Micco, A. (2007). Bank credit to small and medium-sized enterprises: The role of creditor protection (Research Network Working Papers ed.) Inter-American Development Bank.

Garcia, I. A. (2006). Grain receipts as collateral for agribusiness' financing Swedish University of Agricultural Sciences (SLU). Departament of Economics.

Gertler, M. (1988). Financial structure and aggregate economic activity: An overview. Journal of Money, Credit \& Banking, 20(3), 559-588.

Gitman, L. J. (1997). Fundamentos de administración financiera. Oxford University Press. México. Séptima edición

González, V. M., \& González, F. (2008). Influence of bank concentration and institutions on capital structure: New international evidence. Journal of Corporate Finance, 14(4), 363-375.

Goswami, G., Noe, T., \& Rebello, M. (1995). Debt financing under asymmetric information. Journal of Finance, 50(2), 633-659. 
Graham, J. R. (2000). How big are the tax benefits of debt? The Journal of Finance, 55(5), 1901-1941.

Graham, J. R., \& Harvey, C. R. (2001). The theory and practice of corporate finance: Evidence from the field. Journal of Financial Economics, 60(2-3), 187-243. doi:DOI: 10.1016/S0304-405X(01)00044-7

Gregory, B. T., Rutherford, M. W., Oswald, S., \& Gardiner, L. (2005). An empirical investigation of the growth cycle theory of small firm financing. Journal of Small Business Management, 43(4), 382-392.

Hackbarth, D., Hennessy, C. A., \& Leland, H. E. (2007). Can the trade-off theory explain debt structure? Review of Financial Studies, 20(5), 1389-1428. doi:10.1093/revfin/hhl047

Hair, J.F., Black, W.C., Babin, J.B., Anderson, R.E., \& Tatham, R.L. (2006). Multivariate data analysis (6th ed.). Upper Saddle River, N.J.: Pearson Education, Inc.

Hallberg, K. (2001). A market-oriented strategy for small and medium scale enterprises

Han, L., Fraser, S., \& Storey, D. J. (2009). Are good or bad borrowers discouraged from applying for loans? evidence from US small business credit markets. Journal of Banking \& Finance, 33(2), 415-424.

Harhoff, D., \& Körting, T. (1998). Lending relationships in germany empirical evidence from survey data. Journal of Banking \& Finance, 22(10-11), 1317-1353. 
Harris, L. C. (2001). Market orientation and performance: Objective and subjective empirical evidence from UK companies. Journal of Management Studies, 38(1), 17-43.

Harris, M., \& Raviv, A. (1991). The theory of capital structure. Journal of Finance, 46(1), 297-355.

Hashi, Iraj \& Toci, Valentin Z. (2010). Financing constraints, credit rationing and financing obstacles: Evidence from firm-level data in south-eastern europe. Economic and Business Review, 12(1), 29-60.

Haugen, R. A., \& Senbet, L. W. (1978). The insignificance of bankruptcy costs to the theory of optimal capital structure. Journal of Finance, 33(2), 383-393.

Hayes, B. E. (1992). The measurement and meaning of work social support. Eight Annual Conference of the Society for Industrial and Organizational Psychology, San Francisco, CA.

Hernández-Cánovas, G., \& Koëter-Kant, J. (2010). The institutional environment and the number of bank relationships: An empirical analysis of european SMEs. Small Business Economics, 34(4), 375-390.

Hernández-Cánovas, G., \& Martínez-Solano, P. (2006). Banking relationships: Effects on debt terms for small spanish firms. Journal of Small Business Management, 44(3), 315-333.

Hernández-Cánovas, G., \& Martínez-Solano, P. (2010). Relationship lending and SME financing in the continental european bank-based system. Small Business Economics, 34(4), 465-482. 
Hogan, T., \& Hutson, E. (2005). Capital structure in new technology-based firms: Evidence from the irish software sector. Global Finance Journal, 15(3), 369-387.

Holmstitom, B., \& Tirole, J. (1997). Financial intermediation, loanable funds, and the real sector. Quarterly Journal of Economics, 112(3), 663-691.

Honohan, P. (2010). Partial credit guarantees: Principles and practice. Journal of Financial Stability, 6(1), 1-9.

Hovakimian, A. (2004). The role of target leverage in security issues and repurchases. The Journal of Business, 77(4), pp. 1041-1072.

Howorth, C., \& Moro, A. Trustworthiness and interest rates: An empirical study of italian SMEs. Small Business Economics, , 1-17.

Howton, S. D., Howton, S. W., \& Perfect, S. B. (1998). The market reaction to straight debt issues: The effects of free cash flow. Journal of Financial Research, 21(2), 219.

Hulburt, H. M., \& Scherr, F. C. (2003). Determinants of the collateralization of credit by small firms. Managerial and Decision Economics, 24(6-7), 483-501.

Hyytinen, A., \& Pajarinen, M. (2008). Opacity of young businesses: Evidence from rating disagreements. Journal of Banking \& Finance, 32(7), 1234-1241. doi:DOI: 10.1016/j.jbankfin.2007.10.006 
Ivashina, V., \& Kovner, A. (2011). The private equity advantage: Leveraged buyout firms and relationship banking. Review of Financial Studies, 24(7), 2462-2498.

Ivashina, V., \& Scharfstein, D. (2010). Bank lending during the financial crisis of 2008. Journal of Financial Economics, 97(3), 319-338.

Jaffee, D. M., \& Russell, T. (1976). Imperfect information, uncertainty, and credit rationing. Quarterly Journal of Economics, 90(4), 651-666.

Jappelli, T., Pagano, M., \& Bianco, M. (2005). Courts and banks: Effects of judicial enforcement on credit markets. Journal of Money, Credit \& Banking (Ohio State University Press), 37(2), 223-244.

Jensen, M.C. \& Smith, C.W. (1985). Stockholder, manager and creditor interests: Applications of agency theory. Recent Advances in Corporate Finance, , 93-131.

Jensen, M. C. (1986). Agency costs of free cash flow, corporate finance, and takeovers. American Economic Review, 76(2), 323.

Jensen, M. C. (1988). Takeovers: Their causes and consequences. Journal of Economic Perspectives, 2(1), 21-48.

Jensen, M. C., \& Meckling, W. H. (1976). Theory of the firm: Managerial behavior, agency costs and ownership structure. Journal of Financial Economics, 3(4), 305-360. doi:DOI: 10.1016/0304-405X(76)90026-X 
JENTER, D. (2005). Market timing and managerial portfolio decisions. The Journal of Finance, 60(4), 1903-1949. doi:10.1111/j.15406261.2005.00783.x

Jiménez, G., Salas, V., \& Saurina, J. (2009). Organizational distance and use of collateral for business loans. Journal of Banking \& Finance, 33(2), 234-243. doi:DOI: 10.1016/j.jbankfin.2008.07.015

Jiménez, G., \& Saurina, J. (2004). Collateral, type of lender and relationship banking as determinants of credit risk. Journal of Banking \& Finance, 28(9), 2191-2212. doi:DOI: 10.1016/j.jbankfin.2003.09.002

Jöreskog, K. (1971). Statistical analysis of sets of congeneric tests. Psychometrika, 36(2), 109-133.

Ju, N., Parrino, R., Poteshman, A. M., \& Weisbach, M. S. (2005). Horses and rabbits? trade-off theory and optimal capital structure. Journal of Financial \& Quantitative Analysis, 40(2), 259-281.

Kang, J., \& Heshmati, A. (2008). Effect of credit guarantee policy on survival and performance of SMEs in republic of korea. Small Business Economics, 31(4), 445-462.

Kano, M., Uchida, H., Udell, G. F., \& Watanabe, W. (2006). Information verifiability, bank organization, bank competition and bank-borrower relationships The Research Institute of Economy, Trade and Industry.

Kayhan, A., \& Titman, S. (2007). Firms' histories and their capital structures. Journal of Financial Economics, 83(1), 1-32. doi:DOI: 10.1016/j.jfineco.2005.10.007 
Keys, B. J., Mukherjee, T., Seru, A., \& Vig, V. (2010). Did securitization lead to lax screening? evidence from subprime loans. Quarterly Journal of Economics, 125(1), 307-362.

Kisgen, D. J. (2006). Credit ratings and capital structure. Journal of Finance, 61(3), 1035-1072. doi:10.1111/j.1540-6261.2006.00865.x

Klapper, L., Sarria-Allende, V., \& Sulla, V. (2002). Small and medium size enterprise financing in eastern europe (Deveploment Research Group. Finance ed.) The World Bank.

Klein, L. S., O'Brien, T. J., \& Peters, S. R. (2002). Debt vs. equity and asymmetric information: A review. Financial Review, 37(3), 317-349. doi:10.1111/1540-6288.00017

Kon, Y., \& Storey, D. J. (2003). A theory of discouraged borrowers. Small Business Economics, 21(1), 37-49.

Kraus, A., \& Litzenberger, R. H. (1973). A state-preference model of optimal financial leverage. Journal of Finance, 28(4), 911-922.

Kristof-Brown, A., Barrick, M. R., \& Franke, M. (2002). Applicant impression management: Dispositional influences and consequences for recruiter perceptions of fit and similarity. Journal of Management, 28(1), 27-46.

La Rocca, M., La Rocca, T., \& Cariola, A. (2011). Capital structure decisions during a firm's life cycle. Small Business Economics, 37(1), 107-130. 
Leary, M. T., \& Roberts, M. R. (2005). Do firms rebalance their capital structures? Journal of Finance, 60(6), 2575-2619. doi:10.1111/j.15406261.2005.00811.x

Leary, M. T., \& Roberts, M. R. (2010). The pecking order, debt capacity, and information asymmetry. Journal of Financial Economics, 95(3), 332-355. doi:DOI: 10.1016/j.jfineco.2009.10.009

Lehmann, E., \& Neuberger, D. (2001). Do lending relationships matter?: Evidence from bank survey data in germany. Journal of Economic Behavior \& Organization, 45(4), 339-359.

Lehmann, E., Neuberger, D., \& Räthke, S. (2004). Lending to small and medium-sized firms: Is there an east-west gap in germany? Springer Netherlands.

Leland, H. E., \& Pyle, D. H. (1977). Informational asymmetries, financial structure, and financial intermediation. Journal of Finance, 32(2), 371387.

Lemmon, M. L., Roberts, M. R., \& Zender, J. F. (2008). Back to the beginning: Persistence and the cross-section of corporate capital structure. Journal of Finance, 63(4), 1575-1608.

Lemmon, M. L., \& Zender, J. F. (2010). Debt capacity and tests of capital structure theories. Journal of Financial and Quantitative Analysis, 45(05), 1161-1187. 
Liu, M., Margaritis, D., \& Tourani-Rad, A. (2011). Asymmetric information and price competition in small business lending. Journal of Banking \& Finance, 35(9), 2189-2196.

López-Gracia, J., \& Mestre-Barberái, R. (2011). Tax effect on spanish SME optimum debt maturity structure. Journal of Business Research, 64(6), 649-655.

López-Gracia, J., \& Sogorb-Mira, F. (2008). Testing trade-off and pecking order theories financing SMEs. Small Business Economics, 31(2), 117136.

Love, I., \& Mylenko, N. (2003). Credit reporting and financing constraints (World Bank Policy Research Working Paper ed.)

Luque, T. (2000). Técnicas de análisis de datos en investigación de mercados. Madrid, Spain: Pirámide.

Mac an Bhaird, C. (2010). The modigliani?miller proposition after fifty years and its relation to entrepreneurial finance. Strategic Change, 19(1-2), 9-28.

Machauer, A., \& Weber, M. (1998). Bank behavior based on internal credit ratings of borrowers. Journal of Banking \& Finance, 22(10-11), 13551383.

Mahajan, A., \& Tartaroglu, S. (2008). Equity market timing and capital structure: International evidence. Journal of Banking \& Finance, 32(5), 754-766. doi:DOI: 10.1016/j.jbankfin.2007.05.007 
Mann, S. V., \& Sicherman, N. W. (1991). The agency cost of free cash flow: Acquisition activity and equity issues. Journal of Business, 64(2), 213-227.

Margaritis, D., \& Psillaki, M. (2007). Capital structure and firm efficiency. Journal of Business Finance \& Accounting, 34(9-10), 1447-1469.

Maudos, J., \& Solís, L. (2009). The determinants of net interest income in the mexican banking system: An integrated model. Journal of Banking \& Finance, 33(10), 1920-1931.

McCabe, G. M., \& Yook, K. C. (1997). Jensen, myers-majluf, free cash flow and the returns to bidders. The Quarterly Review of Economics and Finance, 37(3), 697-707. doi:DOI: 10.1016/S1062-9769(97)900181

Menkhoff, L., Neuberger, D., \& Suwanaporn, C. (2006). Collateral-based lending in emerging markets: Evidence from thailand. Journal of Banking \& Finance, 30(1), 1-21. doi:DOI: 10.1016/j.jbankfin.2004.12.004

Michaelas, N., Chittenden, F., \& Poutziouris, P. (1999). Financial policy and capital structure choice in U.K. SMEs: Empirical evidence from company panel data. Small Business Economics, 12(2), 113-130.

Miller, E. M. (1977). Risk, uncertainty, and divergence of opinion. Journal of Finance, 32(4), 1151-1168.

Mistrulli, P. E. \&. C., L. (2008). Distance, lending technologies and interest rates. Bank of Italy - Structural Economic Analysis Department, 
Modigliani, F., \& Miller, M. H. (1958). The cost of capital, corporation finance and the theory of investment. American Economic Review, 48(3), 261.

Myers, S. C. (1977). Determinants of corporate borrowing. Journal of Financial Economics, 5(2), 147-175. doi:DOI: 10.1016/0304405X(77)90015-0

Myers, S. C. (1984). The capital structure puzzle. Journal of Finance, 39(3), 575-592.

Myers, S. C. (2001). Capital structure. Journal of Economic Perspectives, 15(2), 81-102.

Myers, S. C. (2003). Chapter 4 financing of corporations. In M. H. a. R. M. S. G.M. Constantinides (Ed.), Handbook of the economics of finance (pp. 215-253) Elsevier. doi:DOI: 10.1016/S1574-0102(03)01008-2

Myers, S. C., \& Majluf, N. S. (1984). Corporate financing and investment decisions when firms have information that investors do not have. Journal of Financial Economics, 13(2), 187-221.

Narayanan, M. P. (1988). Debt versus equity under asymmetric information. Journal of Financial \& Quantitative Analysis, 23(1), 39-51.

Neuberger, D., Pedergnana, M., \& Räthke-Döppner, S. (2008). Concentration of banking relationships in switzerland: The result of firm structure or banking market structure? Journal of Financial Services Research, 33(2), 101-126. 
Nyberg, A. J., Fulmer, I. S., Gerhart, B., \& Carpenter, M. A. (2010). Agency theory revisited: Ceo return and shareholder interest alignment. Academy of Management Journal, 53(5), 1029-1049.

Oded, J. (2009). Payout policy, financial flexibility, and agency costs of free cash flow. Working Paper Series. SSRN,

Ongena, S., \& Smith, D. C. (2000). What determines the number of bank relationships? cross-country evidence. Journal of Financial Intermediation, 9(1), 26-56.

Ono, A., \& Uesugi, I. (2009). Role of collateral and personal guarantees in relationship lending: Evidence from japan's SME loan market. Journal of Money, Credit \& Banking (Wiley-Blackwell), 41(5), 935-960.

Ortiz-Molina, H., \& Penas, M. (2008). Lending to small businesses: The role of loan maturity in addressing information problems. Small Business Economics, 30(4), 361-383.

Perdomo Moreno, A. (2001). Planeación financiera para épocas normales y de inflación. Pema, Sexta edición

Petersen, M. A. (2004). Information: Hard and soft. Kellogg School of Management, , 1-20.

Petersen, M. A., \& Rajan, R. G. (1994). The benefits of lending relationships: Evidence from small business data. Journal of Finance, 49(1), 3-37. 
Petersen, M. A., \& Rajan, R. G. (1995). The effect of credit market competition on lending relationships. Quarterly Journal of Economics, 110(2), 407.

Pissarides, F. (1999). Is lack of funds the main obstacle to growth? ebrd's experience with small- and medium-sized businesses in central and eastern europe. Journal of Business Venturing, 14(5-6), 519-539. doi:DOI: 10.1016/S0883-9026(98)00027-5

Pissarides, F., Singer, M., \& Svejnar, J. (2003). Objectives and constraints of entrepreneurs: Evidence from small and medium size enterprises in russia and bulgaria. Journal of Comparative Economics, 31(3), 503531. doi:DOI: 10.1016/S0147-5967(03)00054-4

Pittman, J. A., \& Fortin, S. (2004). Auditor choice and the cost of debt capital for newly public firms. Journal of Accounting and Economics, 37(1), 113-136.

Popov, A., \& Udell, G. F. (2010). Cross-border banking and the international transmission of financial distress during the crisis of 2007-2008 (1203rd ed.). SSRN: ECB Working paper.

Psillaki, M., \& Daskalakis, N. (2009). Are the determinants of capital structure country or firm specific? Small Business Economics, 33(3), 319-333.

Purnanandam, A. (2008). Financial distress and corporate risk management: Theory and evidence. Journal of Financial Economics, 87(3), 706-739. 
Rahaman, M. M. (2011). Access to financing and firm growth. Journal of Banking \& Finance, 35(3), 709-723.

Rajan, R., \& Winton, A. (1995). Covenants and collateral as incentives to monitor. Journal of Finance, 50(4), 1113-1146.

Rauch, J. H., \& Hendrickson, J. M. (2004). Does bank consolidation hurt the small business borrower? Small Business Economics, 23(3), 219226.

Ray, D. (1998). Development economics Princeton University Press.

Reisinger, Y., \& Turner, L. (1999). Structural equation modeling with lisrel: Application in tourism. Tourism Management, 20(1), 71-88.

Richardson, S. (2006). Over-investment of free cash flow. Review of Accounting Studies, 11(2), 159-189.

Riley, J. C. (2001). Silver signals: Twenty-five years of screening and signaling. Journal of Economic Literature, 39(2), 432.

Riordan, M. H. (1985). Imperfect information and dynamic conjectural variations. RAND Journal of Economics (RAND Journal of Economics), 16(1), 41-50.

Ritter, J. R. (1998). Initial public offerings. Contemporary Finance Digest, 2, 5-30.

Robb, A. M. (2002). Small business financing: Differences between young and old firms. Journal of Entrepreneurial Finance and Business Ventures, 7, 45-65. 
Romano, C. A., Tanewski, G. A., \& Smyrnios, K. X. (2001). Capital structure decision making: A model for family business. Journal of Business Venturing, 16(3), 285-310. doi:DOI: 10.1016/S08839026(99)00053-1

Ross, S. A. (1977). The determination of financial structure: The incentivesignalling approach. Bell Journal of Economics, 8(1), 23-40.

Ross, S. A. (1973). The economic theory of agency: The principal's problem. American Economic Review, 63(2), 134-139.

Ruiz, M. A., Pardo, A., \& San Martín Castellanos, R. (2010). Modelos de ecuaciones estructurales Colegio Oficial de Psicólogos de Madrid.

Sakai, K., Uesugi, I., \& Watanabe, T. (2010). Firm age and the evolution of borrowing costs: Evidence from japanese small firms. Journal of Banking \& Finance, 34(8), 1970-1981.

Sarapaivanich, N., \& Kotey, B. (2006). The effect of financial information quality on ability to access external funds and performance of smes in thailand. Journal of Enterprising Culture, 14(3), 219-239.

Satorra, A. (2011). Advanced aspects in SEM. In: 10th Workshop on quantitative research techniques, 15-16 June 2011, Castelló de la Plana, Spain.

Savignac, F. (2008). Impact of financial constraints on innovation: What can be learned from a direct measure? Economics of Innovation and New Technology, 17(6), 553. 
Schiffer, M. \& Weder, B. (2001). Firm size and the business environment: Worldwide survey results. Papers. World Bank - International Finance Corporation, 43

Scholtens, B. (1999). Analytical issues in external financing alternatives for SBEs. Small Business Economics, 12(2), 137-148.

Scott, J. A. (2006). Loan officer turnover and credit availability for small firms. Journal of Small Business Management, 44(4), 544-562.

Scott, L. O. (1997). Pricing stock options in a jump-diffusion model with stochastic volatility and interest rates: Applications of fourier inversion methods. Mathematical Finance, 7(4), 413-426.

Seifert, B., \& Gonenc, H. (2010). Pecking order behavior in emerging markets*. Journal of International Financial Management \& Accounting, 21(1), 1-31. doi:10.1111/j.1467-646X.2009.01034.X

Serrasqueiro, Z., \& Nunes, P. M. (2011). Is age a determinant of SMEs' financing decisions? empirical evidence using panel data models. Entrepreneurship Theory and Practice, , no-no.

Sharma, A. (1997). Professional as agent: Knowledge asymmetry in agency exchange. Academy of Management Review, 22(3), 758-798.

Sharpe, S. A. (1990). Asymmetric information, bank lending, and implicit contracts: A stylized model of customer relationships. Journal of Finance, 45(4), 1069-1087. 
Shen, Y., Shen, M., Xu, Z., \& Bai, Y. (2009). Bank size and small- and medium-sized enterprise (SME) lending: Evidence from china. World Development, $\quad 37(4), \quad$ 800-811. doi:DOI: 10.1016/j.worlddev.2008.07.014

Shyam-Sunder, L., \& Myers, S. C. (1994). Testing static trade-off against pecking-order models of capital structure National Bureau of Economic Research, Inc.

Sogorb- Mira, Francisco \& Lopez- Gracia, José. (2003). Pecking order versus trade-off: An empirical approach to the small and medium enterprise capital structure. Working Papers. Serie EC, Instituto Valenciano De Investigaciones Económicas, S.A.,

Solís, L., \& Maudos, J. (2008). The social costs of bank market power: Evidence from mexico. Journal of Comparative Economics, 36(3), 467-488.

Starks, L. T. (1987). Performance incentive fees: An agency theoretic approach. Journal of Financial \& Quantitative Analysis, 22(1), 17-32.

Steijvers, T., \& Voordeckers, W. (2009). Collateral and credit rationing: A review of recent empirical studies as a guide for future research. Journal of Economic Surveys, 23(5), 924-946.

Steijvers, T., Voordeckers, W., \& Vanhoof, K. (2010). Collateral, relationship lending and family firms. Small Business Economics, 34(3), 243-259. 
Stephanou, C., \& Rodriguez, C. (2008). Bank financing to small and medium-sized enterprises (SMEs) in colombia (The World Bank. Policy Research Working Paper 4481 ed.)

Stiglitz, J. E., \& Weiss, A. (1981). Credit rationing in markets with imperfect information. American Economic Review, 71(3), 393.

Tagoe, N., Nyarko, E., \& Anuwa-Amarh, E. (2005). Financial challenges facing urban SMEs under financial sector liberalization in ghana. Journal of Small Business Management, 43(3), 331-343.

Thakor, A. V. (1996). The design of financial systems: An overview. Journal of Banking \& Finance, 20(5), 917-948.

Tirole, J. (1990). The theory of industrial organization. The MIT Press. Cambridge, Massachusetts,

Tirole, J. (2006). The theory of corporate finance Princeton University Press.

Uchida, H., Udell, G. F., \& Yamori, N. (2012). Loan officers and relationship lending to SMEs. Journal of Financial Intermediation, 21(1), 97-122.

Van Campenhout, G. \& Van Caneghem, T. (2009). Information availability, information quality and the financial structure of belgian smes. Hogeschool-Universiteit Brussel, Faculteit Economie En Management, 2009/27 
Van Geenhuizen, M., \& Soetanto, D. P. (2009). Academic spin-offs at different ages: A case study in search of key obstacles to growth. Technovation, 29(10), 671-681.

Vanacker, T., \& Manigart, S. (2010). Pecking order and debt capacity considerations for high-growth companies seeking financing. Small Business Economics, 35(1), 53-69.

Varian, H. R. (1980). A model of sales. American Economic Review, 70(4), 651.

Vasiliou, D., Eriotis, N., \& Daskalakis, N. Testing the pecking order theory: The importance of methodology

Vickery, J. (2008). How and why do small firms manage interest rate risk. Journal of Financial Economics, 87(2), 446-470. doi:DOI: 10.1016/j.jfineco.2006.09.011

von Thadden, E. (2004). Asymmetric information, bank lending and implicit contracts: The winner's curse. Finance Research Letters, 1(1), 11-23. doi:DOI: 10.1016/S1544-6123(03)00006-0

Voordeckers, W., \& Steijvers, T. (2006). Business collateral and personal commitments in SME lending. Journal of Banking \& Finance, 30(11), 3067-3086.

Vos, E., Yeh, A. J., Carter, S., \& Tagg, S. (2007). The happy story of small business financing. Journal of Banking \& Finance, 31(9), 2648-2672. doi:DOI: 10.1016/j.jbankfin.2006.09.011 
Wang, Y. (2010). Does collateral cause inefficient resource allocation? Journal of Economics and Business, 62(3), 220-233.

Watson, R., \& Wilson, N. (2002). Small and medium size enterprise financing: A note on some of the empirical implications of a pecking order. Journal of Business Finance \& Accounting, 29(3-4), 557-578.

Wells, B. P., \& Cox, L. A. (1995). Free cash flow in the life insurance industry. Journal of Risk \& Insurance, 62(1), 50-66.

Williamson, O. E. (1975). Markets and herarchies: Analysis and antitrust implications. Free Press-Macmillan, New York,

Williamson, O. E. (1985). The economic institutions of capitalism: Firms, markets, relational contracting

Wright, P., Mukherji, A., \& Kroll, M. J. (2001). A reexamination of agency theory assumptions: Extensions and extrapolations. Journal of SocioEconomics, 30(5), 413-429. doi:DOI: 10.1016/S1053-5357(01)00102-0

Wu, J., Song, J., \& Zeng, C. (2008). An empirical evidence of small business financing in china. Management Research News, 31(12), 959975.

Zambaldi, F., Aranha, F., Lopes, H., \& Politi, R. (2011). Credit granting to small firms: A brazilian case. Journal of Business Research, 64(3), 309-315. 
Zhao, T., Casu, B., \& Ferrari, A. (2009). Competition and risk taking incentives in the lending market: An application to indian banking. Working Paper Series. SSRN. 
Anexo 
Buenos días/tardes. AGRADECERÍAMOS MUCHO SU COLABORACIÓN contestando las siguientes preguntas, cuyo objetivo es desarrollar una investigación sobre su opinión relativa a los factores que afectan la concesión de los créditos. Este estudio se realiza como proyecto de Tesis Doctoral. Respecto a la información que usted nos facilite le garantizamos una total confidencialidad y anonimato, al ser datos tratados de un modo global y no individualmente. Por último, este estudio no tiene fines lucrativos sino meramente de investigación.

Datos Generales

Fecha:

de de 2011

Nombre de la empresa:

Actividad:

Domicilio, Ciudad / Estado:

Nombre del entrevistado:

Edad:

Información General

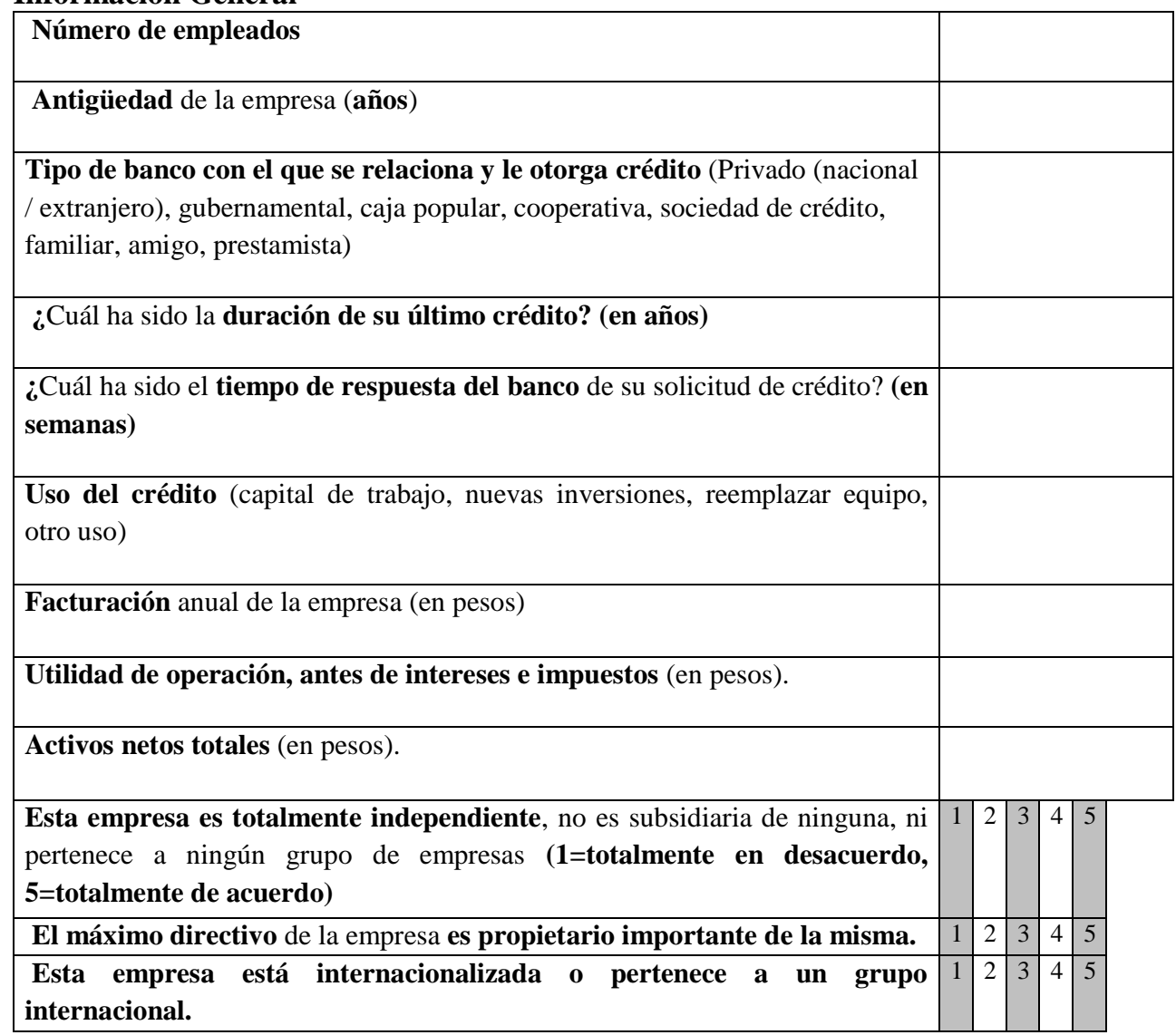


A continuación valore de $\mathbf{1}$ al $\mathbf{5}$ las siguientes afirmaciones relativas a su empresa (donde $\mathbf{1}$ es totalmente en desacuerdo y 5 totalmente de acuerdo)

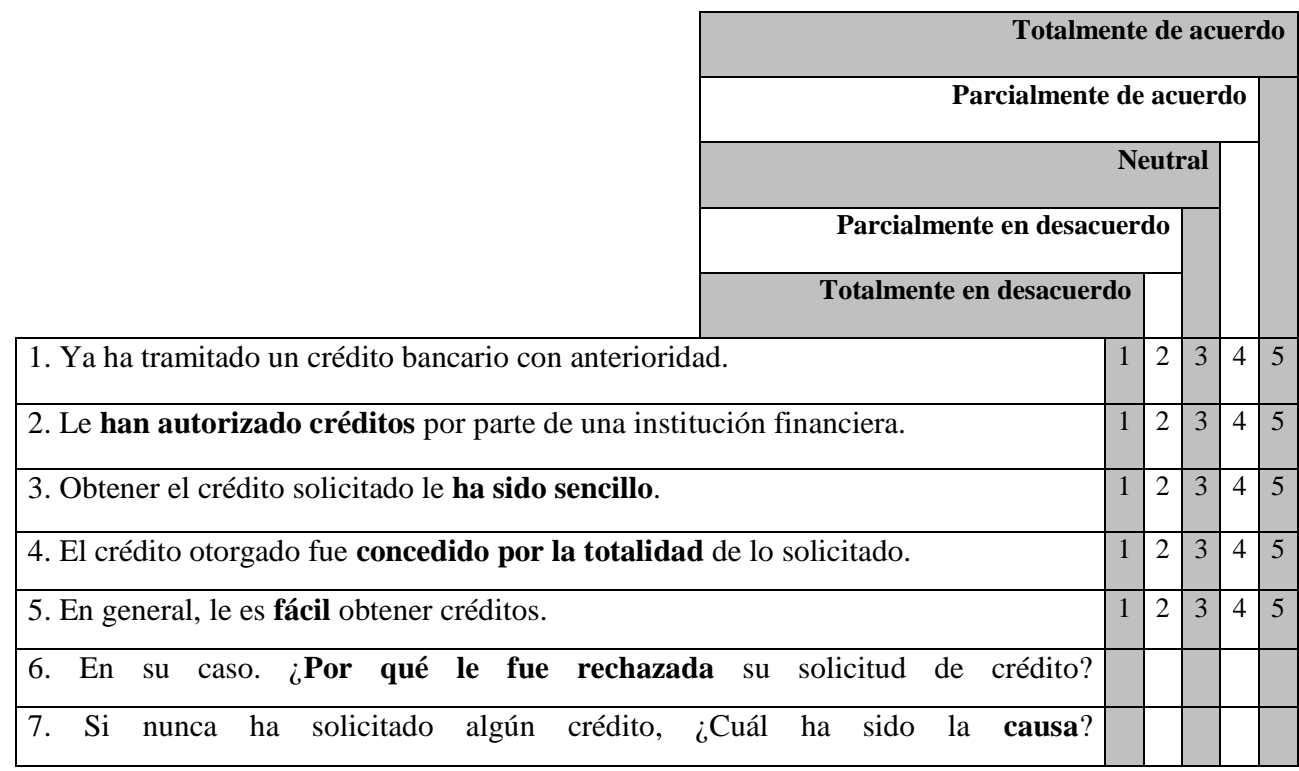

\section{Información}

\begin{tabular}{|l|l|l|l|l|l|}
\hline 1. Se encuentra inscrito en alguna cámara de comercio, industria o del sector. & 1 & 2 & 3 & 4 & 5 \\
\hline 2. Cuenta con los servicios de un contador que elabore sus estados financieros. & 1 & 2 & 3 & 4 & 5 \\
\hline $\begin{array}{l}\text { 3. Sus estados financieros se encuentran revisados y certificados por un auditor } \\
\text { externo. }\end{array}$ & 1 & 2 & 3 & 4 & 5 \\
\hline $\begin{array}{l}\text { 4. El banco puede disponer con facilidad de una proyección financiera de su } \\
\text { empresa. }\end{array}$ & 1 & 2 & 3 & 4 & 5 \\
\hline $\begin{array}{l}\text { 5. Los papeles, información y trámites del banco para obtener un crédito son } \\
\text { sencillos. }\end{array}$ & 1 & 2 & 3 & 4 & 5 \\
\hline $\begin{array}{l}\text { 6. El banco no entiende su negocio. } \\
\text { 7. El banco lo conoce suficiente para no requerir información financiera. }\end{array}$ & 1 & 2 & 3 & 4 & 5 \\
\hline 8. El banco ha investigado su historial en el buró de crédito. & 1 & 2 & 3 & 4 & 4 \\
\hline
\end{tabular}




\section{Tasa de interés}

\begin{tabular}{|l|l|l|l|l|l|}
\hline 1. ¿Cuál es/fue la tasa de interés de su último crédito?_\% & & & & \\
\hline 2. ¿La tasa de interés es fija o variable? Fija __ Variable__. & & & & \\
\hline 3. La tasa de interés es tan alta que prefiere no solicitar ningún crédito. & 1 & 2 & 3 & 4 & 5 \\
\hline $\begin{array}{l}\text { 4. Los interese pagados por créditos representan un porcentaje significativo de } \\
\text { sus ventas. }\end{array}$ & 1 & 2 & 3 & 4 & 5 \\
\hline $\begin{array}{l}\text { 5. Los interese pagados por créditos representan un porcentaje significativo de su } \\
\text { utilidad de operación. }\end{array}$ & 1 & 2 & 3 & 4 & 5 \\
\hline $\begin{array}{l}\text { 6. La tasa de interés es relativamente alta por mi poca experiencia con los bancos. } \\
\text { 7. Prefiere contratar el crédito con una tasa fija de interés. }\end{array}$ & 1 & 2 & 3 & 4 & 5 \\
\hline
\end{tabular}

\section{Relación de préstamo}

\begin{tabular}{|c|c|c|c|c|c|}
\hline 1. ¿Cuántos años lleva de relación con su banco principal? & & & & & \\
\hline 2. Le gusta relacionarse con los bancos o instituciones que le otorgan crédito. & 1 & 2 & 3 & 4 & 5 \\
\hline 3. Se reúne constantemente con el personal del banco que le atiende. & 1 & 2 & 3 & 4 & 5 \\
\hline 4. Cuento con un contacto especial en el banco con el que tramito los créditos. & 1 & 2 & 3 & 4 & 5 \\
\hline $\begin{array}{l}\text { 5. Los ejecutivos del banco se acercan a usted para conocer sus necesidades, } \\
\text { objetivos, requerimientos. }\end{array}$ & 1 & 2 & 3 & 4 & 5 \\
\hline $\begin{array}{l}\text { 6. El banco al que solicita el crédito se considera su banco principal por parte de } \\
\text { ellos mismos. }\end{array}$ & 1 & 2 & 3 & 4 & 5 \\
\hline 7. No existe confianza entre el banco o con quien le otorga crédito y usted. & 1 & 2 & 3 & 4 & 5 \\
\hline 8. ¿Con cuántos bancos trabaja? & & & & & \\
\hline 9. ¿Cuántas veces en el año se reúne con su ejecutivo de banco? & & & & & \\
\hline $\begin{array}{l}\text { 10. ¿Qué porcentaje de operaciones tiene con su (s) banco (s) principal (es)? } \\
\%\end{array}$ & & & & & \\
\hline $\begin{array}{l}\text { 11. ¿Cuántos servicios ocupa de su banco principal? (cheques, nómina, depósitos, } \\
\text { crédito, etc.) }\end{array}$ & & & & & \\
\hline 12. Tiene asignado un ejecutivo específico del banco para atenderlo. & 1 & 2 & 3 & 4 & 5 \\
\hline 13. Cuenta con una relación fuerte con su banco. & 1 & 2 & 3 & 4 & 5 \\
\hline 14. Cuenta con experiencias negativas pasadas en sus relaciones con bancos. & \begin{tabular}{|l|l|l} 
\\
\end{tabular} & 2 & 3 & 4 & 5 \\
\hline $\begin{array}{l}\text { 15. No hay obligación de informar al banco cuando surge un problema importante } \\
\text { en su empresa. }\end{array}$ & 1 & 2 & 3 & 4 & 5 \\
\hline $\begin{array}{l}\text { 16. Se reúne periódicamente con su banco para realizar revisiones sobre su } \\
\text { situación. }\end{array}$ & 1 & 2 & 3 & 4 & 5 \\
\hline 17. Su banco principal es diferente del que tenía hace 5 años. & 1 & 2 & 3 & 4 & 5 \\
\hline
\end{tabular}




\section{Garantía}

\begin{tabular}{|c|c|c|c|c|c|c|}
\hline $\begin{array}{l}\text { 1. ¿Qué porcentaje representa el importe de la garantía del monto del crédito } \\
\text { otorgado? } \%\end{array}$ & & & & & & \\
\hline 2. Le es fácil otorgar una garantía de los bienes de la empresa. & 1 & 2 & 3 & & & 5 \\
\hline 3. Le es fácil otorgar una garantía de sus bienes personales. & 1 & 2 & 3 & & & 5 \\
\hline 4. El banco nunca acepta la garantía que usted le ofrece. & 1 & 2 & 3 & & & 5 \\
\hline $\begin{array}{l}\text { 5. Existe una diversa gama de servicios contratados con el banco. (cheques, } \\
\text { nómina, depósitos, etc.). }\end{array}$ & 1 & 2 & 3 & & & 5 \\
\hline 6. El banco le ha aceptado garantías con valor inferior al monto del crédito. & 1 & 2 & 3 & & & 5 \\
\hline $\begin{array}{l}\text { 7. El requerimiento de garantía significa un problema para su operación y } \\
\text { crecimiento. }\end{array}$ & 1 & 2 & 3 & & & 5 \\
\hline 8. El otorgamiento de una garantía es indispensable en la tramitación de crédito. & 1 & 2 & 3 & & & 5 \\
\hline $\begin{array}{l}\text { 9. La garantía representa un porcentaje importante del total de activos de su } \\
\text { negocio. }\end{array}$ & 1 & 2 & 3 & & & 5 \\
\hline $\begin{array}{l}\text { 10. El monto de la garantía es asignado o valuado por la institución que otorga el } \\
\text { crédito. }\end{array}$ & 1 & 2 & 3 & & & 5 \\
\hline 11. Perder la garantía significa un riesgo para su operación. & 1 & 2 & 3 & & & 5 \\
\hline $\begin{array}{l}\text { 12. El nivel de garantía requerida depende del tipo banco (local, nacional, } \\
\text { pequeño, grande). }\end{array}$ & 1 & 2 & 3 & & & 5 \\
\hline 13. El otorgar una garantía representa un costo importante de sus utilidades. & 1 & 2 & 3 & & & 5 \\
\hline $\begin{array}{l}\text { 14. Sus marcas o patentes registradas han sido otorgadas como garantía de } \\
\text { préstamos. }\end{array}$ & 1 & 2 & 3 & & & 5 \\
\hline
\end{tabular}

